\author{
UNIVERSIDADE DE SÃO PAULO \\ ESCOLA DE ENGENHARIA DE SÃO CARLOS \\ DEPARTAMENTO DE ENGENARIA DE ESTRUTURAS
}

GUSTAVO DE MIRANDA SALEME GIDRÃO

PROPRIEDADES DINÂMICAS DO CONCRETO E RELAÇÕES COM SUA MICROESTRUTURA. 
AUTORIZO A REPRODUÇÃO TOTAL OU PARCIAL DESTE TRABALHO, POR QUALQUER MEIO CONVENCIONAL OU ELETRÔNICO, PARA FINS DE ESTUDO E PESQUISA, DESDE QUE CITADA A FONTE.

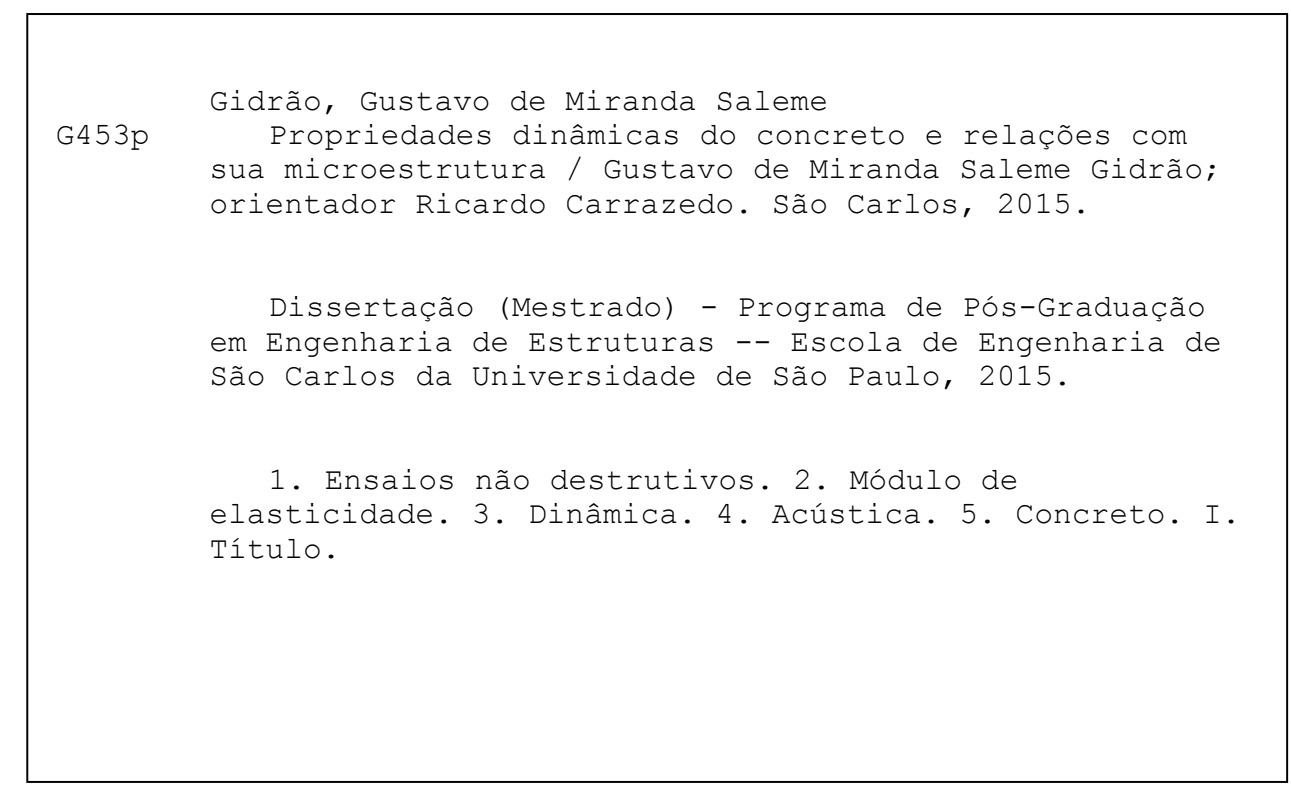




\section{FOLHA DE JULGAMENTO}

Candidato: Engenheiro GUSTAVO DE MIRANDA SALEME GIDRÃO.

Título da dissertação: "Propriedades dinâmicas do concreto e relações com sua microestrutura".

Data da defesa: 17/06/2015

Comissão Julgadora:

Prof. Dr. Ricardo Carrazedo (Orientador)

(Escola de Engenharia de São Carlos/EESC)

Prof. Dr. Vladimir Guilherme Haach

(Escola de Engenharia de São Carlos/EESC)

Prof. Dr. José de Anchieta Rodrigues

(Universidade Estadual de Campinas/UNICAMP)
Resultado:

APROVADO

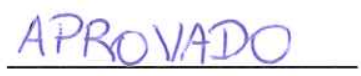

APROVADO

Coordenador do Programa de Pós-Graduação em Engenheira Civil (Engenharia de Estruturas):

Prof. Titular Humberto Breves Coda

Presidente da Comissão de Pós-Graduação:

Prof. Associado Paulo Sergio Lima Segantine 


\title{
PROPRIEDADES DINÂMICAS DO CONCRETO E RELAÇÕES COM SUA MICROESTRUTURA.
}

(VERSÃO CORRIGIDA A versão original encontra-se na biblioteca da Escola de Engenharia de São Carlos)

\author{
Dissertação apresentada à Escola de \\ Engenharia de São Carlos, da Universidade \\ de São Paulo, como parte dos requisitos \\ para obtenção do título de Mestre em \\ Engenharia Civil. \\ Área de concentração: Engenharia de \\ Estruturas. \\ Orientador: Prof. Dr. Ricardo Carrazedo
}




\section{AGRADECIMENTOS}

A Deus, pela vida, energia, equilíbrio, inspiração e lucidez.

À Universidade de São Paulo e à Escola de Engenharia São Carlos (EESC-USP), pelo acolhimento destes maravilhosos 7 anos.

Ao meu orientador, Ricardo Carrazedo, não só pelas ideias, cobranças, empenho e suporte no desenvolvimento de toda a pesquisa, mas pela amizade.

A todos os professores, tanto da escola como da vida, que me auxiliaram na construção de meu conhecimento, em especial José Samuel Giongo.

Aos meus colegas do Programa de Pós Graduação da Escola de Engenharia de São Carlos, que participaram de forma direta e indireta no desenvolvimento deste trabalho.

Aos profissionais e amigos do laboratório de estruturas (LE-EESC-USP) em nome de Amauri Ignácio da Silva, Douglas Dutra Rompa, Fabiano Dornellas, Jorge Luis Rodrigues Brabo, Luiz Vicente Vareda, Mario Botelho, Mauri Sergio Dias Guillen, Romeu Bressan Neto e Fernando Moretto e do Centro Universitário da Fundação Educacional de Barretos Roberto Baldochi que contribuíram para o desenvolvimento deste sonho.

Aos amigos do departamento de Geotecnia da Escola de engenharia de São Carlos (SGS EESC USP), em especial, os técnicos Antônio Garcia, Décio Aparecido Lourenço, Oscar dos Santos Neto, o geólogo e aluno João Cândido Valenga Parizotto e o Professor Rogério Pinto Ribeiro.

Aos amigos e pais Salmen Saleme Gidrão e Benedita de Cássia de Miranda Gidrão pela companhia durante a caminhada. 


\section{RESUMO}

\section{GIDRÃO, G.M.S. PROPRIEDADES DINÂMICAS DO CONCRETO E RELAÇÕES}

COM SUA MICROESTRUTURA. 2015. Dissertação (Mestrado em Engenharia de

Estruturas) - Escola de Engenharia de São Carlos, Universidade de São Paulo, São Carlos.

O módulo de elasticidade do concreto é uma propriedade muito importante para o projeto estrutural. Apesar do comportamento tensão-deformação não linear do concreto, uma estimativa adequada desta propriedade é fundamental para a análise estrutural, avaliação de efeitos de segunda ordem e verificações de deslocamentos. Em especial, o módulo de elasticidade dinâmico é uma propriedade muito importante na análise de vibrações excessivas. Todavia, sua determinação é tipicamente feita a partir do módulo de elasticidade estático. Os códigos normativos usualmente apresentam equações para estimativas do módulo de elasticidade estático a partir da resistência do concreto à compressão, densidade e tipo de agregado utilizado. Logo, outra limitação de tais estimativas é a não consideração de características da zona de transição além do tipo, fração volumétrica e dimensão dos agregados empregados na mistura. Por outro lado, a teoria dos materiais compósitos multifásicos permitiu, nos últimos tempos, o avanço dos modelos de previsão das propriedades do material. Portanto, o entendimento isolado do comportamento da pasta, areia, brita, argamassa e zona de transição é importante para a previsão do comportamento do compósito concreto. Desta forma, utilizou-se do ensaio acústico para a caracterização de variadas dosagens de pasta, argamassa, rocha e concreto. Assim, foi possível investigar a correlação entre as propriedades dinâmicas do compósito concreto e sua microestrutura. Variações de parâmetros como o fator água-cimento, maturidade, presença de superplastificante e tipo de agregado graúdo utilizado na mistura impuseram variados padrões microestruturais, e estes foram avaliados frente às propriedades dinâmicas do material, em especial, ao módulo de elasticidade dinâmico. Também foi possível a constatação da interdependência microestrutural entre o módulo de elasticidade dinâmico, módulo de cisalhamento e coeficiente de amortecimento. Já o coeficiente de Poisson apresentou pouca correlação com as outras propriedades supracitadas. Finalmente fez-se a inferência sobre a precisão das estimativas para módulo de elasticidade dinâmico através das equações empíricas contidas em normas e dos modelos teóricos obtidos via formulação para materiais bifásicos. Uma curva que correlaciona o módulo de elasticidade dinâmico e estático foi proposta para a maturidade referente aos 28 dias.

Palavras-chave: ensaios não destrutivos, módulo de elasticidade, dinâmica, acústica, concreto. 


\section{ABSTRACT \\ GIDRÃO, G.M.S. DYNAMICS PROPERTIES OF CONCRETE AND RELATIONS}

WITH ITS MICROSTRUCTURE. 2015. M. Sc. Dissertation - Escola de Engenharia de

São Carlos, Universidade de São Paulo, São Carlos.

The modulus of elasticity of concrete is a very important property for structural design. Despite the nonlinear stress-strain behavior of concrete, an appropriate estimate of this property is essential for structural analysis, evaluation of second-order effects and excessive deflexions. In particular, the dynamic modulus of elasticity is an important property in analysis of excessive vibration. However, this value is often estimated from the static modulus. Design codes usually contain equations estimating the static modulus based on compressive strength of concrete, density and type of aggregate used. Another limitation of such estimates is neglecting the characteristics of the transition zone, and the type, size and volume fraction of the aggregates used in the mixture. On the other hand, the theory of multiphase composites materials has allowed in recent times, advances of predictive models of material properties. Therefore, the isolated understanding of paste behavior, sand, gravel, mortar and transition zone is important for predicting concrete composite behavior. In this way, the acoustic test it was utilized for characterization of the various mixes of the paste, mortar, rock and concrete. Thus, it was possible to investigate the correlation between the dynamic properties of the composite concrete and its microstructure. Variations in parameters such as the water-cement ratio, maturity, presence of superplasticizer and type of coarse aggregate used in the mix, imposed various microstructural patterns, and these were evaluated face to the material dynamic properties, in particular to the dynamic modulus of elasticity. Detected a microstructural interdependence between the dynamic modulus of elasticity, shear modulus and damping coefficient It was also. On the other hand, the Poisson ratio, presented low correlation with the other properties mentioned. Finally an inference about the accuracy of estimates for dynamic modulus of elasticity through empirical equations contained in standards and theoretical models obtained by the formulation for biphasic materials was made. A curve that correlates the dynamic and static modulus of elasticity was proposed for the age of 28 days.

Keywords: Non-destrutive tests, elastic modulus, dynamics, acoustics, concrete. 


\section{SUMÁRIO}

1. INTRODUÇÃO .......................................................................................................................11

2. JUSTIFICATIVA .......................................................................................................................

3. OBJETIVOS …….................................................................................................................... 12

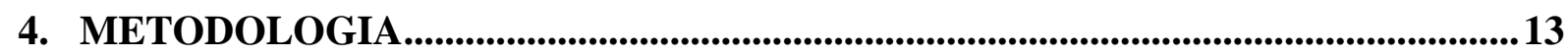

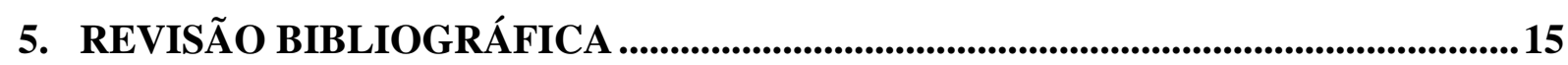

5.1 PROPRIEDADES MECÂNICAS DO CONCRETO ……………………………......15

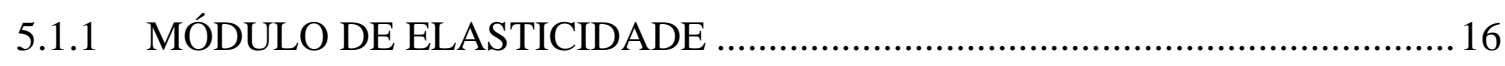

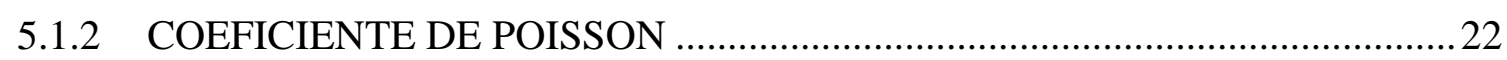

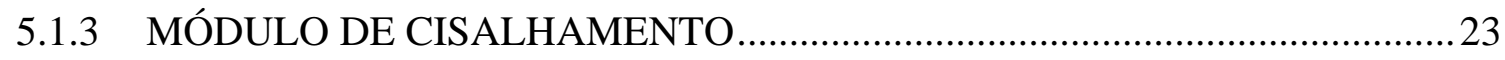

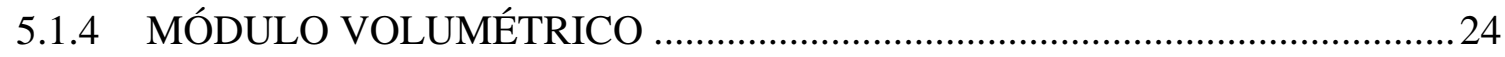

5.1.5 ESTIMATIVAS DO MÓDULO DE ELASTICIDADE ……………………......24

5.1.6 COEFICIENTE DE AMORTECIMENTO ………………………………….......

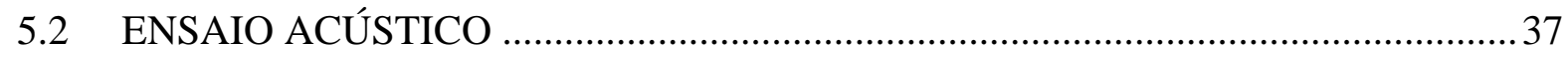

6. PROCEDIMENTO EXPERIMENTAL ............................................................................47

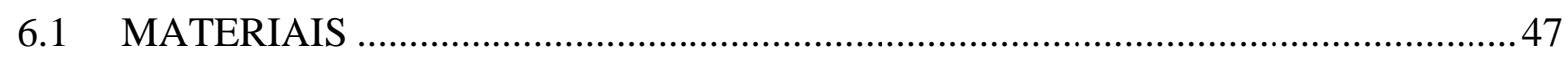

6.2 MOLDAGEM

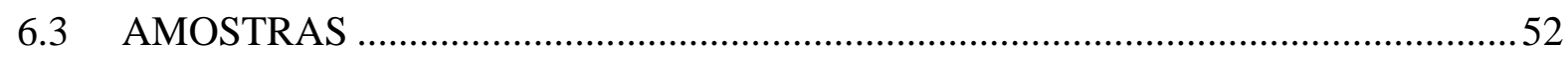

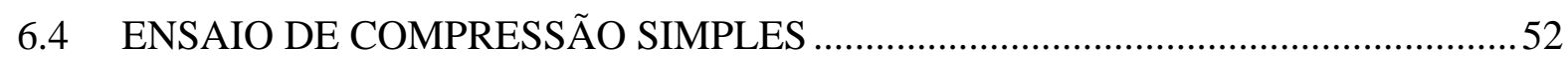

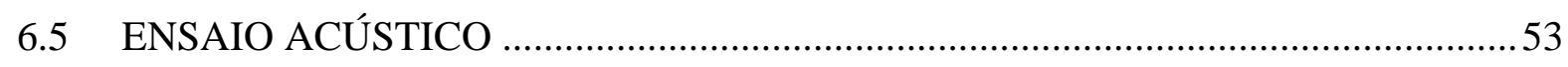

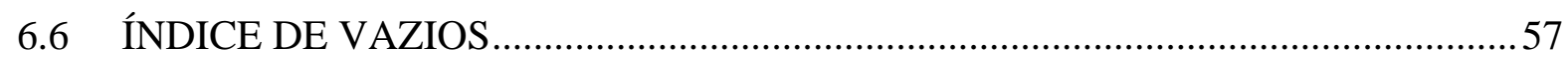

7. RESULTADOS .......................................................................................................................59

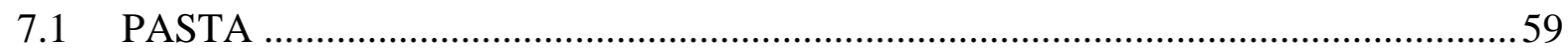

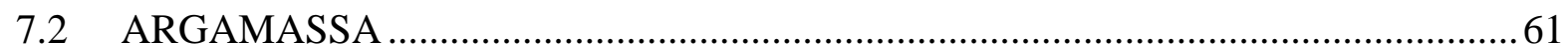

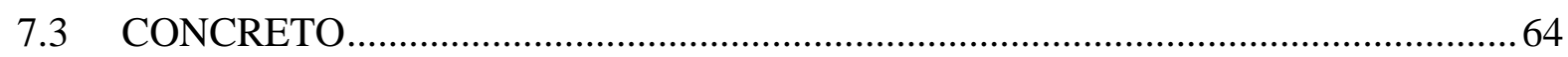

7.4 FATORES INFLUENTES AO MÓDULO DE ELASTICIDADE................................68 
7.5 RELAÇÃO ENTRE MÓDULO DE ELASTICIDADE DETERMINADO NA

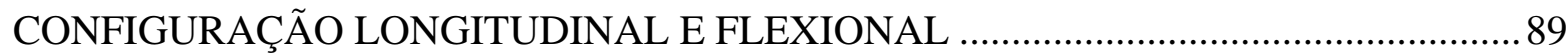

7.6 MÓDULO DE CISALHAMENTO E COEFICIENTE DE POISSON .......................91

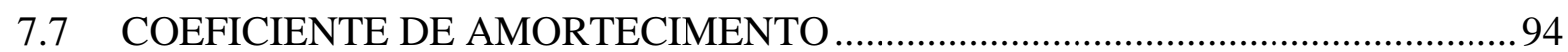

7.8 RELAÇÃO ENTRE MÓDULO DE ELASTICIDADE DINÂMICO E ESTÁTICO AOS 28 DIAS

7.9 RELAÇÃO ENTRE TENSÃO DE RUPTURA E MÓDULO DE ELASTICIDADE DINÂMICO AOS 28 DIAS 100

7.10 RELAÇÃO ENTRE TENSÃO DE RUPTURA E MÓDULO DE ELASTICIDADE DINÂMICO AOS 28 DIAS 101

7.11 EQUAÇÕES EMPÍRICAS 102

7.12 FORMULAÇÃO PARA MATERIAIS COMPÓSITOS 104

8. CONCLUSÃO. 119

9. REFERÊNCIAS BIBLIOGRÁFICAS 122

10. APÊNDICE A - CONTROLE DE MATERIAIS. 126

11. APÊNDICE B - CÁlCULO DO MÓDULO DE ELASTICIDADE DINÂMICO DA AREIA 


\section{INTRODUÇÃO}

Para projetos estruturais usuais, a variável fundamental de controle das características do concreto é a resistência à compressão, determinada facilmente pelo ensaio de compressão simples. Entretanto, em verificações de deslocamentos, aberturas de fissuras, vibrações excessivas, sismos, efeitos de segunda ordem, estabilidade global e controle da estabilidade dimensional, dentre outras situações avaliadas em projetos estruturais, faz-se necessária à adoção do módulo de elasticidade do material. Especialmente para os casos de verificações de vibrações excessivas e sismos é importante a utilização do módulo de elasticidade dinâmico $\left(\mathrm{E}_{\mathrm{d}}\right)$.

Expressões matemáticas de natureza empírica tem como parâmetro fundamental a resistência à compressão característica aos 28 dias $\left(\mathrm{f}_{\mathrm{ck}}\right)$, e são amplamente utilizadas no meio técnico para se estimar o módulo de elasticidade estático tangente inicial $\left(\mathrm{E}_{\mathrm{ci}}\right)$. Assim, para a estimativa do módulo dinâmico, é usual que se admita uma relação com $\mathrm{E}_{\mathrm{ci}}$. Todavia, estes valores nem sempre apresentam boa precisão, já que não há uma lei física que correlacione de maneira exata os valores de tais módulos. Fatores como a maturidade, o tipo do concreto produzido e a resistência na idade de interesse são fatores na determinação do módulo dinâmico. Outro parâmetro importante e pouco explorado nas equações empíricas é a não consideração de parâmetros como a zona de transição, fração volumétrica e natureza dos agregados empregados na mistura. Já a teoria dos materiais compósitos multifásicos permite o avanço dos modelos de previsão, convergindo a resultados mais precisos e realistas.

Por outro lado, com o advento e viabilização dos ensaios não destrutivos, tais como o Ensaio Acústico, houve a possibilidade do rápido e amplo estudo das propriedades dinâmicas do concreto, abrindo espaço, para a avaliação do comportamento de tais propriedades frente a variações de parâmetros atrelados à sua microestrutura. Assim, a aplicabilidade dos modelos compósitos será verificada através de comparações das previsões de modelos de compósitos bifásicos (pasta e agregados) com os resultados experimentais. 


\section{JUSTIFICATIVA}

Há poucos trabalhos que correlacionem a microestrutura do material e suas propriedades dinâmicas. Assim, pretende-se avaliar o módulo de elasticidade dinâmico, coeficiente de Poisson e amortecimento a partir da microestrutura do concreto. Portanto, a contribuição do estudo avança no sentido de melhorar o entendimento do material em situações dinâmicas, na tentativa, de que o mesmo se comporte de forma satisfatória.

\section{OBJETIVOS}

Espera-se assim, que através de variações em parâmetros da microestrutura, os resultados experimentais possibilitem investigar a correlação entre as propriedades dinâmicas a microestrutura do material. Assim, a presente pesquisa pretende:

- Avaliar o comportamento do Módulo de Elasticidade dinâmico ( $\left.\mathrm{E}_{\mathrm{d}}\right)$, Módulo de Cisalhamento $\left(G_{d}\right)$ e coeficiente de Poisson $\left(v_{d}\right)$ frente às variações microestruturais impostas;

- Correlacionar o coeficiente de amortecimento interno $(\xi)$ à microestrutura do material;

- Comparar os módulos de elasticidade estático e dinâmico aos 28 dias;

- Avaliar a aplicabilidade dos modelos teóricos de estimativas para o módulo de elasticidade dinâmico do concreto;

- Inferir a precisão das estimativas contidas em norma para módulo de elasticidade dinâmico $\left(\mathrm{E}_{\mathrm{d}}\right)$;

- Inferir a influência da zona de transição; 


\section{METODOLOGIA}

A metodologia utilizada na pesquisa está dividida em quatro etapas principais: revisão bibliográfica, procedimento experimental e análise e discussão dos resultados e conclusão. Cada etapa pode ser descrita abaixo:

- Revisão bibliográfica: Nesta etapa foram levantadas as informações necessárias sobre as propriedades dinâmicas do concreto. Por exemplo, como os parâmetros microestruturais influenciam o módulo de elasticidade dinâmico, e as outras propriedades dinâmicas tais como o coeficiente de poisson, o módulo de cisalhamento e o coeficiente de amortecimento interno. Também são apresentadas as formas para se estimar o módulo de elasticidade dinâmico conforme as equações empíricas contidas em códigos normativos ou através da formulação para materiais compósitos. $\mathrm{O}$ ensaio acústico também é descrito nesta seção.

- Procedimento Experimental: Esta seção trata a forma com que o estudo experimental foi desenvolvido. Informações como as dosagens estabelecidas, procedimentos adotados e a quantidade de corpos de provas empregados no estudo são apresentadas.

- Resultados: O impacto às propriedades dinâmicas do concreto frente as variações nos padrões de microestrutura pode ser contemplado nesta seção. Parâmetros como a porosidade, relação água-cimento, proporção volumétrica dos constituintes envolvidos na mistura, tipo de agregado graúdo, presença de superplastificante, dentre outros fatores, são correlacionados às propriedades dinâmicas do mesmo.

- Conclusão: Nesta seção são discutidos os resultados obtidos pelo estudo. 


\section{REVISÃO BIBLIOGRÁFICA}

\subsection{PROPRIEDADES MECÂNICAS DO CONCRETO}

MEHTA e MONTEIRO (2008), NEVILLE (1997) e PACELLI DE ANDRADE (1997) afirmam que as fases constituintes do compósito concreto (pasta e agregado) quando isoladas possuem diagramas de tensão-deformação tipicamente lineares. Todavia, quando combinadas em uma mistura apresentam comportamento não linear, conforme a Figura 1:

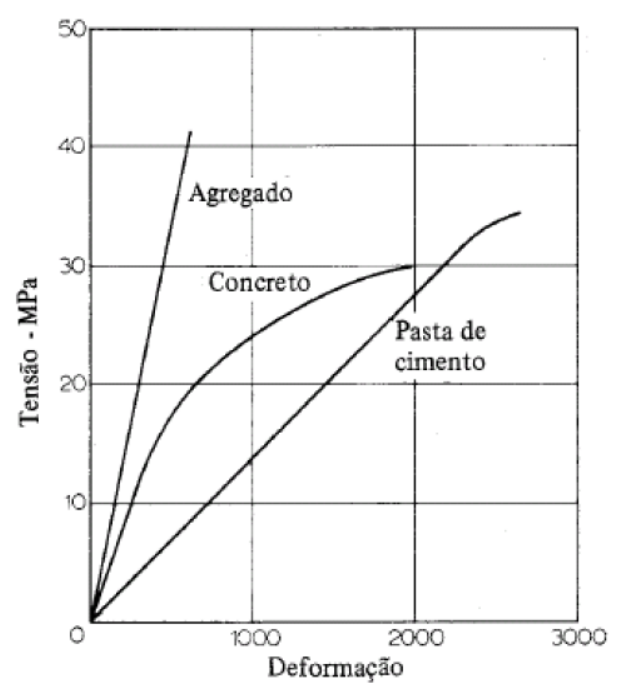

Figura 1 - Comportamento tensão-deformação do concreto e seus constituintes (NEVILLE, 1997).

Além disso, MEHTA e MONTEIRO (2008) relatam que outro fator o qual torna o concreto um material de comportamento tensão-deformação não linear é o fenômeno da microfissuração progressiva. Antes mesmo da aplicação do carregamento, a zona de transição entre o agregado e a matriz apresentará microfissuras prévias, oriundas do processo de exsudação e condições de cura, acentuando ainda mais a não linearidade do diagrama de tensão-deformação. Ou seja, a zona de transição é responsável pela não linearidade do concreto.

Entretanto e segundo PACELLI DE ANDRADE (1997) e MEHTA e MONTEIRO (2008), ainda que o concreto apresente comportamento não linear, é de suma importância à estimativa de suas propriedades elásticas. Assim, é conveniente a adoção de valores de referência para as propriedades elásticas, e que estas sejam adequadas para as diversas verificações de projeto. 
Assim, nas próximas seções serão abordados os principais conceitos atrelados às propriedades elásticas do concreto.

\subsubsection{MÓDULO DE ELASTICIDADE}

Para as várias aplicações do concreto, há diferentes tipos de definições para o módulo de elasticidade. Assim, e de acordo com as principais utilizações, merecem destaque no corrente trabalho: módulo tangente, secante e dinâmico.

SHEHATA (2005) relata que o módulo tangente é obtido através da inclinação de uma reta tangente a qualquer ponto do diagrama de tensão-deformação. Particularmente o módulo de elasticidade calculado na origem é denominado tangente inicial, e convencionado como $\mathrm{E}_{\mathrm{ci}}$. Cabe também a apresentação do que preconiza a ABNT NBR 8522:2003, em que o módulo de elasticidade tangente inicial é equivalente ao módulo de elasticidade secante a $30 \%$ de $\mathrm{f}_{\mathrm{c}}$ ou o cordal entre $0,5 \mathrm{MPa}$ e $30 \%$ de $\mathrm{f}_{\mathrm{c}}$, sendo $\mathrm{f}_{\mathrm{c}}$ a tensão de ruptura à compressão do concreto. É necessário também ressaltar o texto da ABNT NBR 6118:2014, em que se estabelece que o módulo tangente deve ser utilizado, por exemplo, em avaliações do comportamento global da estrutura e cálculo de perdas de protensão.

Já o módulo de elasticidade secante $\left(\mathrm{E}_{\mathrm{cs}}\right)$, segundo os trabalhos desenvolvidos por MEHTA e MONTEIRO (2008), é obtido através da inclinação de uma reta que passa pela origem e por outro ponto em um nível de tensão pré-definido. SHEHATA (2005) destaca que quando não é mencionado tal nível de tensão, admite-se que este esteja entre valores de 0,4 e 0,5 de $f_{c}$. A ABNT NBR 6118:2014 sugere que o módulo secante seja utilizado nas análises elásticas de projeto, como por exemplo, as análises de esforços solicitantes e verificação de estados limites de serviço.

Enfim, o módulo de elasticidade dinâmico $\left(E_{d}\right)$, conforme o que é exposto por SHEHATA (2005), é importante na avaliação do comportamento de estruturas submetidas a ações dinâmicas de diferentes naturezas, sendo esta grandeza determinada através de ensaios ultrassônicos, dinâmicos e acústicos. Ao referir-se a tal assunto, o trabalho de MEHTA e MONTEIRO (2008) relata que o módulo dinâmico é relacionado a uma deformação instantânea muito pequena, podendo vir a ser confundido com o módulo de elasticidade tangente inicial $\left(\mathrm{E}_{\mathrm{ci}}\right)$. Entretanto o autor salienta que para valores absolutos os mesmos diferem, pois geralmente o módulo dinâmico é superior aos módulos estáticos em $20 \%, 30 \%$ e $40 \%$ para os concretos de alta, média e baixa resistência, respectivamente. 
Ainda na mesma linha, NEVILLE (1997), embasado nas propriedades da microestrutura do material, explica o fenômeno da divergência entre os módulos estático e dinâmico, já que conforme o autor, quando se trata do módulo dinâmico, há ausência de tensão significativa, e assim, não é induzida nenhuma microfissura no concreto, fazendo com que a deformação associada ao módulo seja quase que puramente elástica. Assim, os trabalhos de NEVILLE (1997) e SHEHATA (2005) vêm a reforçar que os valores nem sempre apresentam fácil comparação, já que não há uma lei física que correlacione de maneira exata os módulos estático e dinâmico. Todavia, MALHOTRA e SIVASUNDARAM (2004) procuram elaborar uma equação que estabeleça a relação entre os módulos dinâmicos e estáticos, sendo esta em função do módulo estático e determinada conforme a Equação (1):

$$
\frac{E_{c i}}{E_{d}}=0,368+1,263 \cdot 10^{-5} \cdot E_{c i}, \text { em MPa } \quad \text { Equação (1) }
$$

Em que: $E_{\mathrm{ci}}$ e $\mathrm{E}_{\mathrm{d}}$ são o módulo estático tangente inicial e dinâmico, respectivamente;

Posteriormente à apresentação das definições dos tipos de módulo de elasticidade, faz-se necessária e oportuna à exposição dos fatores que influem tal grandeza.

Assim, o primeiro fator impactante apresentado por MEHTA e MONTEIRO (2008) é a relação água-cimento. Segundo o que é relatado, a lei de Abrams estabelece que o fator água-cimento influência fortemente a resistência do concreto, e que por sua vez, tem intima dependência com o módulo de elasticidade. Por exemplo, os concretos com menor relação água-cimento tendem a ser mais resistentes e rígidos, pois a diminuição da quantidade relativa de água na mistura tende a diminuir a porosidade, e assim, tal diminuição da porosidade gera o aumento da capacidade em restringir as deformações solicitantes. Por outro lado, considerando os concretos com maior relação água-cimento, se observará a menor capacidade de restrição às deformações impostas à matriz, graças ao aumento da porosidade. Portanto, o aumento do fator água-cimento gera o progressivo enfraquecimento da matriz, aumentando assim a porosidade e afetando diretamente a resistência e a rigidez do concreto. Cabe também citar os trabalhos de MELO NETO e HELENE (2002), BAWA e GRAFT-JOHNSON (1969) e LYDON e IACOVOU (1995). MELO NETO e HELENE (2002) apresentam os resultados experimentais de medidas do módulo de Elasticidade Tangente Inicial $\left(\mathrm{E}_{\mathrm{ci}}\right)$ para variadas relações água-cimento e consistência fixa. Já BAWA e GRAFT-JOHNSON (1969) e também LYDON e 
IACOVOU (1995) utilizam respectivamente a técnica de excitação por impulso e a técnica do ultrassom para verificar a influência da relação água-cimento ao módulo de elasticidade dinâmico $\left(E_{d}\right)$. Assim, todos os resultados apontam que a diminuição no fator águacimento é acompanhada pelo aumento do Módulo de Elasticidade. Cabe também salientar que uma vez a porosidade sendo causa e consequência da relação água-cimento, a interdependência entre a porosidade e o módulo de elasticidade pode ser apresentada conforme as equações de BOCCACCINI e BOCCACCINI (1997) e MACKENZIE (1950):

Tabela 1 - Relação entre porosidade e módulo de elasticidade

\section{BOCCACCINI e BOCCACCINI (1997)}

$$
E(P)=E_{0}\left(1-P^{2 / 3}\right)^{s}
$$

Em que:

$E$ é o módulo de elasticidade do material;

$P$ é a porosidade;

$E_{0}$ é o módulo de elasticidade intrínseco à porosidade zero;

$s$ é fator dependente da forma dos poros ( $s=1$ para poros circulares)

MACKENZIE (1950)

$$
E(P)=E_{0}\left(1-K \times P+(K-1) \times P^{2}\right)
$$

Em que:

$E$ é o módulo de elasticidade do material;

$P$ é a porosidade;

$E_{0}$ é o módulo de elasticidade intrínseco à porosidade zero;

$K$ é fator dependente do coeficiente de Poisson $(v) \rightarrow K=\frac{15}{7}\left(\frac{1-v}{1-\frac{5 v}{7}}\right)$ 
O segundo fator influente que pode ser levantado por SHAH e AHMAD (1994) e constatado por BESHR, ALMUSALLAM e MASLEHUDDIN (2003) é a influencia das propriedades elásticas do agregado graúdo. Tal fenômeno pode ser devidamente explicado pela regra da mistura, uma vez que, para a mesma proporção volumétrica de materiais envolvidos na mistura, quanto maior for o módulo de elasticidade individual dos componentes, maior será o módulo de elasticidade do concreto resultante. Assim, MEHTA e MONTEIRO (2008) relatam que a porosidade do agregado é um dos fatores mais influentes no módulo de elasticidade. Isto vem ao encontro do que SHAH e AHMAD (1994) relatam, pois os concretos produzidos por rochas de baixa porosidade (como o calcário, basalto e diabásio) tendem a gerar concretos com maior módulo de elasticidade quando comparados a concretos produzidos por rochas de alta porosidade (como os cascalhos e granitos). Cabe também citar o trabalho de KLISZCZEWICZ e AJDUKIEWICZ (2002), em que se propõe um estudo comparativo do módulo de elasticidade tangente inicial $\left(\mathrm{E}_{\mathrm{ci}}\right)$ de amostras contendo três tipos litológicos de agregados graúdos tipicamente utilizados na Polônia (basalto, granito e seixo rolado) e a equação estabelecida pelo EUROCODE 2. Os resultados obtidos, conforme a Figura 2, demostram que para a mesma resistência característica à compressão $\left(\mathrm{f}_{\mathrm{ck}}\right)$, o tipo de agregado graúdo utilizado na mistura tem efeito significativo no valor do módulo de elasticidade tangente $\operatorname{inicial}\left(\mathrm{E}_{\mathrm{ci}}\right)$ :

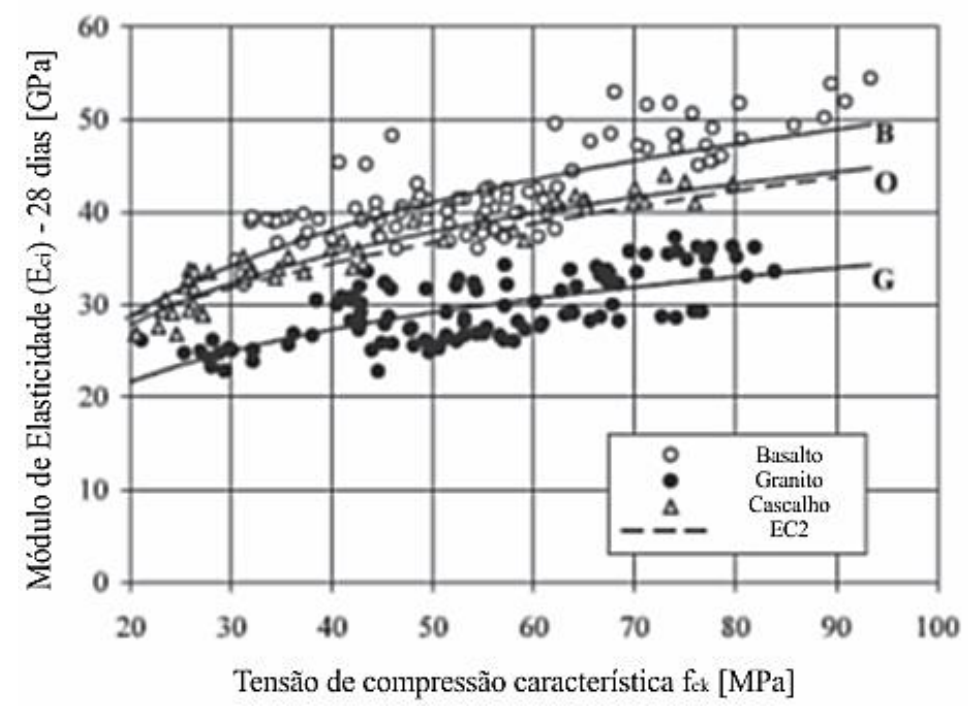

Figura 2 - Módulo de elasticidade de amostras de concreto contendo diferentes tipos de agregados (Fonte: KLISZCZEWICZ E AJDUKIEWICZ (2002)). 
MEHTA e MONTEIRO (2008) e SHAH e AHMAD (1994) ainda salientam que outras características atreladas ao agregado, tais como sua dimensão, forma, distribuição granulométrica, textura e mineralogia também influenciam os valores de módulo de elasticidade do concreto. Estes fatores tendem a impactar fortemente as características da zona de transição, induzindo fissuras no concreto e afetando assim o comportamento do diagrama de tensão-deformação do concreto. Cabe citar o trabalho de ELSHARIEF, COHEN e OLEK (2003), em que se verifica através da microscopia eletrônica que a redução do tamanho do agregado tende a reduzir a porosidade da zona de transição, enrijecendo o concreto e aumentando assim seu módulo de elasticidade. Por sua vez, MONTEIRO, MASO e OLLIVIER (1985) relatam que a espessura da zona de transição é determinada pela intensidade dos efeitos de superfície produzidos pelo agregado graúdo. Assim, os autores salientam que a espessura da "auréola de transição", que surge como "ligação" entre o agregado e a pasta, é determinada pelo tamanho dos agregados graúdos, sendo mais espessa para os agregados maiores, e o oposto para agregados menores. Já SIMEONOV e AHMAD (1995) descrevem que a superfície total dos agregados influenciam o volume e o módulo de elasticidade da zona de transição, que por sua vez, influi nas propriedades elásticas do concreto.

É neste viés, que alguns dos principais pesquisadores da microestrutura do concreto, isto é, MEHTA e MONTEIRO (2008), MASO (1980), MONTEIRO (1985) e BENTUR (1990) estudaram a influência da zona de transição entre o agregado e a matriz na rigidez do concreto. Assim, através dos trabalhos supracitados é consensual que, nas primeiras idades, um filme de água instala-se sobre a superfície do agregado graúdo, graças ao fenômeno da exsudação. Este filme tende a aumentar a relação água-cimento local. Posteriormente, íons de cálcio, sulfato, hidroxila e aluminato de cálcio, combinam-se formando etringita e hidróxido de cálcio, em detrimento ao C-S-H (gel silicato de cálcio hidratado), principal fonte de resistência e rigidez da pasta. Mais que isto, este excesso de água é a condição ideal para que ocorra a difusão de íons, possibilitando assim, a formação de cristais de grande porte, fazendo com que a microestrutura da região seja mais porosa quando comparada à matriz cimentícia. Segundo SIMEONOV e AHMAD (1995), a introdução do agregado graúdo na mistura, gera, nas primeiras idades, um pequeno fluxo de água no sentido da pasta para a superfície do agregado. Assim, graças a variação da relação água-cimento, nota-se o aumento do módulo de elasticidade da argamassa, e paralelamente, a diminuição da rigidez na região periférica ao agregado. A tendência é que 
esta taxa de migração seja maior para concretos com razão água-cimento mais elevadas. Já MONTEIRO, MASO e OLLIVIER (1985) e MONTEIRO (1985) utilizaram-se da técnica da microscopia eletrônica e raios-X para se constatar experimentalmente a grande concentração de etringita e hidróxido de cálcio na periferia dos agregados graúdos, quando comparados aos níveis da matriz. Por sua vez, MASO, OLLIVIER e BOURDETTE (1995) salientam que o excesso de porosidade é, ao mesmo tempo, a causa e a consequência da existência desta zona de transição. Outro aspecto que também contribui intensamente no desenvolvimento de planos de fraqueza desta região é revelado por MEHTA e MONTEIRO (2008), MASO (1980), BENTUR (1990) e MONTEIRO (1985). Conforme os pesquisadores, a existência de um plano de orientação preferencial para a formação dos cristais de hidróxido de cálcio tende a ser o segundo fator crítico para a formação do "elo mais fraco", contribuindo assim, na formação de planos de fraqueza e diminuindo ainda mais a resistência e a rigidez não somente da zona de transição, mas de toda mistura de concreto. Portanto, mesmo que os constituintes da mistura tenham elevada rigidez, as características elásticas da zona de transição serão determinantes para a transferência de energia entre todos os componentes da mistura, influenciando assim, o módulo de elasticidade do concreto.

Em outra frente de trabalho, BAWA e GRAFT-JOHNSON (1969) realizam um importante e amplo estudo sobre os fatores que influenciam o módulo de elasticidade dinâmico do concreto. $\mathrm{O}$ trabalho demonstra então que a maturidade e a condição de cura também são fatores atuantes ao módulo de elasticidade dinâmico $\left(\mathrm{E}_{\mathrm{d}}\right)$. Os resultados desta pesquisa demonstraram que para uma mesma relação água-cimento o valor do módulo de elasticidade dinâmico $\left(\mathrm{E}_{\mathrm{d}}\right)$ é afetado tanto pela idade quanto pelas condições de cura. Assim, nota-se o que o módulo de elasticidade dinâmico $\left(\mathrm{E}_{\mathrm{d}}\right)$ permanece aproximadamente constante para a condição de cura seca, e por outro lado, se desenvolve de forma significativa para as condições de cura ao ar livre, úmida e com polietileno. Por sua vez, LYDON e IACOVOU (1995) afirmam que o módulo de elasticidade dinâmico $\left(E_{d}\right)$ aumenta com o decorrer do tempo, atingindo uma assíntota para as idades mais avançadas. É necessário ressaltar que o efeito da maturidade sobre o módulo de elasticidade pode ser avaliado conforme a equação a seguir, contida no CEB-FIP de 2010:

$$
E(t)=\beta_{E} \times E_{28} \quad \text { Equação (2) }
$$


Em que:

$E(t)$ é a função que representa a evolução do módulo de elásticidade em relação ao tempo;

$E_{28}$ é o termo que representa o módulo de elasticidade aos 28 dias;

$\beta_{E}$ é o termo que representa a contribuição do tempo, conforme a Equação (3):

$$
\beta_{E}=\left\{\exp \left\{s\left[1-\left(\frac{28}{t}\right)^{0,5}\right]\right\}\right\}^{0,5} \quad \text { Equação (3) }
$$

\subsubsection{COEFICIENTE DE POISSON}

O coeficiente de Poisson $(v)$ é a razão entre as deformações na direção transversal e axial, quando aplicado o carregamento axial. É correntemente utilizado no cálculo de estruturas estaticamente indeterminadas, tais como as barragens e túneis. De acordo com MEHTA e MONTEIRO (2008), os autores ainda relatam que para o caso do concreto, os valores do coeficiente de Poisson estático variam no intervalo de 0,15 a 0,20 . Por fim, os pesquisadores explicam que não há uma relação coerente entre o coeficiente de Poisson e as características do concreto, tais como a relação água-cimento, o tempo de cura e a distribuição granulométrica do agregado.

Já NEVILLE (1997) explica que o concreto é um material anisotrópico, sendo o coeficiente de Poisson influenciado por vários fatores, tais como o módulo de elasticidade e o peso específico do agregado. Entretanto o autor salienta que não se podem fazer generalizações sobre o parâmetro, já que os fatores que influenciam tal grandeza ainda não estão bem estabelecidos. Para as atividades de projeto, o autor estabelece o intervalo de 0,17 a 0,20 como uma estimativa coerente. Finalmente se estabelece que o Poisson obtido através de ensaios dinâmicos difere do obtido por meio de ensaios estáticos, uma vez que se trata de duas situações físicas distintas, em que a heterogeneidade do concreto responde de forma diferente às duas situações.

Finalmente cabe citar o trabalho de KLISZCZEWICZ e AJDUKIEWICZ (2002), que realizam uma análise do coeficiente de Poisson estático para amostras contendo três tipos litológicos de agregados graúdos tipicamente utilizados na Polônia (basalto, granito e seixo rolado). $\mathrm{O}$ estudo demonstra que há divergência significativa nos valores de coeficiente de 
Poisson em função dos agregados empregados na mistura, variando de 0,155 para o cascalho até 0,205 para o basalto.

\subsubsection{MÓDULO DE CISALHAMENTO}

Por definição, o Módulo de cisalhamento $(G)$ é a razão entre a tensão de cisalhamento aplicada $(\tau)$ e a deformação associada a esta tensão $(\gamma)$, conforme a Equação (4):

$$
G=\frac{\tau}{\gamma}
$$

Assim, tal propriedade elástica exprime a capacidade de um material em se deformar na componente de cisalhamento. A partir do coeficiente de Poisson e o módulo de elasticidade longitudinal poderá se definir o módulo de cisalhamento através da seguinte relação para materiais isotrópicos:

$$
G=\frac{E}{2(1+v)}
$$

Em que:

E é o módulo de elasticidade;

G é o módulo de cisalhamento;

$v$ é o coeficiente de Poisson.

Entretanto, NEVILLE (1997) ressalta que o concreto é um material anisotrópico, e assim, esta relação pode não ser verdadeira. Todavia, reconhecendo esta limitação de modelo, se adotará, na presente pesquisa, a hipótese simplificadora onde o concreto seja um material isotrópico, e assim, a Equação (5) será admitida como válida.

Portanto e considerando tal abordagem, poderá se concluir que o valor do módulo de cisalhamento tem variação aproximadamente linear em relação ao módulo de Elasticidade. Isto se dá pelo fato de que o coeficiente de Poisson varia pouco em relação às outras propriedades, como foi anteriormente abordado. 


\subsubsection{MÓDULO VOLUMÉTRICO}

O módulo volumétrico de um material (K) é a constante elástica que exprime a razão entre tensão volumétrica e a deformação volumétrica. Esta propriedade descreve a capacidade do material em se deformar volumetricamente quando carregado em todas as direções (ou seja, carregado hidrostaticamente). O mesmo pode ser obtido, segundo a seguinte relação, para o caso de materiais isotrópicos:

$$
K=\frac{2 G(1+v)}{3(1-2 v)} \quad \text { Equação (6) }
$$

\subsubsection{ESTIMATIVAS DO MÓDULO DE ELASTICIDADE}

As estimativas do módulo de elasticidade são importantes nas etapas preliminares de projeto. $\mathrm{Na}$ falta de maiores especificações, as estimativas ajudam a avaliar o comportamento do material antes mesmo da realização dos ensaios de caracterização. Assim e de acordo com o objetivo do corrente trabalho, faz-se justa e necessária a exposição dos modelos de estimativas utilizados nas variadas práticas da engenharia. Desta forma, a estimativa do módulo de elasticidade (e das outras propriedades elásticas) pode ser feita através das equações empíricas ou dos modelos teóricos de previsão, conforme o que será apresentado nos parágrafos subsequentes.

Conforme MEHTA e MONTEIRO (2008), os modelos empíricos deram origem às equações de estimativa encontradas em norma. Estas equações geralmente relacionam o módulo de elasticidade com a densidade e a resistência do concreto, e devem ser utilizadas em etapas iniciais de projeto, onde não há especificação detalhada sobre os materiais que irão compor a mistura. Assim, como estimativa inicial as equações empíricas são coerentes. Isto porque as resistências individuais dos materiais constituintes do concreto, agregados, pasta e zona de transição, estão intimamente ligadas à resistência final do produto. Logo, a resistência do concreto produzido influirá diretamente na capacidade de restrição às deformações impostas à matriz. Por sua vez, a porosidade do agregado está atrelada a seu módulo de elasticidade, e assim, uma boa estimativa desta porosidade do agregado será através do peso unitário do concreto produzido. Alternativamente pode-se também considerar algum coeficiente que represente o tipo de agregado empregado na mistura. Logo, a tabela a seguir contempla alguns dos modelos de previsão empírica 
contidos em norma, utilizados para se estimar o módulo de elasticidade tangente inicial $\left(\mathrm{E}_{\mathrm{ci}}\right)$ :

Tabela 2 - Módulo de Elasticidade Tangente Inicial - Equações Normativas

\section{ACI 318 de 2011}

$$
E_{c i}=w_{c}^{1,5} \times 0,043 \times \sqrt{f_{c}^{\prime}}, \mathrm{em} \mathrm{MPa}
$$

Em que: $f_{c}^{\prime}$ é a resistência de compressão característica aos 28 dias, em MPa, conforme o que é preconizado por esta norma;

$w_{c}$ é a densidade do concreto em $\mathrm{kg} / \mathrm{m}^{3}$;

Obs.: Equação válida para concretos com densidade entre 1500 e 2500 kg/m³;

\section{CEB-FIP de 2010}

$$
E_{c i}=\alpha_{e} \times 2,15 \times 10^{4} \times\left(\frac{f_{c m}}{10}\right)^{1 / 3}, \text { em MPa }
$$

Em que: $f_{c m}$ é a resistência à compressão média na idade de interesse, em MPa;

$\alpha_{\mathrm{e}}$ é um fator incorporado à fórmula que depende da natureza do agregado, sendo 1,2 para basalto e diabásio, 1,0 para granito e gnaisse, 0,9 para calcário e 0,7 para arenito.

\section{ABNT NBR 6118:2014}

$$
E_{c i}=\alpha_{e} \times 5600 \times \sqrt{f_{c k}}, \text { em MPa; }
$$

Em que: $f_{c k}$ é a resistência a compressão característica aos 28 dias, em MPa, conforme o que é preconizado por esta norma;

$\alpha_{\mathrm{e}}$ é um fator incorporado à fórmula que depende da natureza do agregado, sendo 1,2 para basalto e diabásio, 1,0 para granito e gnaisse, 0,9 para calcário e 0,7 para arenito. 
Assim, o procedimento que é usualmente utilizado para a estimativa do módulo de elasticidade dinâmico $\left(\mathrm{E}_{\mathrm{d}}\right)$ consiste no emprego de alguma das equações empíricas apresentadas acima, juntamente com a hipótese da relação entre os módulos estático e dinâmico, valendo-se, por exemplo, da Equação (7):

$$
\frac{E_{c i}}{E_{d}}=0,368+1,263 \cdot 10^{-5} \cdot E_{c i}, \text { em MPa } \quad \text { Equação (7) }
$$

Entretanto, este procedimento tende a causar incerteza, pois conforme o que foi abordado anteriormente por NEVILLE (1997) e SHEHATA (2005), não há uma lei física que correlacione de maneira exata os valores de tais módulos.

Já o trabalho de BAWA e GRAFT-JOHNSON (1969) traz em sua revisão bibliográfica algumas das equações para estimativas do módulo de elasticidade dinâmico em função da tensão de ruptura das amostras $\left(f_{c}\right)$, sendo estas apresentadas conforme a tabela a seguir:

Tabela 3 - Módulo de Elasticidade Dinâmico - Equações de Estimativa (Fonte: BAWA E GRAFT-JOHNSON (1969))

\section{TAKABAYASHI, 1954}

$$
E_{d}=2,60 \times 10^{4} \times \sqrt{f_{c}}, \mathrm{em} \mathrm{kg} / \mathrm{cm}^{2} ;
$$

Em que: $\mathrm{f}_{\mathrm{c}}$ é a tensão de ruptura à compressão em $\mathrm{kg} / \mathrm{cm}^{2}$;

TAKANO, 1954

$$
E_{d}=5,21 \times 10^{4} \times \sqrt{f_{c}}, \mathrm{em} \mathrm{kg} / \mathrm{cm}^{2} ;
$$

Em que: $\mathrm{f}_{\mathrm{c}}$ é a tensão de ruptura à compressão em $\mathrm{kg} / \mathrm{cm}^{2}$; 


\section{KAMEDA, 1954}

$$
E_{d}=(0,5+3,4(a / c)) \cdot 10^{4} \cdot \sqrt{f_{c}}, \mathrm{em} \mathrm{kg} / \mathrm{cm}^{2}
$$

Em que: $\mathrm{f}_{\mathrm{c}}$ é a tensão de ruptura à compressão em $\mathrm{kg} / \mathrm{cm}^{2}$ e o termo a/c é a relação águacimento;

SHARMA E GRUPTA, 1960

$$
E_{d}=8,67 \cdot 10^{6} \cdot\left(\frac{f_{c}}{f_{c}+15550}\right), \mathrm{em} \mathrm{kg} / \mathrm{cm}^{2}
$$

Em que: $\mathrm{f}_{\mathrm{c}}$ é a tensão de ruptura à compressão em $\mathrm{kg} / \mathrm{cm}^{2}$;

Entretanto e de acordo com o que foi anteriormente exposto sobre os fatores de influência no módulo de elasticidade, a grandeza não depende somente da tensão de ruptura à compressão aos 28 dias, mas também de outros fatores. Estes fatores são: maturidade, o tipo de cimento empregado, natureza do agregado, resistência na idade de interesse, zona de transição, fração volumétrica dos componentes da mistura, dentre outros. Assim, BAWA e GRAFT-JOHNSON (1969), após demonstrar experimentalmente que o módulo de elasticidade dinâmico do concreto é afetado por alguns destes vários fatores, concluem que é difícil encontrar uma relação universal entre o módulo dinâmico e a resistência à compressão. Logo, fica evidente, que as equações contidas, tanto na Tabela 2, quanto na Tabela 3, apresentam as mesmas limitações de modelo.

AÏTCIN e MEHTA (1990) então comprovam a dependência entre o módulo de elasticidade do concreto e as propriedades dos constituintes da mistura. Desta forma, outra abordagem para o problema seria a estimativa utilizando a formulação para materiais compósitos. De acordo com MEHTA e MONTEIRO (2008), uma vez conhecidos os módulos de elasticidade individuais para cada constituinte do compósito, poderá se obter uma solução coerente para o problema da estimativa do módulo de elasticidade do concreto. Portanto, o problema agora se resume em obter de forma precisa o módulo de elasticidade de cada componente da mistura, e assim, realizar a ponderação de tais de 
acordo com sua contribuição volumétrica no produto final. Assim, seguem alguns dos modelos bifásicos que tem por finalidade a avaliação do comportamento dos materiais compósitos:

O primeiro modelo apresentado fora proposto por VOIGT (1889). Sua aplicação ao concreto é conforme os estudos de MONTEIRO e CHANG, (1995), TOPÇU, BILIR e BOĞA (2010), TOPÇU (2005) e MEHTA e MONTEIRO (2008). Este modelo bifásico considera que os constituintes do compósito estejam dispostos em paralelo, conforme a Figura 3. As deformações sempre serão simultâneas e iguais $\left(\varepsilon_{1}=\varepsilon_{2}=\varepsilon\right)$, configurando assim a condição de compatibilidade do modelo. A soma das tensões absorvidas pelos componentes é sempre igual à tensão total, sendo esta a condição de equilíbrio do modelo $\left(\sigma=\sigma_{1}+\sigma_{2}\right)$. Quanto à relação constitutiva, pode-se afirmar que o modelo é linear, podendo ser análogo a um sistema de molas lineares dispostas em paralelo, de acordo com o que é ilustrado também pela Figura 3:

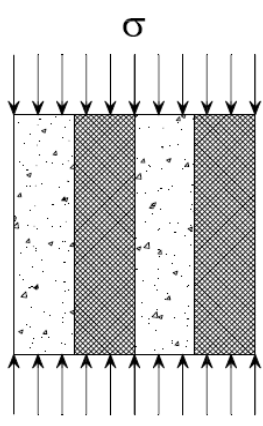

$\sigma$

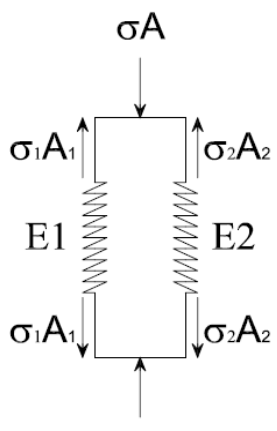

$\sigma \mathrm{A}$

Figura 3 - Modelo de Voigt (MEHTA E MONTEIRO (2008) adaptado).

Com as equações obtidas de compatibilidade, equilíbrio e lei constitutiva chega-se finalmente a Equação (8), que relaciona o módulo de elasticidade do compósito $\left(\mathrm{E}_{\text {eq }}\right)$ com os módulos de elasticidade de seus constituintes $\left(E_{1}\right.$ e $\left.E_{2}\right)$, sempre ponderados por sua fração volumétrica $\left(\mathrm{c}_{1}=\mathrm{V}_{1} / \mathrm{V}\right.$ e $\left.\mathrm{c}_{2}=\mathrm{V}_{2} / \mathrm{V}\right)$.

$$
E_{e q}=E_{1} \times c_{1}+E_{2} \times c_{2} \quad \text { Equação (8) }
$$

Já o modelo bifásico proposto por REUSS (1929), conforme os estudos e aplicações de MONTEIRO e CHANG, (1995), TOPÇU, BILIR e BOĞA (2010), TOPÇU 
(2005) e MEHTA e MONTEIRO (2008), considera que os constituintes do compósito estejam dispostos em série, conforme a Figura 4. As deformações nos componentes podem ser diferentes, e a condição de compatibilidade é tal que a deformação total deverá ser igual à soma das deformações individuais dos elementos $\left(\varepsilon_{1}+\varepsilon_{2}=\varepsilon\right)$. Toda a tensão é suportada integralmente por todos os elementos, sendo essa a condição de equilíbrio para o modelo $\left(\sigma=\sigma_{1}=\sigma_{2}\right)$. Quanto à relação constitutiva, pode-se afirmar que o modelo é linear, podendo ser análogo a um sistema de molas dispostas em série, de acordo com o que é ilustrado também pela Figura 4.

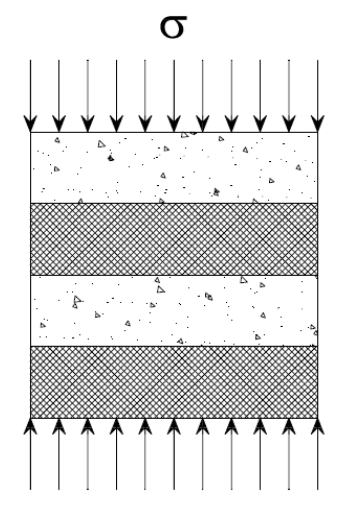

$\sigma$

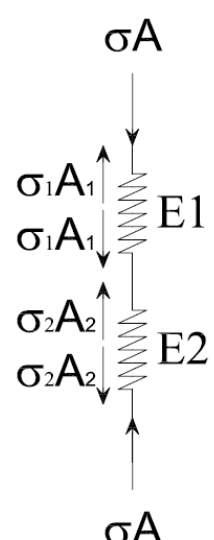

$\sigma \mathrm{A}$

Figura 4 - Modelo de Reuss (MEHTA E MONTEIRO. (2008) adaptado).

Com as equações obtidas de compatibilidade, equilíbrio e lei constitutiva chega-se finalmente a Equação (9), que relaciona o módulo de elasticidade do compósito $\left(\mathrm{E}_{\mathrm{eq}}\right)$ com os módulos de elasticidade de suas fases constituintes $\left(E_{1}\right.$ e $\left.E_{2}\right)$, sempre ponderados por sua fração volumétrica.

$$
\frac{1}{E_{e q}}=\frac{c_{1}}{E_{1}}+\frac{c_{2}}{E_{2}}
$$

MEHTA e MONTEIRO (2008) ainda afirma que os modelos de Voigt e Reuss são aproximações, uma vez que a hipótese de tensões iguais satisfaz somente as equações de equilíbrio, porém dá margem a deslocamentos descontínuos nas interfaces das fases. Por outro lado, o modelo de deformações iguais leva a um campo de deformações admissível, entretanto as tensões são descontinuas em tais interfaces. Do trabalho de HILL (1952) vem 
a comprovação de que os modelos em série e paralelo (Reuss e Voigt, respectivamente) são situações limítrofes para as estimativas do módulo de elasticidade de um determinado material compósito bifásico. Assim, qualquer estimativa através da teoria dos materiais compósitos estará contida em um intervalo de valores tais, que os limites superior e inferior serão, respectivamente, o valor do módulo de elasticidade calculado por Voigt (Paralelo) e Reuss (Série). Desta forma, MEHTA e MONTEIRO (2008) salientam que quando tais valores limites são próximos, é imediata à solução para o problema, já que um valor intermediário entre tais limites será o suficiente para representar com precisão a grandeza estudada. Entretanto, há situações onde estes intervalos serão demasiadamente grandes para as aplicações de engenharia. Assim, a solução esperada para o problema será a adoção de limites mais estreitos, que representem a grandeza de forma mais precisa.

Assim, o trabalho de HASHIN e SHTRIKMAN (1963) vem estabelecer limites mais rigorosos para a estimativa dos módulos de elasticidade, utilizando para tanto, o auxílio dos princípios variacionais da teoria linear da elasticidade para materiais multifásicos de geometria de fase arbitrária. Além disso, os trabalhos de MEHTA e MONTEIRO (2008) e SIMEONOV e AHMAD (1995) relatam a eficiência da aplicação do método para os problemas de estimativa do concreto, já que os limites são mais rigorosos, e convergem a resultados mais precisos, graças a seu forte embasamento teórico implícito.

Por conseguinte, o procedimento utilizado para o cálculo dos limites de HASHIN e SHTRIKMAN (1963) consiste basicamente em se conhecer o módulo volumétrico e de cisalhamento individuais a cada fase constituinte do compósito $\left(\mathrm{K}_{\mathrm{i}}\right.$ e $\left.\mathrm{G}_{\mathrm{i}}\right)$, e assim, através das equações a seguir apresentadas, poderá se determinar os valores limites para uma estimativa de módulo volumétrico $\left(\mathrm{K}_{\mathrm{up}}, \mathrm{K}_{\mathrm{low}}\right)$ e módulo de cisalhamento $\left(\mathrm{G}_{\mathrm{up}}, \mathrm{G}_{\mathrm{low}}\right)$. Posteriormente à definição de tais limites, valendo-se das relações entre as propriedades elásticas de materiais isotrópicos, obtêm-se finalmente os valores limites para estimativas do módulo de elasticidade efetivo. Tal procedimento de cálculo pode ser ilustrado conforme a figura subsequente: 


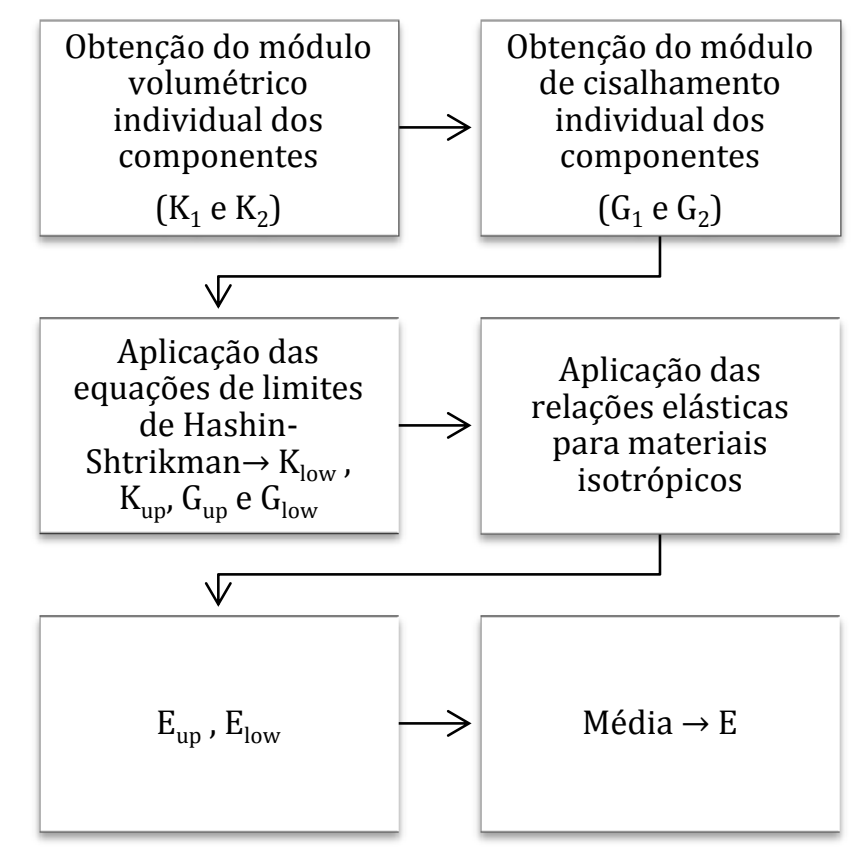

Figura 5 - Procedimento utilizado no cálculo dos limites de HASHIN e SHTRIKMAN (1963).

Desta forma, a representação do limite inferior para o módulo volumétrico $\mathrm{K}_{\text {low }}$, para um determinado compósito bifásico com constantes elásticas conhecidas $\left(\mathrm{K}_{1}, \mathrm{~K}_{2}, \mathrm{G}_{1}\right.$ e $\mathrm{G}_{2}$, com $\mathrm{K}_{1}<\mathrm{K}_{2}$ e $\mathrm{G}_{1}<\mathrm{G}_{2}$ ), é determinado pela Equação (10):

$$
K_{\text {Low }}=K_{1}+\frac{c_{2}}{\frac{1}{K_{2}-K_{1}}+\frac{3 c_{1}}{3 K_{1}+4 G_{1}}}
$$

Em que $c_{1}$ e $c_{2}$ são ponderações de volume, ou seja, $c_{1}=V_{1} / V$ e $c_{2}=V_{2} / V$ com $V=V_{1}+V_{2}$;

Já a representação do limite superior para o módulo volumétrico $\mathrm{K}_{\mathrm{Up}}$, é de acordo com a Equação (11):

$$
K_{U p}=K_{2}+\frac{c_{1}}{\frac{1}{K_{1}-K_{2}}+\frac{3 c_{2}}{3 K_{2}+4 G_{2}}}
$$

Por sua vez, a representação do limite inferior para o módulo de cisalhamento $\mathrm{G}_{\mathrm{Low}}$ é determinado pela Equação (12): 


$$
G_{\text {Low }}=G_{1}+\frac{c_{2}}{\frac{1}{G_{2}-G_{1}}+\frac{6\left(K_{1}+2 G_{1}\right) c_{1}}{5 G_{1}\left(3 K_{1}+4 G_{1}\right)}}
$$

E finalmente, a representação do limite superior para o módulo de cisalhamento $\mathrm{G}_{\mathrm{Up}}$, determinada pela Equação (13):

$$
G_{U p}=G_{2}+\frac{c_{1}}{\frac{1}{G_{1}-G_{2}}+\frac{6\left(K_{2}+2 G_{2}\right) c_{2}}{5 G_{2}\left(3 K_{2}+4 G_{2}\right)}}
$$

Desta forma, fica claro que as expressões de HASHIN e SHTRIKMAN (1963) não encontram valores limites para E, mas sim para as constantes $\mathrm{K}$ e G, que por sua vez, são relacionadas a E através de equações de materiais isotrópicos, conforme a Equação (14):

$$
E=\frac{4 K G}{3 K+G}=2 G(1+v)=3 K(1-2 v) \quad \text { Equação (14) }
$$

Em que $v$ é o coeficiente de Poisson.

Assim, uma estimativa para o módulo de elasticidade do concreto poderá ser feita, com a condição de estar contida no intervalo [ $\left.\mathrm{E}_{\mathrm{up}} ; \mathrm{E}_{\mathrm{low}}\right]$.

Elaborada através dos estudos de MEHTA e MONTEIRO (2008), TOPÇU, BILIR e BOĞA (2010), e MONTIJA (2007), a tabela a seguir trás outros modelos de compósitos bifásicos que também merecem destaque na tentativa de se estimar o módulo de elasticidade do concreto:

Tabela 4 - Modelos compósitos bifásicos (MEHTA e MONTEIRO (2008))

\section{HIRSCH (1962)}

$$
\frac{1}{E_{e q}}=(1-x)\left(\frac{c_{a}}{E_{a}}+\frac{1-c_{a}}{E_{m}}\right)+x\left(\frac{1}{c_{a} E_{a}+\left(1-c_{a}\right) E_{m}}\right)
$$

Em que,

x e (1-x) são respectivamente a contribuição relativa entre os modelos de Voigt e Reuss;

$\mathrm{E}_{\mathrm{m}}$ e $\mathrm{E}_{\mathrm{a}}$ são respectivamente o módulo de elasticidade da argamassa e do agregado graúdo; $\mathrm{c}_{\mathrm{a}}$ é a contribuição volumétrica do agregado graúdo na mistura, isto é, $\mathrm{c}_{\mathrm{a}}=\mathrm{V}_{\mathrm{a}} / \mathrm{V}_{\mathrm{c}}$; 


\section{COUNTO, 1964}

$$
\frac{1}{E_{e q}}=\left(\frac{1-\sqrt{c_{a}}}{E_{m}}\right)+\frac{1}{\left(\frac{1-\sqrt{c_{a}}}{\sqrt{c_{a}}}\right) E_{m}+E_{a}}
$$

Em que,

$\mathrm{E}_{\mathrm{m}}$ e $\mathrm{E}_{\mathrm{a}}$ são respectivamente o módulo de elasticidade da argamassa e do agregado graúdo; $\mathrm{c}_{\mathrm{a}}$ é a contribuição volumétrica do agregado graúdo na mistura, isto é, $\mathrm{c}_{\mathrm{a}}=\mathrm{V}_{\mathrm{a}} / \mathrm{V}_{\mathrm{c}}$;

\section{HANSEN, 1965}

$$
E_{c}=\left(\frac{c_{m} E_{m}+\left(1+c_{a}\right) E_{a}}{\left(1+c_{a}\right) E_{m}+c_{m} E_{a}}\right) E_{m}
$$

Em que,

$\mathrm{E}_{\mathrm{m}}$ e $\mathrm{E}_{\mathrm{a}}$ são respectivamente o módulo de elasticidade da argamassa e do agregado graúdo; $\mathrm{c}_{\mathrm{a}}$ é a contribuição volumétrica do agregado graúdo na mistura, isto é, $\mathrm{c}_{\mathrm{a}}=\mathrm{V}_{\mathrm{a}} / \mathrm{V}_{\mathrm{c}}$;

COUNTO (1964) tomou por hipótese um agregado prismático no centro de um prisma de concreto, conforme a Figura 6.a. Já HANSEN (1965) tomou por hipótese um agregado esférico localizado no centro de uma matriz de massa esférica, conforme Figura 6.b. 


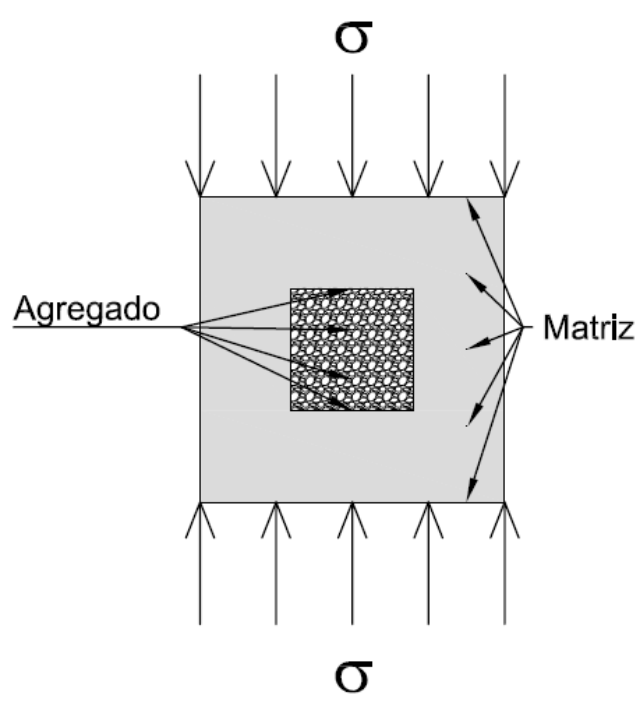

Figura 6.a - Modelo de Counto (MEHTA e MONTEIRO (2008) adaptado).

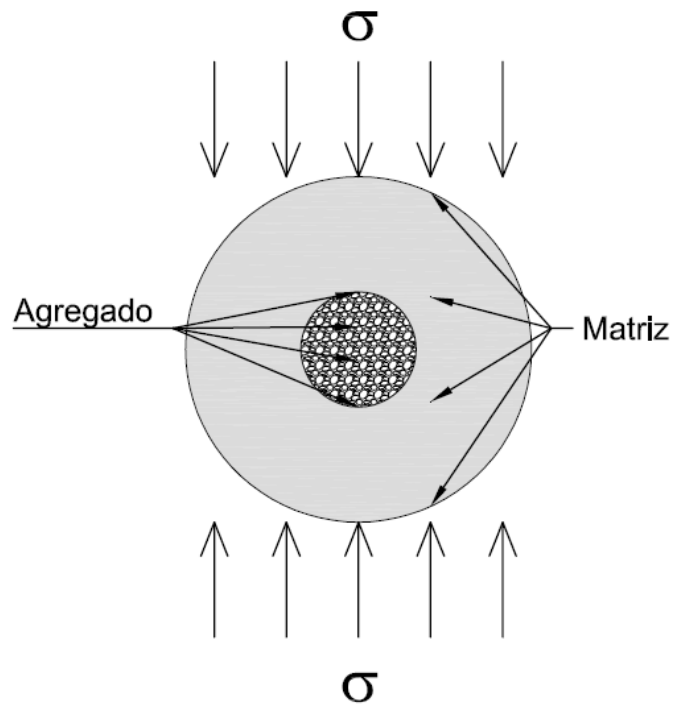

Figura 6.b - Modelo de Hansen (MEHTA e MONTEIRO (2008) adaptado).

Segundo o que foi anteriormente abordado e conforme a complementação feita por NILSEN e MONTEIRO (1993), o concreto é usualmente abordado como compósito bifásico, constituído por agregados inseridos em uma matriz cimentícia. Logo, o modelo bifásico é o mais simples para aplicação no concreto, fornecendo uma estimativa razoável para o módulo de elasticidade. Entretanto, os trabalhos de TOPÇU, BILIR e BOĞA (2010) e SIMEONOV e AHMAD (1995), afirmam que há certo erro inerente à estimativa realizada pelo modelo bifásico, unicamente pelo fato da não consideração das propriedades elásticas da zona de transição.

Além disso, SIMEONOV e AHMAD (1995) desenvolvem um importante estudo sobre a limitação dos modelos teóricos bifásicos. Os autores salientam que as propriedades elásticas da zona de transição diferem significativamente da matriz, resultando na divergência da tendência dos limites de Hashin-Shtrikman (H-S) para alguns dados experimentais. Assim, se considera que a zona de transição seja uma terceira fase, devendo ser caracterizada por propriedades médias ou equivalentes como a quantidade relativa de água na matriz de cimento. Uma vez, admitindo a hipótese de que a zona de transição seja consequência do fluxo de água no sentido da pasta para a periferia do agregado, os autores constatam que, para um dado aumento do volume de agregados na mistura $\left(\mathrm{V}_{\mathrm{a}}\right)$ : 
- Para relações água-cimento iguais ou próximas a 0,4: Não há nenhum efeito notável no módulo de elasticidade do concreto quando é realizado o aumento do volume total de agregados na mistura $\left(\mathrm{V}_{\mathrm{a}}\right)$. $\mathrm{O}$ efeito redutor de rigidez na zona de transição é paralelamente compensado pelo efeito positivo do aumento da elasticidade da pasta de cimento. Logo, os resultados experimentais demonstram o respeito aos limites de Hashin-Shtrikman (H-S) para materiais bifásicos.

- Para relações água-cimento maiores que 0,4: Com o aumento do volume total de agregados na mistura $\left(\mathrm{V}_{\mathrm{a}}\right)$, a zona de transição apresentará não só menor módulo de elasticidade quando comparado a matriz cimentícia, mas também maior espessura. A combinação desses efeitos redutores gera a divergência entre os limites HashinShtrikman (H-S) e os valores experimentais, implicando assim, em resultados experimentais menores que a previsão teórica.

- Para relações água-cimento menores que 0,4: Com um aumento do volume total de agregados na mistura $\left(\mathrm{V}_{\mathrm{a}}\right)$, o fluxo de água diminuirá a relação água-cimento da pasta, e a influência da zona de transição será insignificante ou até positiva. A zona de transição será menor, tendo suas propriedades elásticas próximas às verificadas na matriz. Estes fatores fazem com que o módulo de elasticidade experimental seja maior que o valor teórico para um compósito bifásico obtido pelos limites de Hashin-Shtrikman (H-S).

SIMEONOV e AHMAD (1995) então concluem que o comportamento elástico do concreto é estatisticamente próximo ao de uma composição bifásica, podendo ser modelado com sucesso pela lei de Hashin-Shtrikman (H-S). Além disso, tais limites também se revelam como uma ferramenta eficaz para detecção dos efeitos da zona de transição sobre as propriedades elásticas do concreto.

Por sua vez, NILSEN e MONTEIRO (1993), demonstram as limitações dos limites de Hashin-Shtrikman (H-S), alertando que o concreto não pode ser considerado um compósito bifásico perfeito, e sugerindo ainda, a inclusão nos modelos de um terceiro componente aos modelos: a zona de transição. Este trabalho tem por hipótese básica que um material bifásico perfeito sempre deverá satisfazer os limites de Hashin-Shtrikman (HS), e se ele não os respeita, este não pode ser considerado como tal. De fato, alguns dos resultados obtidos por estes pesquisadores comprovam experimentalmente a existência da terceira fase do concreto, isto porque os resultados não estão contidos nos limites propostos por Hashin-Shtrikman (H-S). 
Em suma, a hipótese bifásica é uma aproximação para o comportamento trifásico do concreto, sendo este na verdade, composto por agregado, matriz e zona de transição. A utilização do modelo bifásico como aproximação do comportamento do concreto provoca um determinado erro na estimativa, que deve então ser considerado em uma análise criteriosa.

\subsubsection{COEFICIENTE DE AMORTECIMENTO}

No presente estudo, além das propriedades elásticas, também se dará enfoque a uma propriedade de natureza dinâmica muito importante em análises de vibrações: $\mathrm{O}$ coeficiente de Amortecimento $(\xi)$.

Esta é a grandeza física responsável pela dissipação de energia de um sistema oscilatório. SILVA et al. (2000) relatam que o coeficiente de amortecimento de um sistema ou material pode ser classificado como interno, estrutural e viscoso. O interno está associado a parâmetros da microestrutura. Já o estrutural está atrelado a perdas de energia por atrito em articulações semirrígidas. Por último, o viscoso ocorre por resistência ao arraste em meio fluídico, por exemplo, a interação fluído-estrutura.

Na visão de BAWA e GRAFT-JOHNSON (1969), quando o concreto está em regime de vibração, imperfeições tais como vazios, fendas e zona de transição dão origem ao fenômeno do amortecimento. Logo, neste trabalho é confirmada experimentalmente a hipótese de que o coeficiente de amortecimento, por definição, é uma função inversa do módulo de elasticidade, e assim, quanto maior o módulo de elasticidade menor será o amortecimento, e vice-versa. Os autores ainda comprovam que para amostras com diferentes proporções volumétricas, relações água-cimento e condições de cura, houve queda do coeficiente de amortecimento para o aumento da idade, densidade e resistência à compressão. Já BACHMANN et al. (1995) relatam que para baixos níveis de tensão e pouca fissuração, o concreto apresenta valores de amortecimento interno inferior à $1 \%$.

Assim e de acordo com o que foi anteriormente exposto, há poucos estudos que relacionam o coeficiente de amortecimento à microestrutura do concreto. Portanto, faz-se justa e necessária tal investigação. 


\subsection{ENSAIO ACÚSTICO}

A caracterização dinâmica das amostras de concreto e seus constituintes será realizada através do ensaio acústico. Portanto, para o apropriado desenvolvimento do trabalho, faz-se necessária a apresentação de tal técnica.

Conforme os textos normativos ASTM E1876-01 e ASTM C215-02, o processo de obtenção das propriedades dos materiais através da frequência natural utilizando um impacto de curta duração é chamado de técnica de excitação por impulso. Conforme estas normas internacionais, quando tal técnica lança mão de captadores de aúdio para a determinação das frequências de ressonância a mesma passa a ser chamada de ensaio acústico, cujos equipamentos podem ser contemplados conforme a figura a seguir:

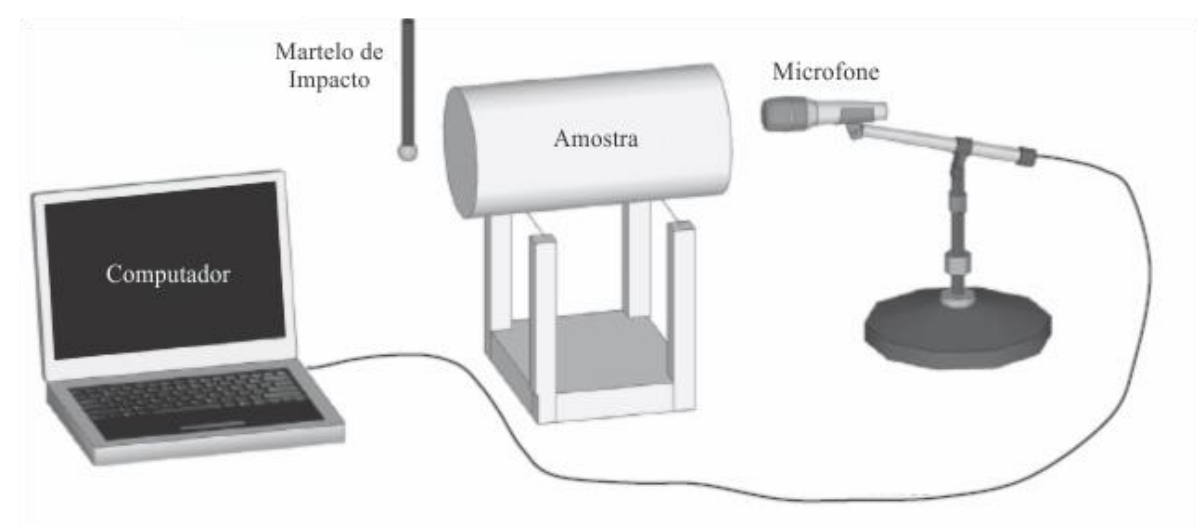

Figura 7 - Esquema do ensaio acústico (Fonte: HAACH et al., (2013)).

As vantagens e aplicações dos ensaios acústicos não destrutivos são destacadas em COSSOLINO e PEREIRA (2010) e MALHOTRA e SIVASUNDARAM (2004), uma vez que os métodos dinâmicos possibilitam a investigação de informações quantitativas e qualitativas sobre a integridade de um determinado componente estrutural. Por ser um método não destrutivo, ou não invasivo, o objeto de estudo não fica inutilizado após o ensaio e este pode ser empregado ou ensaiado muitas outras vezes. Assim, aplicam-se os métodos dinâmicos não destrutivos em uma ampla gama de problemas, com destaque para compósitos frágeis, como é o caso do concreto.

O procedimento do ensaio acústico é relatado por COSSOLINO e PEREIRA (2010) e MALHOTRA e SIVASUNDARAM (2004). Este pode ser entendido e contemplado conforme o esquema ilustrado na Figura 8.a. Impondo ao sistema uma excitação com impacto de duração muito curta, o microfone (Figura 8.b) capta as 
amplitudes no domínio do tempo. Estes dados discretos serão processados por um software que realiza a transformada rápida de Fourier (FFT) levando o problema do domínio do tempo para o da frequência. Neste estágio, já é fácil identificar as frequências naturais no gráfico de Amplitude por Frequência (como na Figura 8.c), já que as frequências naturais estão associadas às amplitudes máximas. Uma vez aplicadas as equações matemáticas, como as contempladas na ASTM E1876-01, que correlacionam a frequência natural às propriedades elásticas do material, o problema estará solucionado. Em suma, a hipótese básica em que o ensaio se apoia é que a frequência natural de vibração de um determinado corpo de prova está intimamente relacionada ao módulo de elasticidade dinâmico do material que o constitui, características geométricas e densidade. Assim, o módulo de elasticidade dinâmico pode ser determinado a partir da medição da frequência natural de vibração.
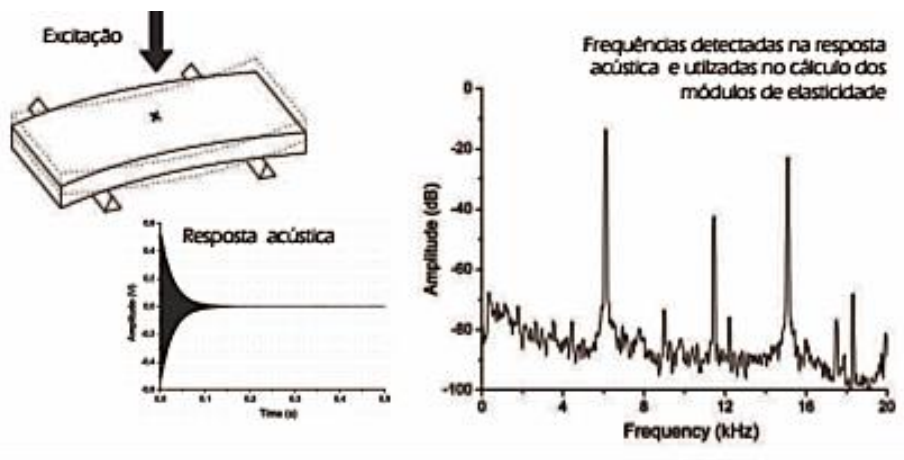

(a) 


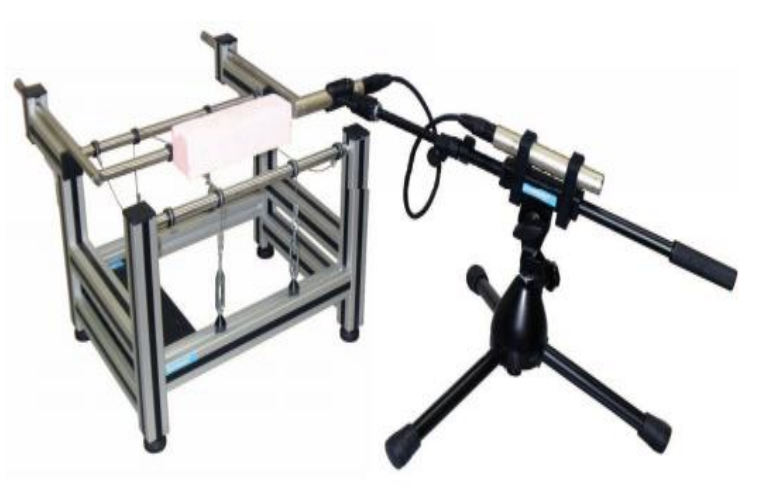

(b)

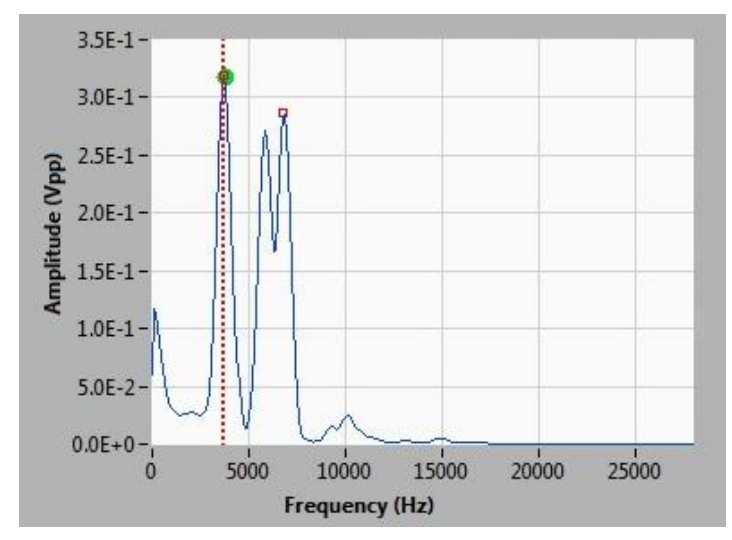

(c)

Figura 8 - Procedimento do ensaio acústico (Fonte: ATCP Engenharia Física)

(a) Resumo da técnica de excitação por impulso;

(b) Sistema de captação de dados.

(c) Picos de frequências naturais.

Para o desenvolvimento teórico da hipótese básica que foi anteriormente abordada, pode-se valer do trabalho realizado por COSSOLINO e PEREIRA (2010) e complementado por EWINS (1994). Assim, pode-se escrever, na forma tensorial, que o equilíbrio dinâmico de uma estrutura com número de graus de liberdade arbitrário é conforme a Equação (15):

$$
[M] \ddot{u}+[C] \dot{u}+[K] u=p(t)
$$

Em que:

$[M]$ ü é o termo que representa a inércia do sistema;

[C]ủ é o termo que representa a força de amortecimento viscoso;

[K]u é o termo que representa a força elástica.

Uma vez que o impulso aplicado à estrutura tem intervalo de tempo muito pequeno, podese assumir, que após certo tempo, o tensor p(t) seja nulo. Assim, é possivel reescrever a Equação (15), conforme a equação subsequente:

$$
[M] \ddot{u}+[C] \dot{u}+[K] u=0
$$

Como hipótese simplificadora, pode-se aceitar que o ensaio esteja sob vibração livre e sem amortecimento, e assim, tem-se que $[\mathrm{C}]=0$, conforme à seguir: 


$$
[M] \ddot{u}+[K] u=0 \quad \text { Equação }(17)
$$

Pela simples substituição, verifica-se facilmente que $u=\phi_{i j} \sin \left(w_{i j} t\right)$ é solução da Equação (17). Sendo este sistema de equações válidas para qualquer instante de tempo, implica-se na existência da Equação (18):

$$
\left([K]-\omega^{2}[M]\right) \phi=0 \quad \text { Equação (18) }
$$

Portanto, conclui-se que além da solução trivial, este sistema apresentará solução não nula e indeterminada, se e somente se, o respectivo determinante for nulo, conforme a equação a seguir:

$$
\operatorname{det}\left|[K]-\omega^{2}[M]\right|=0 \quad \text { Equação (19) }
$$

Desta forma, chega-se a um problema generalizado de autovetores $\left(\phi_{\mathrm{ij}}\right)$ e autovalores $\left(\omega_{i j}\right)$, onde para um sistema oscilatório de $\mathrm{N}$ graus de liberdade, os autovalores encontrados serão as frequências naturais angulares e os autovetores serão os modos de vibração correspondentes a tais frequências naturais. Conclui-se então que o fenômeno da ressonância está atrelado à matriz de rigidez $[\mathrm{K}]$ e de massa $[\mathrm{M}]$. Logo, fica estabelecido físicamente que as frequências naturais $\left(\omega_{i j}\right)$ e modos de vibração $\left(\phi_{\mathrm{ij}}\right)$ estão vinculados à parâmetros como densidade, características geométricas e módulo de elasticidade.

Utilizando o procedimento matemático supracitado, HAACH et al. (2013) encontram os modos de vibração de um corpo de prova com geometria cilíndrica. Através do método dos elementos finitos, realiza-se a análise modal teórica e conclui-se que este tipo de corpo de prova pode vibrar fundamentalmente nos sentidos flexional (Figura 9.a), longitudinal (Figura 9.b) e torcional (Figura 9.c). Logo, os dois primeiros modos de vibração permitem o cálculo do módulo de Young transversal $\left(\mathrm{E}_{\mathrm{d}, \mathrm{f}}\right)$ e longitudinal $\left(\mathrm{E}_{\mathrm{d}, \mathrm{l}}\right)$, respectivamente, e o último possibilita a determinação do módulo de cisalhamento $\left(G_{d}\right)$ e coeficiente de Poisson $\left(v_{\mathrm{d}}\right)$. 


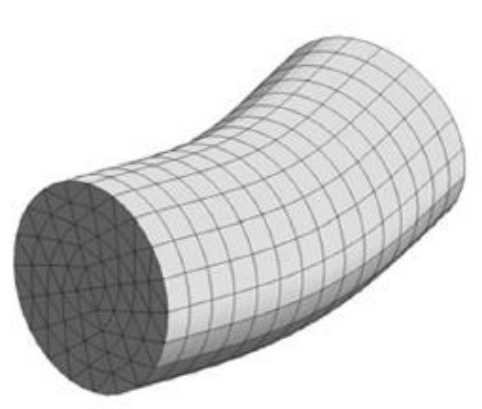

(a)

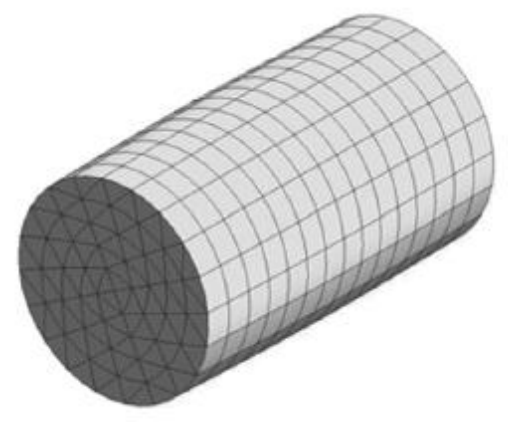

(b)

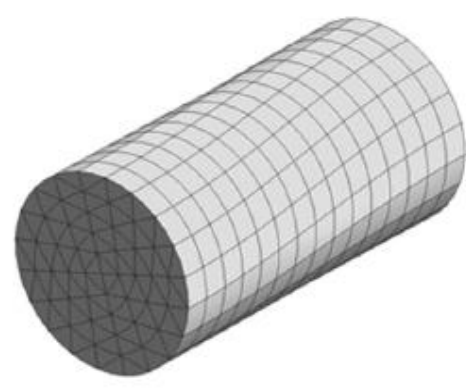

(c)

Figura 9 - Modos de vibração de um corpo de prova cilíndrico (Fonte: HAACH et al. (2013))

(a) Primeiro modo flexional (b) Primeiro modo longitudinal

(c) Primeiro modo torcional

De forma análoga, utilizando o software de elementos finítos ABAQUS ${ }^{\circledR}$, pode-se estabelecer os três primeiros modos vibracionais (para um prisma de $15 \mathrm{~cm}$ x $15 \mathrm{~cm}$ x 50 $\mathrm{cm}$, com $\mathrm{E}_{\mathrm{d}}=30 \mathrm{GPa}$ :

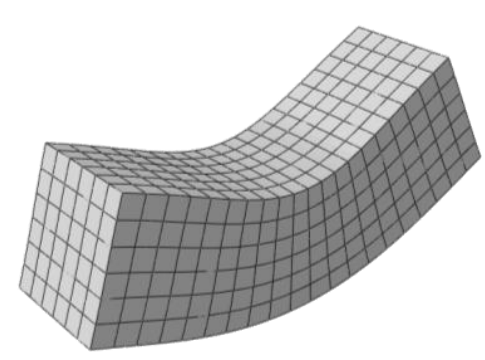

(a)

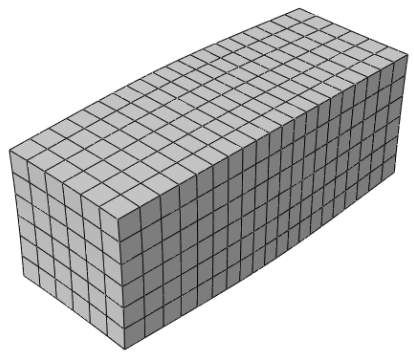

(b)

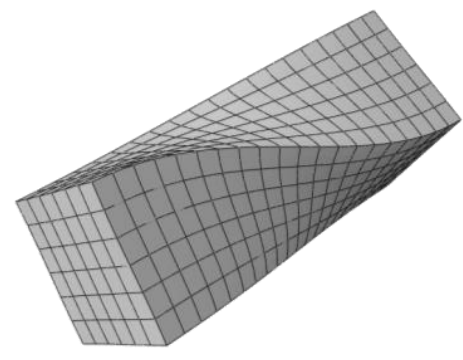

(c)

Figura 10 - Modos de vibração de um corpo de prova prismático

(a) Primeiro modo flexional (b) Primeiro modo longitudinal

(c) Primeiro modo torcional 
As normas técnicas ASTM C215-02 e ASTM E1876-01, baseadas no trabalho de PICKETT (1945), propõem algumas equações que relacionam o módulo de elasticidade dinâmico à frequência natural. Assim, tais equações são contempladas através das Equações Equação (20) à Equação (25). Posteriormente, COSSOLINO e PEREIRA (2010), MCCONNELL e VAROTO (2008) e BACHMANN et al. (1995) apresentam o procedimento de cálculo para a determinação do coeficiente de amortecimento, conforme a Equação (26).

\section{Corpo de prova de secção circular excitado em flexão:}

$\mathrm{O}$ módulo de elasticidade flexional $\left(\mathrm{E}_{\mathrm{d}, \mathrm{f}}, \mathrm{em} \mathrm{Pa}\right)$ é obtido através da excitação do modo de vibração flexional (Figura 9.a), sendo determinado através da seguinte equação:

$$
E_{d, f}=1,6067\left(\frac{L^{3}}{D^{4}}\right) m \cdot f_{N, 1, f}{ }^{2} \cdot T_{1}{ }^{\prime} \quad \text { Equação (20) }
$$

Em que m é a massa do corpo de prova (em gramas), D é o diâmetro do corpo de prova (em $\mathrm{mm}$ ), L é o comprimento do corpo de prova (em $\mathrm{mm}), \mathrm{f}_{\mathrm{N}, 1, \mathrm{f}}$ é a frequência natural fundamental flexional (em hertz) e $\mathrm{T}_{1}{ }^{\prime}$ é um fator de correção para o modo fundamental flexional dado pela seguinte equação

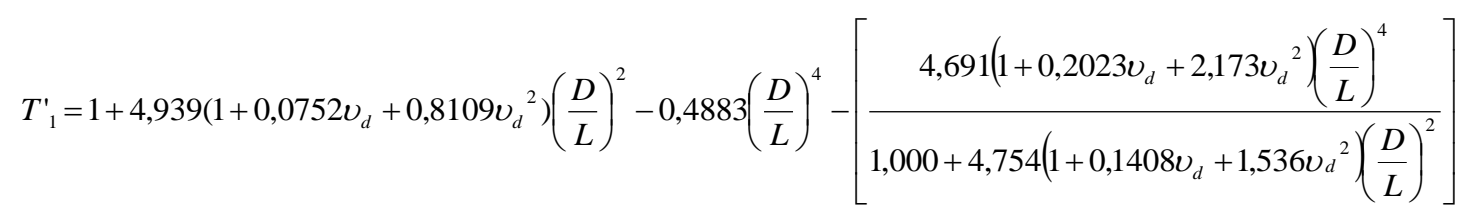

Em que $v_{\mathrm{d}}$ é o coeficiente de Poisson dinâmico.

\section{Corpo de prova de secção circular excitado longitudinalmente:}

O módulo de elasticidade longitudinal $\left(\mathrm{E}_{\mathrm{d}, 1}, \mathrm{em} \mathrm{Pa}\right)$ é obtido através do modo de vibração longitudinal (Figura 9.b), sendo conforme a seguinte equação:

$$
E_{d, l}=5,093\left(\frac{L}{D^{2}}\right) m \cdot f_{N, 1, l}^{2}
$$


Em que m é a massa do corpo de prova (em gramas), D é o diâmetro do corpo de prova (em $\mathrm{mm}), \mathrm{L}$ é o comprimento do corpo de prova (em $\mathrm{mm}$ ) e $\mathrm{f}_{\mathrm{N}, 1,1}$ é a frequência natural fundamental longitudinal (em hertz).

\section{Corpo de prova prismático de seção retangular excitado em flexão:}

O módulo de elasticidade flexional $\left(\mathrm{E}_{\mathrm{d}, \mathrm{f}}, \mathrm{em} \mathrm{Pa}\right)$ é obtido através da excitação ao modo de vibração flexional (Figura 10.a), sendo determinado através da seguinte equação:

$$
E_{d, f}=0,9465\left(m \times f_{N, 1, f}^{2} / b\right)\left(L^{3} / t^{3}\right) T_{1} \quad \text { Equação (22) }
$$

Em que m é a massa do corpo de prova (em gramas), b e t são as espessuras do corpo de prova (em mm), L é o comprimento do corpo de prova (em $\mathrm{mm}$ ), $\mathrm{f}_{\mathrm{N}, 1, \mathrm{f}}$ é a frequência natural fundamental flexional (em hertz) e $\mathrm{T}_{1}$ é um fator de correção para o modo fundamental flexional dado pela seguinte equação:

$$
T_{1}^{\prime}=1+6,585\left(1+0,0752 v_{d}+0,8109 v_{d}{ }^{2}\right)\left(\frac{t}{L}\right)^{2}-0,868\left(\frac{t}{L}\right)^{4}-\left[\frac{8,340\left(1+0,2023 v_{d}+2,173 v^{2}\right)\left(\frac{t}{L}\right)^{4}}{1,000+6,338\left(1+0,1408 v_{d}+1,536 v^{2}\right)\left(\frac{t}{L}\right)^{2}}\right]
$$

Em que $v_{\mathrm{d}}$ é o coeficiente de Poisson dinâmico.

Vale ressaltar, que o corpo de prova utilizado tem base quadrada, ou seja, é o caso particular em que $b=t$;

\section{Corpo de prova prismático retangular excitado longitudinalmente:}

O módulo de elasticidade longitudinal $\left(\mathrm{E}_{\mathrm{d}, 1}\right.$, em $\left.\mathrm{Pa}\right)$ é obtido através do modo de vibração longitudinal (Figura 10.b), sendo conforme a seguinte equação:

$$
E_{d, l}=16 \times m \times f_{N, 1, l}^{2}\left[L /\left(\pi \times \frac{2}{3}\left(b^{2}+t^{2}\right)\right) \times K\right) \quad \text { Equação (23) }
$$

Em que m é a massa do corpo de prova (em gramas), b e t são as espessruras do corpo de prova (em mm), L é o comprimento do corpo de prova (em $\mathrm{mm}$ ), $\mathrm{f}_{\mathrm{N}, 1,1}$ é a frequência natural fundamental longitudinal (em hertz) e $\mathrm{K}$ é um fator de correção para o modo fundamental longitudinal dado pela seguinte equação: 


$$
K=1-\left[\left(\pi^{2} v_{d}^{2}\left(\frac{4 b^{2}}{3}\right)^{2} /\left(8 L^{2}\right)\right] \quad\right. \text { Equação (24) }
$$

Em que $v_{\mathrm{d}}$ é o coeficiente de Poisson dinâmico.

\section{Módulo de cisalhamento dinâmico para uma barra de secção retangular excitada em torção}

O módulo de cisalhamento dinâmico $\left(\mathrm{G}_{\mathrm{d}}\right.$, em Pa) é obtido através do modo torcional (Figura 10.c), sendo determinado através da equação:

$$
G_{d}=\frac{4 L m f_{N, 1, t}^{2}}{b_{t}}\left(\frac{B}{1+A}\right)
$$

Em que $f_{N, 1, t}$ é a frequência de ressonância fundamental torcional (em hertz) e os fatores $\mathrm{A}$ e B são determinados pelas seguintes equações:

$$
A=\left(\frac{0,5062-0,8776(b / t)+0,3504(b / t)^{2}-0,0078(b / t)^{3}}{12,03(b / t)+9,892(b / t)^{2}}\right) \quad B=\left(\frac{b / t+t / b}{4(t / b)-2,52(t / b)^{2}+0,21(t / b)^{6}}\right)
$$

\section{Coeficiente de Poisson para uma barra de secção retangular excitada em torção e flexão simultaneamente}

Excitando o corpo de prova simultâneamente flexão e torção, de forma que se apareça simultâneamente o primeiro e o terceiro modo vibracional, que corresponderão respectivamente ao $1^{\circ}$ modo flexional e $1^{\circ}$ modo torcional, determina-se o Módulo de Elasticidade Flexional $\left(\mathrm{E}_{\mathrm{d}, \mathrm{f}}\right)$, o Módulo de Cisalhamento $\left(\mathrm{G}_{\mathrm{d}}\right)$ e o coeficiente de Poisson $\left(v_{\mathrm{d}}\right)$. O procedimento iterativo para determinação de tal propriedade pode ser ilustrado conforme a figura à seguir: 


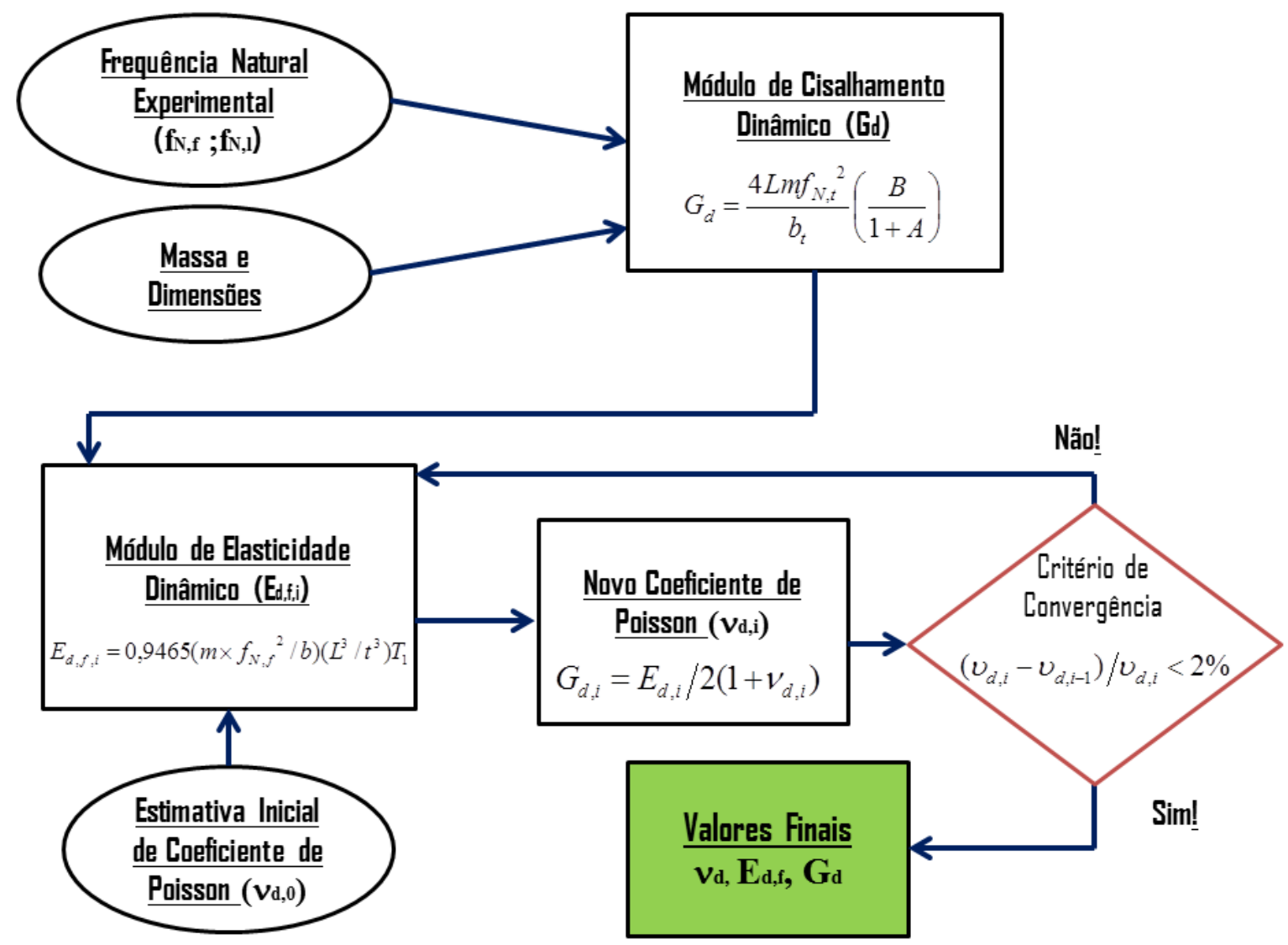

Figura 11 - Processo iterativo para a determinação do coeficiente de Poisson dinâmico (Fonte: ASTM E1876-01 (adaptada)).

Assim e de acordo com a Figura 11, primeiramente são determinadas as frequências naturais de flexão e torção $\left(\mathrm{f}_{\mathrm{N}, 1, \mathrm{f}}\right.$ e $\left.\mathrm{f}_{\mathrm{N}, 1, \mathrm{t}}\right)$. Assim, através da massa, características geométricas do corpo de prova e frequência natural do modo torcional, pode-se calcular, através da Equação (25), o módulo de cisalhamento dinâmico $\left(\mathrm{G}_{\mathrm{d}}\right)$. Posteriormente, com a entrada de uma estimativa inicial de coeficiente de Poisson dinâmico $\left(v_{\mathrm{d}, 0}\right)$, pode-se calcular, através da Equação (22), o módulo de elasticidade dinâmico flexional $\left(\mathrm{E}_{\mathrm{d}, \mathrm{f}, 0}\right)$. Através da relação entre módulos elásticos para materiais isotrópicos $G_{d}=E_{d} / 2\left(1+v_{d}\right)$, pode-se calcular um novo coeficiente de Poisson dinâmico $\left(v_{\mathrm{d}, 1}\right)$. Se o critério de convergência for menor que $2 \%$, isto é $\left(v_{d, 1}-v_{d, 0}\right) / v_{d, 1}<2 \%$, o problema estará resolvido. Ao contrário, mais uma iteração será necessária. Assim, para a i-ésima iteração, calcula-se $E_{\mathrm{d}, \mathrm{f}, \mathrm{i}}$, posteriormente $v_{\mathrm{d}, \mathrm{i}} \mathrm{e}$ verifica-se se o critério de convergência é respeitado conforme $\left(v_{d, i}-v_{d, i-1}\right) / v_{d, i}<2 \%$, e assim por diante. 
VII. Coeficiente de amortecimento

Conforme o que foi desenvolvido por COSSOLINO e PEREIRA (2010), MCCONNELL e VAROTO (2008) e BACHMANN et al. (1995) o coeficiente de amortecimento é uma propriedade do material responsável pela dissipação de energia mecânica de um sistema que se encontra em regime vibratório. Para um impacto com duração muito curta, o decaimento da amplitude respeita a função logaritimica. Assim, este decaimento depende da razão entre duas amplitudes, sendo calculado conforme a equação a seguir:

$$
\xi=\frac{1}{2 \pi \cdot m} \ln \left(\frac{x_{n}}{x_{n+m}}\right)
$$

Em que $x_{n}$ e $x_{n+m}$ são as duas amplitudes consideradas na análise e $\mathrm{m}$ o número de períodos que separam estas amplitudes, conforme a figura a seguir:

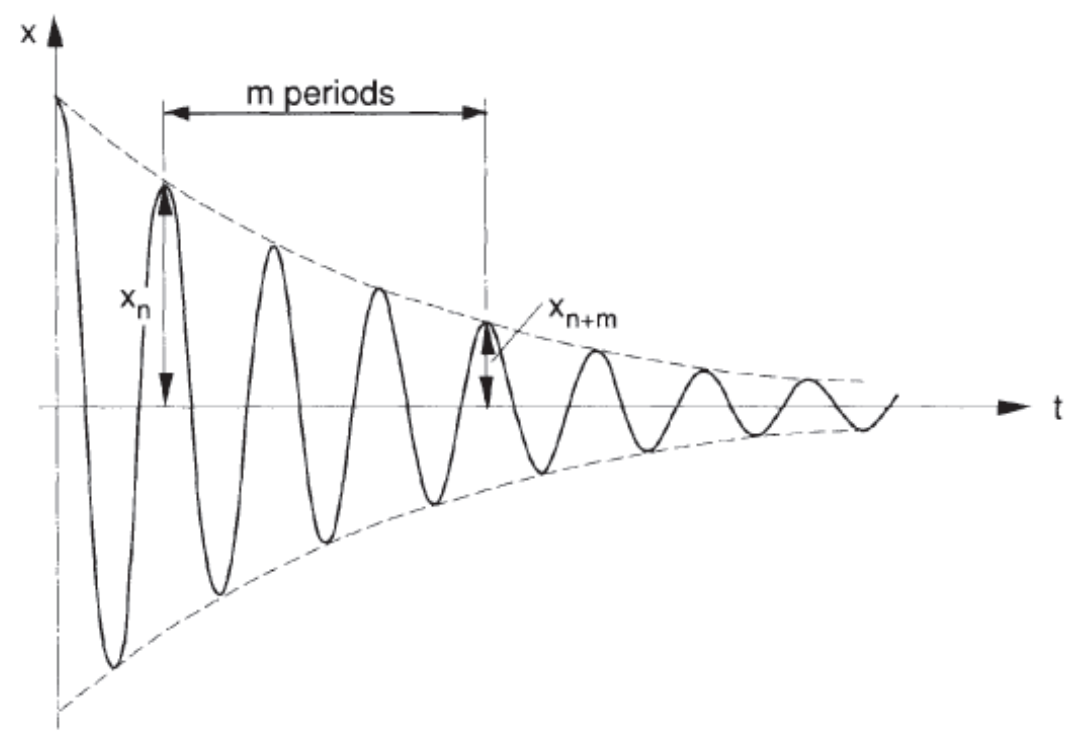

Figura 12 - Resposta ao impulso para um oscilador simples (Fonte:

BACHMANN et al. (1995)) 


\section{PROCEDIMENTO EXPERIMENTAL}

\subsection{MATERIAIS}

Para o estudo ter a representatividade necessária, foram propostas as seguintes dosagens para amostras de concreto, conforme a Tabela 5:

Tabela 5 - Planejamento de dosagens (Concreto)

\begin{tabular}{|c|c|c|c|c|c|c|c|c|c|}
\hline ID & $\begin{array}{c}\text { Cimento } \\
\text { (CPV-ARI) } \\
{[\mathrm{kg}]}\end{array}$ & $\begin{array}{c}\text { Areia } \\
{[\mathrm{kg}]}\end{array}$ & $\begin{array}{l}\text { Brita } \\
{[\mathrm{kg}]}\end{array}$ & B0/B1/B1L* & Rocha & $\mathbf{a} / \mathbf{c}^{* *}$ & $\begin{array}{c}\text { SP.*** } \\
{[\%]}\end{array}$ & $\begin{array}{r}\text { Slump } \\
{[\mathrm{mm}]}\end{array}$ & Traço \\
\hline 1 & 1 & 2 & 1 & Brita 1 & Diabásio & 0,5 & $0 \%$ & 215 & Rico \\
\hline 2 & 1 & 1 & 2 & Brita 1 & Diabásio & 0,5 & $0 \%$ & & Rico \\
\hline 3 & 1 & 3 & 4 & Brita 1 & Diabásio & 0,5 & $0 \%$ & 10 & Pobre \\
\hline 4 & 1 & 3 & 2 & Brita 1 & Diabásio & 0,5 & $0 \%$ & 50 & Médio \\
\hline 5 & 1 & 2 & 3 & Brita 1 & Diabásio & 0,3 & $1 \%$ & 0 & Médio \\
\hline 6 & 1 & 2 & 3 & Brita 1 & Diabásio & 0,5 & $1 \%$ & 290 & Médio \\
\hline 7 & 1 & 2 & 3 & Brita 1 & Diabásio & 0,7 & $0 \%$ & 260 & Médio \\
\hline 8 & 1 & 2 & 3 & Brita 1 & Diabásio & 0,5 & $0 \%$ & 95 & Médio \\
\hline 9 & 1 & 2 & 3 & Brita 1 & Diabásio & 0,3 & $1 \%$ & 0 & Médio \\
\hline 10 & 1 & 2 & 3 & Brita 1 & Diabásio & 0,5 & $1 \%$ & & Médio \\
\hline 11 & 1 & 2 & 3 & Brita 1 & Diabásio & 0,7 & $0 \%$ & & Médio \\
\hline 12 & 1 & 2 & 3 & Brita 1 & Diabásio & 0,5 & $0 \%$ & & Médio \\
\hline 13 & 1 & 2 & 3 & Brita 0 & Diabásio & 0,5 & $1 \%$ & 125 & Médio \\
\hline 14 & 1 & 2 & 3 & Brita 0 & Diabásio & 0,3 & $1 \%$ & 0 & Médio \\
\hline 15 & 1 & 2 & 3 & Brita 0 & Diabásio & 0,7 & $0 \%$ & & Médio \\
\hline 16 & 1 & 2 & 3 & Brita 0 & Diabásio & 0,5 & $0 \%$ & & Médio \\
\hline 17 & 1 & 2 & 3 & Brita 1 & Arenito & 0,5 & $0 \%$ & & Médio \\
\hline 18 & 1 & 2 & 3 & Brita 1 & Arenito & 0,7 & $0 \%$ & & Médio \\
\hline \multicolumn{10}{|c|}{$\begin{array}{l}\text { *B0=Brita } 0 \\
* \mathrm{~B} 1=\text { Brita } 1 \\
\mathrm{~B} 1 \mathrm{~L}=\text { Brita } 1 \text { "Larga" } \\
* * \mathrm{a} / \mathrm{c}=\text { Relação água-cimento } \\
\text { ***SP=Porcentagem de Superplastificante }\end{array}$} \\
\hline
\end{tabular}

Assim, a justificativa para as dosagens estabelecidas podem ser listadas conforme os itens a seguir:

I. Cimento: Para o corrente estudo, utilizou-se somente o cimento CPV ARI, por suas vantagens de cura acelerada;

II. Graduação: Utilizou-se as graduações de brita $0\left(\mathrm{D}_{\text {máx }}=9,52 \mathrm{~mm}\right)$, brita $1\left(\mathrm{D}_{\text {máx }}=\right.$ $16 \mathrm{~mm}$ ) e brita 1 "larga" ( $\left.\mathrm{D}_{\text {máx }}=19 \mathrm{~mm}\right)$. Esperava-se que o tamanho do agregado graúdo influenciasse as caracteristicas da zona de transição; É necessário salientar que o objetivo inicial do trabalho era a utilização da brita 2 ao invés da brita 1 
"Larga", entretanto, por motivo de demanda, esta não estava sendo produzida na pedreira do "Vinte e Nove" (Grupo Bandeirantes - São Carlos, SP), mesma que produziu as britas 0 e 1 utilizadas no estudo. Assim, optou-se pelo tipo Brita 1 "larga;

III. Classificação litológica do Agregado Graúdo: Utilizaram-se agregados graúdos de diferentes classificações litológicas, isto é, agregados graúdos de natureza ígnea (Diabásio) e sedimentar (Arenito Silicificado Botucatu). A variação do tipo litológico do agregado teve por objetivo verificar o impacto do módulo de elasticidade individual do agregado ao módulo de elasticidade do concreto e sua fração volumétrica, conforme o que foi anteriormente exposto; O Diabásio é explorado pela pedreira "Vinte e Nove" (Grupo Bandeirantes - São Carlos, SP) e o Arenito pela pedreira do "Araújo" (São Carlos, SP);

IV. Relação água-cimento: A variação da relação água-cimento tende a gerar mudanças de rigidez tanto na matriz quanto na zona de transição.

V. Superplastificante: Para traços mais secos, em que seria impossível atingir a trabalhabilidade necessária para a moldagem, optou-se pelo uso do Superplastificante Glenium ${ }^{\circledR}$. Assim, o aditivo foi utilizado para traços com relação água cimento de 0,3 e 0,5. É necessário ressaltar que os concretos com relação água-cimento de 0,5 tinham boa trabalhabilidade, todavia foi necessário a compararação destes traços com os mesmos traços sem adição de Superplastificante.

VI. Trabalhabilidade: Não foi pré fixada neste estudo uma consistência padronizada. No entanto para parte das moldagens seu valor foi determinado pelo ensaio de abatimento de tronco de cone. O critério adotado para trabalhabilidade era atender um estado mínimo que permitisse o lançamento, adensamento e acabamento dos corpos de prova de forma satisfatória, sem que houvesse vazios e segregação pronunciada.

VII. Traco: Foram estabelecidos traços rico(1:3), médio(1:5) e médio(1:7). Esta variação foi proposta para que houvessse mudanças nas frações volumétricas dos constituintes da mistura. 
Logo, todos os parâmetros de dosagem que foram variados podem ser contemplados resumidamente conforme a figura a seguir:

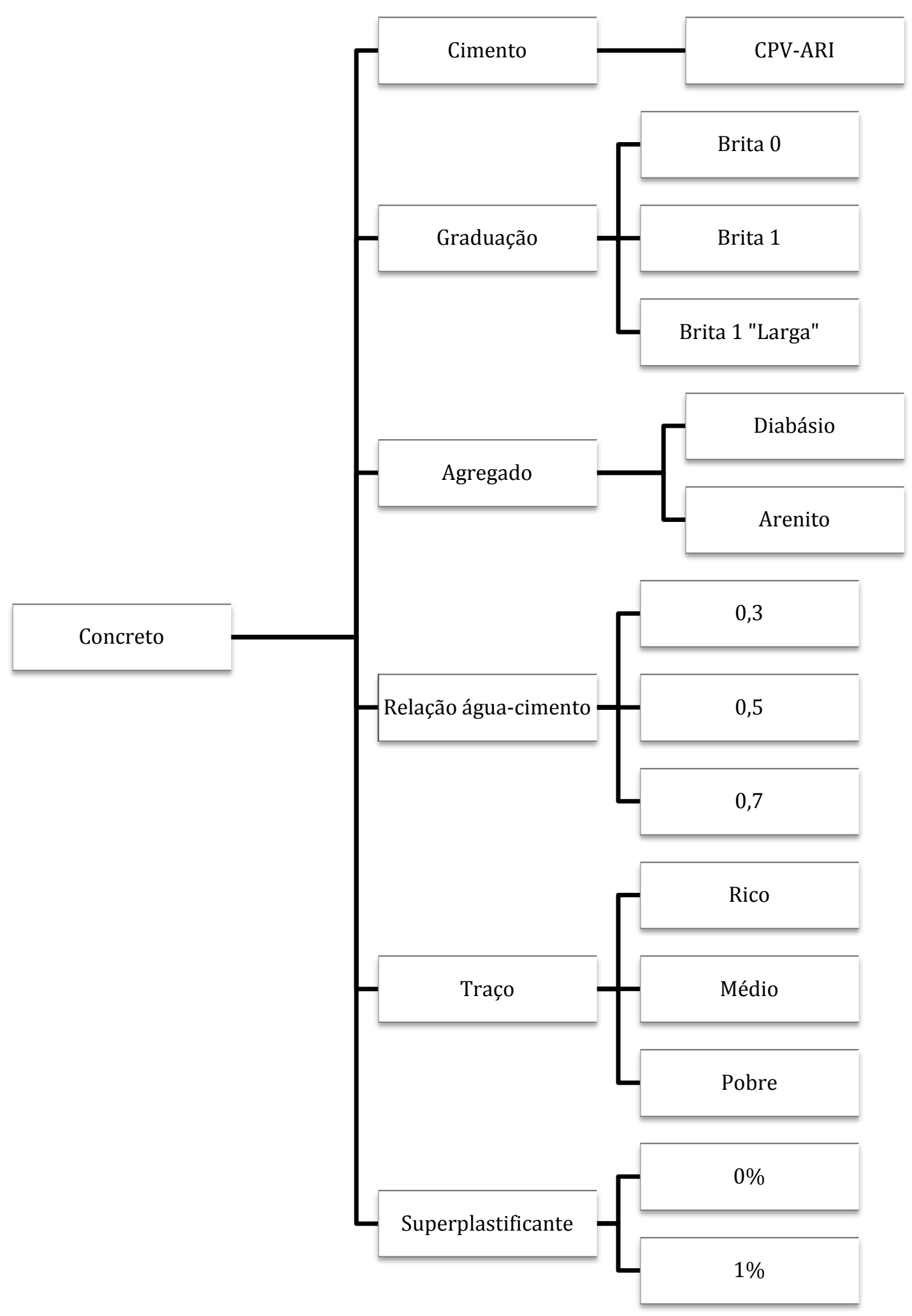

Figura 13 - Parâmetros de dosagem (Concreto) 
Também foram propostas as seguintes dosagens para amostras de argamassa, conforme a Tabela 6:

Tabela 6 - Planejamento de dosagens (Argamassa)

\begin{tabular}{|cccccc|}
\hline ID & $\begin{array}{c}\text { Cimento } \\
{[\mathbf{k g}]}\end{array}$ & $\begin{array}{c}\text { Areia } \\
{[\mathbf{k g}]}\end{array}$ & $\mathbf{a / \mathbf { c } ^ { * }}$ & $\begin{array}{c}\text { SP*** } \\
{[\%]}\end{array}$ & Traço \\
\hline 1 & 1 & 1 & 0,5 & 1 & Rico \\
\hline 2 & 1 & 2 & 0,5 & 1 & Médio \\
\hline 3 & 1 & 2 & 0,3 & 1 & Médio \\
\hline 4 & 1 & 1 & 0,5 & 1 & Rico \\
\hline 5 & 1 & 1 & 0,3 & 1 & Rico \\
\hline 6 & 1 & 3 & 0,5 & 0 & Pobre \\
\hline 7 & 1 & 3 & 0,7 & 0 & Pobre \\
\hline 8 & 1 & 2 & 0,5 & 0 & Médio \\
\hline 9 & 1 & 2 & 0,3 & 0 & Médio \\
\hline 10 & 1 & 1 & 0,7 & 0 & Rico \\
\hline 11 & 1 & 1 & 0,5 & 0 & Rico \\
\hline 12 & 1 & 1 & 0,3 & 0 & Rico \\
\hline *a/c=Relação água-cimento & & & & \\
**SP=Porcentagem de Superplastificante & & & & \\
\hline
\end{tabular}

A justificativa para estas dosagens estabelecidas podem ser listadas conforme os itens a seguir:

I. Cimento: Este parâmetro foi constante, conforme a matriz de dosagens de concreto;

II. Relacão água-cimento: As relações água-cimento foram de 0,3, 0,5 e 0,7. A variação deste parâmetro representou a modificação da rigidez e porosidade da argamassa;

VIII. Superplastificante: Para os traços mais secos, onde foi constatada a difículdade em atingir trabalhabilidade necessária para moldagem, assim, optou-se pelo uso do Superplastificante Glenium ${ }^{\circledR}$.

III. Traço: Os traços utilizados foram o pobre (1:3), médio(1:2) e rico(1:1). A variação fora proposta para induzir mudanças nas frações volumétricas dos constituintes da argamassa. 
Da mesma forma que no concreto e argamassa, foram propostas as seguintes dosagens para amostras de pasta, conforme a Tabela 7:

Tabela 7 - Planejamento de dosagens (Pasta)

\begin{tabular}{|ccccc|}
\hline ID & $\begin{array}{c}\text { Cimento } \\
{[\mathbf{k g}]}\end{array}$ & $\begin{array}{c}\text { Água } \\
{[\mathbf{k g}]}\end{array}$ & $\mathbf{a / \mathbf { c } ^ { * }}$ & $\begin{array}{c}\text { SP*** } \\
{[\%]}\end{array}$ \\
\hline 1 & 1 & 0,2 & 0,2 & 0 \\
\hline 2 & 1 & 0,4 & 0,4 & 0 \\
\hline 3 & 1 & 0,6 & 0,6 & 0 \\
\hline 4 & 1 & 0,8 & 0,8 & 0 \\
\hline 5 & 1 & 0,2 & 0,2 & 0,6 \\
\hline 6 & 1 & 0,4 & 0,4 & 0,6 \\
\hline 7 & 1 & 0,6 & 0,6 & 0,6 \\
\hline 8 & 1 & 0,8 & 0,8 & 0,6 \\
\hline 9 & 1 & 0,2 & 0,2 & 1 \\
\hline 10 & 1 & 0,4 & 0,4 & \\
\hline *a/c=Relação água-cimento & & & \\
**SP=Porcentagem de Superplastificante & & & \\
\hline
\end{tabular}

E da mesma forma, a justificativa para as dosagens podem ser listadas conforme a seguir:

I. Cimento: Este parâmetro novamente foi constante, conforme a matriz de dosagens de concreto e argamassa;

II. Relacão água-cimento: Foi feito o estudo das relações água-cimento no intervalo de 0,2 a 0,8, com incrementos de 0,2. Assim como as matrizes de Concreto e Argamassa, variar este parâmetro significa modificar a rigidez e a porosidade da pasta;

É necessário ainda salientar que maiores informações sobre os materiais utilizados no estudo podem ser encontradas no Anexo A - controle dos materiais.

\subsection{MOLDAGEM}

O procedimento de moldagem, conforme retratado na Figura 14, consistiu na pesagem de materiais, imprimação da betoneira com água, lançamento dos constituintes (Figura 14.a), mistura (Figura 14.b), retirada de slump (Figura 14.c-d) e concretagem na mesa vibratória. 


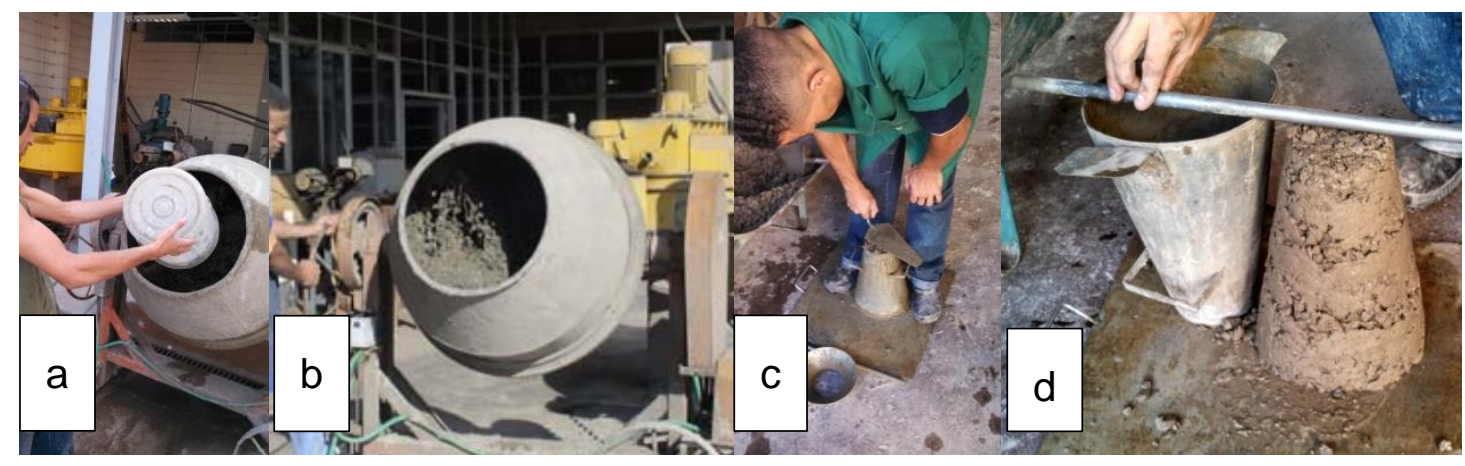

Figura 14 - Procedimento de concretagem

\subsection{AMOSTRAS}

Para o desenvolvimento do projeto foram produzidas as seguintes amostras:

I. Agregado: 5 corpos de prova para cada tipo litológico de agregado, sendo 2 prismáticos e 3 cilíndricos;

II. Pasta: 10 corpos de prova cilíndricos com dimensões padronizadas de $5 \mathrm{~cm}$ por 10 $\mathrm{cm}$, para cada dosagem de pasta.

III. Argamassa: 5 corpos de prova prismáticos $(4 \mathrm{~cm} \mathrm{x} 4 \mathrm{~cm} \mathrm{x} 16 \mathrm{~cm})$ e 15 corpos de prova cilíndricos $(5 \mathrm{~cm} \times 10 \mathrm{~cm})$, para cada dosagem de argamassa.

IV. Concreto: 5 corpos de prova prismáticos $(15 \mathrm{~cm} \times 15 \mathrm{~cm} \times 50 \mathrm{~cm})$ e 20 corpos de prova cilíndricos $(10 \mathrm{~cm}$ x $20 \mathrm{~cm})$, para cada dosagem de concreto estabelecida.

Em linhas gerais, foram produzidos 90 prismas e 360 cilíndros para o estudo do concreto. Adicionalmente, 300 amostras de argamassa (60 prismáticas e 240 cilíndricas), 50 amostras de pasta (50 cilíndricas) e 10 amostras de agregado (6 prismáticas e 4 cilíndricas) foram utilizadas, como comentado anteriormente, na verificação da influência destes componentes nas propriedades dinâmicas do concreto. As amostras foram mantidas em processo de cura úmida e à temperatura ambiente. O procedimento de ensaio foi realizado na condição de umidade saturada com superfície seca.

\subsection{ENSAIO DE COMPRESSÃO SIMPLES}

$\mathrm{Na}$ idade de interesse de 28 dias foram ensaiadas à compressão uniaxial cinco amostras de cada traço de concreto. O objetivo deste ensaio foi obter informações como o módulo de elasticidade estático e a tensão de ruptura para as mais variadas amostras experimentadas. Para tanto, foi utilizado o regime estático de carregamento, conforme os 
procedimentos da ABNT NBR 8522:2003. Os resultados deste ensaio, além da tensão de ruptura à compresão $\left(\mathrm{f}_{\mathrm{c}}\right)$, foram o módulo de elasticidade estático tangente inicial $\left(\mathrm{E}_{\mathrm{ci}}\right)$. Assim, seguem os materiais e instrumentos que foram necessários para este estágio do trabalho:

I. Prensa INSTRON (Figura 15.1) com capacidade de $2500 \mathrm{kN}$, servo-hidráulica, controlada por computador, que se encontra no Laboratório de Estruturas da Escola de Engenharia de São Carlos LE EESC-USP;

II. Prensa EMIC PC200 com capacidade de 2000 kN, servo-hidráulica, controlada por computador, que se encontra no Laboratório de Sistemas Estruturais da Universidade Federal de São Carlos - UFSCar;

III. Extensômetros do tipo clipgage (Figura 15.2);

Os dados oriundos dos ensaios destrutivos foram confrontados com os obtidos pelos ensaios não destrutivos aos 28 dias.

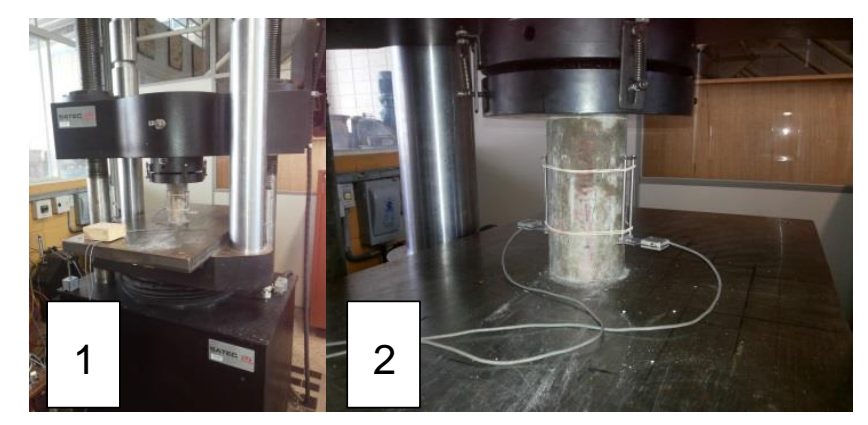

Figura 15 - Determinação do Módulo de Elasticidade Estático

\subsection{ENSAIO ACÚSTICO}

O ensaio acústico anteriormente abordado, foi utilizado para a caracterização das amostras de concreto e das fases constituintes do compósito. Logo, para cada componente da mistura de concreto foram ensaiadas as seguintes amostras:

I. Agregado: 5 corpos de prova para cada tipo litológico de agregado, sendo 2 prismáticos e 3 cilíndricos;

II. Pasta: 5 corpos de prova cilíndricos com dimensões padronizadas de $5 \mathrm{~cm}$ por 10 $\mathrm{cm}$, para cada dosagem de pasta.

III. Argamassa: 5 corpos de prova prismáticos $(4 \mathrm{~cm} \mathrm{x} 4 \mathrm{~cm} \times 16 \mathrm{~cm})$, para cada dosagem de argamassa; 
IV. Concreto: 5 corpos de prova prismáticos $(15 \mathrm{~cm} \times 15 \mathrm{~cm} \times 50 \mathrm{~cm})$, para cada dosagem de concreto;

Em amostras de concreto, argamassa e pasta, os ensaios foram executados em idades de interesse de 1 à 56 dias.

Dessa maneira, os materiais e instrumentos que foram necessarios para este estágio de trabalho podem ser descritos resumidamente a seguir:

I. Sistema Sonelastic ${ }^{\circledR}$ fornecido pelo fabricante ATCP ENGENHARIA FÍSICA, que se encontra no Laboratório de Estruturas da Escola de Engenharia de São Carlos LE EESC-USP;

II. Pórtico de Apoio;

III. Martelo de impacto excitador com cabeça metálica;

IV. Balança;

Uma vez apresentados os materiais e instrumentos necessários, o procedimento experimental utilizado no ensaio pode ser contemplado conforme a Figura 16. Primeiramente faz-se necessária a pesagem de todos os corpos de prova à serem ensaiados. Posteriormente, se posicionam as amostras à serem ensaiadas no pórtico, aciona-se a captura de sinal do microfone e excita-se o corpo de prova somente ao modo flexional (Figura 17). Através deste procedimento obtém-se a frequência natural fundamental de flexão $\left(\mathrm{f}_{\mathrm{N}, 1, \mathrm{flex}}\right)$, e consequentemente o módulo de elasticidade dinâmico obtido através do modo de vibração flexional $\left(\mathrm{E}_{\mathrm{d}, \mathrm{flex}}\right)$. Novamente excita-se $\mathrm{o}$ corpo de prova simultâneamente para o modo de vibração longitudinal e flexional (Conforme a Figura 18). Obtém-se os valores experimentais de frequência fundamental longitudinal e flexional, respectivamente $f_{N, 1, \text { Long }}$ e $f_{N, 1, F l e x}$. Com a excitação destes dois modos de vibração é possível se calcular o valor de módulo de elasticidade dinâmico obtido através do modo de vibração flexional $\left(E_{d, f l e x}\right)$ e longitudinal $\left(E_{d, l o n g}\right)$, além do coeficiente de amortecimento

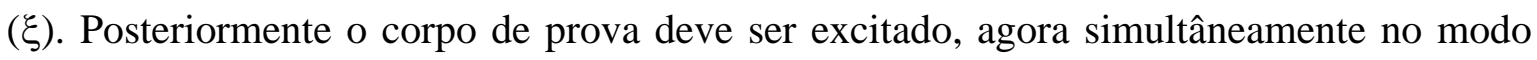
de vibração flexional e torcional (Figura 19). Através de tal torção e flexão é possível se obter as frequências fundamentais de flexão e torção, respectivamente $f_{N 1 \text {,Flex }}$ e $f_{N, 1, \text { Tors }}$. Finalmente, é possível se obter o módulo de cisalhamento dinâmico $\left(\mathrm{G}_{\mathrm{d}}\right)$ e o coeficiente de Poisson dinâmico $\left(v_{\mathrm{d}}\right)$. 


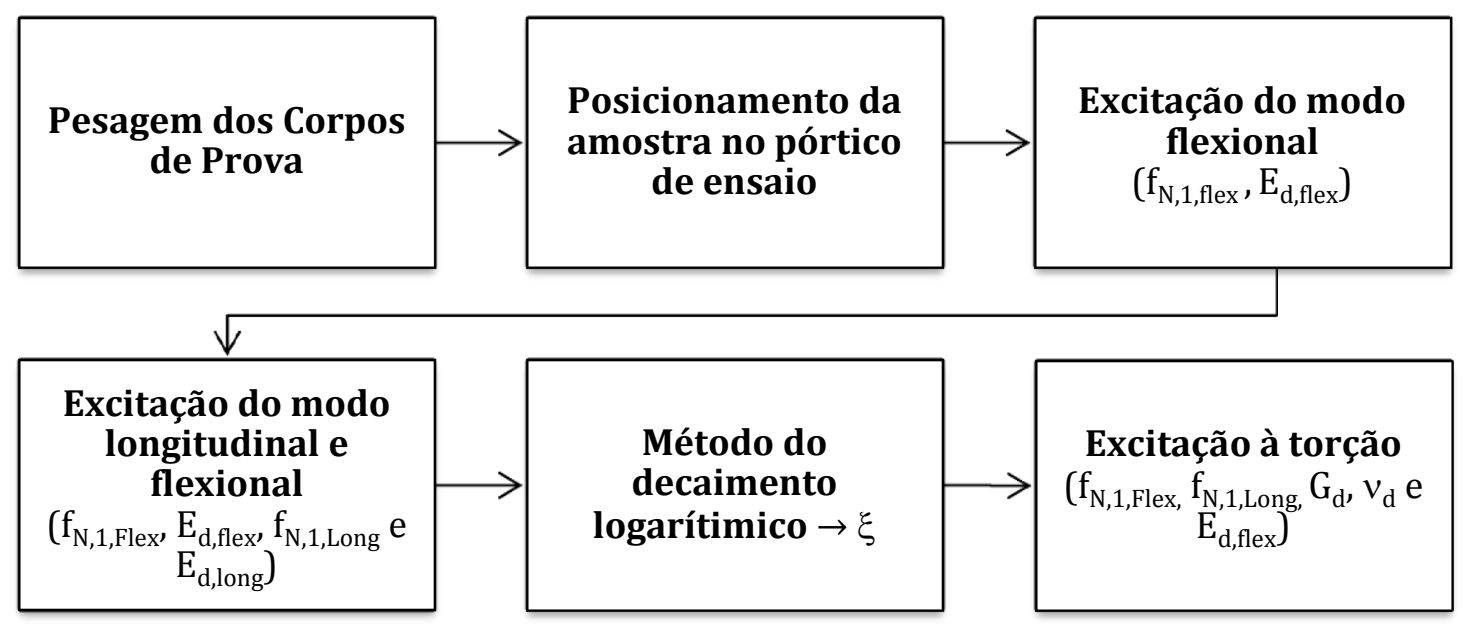

Figura 16 - Determinação das propriedades dinâmicas

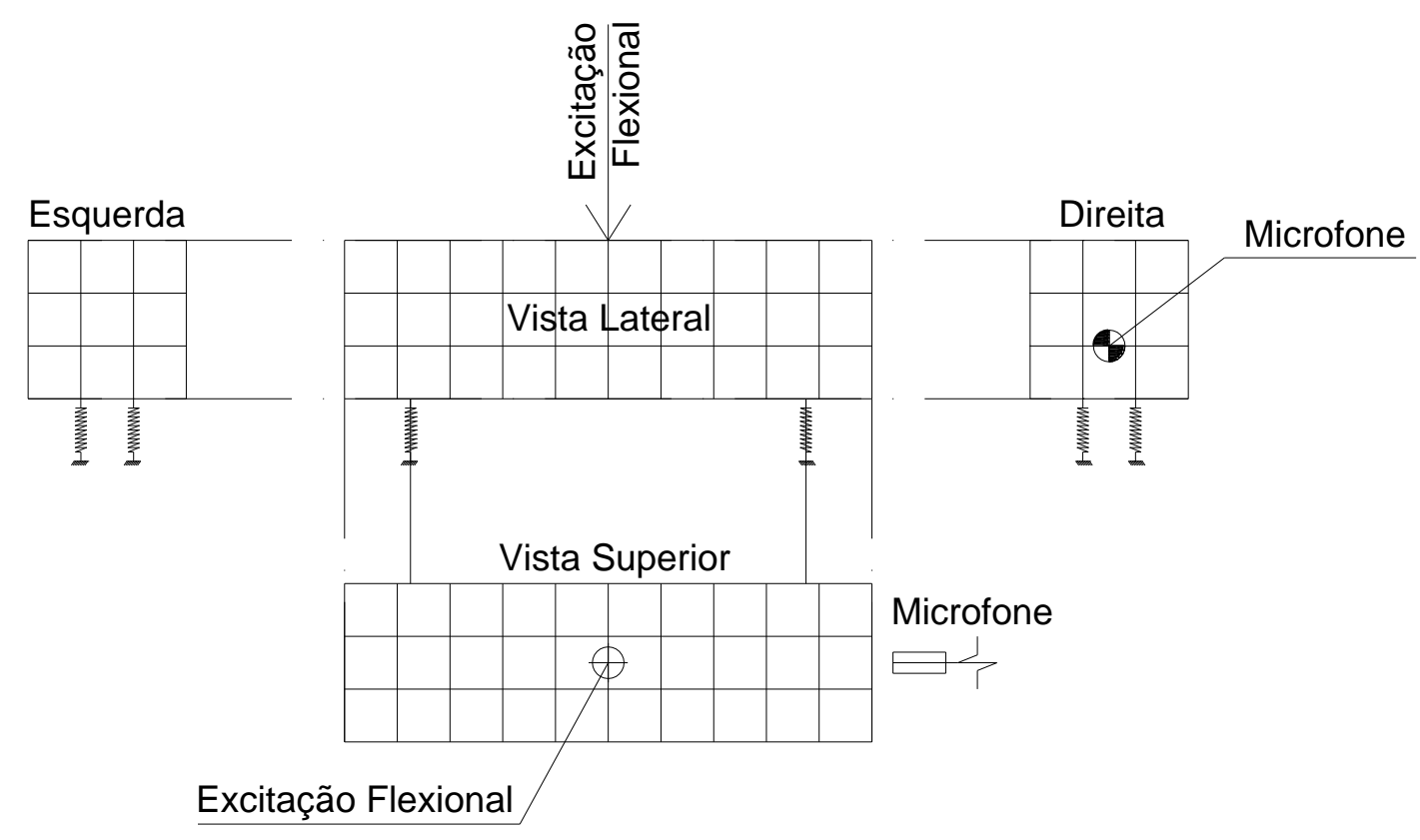

Figura 17 - Exemplo de excitação do modo de vibração flexional 


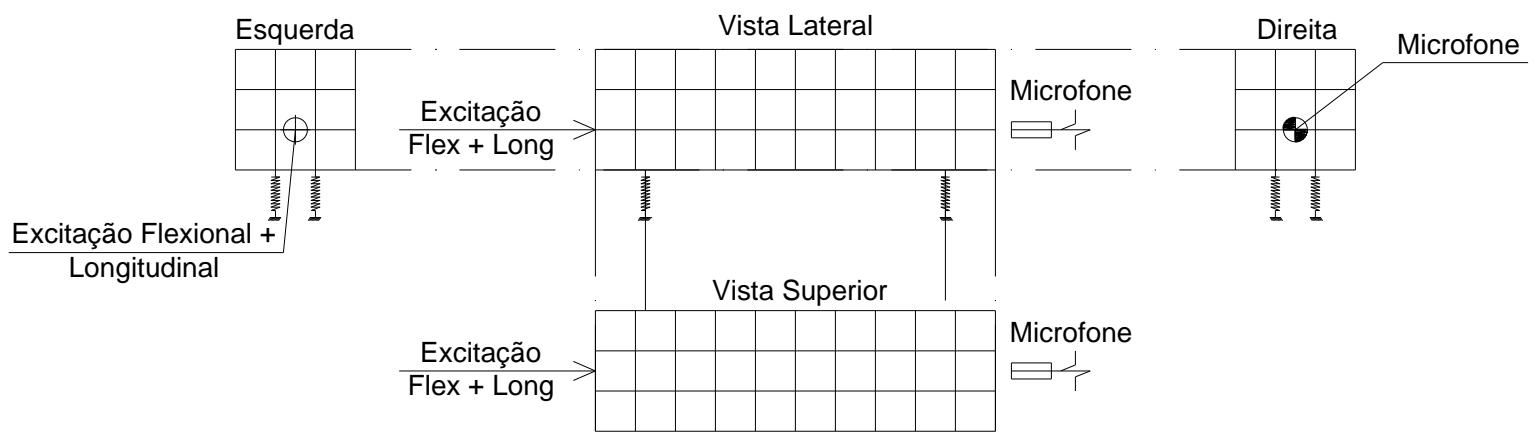

Figura 18 - Exemplo de excitação do modo de vibração flexional e longitudinal

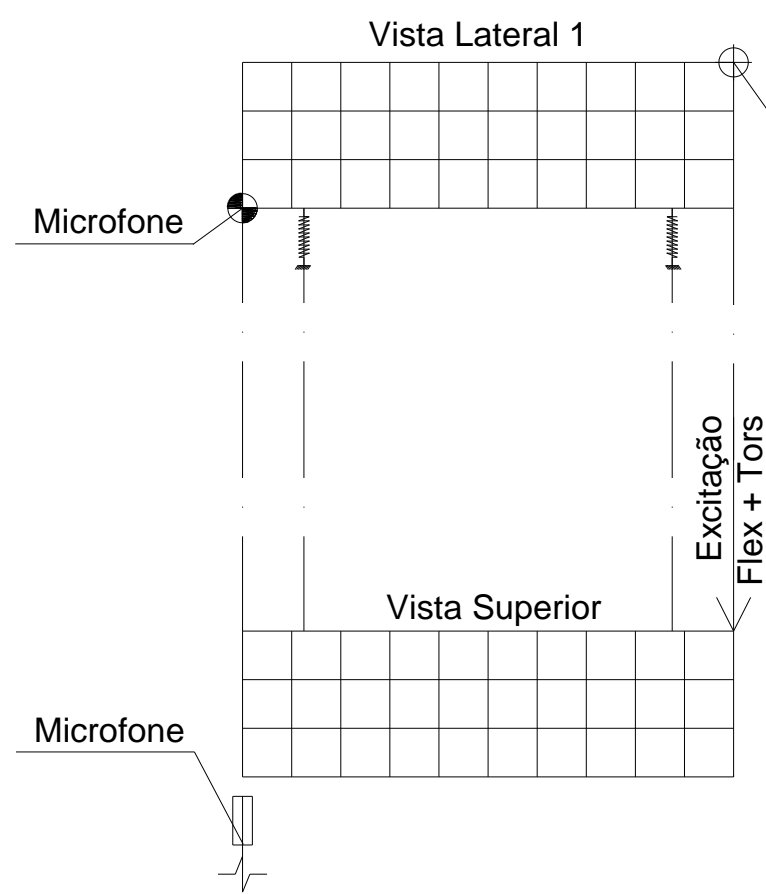

Excitação

Flex + Tors

Figura 19 - Exemplo de excitação do modo de vibração flexional e Torcional 
É necessário ressaltar que o programa contém um módulo de simulador de frequência (Frequency Simulator), muito útil para a devida caracterização dos picos de frequência fundamental flexional, longitudinal e torcional.

\section{6 ÍNDICE DE VAZIOS}

Com o objetivo de se obter informações sobre a porosidade da argamassa e concreto utilizou-se o ensaio de determinação de índice de vazios, conforme a ABNT NBR 9778:1987. A medida representa a razão entre o volume de poros permeáveis e o volume total. O ensaio consiste em submergir corpos de prova por 72 horas, posteriormente pesálos em uma balança de precisão e uma balança hidrostática, levá-los a estufa sob temperatura de $105^{\circ} \mathrm{C} \pm 5^{\circ} \mathrm{C}$. Novamente, após 72 horas, uma nova pesagem da massa seca na balança de precisão. O índice de vazios $\left(I_{v}\right)$, que é a relação entre os volumes de poros permeáveis pelo volume total, é determinado pela seguinte relação:

$$
I_{v}=\frac{M_{s a t}-M_{s}}{M_{s a t}-M_{i}}
$$

Em que,

$M_{s a t}$ é a massa saturada do corpo de prova;

$M_{s}$ é a massa seca do corpo de prova;

$M_{i}$ é a massa medida na balança hidrostática.

Logo, para cada ensaio de determinação de índice de vazios foram avaliadas a seginte quantidade de amostras:

V. Pasta: 5 corpos de prova cilíndricos com dimensões padronizadas de $5 \mathrm{~cm}$ por 10 $\mathrm{cm}$.

VI. Argamassa: 5 corpos de prova cilíndricos com dimensões padronizadas de $5 \mathrm{~cm}$ por $10 \mathrm{~cm}$.

VII. Concreto: 5 corpos de prova cilíndricos com dimensões padronizadas de $10 \mathrm{~cm}$ por $20 \mathrm{~cm}$. 


\section{RESULTADOS}

\subsection{PASTA}

Os resultados gerais de módulo de elasticidade dinâmico flexional e longitudinal, respectivamente $E_{d, f}$ e $E_{d, l}$, para o caso do estudo das pastas podem ser condensados conforme a Tabela 8:

Tabela 8 - Resultados gerais da Pasta

\begin{tabular}{|c|c|c|c|c|c|c|c|}
\hline \multirow{3}{*}{ ID } & \multirow{3}{*}{$\mathbf{a} / \mathbf{c}$} & \multirow{3}{*}{$\begin{array}{l}\text { SP. } \\
{[\%]}\end{array}$} & \multirow{3}{*}{$\begin{array}{c}\mathbf{t} \\
\text { [Dias] }\end{array}$} & \multicolumn{2}{|c|}{$\mathbf{E}_{\mathrm{d}, \mathrm{f}}$} & \multicolumn{2}{|c|}{$\mathbf{E}_{\mathrm{d}, \mathrm{I}}$} \\
\hline & & & & [GPa] & C.V. & [GPa] & C.V. \\
\hline & & & & Média & {$[\%]$} & Média & {$[\%]$} \\
\hline \multirow{6}{*}{1} & \multirow{6}{*}{0,2} & \multirow{6}{*}{0} & 1 & 26,463 & $0,603 \%$ & 25,220 & $0,634 \%$ \\
\hline & & & 5 & 31,840 & $8,589 \%$ & 28,167 & $4,938 \%$ \\
\hline & & & 7 & 33,455 & $6,513 \%$ & 28,803 & $4,840 \%$ \\
\hline & & & 14 & 33,902 & $8,227 \%$ & 30,303 & $4,822 \%$ \\
\hline & & & 28 & 32,630 & $1,219 \%$ & 30,730 & $0,782 \%$ \\
\hline & & & 56 & 34,035 & $1,574 \%$ & 32,400 & $0,351 \%$ \\
\hline \multirow{6}{*}{2} & \multirow{6}{*}{0,4} & \multirow{6}{*}{0} & 1 & 15,673 & $1,817 \%$ & 15,350 & $2,053 \%$ \\
\hline & & & 3 & 19,693 & $1,306 \%$ & 19,182 & $1,824 \%$ \\
\hline & & & 7 & 21,420 & $1,682 \%$ & 20,765 & $1,327 \%$ \\
\hline & & & 14 & 21,743 & $1,657 \%$ & 21,383 & $1,415 \%$ \\
\hline & & & 28 & 22,977 & $1,372 \%$ & 22,520 & $1,369 \%$ \\
\hline & & & 56 & 24,283 & $2,162 \%$ & 23,412 & $1,921 \%$ \\
\hline \multirow{6}{*}{3} & \multirow{6}{*}{0,6} & \multirow{6}{*}{0} & 1 & 9,263 & $1,886 \%$ & 9,120 & $1,812 \%$ \\
\hline & & & 3 & 13,353 & $1,779 \%$ & 13,073 & $2,076 \%$ \\
\hline & & & 7 & 14,930 & $3,554 \%$ & 14,664 & $3,499 \%$ \\
\hline & & & 14 & 15,793 & $2,469 \%$ & 15,498 & $2,505 \%$ \\
\hline & & & 28 & 16,455 & $2,731 \%$ & 15,980 & $1,952 \%$ \\
\hline & & & 56 & 16,998 & $2,750 \%$ & 16,513 & $1,906 \%$ \\
\hline \multirow{6}{*}{4} & \multirow{6}{*}{0,8} & \multirow{6}{*}{0} & 1 & 7,020 & $7,248 \%$ & 5,620 & $8,977 \%$ \\
\hline & & & 2 & 11,715 & $5,612 \%$ & 9,070 & $5,389 \%$ \\
\hline & & & 7 & 14,208 & $9,003 \%$ & 11,607 & $3,202 \%$ \\
\hline & & & 14 & 15,438 & $6,782 \%$ & 12,695 & $4,777 \%$ \\
\hline & & & 28 & 11,602 & $3,907 \%$ & 11,228 & $3,111 \%$ \\
\hline & & & 56 & 12,050 & $4,159 \%$ & 11,645 & $3,238 \%$ \\
\hline
\end{tabular}


Tabela 9 - Resultados gerais da Pasta

\begin{tabular}{|c|c|c|c|c|c|c|c|}
\hline \multirow{3}{*}{ ID } & \multirow{3}{*}{$\mathbf{a} / \mathbf{c}$} & \multirow{3}{*}{$\begin{array}{l}\text { SP. } \\
{[\%]}\end{array}$} & \multirow{3}{*}{$\begin{array}{c}\mathbf{t} \\
{[\text { Dias }]}\end{array}$} & \multicolumn{2}{|c|}{$\mathbf{E}_{\mathbf{d}, \mathbf{f}}$} & \multicolumn{2}{|c|}{$\mathbf{E}_{\mathrm{d}, \mathrm{I}}$} \\
\hline & & & & [GPa] & C.V. & [GPa] & C.V. \\
\hline & & & & Média & {$[\%]$} & Média & {$[\%]$} \\
\hline \multirow{7}{*}{5} & \multirow{7}{*}{0,2} & \multirow{7}{*}{0,6} & 1 & 28,926 & $10,005 \%$ & 29,310 & $9,674 \%$ \\
\hline & & & 2 & 32,718 & $9,131 \%$ & 32,148 & $5,919 \%$ \\
\hline & & & 5 & 35,087 & $6,496 \%$ & 33,767 & $6,459 \%$ \\
\hline & & & 7 & 35,020 & $5,920 \%$ & 33,825 & $5,412 \%$ \\
\hline & & & 14 & 35,900 & $7,054 \%$ & 35,028 & $4,812 \%$ \\
\hline & & & 28 & 37,715 & $4,613 \%$ & 36,145 & $4,683 \%$ \\
\hline & & & 56 & 37,812 & $7,801 \%$ & 36,410 & $8,738 \%$ \\
\hline \multirow{6}{*}{6} & \multirow{6}{*}{0,4} & \multirow{6}{*}{0,6} & 1 & 13,005 & $1,779 \%$ & 12,995 & $0,464 \%$ \\
\hline & & & 3 & 20,083 & $1,798 \%$ & 19,718 & $1,228 \%$ \\
\hline & & & 7 & 21,323 & $2,699 \%$ & 21,033 & $2,182 \%$ \\
\hline & & & 14 & 22,323 & $3,116 \%$ & 22,045 & $2,520 \%$ \\
\hline & & & 28 & 22,728 & $2,762 \%$ & 22,210 & $1,917 \%$ \\
\hline & & & 56 & 22,176 & $6,077 \%$ & 22,128 & $3,729 \%$ \\
\hline \multirow{6}{*}{7} & \multirow{6}{*}{0,6} & \multirow{6}{*}{0,6} & 1 & 7,564 & $3,612 \%$ & 7,553 & $2,761 \%$ \\
\hline & & & 3 & 13,293 & $0,804 \%$ & 13,000 & $2,450 \%$ \\
\hline & & & 7 & 14,733 & $2,837 \%$ & 14,685 & $2,739 \%$ \\
\hline & & & 14 & 15,145 & $3,364 \%$ & 15,238 & $1,956 \%$ \\
\hline & & & 28 & 16,115 & $3,706 \%$ & 16,110 & $1,956 \%$ \\
\hline & & & 56 & 17,052 & $12,656 \%$ & 16,602 & $6,827 \%$ \\
\hline \multirow{6}{*}{8} & \multirow{6}{*}{0,8} & \multirow{6}{*}{0,6} & 1 & 4,253 & $3,463 \%$ & 5,120 & - \\
\hline & & & 3 & 5,707 & $1,922 \%$ & 4,330 & $9,798 \%$ \\
\hline & & & 7 & 7,535 & $8,934 \%$ & 8,430 & - \\
\hline & & & 14 & 8,488 & $2,596 \%$ & 7,340 & $2,324 \%$ \\
\hline & & & 28 & 9,276 & $6,247 \%$ & 7,760 & - \\
\hline & & & 56 & 9,290 & $7,192 \%$ & 7,760 & - \\
\hline \multirow{6}{*}{9} & \multirow{6}{*}{0,2} & \multirow{6}{*}{1} & 1 & 29,950 & $2,949 \%$ & 29,640 & $2,747 \%$ \\
\hline & & & 5 & 32,718 & $9,131 \%$ & 32,148 & $5,919 \%$ \\
\hline & & & 7 & 34,775 & $5,644 \%$ & 33,480 & $5,588 \%$ \\
\hline & & & 14 & 34,982 & $8,587 \%$ & 35,028 & $4,812 \%$ \\
\hline & & & 28 & 36,076 & $1,398 \%$ & 34,992 & $2,493 \%$ \\
\hline & & & 56 & 36,820 & $4,693 \%$ & 35,722 & $4,746 \%$ \\
\hline \multirow{6}{*}{10} & \multirow{6}{*}{0,4} & \multirow{6}{*}{1} & 1 & 10,870 & $3,641 \%$ & 10,918 & $2,520 \%$ \\
\hline & & & 2 & 18,784 & $3,007 \%$ & 18,632 & $2,104 \%$ \\
\hline & & & 7 & 20,714 & $2,801 \%$ & 20,496 & $1,777 \%$ \\
\hline & & & 14 & 21,498 & $1,695 \%$ & 21,272 & $1,201 \%$ \\
\hline & & & 28 & 22,346 & $1,741 \%$ & 21,964 & $1,509 \%$ \\
\hline & & & 56 & 25,311 & $5,286 \%$ & 13,415 & $6,912 \%$ \\
\hline
\end{tabular}




\subsection{ARGAMASSA}

Os resultados gerais de módulo de elasticidade dinâmico flexional e longitudinal, respectivamente $E_{d, f}$ e $E_{d, 1}$, para os traços de argamassa (cimento:areia:água) são conforme a Tabela 10:

Tabela 10 - Resultados gerais da Argamassa

\begin{tabular}{|c|c|c|c|c|c|c|c|}
\hline \multirow[b]{2}{*}{ ID } & \multirow[b]{2}{*}{ Traço } & \multirow{2}{*}{$\begin{array}{c}\text { SP } \\
{[\%]}\end{array}$} & \multirow{2}{*}{$\begin{array}{c}\mathbf{t} \\
\text { [Dias] }\end{array}$} & \multicolumn{2}{|c|}{$\mathbf{E}_{\mathbf{d}, \mathbf{f}}$} & \multicolumn{2}{|c|}{$\mathbf{E}_{\mathrm{d}, \mathrm{I}}$} \\
\hline & & & & $\begin{array}{l}\text { [GPa] } \\
\text { Média }\end{array}$ & $\begin{array}{l}\text { C.V. } \\
{[\%]}\end{array}$ & $\begin{array}{l}\text { [GPa] } \\
\text { Média }\end{array}$ & $\begin{array}{l}\text { C.V. } \\
{[\%]}\end{array}$ \\
\hline \multirow{5}{*}{1} & \multirow{5}{*}{$1: 3: 0,5$} & \multirow{5}{*}{1} & 1 & 25,134 & $4,174 \%$ & 23,510 & $5,719 \%$ \\
\hline & & & 7 & 42,442 & $1,651 \%$ & 39,720 & $0,998 \%$ \\
\hline & & & 14 & 43,558 & $2,735 \%$ & 41,306 & $1,038 \%$ \\
\hline & & & 28 & 44,942 & $2,534 \%$ & 42,484 & $1,028 \%$ \\
\hline & & & 58 & 46,618 & $2,475 \%$ & 43,772 & $1,162 \%$ \\
\hline \multirow{6}{*}{2} & \multirow{6}{*}{$1: 2: 0,5$} & \multirow{6}{*}{1} & 1 & 25,790 & $9,221 \%$ & 25,998 & $10,098 \%$ \\
\hline & & & 3 & 33,444 & $8,201 \%$ & 33,666 & $9,105 \%$ \\
\hline & & & 9 & 37,126 & $1,601 \%$ & 38,324 & $3,105 \%$ \\
\hline & & & 14 & 37,286 & $5,258 \%$ & 37,184 & $7,916 \%$ \\
\hline & & & 28 & 38,752 & $4,949 \%$ & 38,452 & $6,267 \%$ \\
\hline & & & 61 & 40,928 & $4,434 \%$ & 41,954 & $4,085 \%$ \\
\hline \multirow{6}{*}{3} & \multirow{6}{*}{$1: 2: 0,3$} & \multirow{6}{*}{1} & 1 & 36,972 & $2,588 \%$ & 38,906 & $2,657 \%$ \\
\hline & & & 3 & 40,132 & $2,658 \%$ & 42,198 & $3,495 \%$ \\
\hline & & & 7 & 42,710 & $2,136 \%$ & 45,778 & $2,041 \%$ \\
\hline & & & 15 & 43,608 & $2,006 \%$ & 46,510 & $3,369 \%$ \\
\hline & & & 28 & 45,406 & $1,974 \%$ & 48,740 & $2,363 \%$ \\
\hline & & & 57 & 46,698 & $2,125 \%$ & 50,146 & $2,365 \%$ \\
\hline \multirow{7}{*}{4} & \multirow{7}{*}{$1: 1: 0,5$} & \multirow{7}{*}{1} & 1 & 15,610 & $9,477 \%$ & 15,002 & $9,354 \%$ \\
\hline & & & 2 & 22,073 & $4,871 \%$ & 20,828 & $2,803 \%$ \\
\hline & & & 5 & 25,485 & $5,548 \%$ & 25,923 & $5,665 \%$ \\
\hline & & & 7 & 25,843 & $4,971 \%$ & 26,747 & $4,791 \%$ \\
\hline & & & 14 & 26,605 & $0,452 \%$ & 27,625 & $3,814 \%$ \\
\hline & & & 28 & 28,273 & $5,083 \%$ & 29,213 & $5,286 \%$ \\
\hline & & & 56 & 29,286 & $4,696 \%$ & 28,214 & $9,228 \%$ \\
\hline \multirow{5}{*}{5} & \multirow{5}{*}{$1: 1: 0,3$} & \multirow{5}{*}{1} & 1 & 31,492 & $0,974 \%$ & 32,614 & $2,307 \%$ \\
\hline & & & 8 & 38,540 & $1,198 \%$ & 41,760 & $2,135 \%$ \\
\hline & & & 14 & 40,024 & $2,149 \%$ & 42,322 & $2,289 \%$ \\
\hline & & & 29 & 41,280 & $0,523 \%$ & 44,670 & $1,509 \%$ \\
\hline & & & 56 & 41,738 & $8,060 \%$ & 44,760 & $7,824 \%$ \\
\hline
\end{tabular}


Tabela 11 - Resultados gerais da Argamassa

\begin{tabular}{|c|c|c|c|c|c|c|c|}
\hline \multirow[b]{2}{*}{ ID } & \multirow[b]{2}{*}{ Traço } & \multirow{2}{*}{$\begin{array}{c}\text { SP } \\
{[\%]}\end{array}$} & \multirow{2}{*}{$\begin{array}{c}\mathbf{t} \\
{[\text { Dias }]}\end{array}$} & \multicolumn{2}{|c|}{$\mathbf{E}_{\mathbf{d}, \mathbf{f}}$} & \multicolumn{2}{|c|}{$\mathbf{E}_{\mathrm{d}, \mathrm{I}}$} \\
\hline & & & & $\begin{array}{l}\text { [GPa] } \\
\text { Média }\end{array}$ & $\begin{array}{l}\text { C.V. } \\
{[\%]}\end{array}$ & $\begin{array}{l}\text { [GPa] } \\
\text { Média }\end{array}$ & $\begin{array}{l}\text { C.V. } \\
{[\%]}\end{array}$ \\
\hline \multirow{7}{*}{6} & \multirow{7}{*}{$1: 3: 0,5$} & \multirow{7}{*}{0} & 1 & 26,426 & $5,499 \%$ & 28,47 & 5,325 \\
\hline & & & 2 & 29,574 & $3,007 \%$ & 31,57 & $4,772 \%$ \\
\hline & & & 5 & 35,666 & $2,715 \%$ & 38,672 & $3,554 \%$ \\
\hline & & & 7 & 36,576 & $2,737 \%$ & 39,574 & $3,725 \%$ \\
\hline & & & 14 & 38,276 & $1,635 \%$ & 40,850 & $2,834 \%$ \\
\hline & & & 28 & 39,612 & $1,729 \%$ & 42,100 & $2,386 \%$ \\
\hline & & & 56 & 40,668 & $1,900 \%$ & 44,270 & $1,993 \%$ \\
\hline \multirow{6}{*}{7} & \multirow{6}{*}{$1: 3: 0,7$} & \multirow{6}{*}{0} & 1 & 15,024 & $3,123 \%$ & 15,938 & $4,138 \%$ \\
\hline & & & 3 & 26,186 & $2,969 \%$ & 26,290 & $2,748 \%$ \\
\hline & & & 7 & 28,114 & $2,028 \%$ & 28,838 & $4,646 \%$ \\
\hline & & & 14 & 28,922 & $2,736 \%$ & 30,362 & $2,878 \%$ \\
\hline & & & 28 & 30,436 & $2,538 \%$ & 31,468 & $4,058 \%$ \\
\hline & & & 56 & 31,380 & $2,724 \%$ & 32,020 & $2,476 \%$ \\
\hline \multirow{6}{*}{8} & \multirow{6}{*}{$1: 2: 0,5$} & \multirow{6}{*}{0} & 1 & 20,852 & $4,283 \%$ & 22,718 & $4,651 \%$ \\
\hline & & & 3 & 29,460 & $2,746 \%$ & 30,350 & $5,497 \%$ \\
\hline & & & 7 & 32,7825 & $0,662 \%$ & 33,9625 & $2,884 \%$ \\
\hline & & & 14 & 34,392 & $0,307 \%$ & 35,398 & $1,841 \%$ \\
\hline & & & 29 & 35,306 & $3,292 \%$ & 37,030 & $2,714 \%$ \\
\hline & & & 56 & 36,902 & $0,319 \%$ & 38,160 & $1,781 \%$ \\
\hline \multirow{7}{*}{9} & \multirow{7}{*}{$1: 2: 0,3$} & \multirow{7}{*}{0} & 1 & 38,066 & $4,381 \%$ & 40,254 & $6,908 \%$ \\
\hline & & & 4 & 41,508 & $1,071 \%$ & 44,722 & $2,367 \%$ \\
\hline & & & 5 & 42,01 & $1,188 \%$ & 45,318 & $1,562 \%$ \\
\hline & & & 7 & 42,395 & $1,170 \%$ & 45,480 & $1,256 \%$ \\
\hline & & & 14 & 43,708 & $1,274 \%$ & 46,580 & $1,532 \%$ \\
\hline & & & 28 & 45,078 & $1,319 \%$ & 48,364 & $0,677 \%$ \\
\hline & & & 56 & 46,252 & $1,700 \%$ & 49,806 & $2,420 \%$ \\
\hline \multirow{7}{*}{10} & \multirow{7}{*}{$1: 1: 0,7$} & \multirow{7}{*}{0} & 1 & 10,820 & $5,048 \%$ & 10,820 & $5,048 \%$ \\
\hline & & & 2 & 15,858 & $2,584 \%$ & 15,818 & $2,351 \%$ \\
\hline & & & 5 & 18,304 & $4,862 \%$ & 19,002 & $2,688 \%$ \\
\hline & & & 7 & 19,028 & $2,958 \%$ & 19,845 & $3,679 \%$ \\
\hline & & & 14 & 18,740 & $2,421 \%$ & 20,286 & $3,758 \%$ \\
\hline & & & 28 & 19,932 & $2,714 \%$ & 21,298 & $4,018 \%$ \\
\hline & & & 56 & 20,786 & $5,236 \%$ & 21,868 & $3,686 \%$ \\
\hline
\end{tabular}


Tabela 12 - Resultados gerais da Argamassa

\begin{tabular}{|c|c|c|c|c|c|c|c|}
\hline \multirow[b]{2}{*}{ ID } & \multirow[b]{2}{*}{ Traço } & \multirow{2}{*}{$\begin{array}{l}\text { SP } \\
{[\%]}\end{array}$} & \multirow{2}{*}{$\begin{array}{c}\mathbf{t} \\
\text { [Dias] }\end{array}$} & \multicolumn{2}{|c|}{$\mathbf{E}_{\mathrm{d}, \mathbf{f}}$} & \multicolumn{2}{|c|}{$\mathbf{E}_{\mathrm{d}, \mathrm{I}}$} \\
\hline & & & & $\begin{array}{l}\text { [GPa] } \\
\text { Média }\end{array}$ & $\begin{array}{l}\text { C.V. } \\
{[\%]}\end{array}$ & $\begin{array}{l}\text { [GPa] } \\
\text { Média }\end{array}$ & $\begin{array}{l}\text { C.V. } \\
{[\%]}\end{array}$ \\
\hline \multirow{6}{*}{11} & \multirow{6}{*}{$1: 1: 0,5$} & \multirow{6}{*}{0} & 1 & 16,238 & $3,471 \%$ & 17,200 & $1,811 \%$ \\
\hline & & & 3 & 22,682 & $3,876 \%$ & 23,616 & $3,097 \%$ \\
\hline & & & 7 & 25,492 & $2,206 \%$ & 26,702 & $1,581 \%$ \\
\hline & & & 14 & 26,836 & $4,235 \%$ & 28,064 & $3,336 \%$ \\
\hline & & & 28 & 26,508 & $3,068 \%$ & 29,040 & $2,676 \%$ \\
\hline & & & 56 & 29,003 & $1,531 \%$ & 29,692 & $1,829 \%$ \\
\hline \multirow{7}{*}{12} & \multirow{7}{*}{ 1:1:0,3 } & \multirow{7}{*}{0} & 1 & 31,960 & $4,675 \%$ & 32,932 & $5,099 \%$ \\
\hline & & & 2 & 33,040 & $4,925 \%$ & 34,384 & $4,057 \%$ \\
\hline & & & 5 & 35,378 & $3,835 \%$ & 38,036 & $6,373 \%$ \\
\hline & & & 7 & 36,378 & $3,772 \%$ & 38,672 & $4,501 \%$ \\
\hline & & & 14 & 38,562 & $1,464 \%$ & 41,760 & $2,699 \%$ \\
\hline & & & 28 & 40,044 & $1,198 \%$ & 43,988 & $1,833 \%$ \\
\hline & & & 56 & 39,840 & $7,489 \%$ & 42,628 & $5,857 \%$ \\
\hline
\end{tabular}




\subsection{CONCRETO}

Os resultados gerais de módulo de elasticidade dinâmico flexional e longitudinal, respectivamente $E_{d, f}$ e $E_{d, l}$, para os traços de concreto (cimento:areia:brita:água, em massa) podem ser de acordo com a Tabela 13:

Tabela 13 - Resultados gerais do Concreto

\begin{tabular}{|c|c|c|c|c|c|c|c|c|c|c|}
\hline \multirow[b]{2}{*}{ ID } & \multirow[b]{2}{*}{ Traço } & \multirow[b]{2}{*}{ Rocha } & \multirow{2}{*}{$\begin{array}{l}\text { SP. } \\
{[\%]}\end{array}$} & \multirow{2}{*}{$\begin{array}{c}\mathbf{t} \\
\text { [Dias] }\end{array}$} & \multicolumn{2}{|c|}{$\mathbf{E}_{\mathrm{d}, \mathbf{f}}$} & \multicolumn{2}{|c|}{$\mathbf{E}_{\mathrm{d}, \mathrm{l}}$} & \multicolumn{2}{|c|}{$\mathrm{E}_{\mathrm{ci}}(28$ dias $)$} \\
\hline & & & & & $\begin{array}{l}\text { Média } \\
\text { [GPa] }\end{array}$ & $\begin{array}{l}\text { C.V } \\
{[\%]} \\
\end{array}$ & $\begin{array}{l}\text { Média } \\
\text { [GPa] }\end{array}$ & $\begin{array}{l}\text { C.V } \\
{[\%]}\end{array}$ & $\begin{array}{l}\text { Média } \\
\text { [GPa] }\end{array}$ & $\begin{array}{c}\text { C.V } \\
{[\%]}\end{array}$ \\
\hline \multirow{6}{*}{1} & \multirow{6}{*}{$\begin{array}{c}1: 2: 1 \mathrm{~B} 1: 0,5 \\
\text { TRAÇO } \\
\text { RICO }\end{array}$} & \multirow{6}{*}{$\mathrm{D}$} & \multirow{6}{*}{$0 \%$} & 1 & 28,738 & $4,992 \%$ & 29,008 & $3,803 \%$ & \multirow{6}{*}{33,025} & \multirow{6}{*}{$5,919 \%$} \\
\hline & & & & 5 & 35,323 & $2,541 \%$ & 36,145 & $0,986 \%$ & & \\
\hline & & & & 8 & 35,873 & $1,249 \%$ & 36,620 & $1,468 \%$ & & \\
\hline & & & & 15 & 37,508 & $2,210 \%$ & 39,287 & $1,215 \%$ & & \\
\hline & & & & 28 & 38,130 & $0,466 \%$ & 37,338 & $1,030 \%$ & & \\
\hline & & & & 56 & 39,615 & $0,411 \%$ & 41,415 & $0,051 \%$ & & \\
\hline \multirow{6}{*}{2} & \multirow{6}{*}{$\begin{array}{c}\text { 1:1:2B1:0,5 } \\
\text { TRAÇO } \\
\text { RICO }\end{array}$} & \multirow{6}{*}{$\mathrm{D}$} & \multirow{6}{*}{$0 \%$} & 1 & 31,595 & $0,887 \%$ & 32,224 & $2,779 \%$ & \multirow{6}{*}{30,550} & \multirow{6}{*}{$7,947 \%$} \\
\hline & & & & 4 & 37,028 & $1,076 \%$ & 35,958 & $0,186 \%$ & & \\
\hline & & & & 8 & 37,952 & $1,972 \%$ & 37,740 & $0,676 \%$ & & \\
\hline & & & & 15 & 39,450 & $1,243 \%$ & 38,437 & $1,159 \%$ & & \\
\hline & & & & 28 & 40,685 & $1,048 \%$ & 39,463 & $1,452 \%$ & & \\
\hline & & & & 56 & 41,420 & $1,708 \%$ & 43,343 & $2,209 \%$ & & \\
\hline \multirow{6}{*}{3} & \multirow{6}{*}{$\begin{array}{c}\text { 1:3:4B1:0,5 } \\
\text { TRAÇO } \\
\text { POBRE }\end{array}$} & \multirow{6}{*}{$\mathrm{D}$} & \multirow{6}{*}{$0 \%$} & 1 & 43,193 & $1,193 \%$ & 42,885 & $2,090 \%$ & \multirow{6}{*}{46,893} & \multirow{6}{*}{$9,617 \%$} \\
\hline & & & & 3 & 49,563 & $1,378 \%$ & 49,898 & $4,196 \%$ & & \\
\hline & & & & 8 & 51,937 & $1,195 \%$ & 49,873 & $1,164 \%$ & & \\
\hline & & & & 14 & 52,985 & $0,601 \%$ & 50,520 & $1,584 \%$ & & \\
\hline & & & & 28 & 53,358 & $1,143 \%$ & 51,708 & $0,460 \%$ & & \\
\hline & & & & 56 & 54,883 & $1,248 \%$ & 56,748 & $4,168 \%$ & & \\
\hline \multirow{6}{*}{4} & \multirow{6}{*}{$1: 3: 2 \mathrm{~B} 1: 0,5$} & & & 1 & 34,105 & $1,136 \%$ & 35,503 & $0,974 \%$ & & \\
\hline & & & & 3 & 39,060 & $0,951 \%$ & 39,682 & $3,643 \%$ & & \\
\hline & & $\mathrm{D}$ & $0 \%$ & 8 & 41,030 & $0,042 \%$ & 42,343 & $2,443 \%$ & 36827 & 0,5440 \\
\hline & & D & $0 \%$ & 14 & 41,785 & $1,193 \%$ & 44,368 & $0,737 \%$ & 30,021 & $9,044 \%$ \\
\hline & & & & 28 & 42,985 & $0,280 \%$ & 44,640 & $0,719 \%$ & & \\
\hline & & & & 60 & 43,867 & $0,356 \%$ & 44,798 & $5,210 \%$ & & \\
\hline & & & & 1 & 50,965 & $1,402 \%$ & 52,035 & $1,064 \%$ & & \\
\hline & & & & 3 & 55,070 & $0,302 \%$ & 57,483 & $2,381 \%$ & & \\
\hline 5 & $1 \cdot 2 \cdot 3 \mathrm{RI} \cdot 03$ & $D$ & $1 \%$ & 8 & 55,575 & $1,769 \%$ & 55,460 & $1,785 \%$ & 50117 & $0503 \%$ \\
\hline 5 & $1: 2: 3 B L: 0,3$ & D & $1 \%$ & 16 & 55,557 & $1,486 \%$ & 57,613 & $1,683 \%$ & $50,11 /$ & $0,593 \%$ \\
\hline & & & & 28 & 57,597 & $0,903 \%$ & 59,190 & $3,074 \%$ & & \\
\hline
\end{tabular}


Tabela 14 - Resultados gerais do Concreto

\begin{tabular}{|c|c|c|c|c|c|c|c|c|c|c|}
\hline \multirow[b]{2}{*}{ ID } & \multirow[b]{2}{*}{ Traço } & \multirow[b]{2}{*}{ Rocha } & \multirow{2}{*}{$\begin{array}{l}\text { SP. } \\
{[\%]}\end{array}$} & \multirow{2}{*}{$\begin{array}{c}\mathbf{t} \\
{[\text { Dias }]}\end{array}$} & \multicolumn{2}{|c|}{$\mathbf{E}_{\mathbf{d}, \mathbf{f}}$} & \multicolumn{2}{|c|}{$\mathbf{E}_{\mathrm{d}, \mathrm{I}}$} & \multicolumn{2}{|c|}{$\mathrm{E}_{\mathrm{ci}}(28$ dias $)$} \\
\hline & & & & & $\begin{array}{c}\text { Média } \\
\text { [GPa] }\end{array}$ & $\begin{array}{c}\text { C.V } \\
{[\%]}\end{array}$ & $\begin{array}{l}\text { Média } \\
\text { [GPa] }\end{array}$ & $\begin{array}{c}\text { C.V } \\
{[\%]}\end{array}$ & $\begin{array}{l}\text { Média } \\
\text { [GPa] }\end{array}$ & $\begin{array}{c}\text { C.V } \\
{[\%]}\end{array}$ \\
\hline \multirow{5}{*}{6} & \multirow{5}{*}{$1: 2: 3 B L: 0,5$} & \multirow{5}{*}{$\mathrm{D}$} & \multirow{5}{*}{$1 \%$} & 1 & 40,847 & $2,402 \%$ & 41,313 & $0,627 \%$ & \multirow{5}{*}{36,783} & \multirow{5}{*}{$6,508 \%$} \\
\hline & & & & 5 & 46,187 & $1,131 \%$ & 49,517 & $2,111 \%$ & & \\
\hline & & & & 8 & 48,950 & $1,792 \%$ & 47,460 & $0,775 \%$ & & \\
\hline & & & & 16 & 50,133 & $1,661 \%$ & 49,898 & $7,172 \%$ & & \\
\hline & & & & 28 & 50,297 & $2,021 \%$ & 52,627 & $3,244 \%$ & & \\
\hline \multirow{5}{*}{7} & \multirow{5}{*}{$1: 2: 3 B L: 0,7$} & \multirow{5}{*}{$\mathrm{D}$} & \multirow{5}{*}{$0 \%$} & 1 & 25,740 & $1,990 \%$ & 26,098 & $0,896 \%$ & \multirow{5}{*}{24,147} & \multirow{5}{*}{$7,902 \%$} \\
\hline & & & & 5 & 33,410 & $3,503 \%$ & 32,747 & $3,083 \%$ & & \\
\hline & & & & 8 & 33,680 & $2,813 \%$ & 33,050 & $0,438 \%$ & & \\
\hline & & & & 14 & 35,050 & $2,669 \%$ & 35,058 & $3,466 \%$ & & \\
\hline & & & & 28 & 35,813 & $3,005 \%$ & 35,750 & $1,752 \%$ & & \\
\hline \multirow{5}{*}{8} & \multirow{5}{*}{$1: 2: 3 B L: 0,5$} & \multirow{5}{*}{$\mathrm{D}$} & \multirow{5}{*}{$0 \%$} & 1 & 37,783 & $0,424 \%$ & 37,062 & $0,738 \%$ & \multirow{5}{*}{38,067} & \multirow{5}{*}{$5,252 \%$} \\
\hline & & & & 4 & 44,515 & $1,137 \%$ & 46,165 & $2,874 \%$ & & \\
\hline & & & & 8 & 45,257 & $0,718 \%$ & 48,063 & $1,722 \%$ & & \\
\hline & & & & 14 & 47,433 & $0,700 \%$ & 47,384 & $4,926 \%$ & & \\
\hline & & & & 29 & 48,060 & $2,189 \%$ & 45,543 & $0,517 \%$ & & \\
\hline \multirow{6}{*}{9} & \multirow{6}{*}{$1: 2: 3 \mathrm{~B} 1: 0,3$} & \multirow{6}{*}{$\mathrm{D}$} & & 1 & 56,635 & $4,118 \%$ & 56,320 & $1,210 \%$ & & \\
\hline & & & & 3 & 58,448 & $2,352 \%$ & 58,300 & $2,811 \%$ & & \\
\hline & & & 10 & 6 & 57,843 & $1,712 \%$ & 55,418 & $4,538 \%$ & 52000 & 30600 \\
\hline & & & $1 \%$ & 13 & 60,720 & $6,864 \%$ & 59,224 & $0,963 \%$ & 53,990 & $3,868 \%$ \\
\hline & & & & 29 & 59,527 & $0,870 \%$ & 59,628 & $3,208 \%$ & & \\
\hline & & & & 56 & 61,813 & $3,725 \%$ & 63,215 & $4,416 \%$ & & \\
\hline & & & & 1 & 38,990 & $1,814 \%$ & 40,695 & $3,578 \%$ & & \\
\hline & & & & 2 & 41,293 & $2,417 \%$ & 40,907 & $0,886 \%$ & & \\
\hline & & & & 5 & 43,910 & $1,546 \%$ & 44,000 & $3,889 \%$ & & \\
\hline 10 & $1: 2: 3 \mathrm{~B} 1: 0,5$ & $\mathrm{D}$ & $1 \%$ & 7 & 45,160 & $1,745 \%$ & 44,477 & $1,359 \%$ & 39,200 & $3,434 \%$ \\
\hline & & & & 14 & 46,747 & $0,329 \%$ & 49,193 & $1,486 \%$ & & \\
\hline & & & & 26 & 46,753 & $1,039 \%$ & 49,865 & $0,838 \%$ & & \\
\hline
\end{tabular}


Tabela 15 - Resultados gerais do Concreto

\begin{tabular}{|c|c|c|c|c|c|c|c|c|c|c|}
\hline \multirow[b]{2}{*}{ ID } & \multirow[b]{2}{*}{ Traço } & \multirow[b]{2}{*}{ Rocha } & \multirow{2}{*}{$\begin{array}{l}\text { SP. } \\
{[\%]}\end{array}$} & \multirow{2}{*}{$\begin{array}{c}\mathbf{t} \\
{[\text { Dias] }}\end{array}$} & \multicolumn{2}{|c|}{ Ed,f } & \multicolumn{2}{|c|}{ Ed,l } & \multicolumn{2}{|c|}{ Eci (28 dias) } \\
\hline & & & & & $\begin{array}{l}\text { Média } \\
\text { [GPa] }\end{array}$ & $\begin{array}{l}\text { C.V } \\
{[\%]} \\
\end{array}$ & $\begin{array}{l}\text { Média } \\
\text { [GPa] }\end{array}$ & $\begin{array}{l}\text { C.V } \\
{[\%]} \\
\end{array}$ & $\begin{array}{l}\text { Média } \\
\text { [GPa] }\end{array}$ & $\begin{array}{l}\text { C.V } \\
{[\%]}\end{array}$ \\
\hline \multirow{6}{*}{11} & \multirow{6}{*}{$1: 2: 3 \mathrm{~B} 1: 0,7$} & \multirow{6}{*}{$\mathrm{D}$} & \multirow{6}{*}{$0 \%$} & 1 & 23,875 & $1,807 \%$ & 25,240 & $6,780 \%$ & \multirow{6}{*}{27,993} & \multirow{6}{*}{$11,782 \%$} \\
\hline & & & & 4 & 30,478 & $2,040 \%$ & 32,800 & $1,847 \%$ & & \\
\hline & & & & 7 & 31,820 & $1,590 \%$ & 31,653 & $0,666 \%$ & & \\
\hline & & & & 13 & 33,270 & $0,213 \%$ & 33,173 & $1,255 \%$ & & \\
\hline & & & & 29 & 34,663 & $0,565 \%$ & 34,300 & $0,440 \%$ & & \\
\hline & & & & 56 & 35,398 & $0,840 \%$ & 35,278 & $0,412 \%$ & & \\
\hline \multirow{6}{*}{12} & \multirow{6}{*}{$1: 2: 3 B 1: 0,5$} & \multirow{6}{*}{$\mathrm{D}$} & \multirow{6}{*}{$0 \%$} & 1 & 36,268 & $0,964 \%$ & 37,998 & $0,859 \%$ & \multirow{6}{*}{41,175} & \multirow{6}{*}{$17,762 \%$} \\
\hline & & & & 3 & 41,246 & $2,703 \%$ & 41,057 & $1,832 \%$ & & \\
\hline & & & & 7 & 41,983 & $0,790 \%$ & 44,660 & $3,767 \%$ & & \\
\hline & & & & 14 & 43,935 & $0,496 \%$ & 42,255 & $0,810 \%$ & & \\
\hline & & & & 28 & 44,905 & $1,834 \%$ & 45,430 & $4,513 \%$ & & \\
\hline & & & & 56 & 45,250 & $0,480 \%$ & 44,803 & $4,114 \%$ & & \\
\hline \multirow{6}{*}{13} & \multirow{6}{*}{$1: 2: 3 B 0: 0,5$} & \multirow{6}{*}{$\mathrm{D}$} & \multirow{6}{*}{$1 \%$} & 1 & 32,863 & $3,278 \%$ & 34,843 & $1,450 \%$ & \multirow{6}{*}{49,650} & \\
\hline & & & & 3 & 39,615 & $0,649 \%$ & 42,040 & $1,030 \%$ & & \\
\hline & & & & 7 & 40,780 & $0,737 \%$ & 43,513 & $0,564 \%$ & & $0402 \%$ \\
\hline & & & & 18 & 42,745 & $0,306 \%$ & 44,348 & $5,712 \%$ & & $0,402 \%$ \\
\hline & & & & 27 & 44,037 & $1,727 \%$ & 43,685 & $2,100 \%$ & & \\
\hline & & & & 56 & 45,113 & $1,075 \%$ & 48,320 & $2,308 \%$ & & \\
\hline & & & & 1 & 46,470 & $4,023 \%$ & 48,420 & $9,416 \%$ & & \\
\hline & & & & 3 & 52,548 & $3,047 \%$ & 50,874 & $5,066 \%$ & & \\
\hline 14 & & $\mathrm{D}$ & $1 \%$ & 7 & 52,655 & $1,598 \%$ & 50,303 & $4,143 \%$ & 15883 & $4263 \%$ \\
\hline 14 & $1: 2: 3 \mathrm{~B} 0: 0,3$ & D & $1 \%$ & 15 & 54,703 & $3,155 \%$ & 57,187 & $5,193 \%$ & 45,883 & $4,205 \%$ \\
\hline & & & & 29 & 56,878 & $2,629 \%$ & 51,785 & $2,715 \%$ & & \\
\hline & & & & 58 & 57,233 & $1,810 \%$ & 60,347 & $0,662 \%$ & & \\
\hline & & & & 1 & 24,307 & $1,101 \%$ & 23,223 & $1,042 \%$ & & \\
\hline & & & & 3 & 31,088 & $1,291 \%$ & 32,818 & $0,922 \%$ & & \\
\hline 15 & $1 \cdot 2 \cdot 3 \mathrm{~B} 0 \cdot 07$ & $\mathrm{D}$ & & 9 & 32,670 & $0,340 \%$ & 34,743 & $0,442 \%$ & & \\
\hline 15 & $1: 2: 3 \mathrm{~B} 0: 0,7$ & D & $0 \%$ & 16 & 33,695 & $0,336 \%$ & 33,653 & $2,204 \%$ & & \\
\hline & & & & 29 & 34,844 & $3,118 \%$ & 33,703 & $1,187 \%$ & & \\
\hline & & & & 58 & 35,843 & $0,948 \%$ & 34,970 & $0,444 \%$ & & \\
\hline & & & & 1 & 33,720 & $1,539 \%$ & 35,870 & $0,752 \%$ & & \\
\hline & & & & 7 & 41,085 & $1,341 \%$ & 42,955 & $0,700 \%$ & & \\
\hline 16 & $1: 2: 3 \mathrm{~B} 0: 0,5$ & $\mathrm{D}$ & $0 \%$ & 14 & 42,427 & $1,287 \%$ & 43,730 & $0,770 \%$ & & \\
\hline & & & & 28 & 41,303 & $2,510 \%$ & 42,680 & $2,170 \%$ & & \\
\hline & & & & 80 & 45,735 & $1,938 \%$ & 47,825 & $2,524 \%$ & & \\
\hline
\end{tabular}


Tabela 16 - Resultados gerais do Concreto

\begin{tabular}{|c|c|c|c|c|c|c|c|c|c|c|}
\hline \multirow[b]{2}{*}{ ID } & \multirow[b]{2}{*}{ Traço } & \multirow[b]{2}{*}{ Rocha } & \multirow{2}{*}{$\begin{array}{l}\text { SP. } \\
{[\%]}\end{array}$} & \multirow{2}{*}{$\begin{array}{c}\mathbf{t} \\
{[\text { Dias] }}\end{array}$} & \multicolumn{2}{|c|}{ Ed,f } & \multicolumn{2}{|c|}{ Ed,I } & \multicolumn{2}{|c|}{ Eci (28 dias) } \\
\hline & & & & & $\begin{array}{l}\text { Média } \\
\text { [GPa] }\end{array}$ & $\begin{array}{l}\text { C.V } \\
{[\%]}\end{array}$ & $\begin{array}{l}\text { Média } \\
\text { [GPa] }\end{array}$ & $\begin{array}{l}\text { C.V } \\
{[\%]}\end{array}$ & $\begin{array}{l}\text { Média } \\
\text { [GPa] }\end{array}$ & $\begin{array}{l}\text { C.V } \\
\text { [\%] }\end{array}$ \\
\hline \multirow{6}{*}{17} & \multirow{6}{*}{$1: 2: 3 \mathrm{~A}: 0,5$} & \multirow{6}{*}{ A } & \multirow{6}{*}{$0 \%$} & 1 & 24,737 & $2,023 \%$ & 24,620 & $0,712 \%$ & & \\
\hline & & & & 2 & 28,100 & $0,308 \%$ & 28,807 & $1,924 \%$ & & \\
\hline & & & & 5 & 34,990 & $11,220 \%$ & 28,628 & $12,445 \%$ & & \\
\hline & & & & 7 & 33,507 & $4,181 \%$ & 32,540 & $2,998 \%$ & & \\
\hline & & & & 15 & 34,027 & $1,237 \%$ & 34,020 & $4,099 \%$ & & \\
\hline & & & & 30 & 34,793 & $0,294 \%$ & 35,520 & $2,720 \%$ & & \\
\hline \multirow{6}{*}{18} & \multirow{6}{*}{$1: 2: 3 \mathrm{~A}: 0,7$} & \multirow{6}{*}{ A } & \multirow{6}{*}{$0 \%$} & 1 & 33,650 & $2,424 \%$ & 32,483 & $0,539 \%$ & & \\
\hline & & & & 2 & 37,527 & $1,506 \%$ & 35,067 & $1,299 \%$ & & \\
\hline & & & & 5 & 41,523 & $0,423 \%$ & 38,263 & $0,918 \%$ & & \\
\hline & & & & 7 & 41,850 & $2,433 \%$ & 39,250 & & & \\
\hline & & & & 15 & 41,520 & $1,771 \%$ & 40,603 & $5,050 \%$ & & \\
\hline & & & & 30 & 45,210 & & 39,300 & & & \\
\hline
\end{tabular}




\subsection{FATORES INFLUENTES AO MÓDULO DE ELASTICIDADE}

Os fatores que influem no módulo de elasticidade dinâmico da pasta, argamassa e concreto são basicamente a relação água-cimento, maturidade, proporção volumétrica de componentes nas misturas, tipo e dimensão máxima do agregado graúdo utilizado. Tomando como medida de módulo de elasticidade dinâmico a média entre os valores obtidos sob vibração flexional $\left(\mathrm{E}_{\mathrm{d}, \mathrm{flex}}\right)$ e longitudinal $\left(\mathrm{E}_{\mathrm{d}, \text { long }}\right)$ pode-se inferir sobre o impacto desses parâmetros sobre a microestrutura destes materiais.

Como primeiro fator, a porosidade afeta diretamente o módulo de elasticidade da pasta, argamassa e concreto. Assim, admitiu-se há relação inversa fundamental entre a porosidade e o módulo de elasticidade dinâmico, conforme a curva proposta por MACKENZIE (1950):

$$
E_{d}=E_{d, 0}\left(1-K \times P+(K-1) \times P^{2}\right) \quad \text { Equação (28) }
$$

Em que:

$E_{d}$ é o módulo de elasticidade dinâmico da pasta;

$E_{d, 0}$ é o módulo de elasticidade dinâmico intrínseco sob porosidade zero;

$P$ é a porosidade do material, admitida igual ao índice de vazios comunicáveis - Razão entre o volume de vazios e volume total, isto é, $\mathrm{p}=\mathrm{V}_{\mathrm{v}} / \mathrm{V}_{\mathrm{t}}$.

Para o caso da pasta, o gráfico da Figura 20 e a Tabela 17 demonstram a correlação entre a porosidade $(\mathrm{P})$ e o módulo de elasticidade dinâmico $\left(\mathrm{E}_{\mathrm{d}}\right)$, para o coeficiente de poisson de $v_{\mathrm{d}}=0,23, \mathrm{~K}=1,97$ e $\mathrm{E}_{\mathrm{d}, 0}=52,78 \mathrm{GPa}$ :

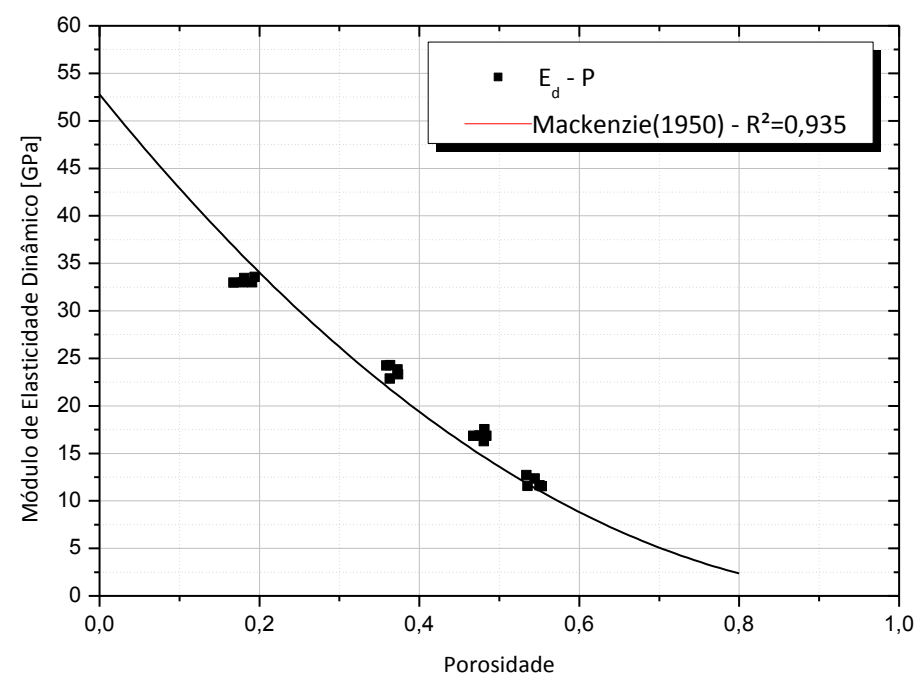

Figura 20 - Influência da Porosidade ao Módulo de Elasticidade Dinâmico (Pasta) 
Tabela 17 - Relação entre Porosidade e Módulo de Elasticidade Dinâmico (Pasta).

\begin{tabular}{|c|c|c|c|}
\hline $\mathbf{a} / \mathbf{c}$ & Idade [Dias] & Porosidade [\%] & $\mathbf{E}_{\mathbf{d}}[\mathbf{G P a}]$ \\
\hline 0,2 & 56 & 0,167 & 32,97 \\
\hline 0,2 & 56 & 0,191 & 32,99 \\
\hline 0,2 & 56 & 0,179 & 32,99 \\
\hline 0,2 & 56 & 0,194 & 33,575 \\
\hline 0,2 & 56 & 0,181 & 33,435 \\
\hline 0,4 & 56 & 0,359 & 24,235 \\
\hline 0,4 & 56 & 0,363 & 24,28 \\
\hline 0,4 & 56 & 0,363 & 22,86 \\
\hline 0,4 & 56 & 0,373 & 23,84 \\
\hline 0,4 & 56 & 0,373 & 23,31 \\
\hline 0,6 & 56 & 0,481 & 17,54 \\
\hline 0,6 & 56 & 0,467 & 16,84 \\
\hline 0,6 & 56 & 0,484 & 16,84 \\
\hline 0,6 & 56 & 0,475 & 16,88 \\
\hline 0,6 & 56 & 0,481 & 16,275 \\
\hline 0,8 & 56 & 0,550 & 11,62 \\
\hline 0,8 & 56 & 0,544 & 12,345 \\
\hline 0,8 & 56 & 0,553 & 11,535 \\
\hline 0,8 & 56 & 0,534 & 12,7 \\
\hline 0,8 & 56 & 0,536 & 11,565 \\
\hline
\end{tabular}

Considerando a argamassa um compósito entre areia e pasta, o mesmo comportamento é observado. Ou seja, a porosidade afeta diretamente seu módulo de elasticidade dinâmico. O gráfico da Figura 21 e a Tabela 18 e Tabela 19 correlacionam a porosidade (P) ao módulo de elasticidade dinâmico $\left(\mathrm{E}_{\mathrm{d}}\right)$ para o caso da argamassa, para o coeficiente de poisson de $v_{\mathrm{d}}=0,23, \mathrm{~K}=1,97$ e $\mathrm{E}_{\mathrm{d}, 0}=39,48 \mathrm{GPa}$ : 


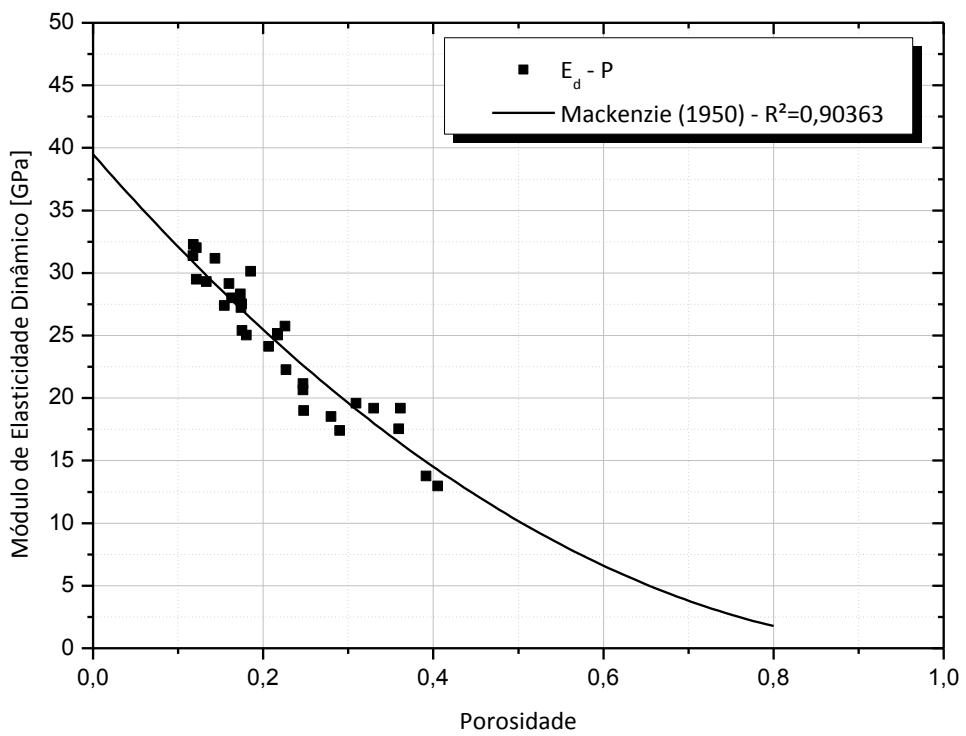

Figura 21 - Influência da Porosidade ao Módulo de Elasticidade Dinâmico (Argamassa)

Tabela 18 - Relação entre Porosidade e Módulo de Elasticidade Dinâmico (Argamassa).

\begin{tabular}{|c|c|c|c|}
\hline Traço & Idade [dias] & Porosidade [\%] & $E_{d}[G P a]$ \\
\hline $1: 3: 0,5: 1 \%$ & 7 & 0,154 & 27,393 \\
\hline $1: 3: 0,5: 1 \%$ & 28 & 0,160 & 29,150 \\
\hline $1: 3: 0,5: 1 \%$ & 62 & 0,186 & 30,138 \\
\hline $1: 2: 0,5: 1 \%$ & 9 & 0,217 & 25,155 \\
\hline $1: 2: 0,5: 1 \%$ & 28 & 0,226 & 25,751 \\
\hline $1: 2: 0,5: 1 \%$ & 56 & 2,266 & 27,642 \\
\hline $1: 2: 0,3: 1 \%$ & 7 & 0,122 & 29,503 \\
\hline $1: 2: 0,3: 1 \%$ & 28 & 0,118 & 31,389 \\
\hline $1: 2: 0,3: 1 \%$ & 56 & 0,118 & 32,288 \\
\hline $1: 1: 0,5: 1 \%$ & 7 & 0,359 & 17,547 \\
\hline $1: 1: 0,5: 1 \%$ & 28 & 0,361 & 19,179 \\
\hline $1: 1: 0,5: 1 \%$ & 56 & 0,330 & 19,182 \\
\hline $1: 3: 0,5$ & 7 & 0,175 & 25,392 \\
\hline $1: 3: 0,5$ & 28 & 0,174 & 27,243 \\
\hline $1: 3: 0,5$ & 56 & 0,173 & 28,319 \\
\hline $1: 3: 0,7$ & 7 & 0,248 & 18,991 \\
\hline $1: 3: 0,7$ & 0 & 0,247 & 20,643 \\
\hline $1: 3: 0,7$ & 0 & 0,247 & 21,142 \\
\hline $1: 2: 0,5$ & 7 & 0,227 & 22,251 \\
\hline $1: 2: 0,5$ & 28 & 0,207 & 24,123 \\
\hline $1: 2: 0,5$ & 56 & 0,217 & 25,022 \\
\hline
\end{tabular}


Tabela 19 - Relação entre Porosidade e Módulo de Elasticidade Dinâmico (Argamassa).

\begin{tabular}{|c|c|c|c|}
\hline Traço & Idade [dias] & Porosidade [\%] & $\mathbf{E}_{\mathbf{d}}[\mathbf{G P a}]$ \\
\hline $1: 2: 0,3$ & 7 & 0,133 & 29,296 \\
\hline $1: 2: 0,3$ & 28 & 0,143 & 31,152 \\
\hline $1: 2: 0,3$ & 56 & 0,122 & 32,025 \\
\hline $1: 1: 0,7$ & 7 & 0,405 & 12,967 \\
\hline $1: 1: 0,7$ & 27 & 0,391 & 13,752 \\
\hline $1: 1: 0,5$ & 7 & 0,290 & 17,405 \\
\hline $1: 1: 0,5$ & 28 & 0,280 & 18,526 \\
\hline $1: 1: 0,5$ & 56 & 0,309 & 19,570 \\
\hline $1: 1: 0,3$ & 7 & 0,180 & 25,029 \\
\hline $1: 1: 0,3$ & 27 & 0,163 & 28,015 \\
\hline $1: 1: 0,3$ & 56 & 0,175 & 27,514 \\
\hline
\end{tabular}

Considerando ainda que o concreto seja um compósito entre argamassa e brita, o mesmo fenômeno que ocorre nos casos da argamassa e pasta é igualmente observado no concreto. Ou seja, a porosidade afeta diretamente seu módulo de elasticidade dinâmico e influi diretamente na capacidade de restrição às deformações impostas. A Figura 22 e a Tabela 20 correlacionam a porosidade ao módulo de elasticidade dinâmico $\left(\mathrm{E}_{\mathrm{d}}\right)$ para o caso da argamassa, , para o coeficiente de poisson de $v \mathrm{~d}=0,23, \mathrm{~K}=1,97$ e $\mathrm{E}_{\mathrm{d}, 0}=61,18 \mathrm{GPa}$ :

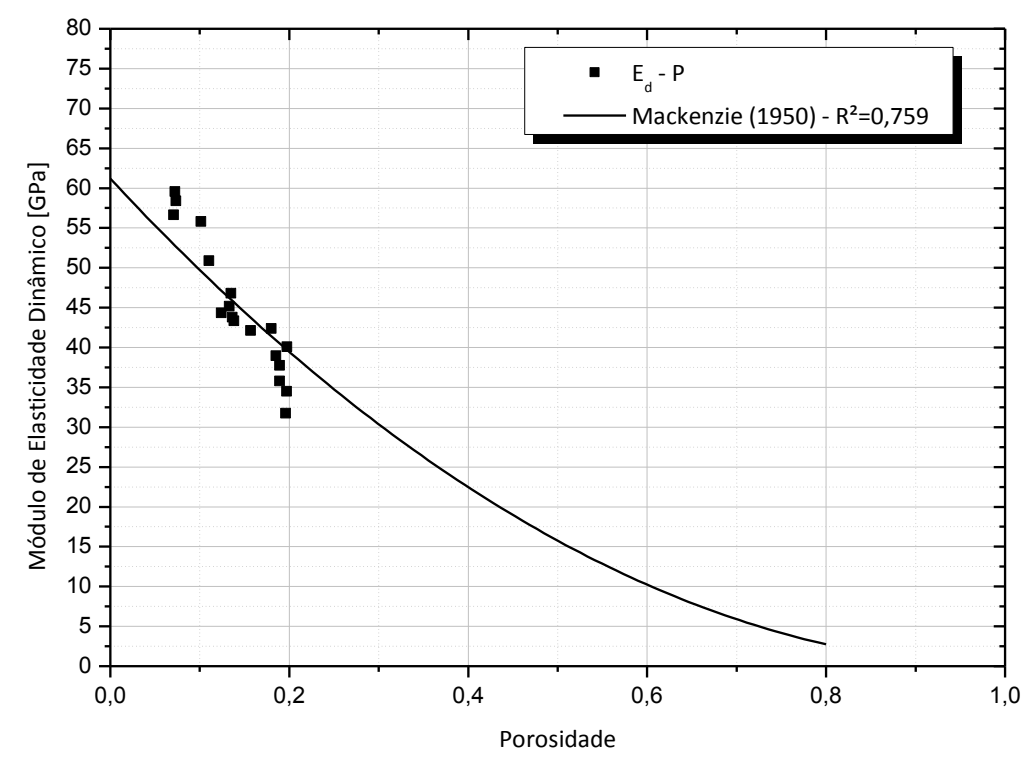

Figura 22 - Influência da Porosidade ao Módulo de Elasticidade Dinâmico (Concreto) 
Tabela 20 - Relação entre Porosidade e Módulo de Elasticidade Dinâmico (Concreto).

\begin{tabular}{|c|c|c|c|}
\hline Traço & Idade & Porosidade [\%] & $\mathbf{E}_{\mathbf{d}}[\mathbf{G P a}]$ \\
\hline $1: 2: 3: 0,5$ & 7 & 0,1383 & 43,3213 \\
\hline $1: 2: 3: 0,7$ & 7 & 0,19603 & 31,7363 \\
\hline $1: 2: 3: 0,3: 1 \%$ & 6 & 0,07081 & 56,63 \\
\hline $1: 2: 3: 0,5$ & 28 & 0,13288 & 45,1675 \\
\hline $1: 2: 3: 0,7$ & 29 & 0,19712 & 34,4813 \\
\hline $1: 3: 2: 0,5$ & 28 & 0,13619 & 43,8125 \\
\hline $1: 2: 3 \mathrm{~B} 0: 0,5: 1 \%$ & 6 & 0,15672 & 42,1467 \\
\hline $1: 3: 2: 0,5$ & 45 & 0,12399 & 44,3323 \\
\hline $1: 2: 3: 0,3: 1 \%$ & 41 & 0,07219 & 59,5771 \\
\hline $1: 3: 4: 0,5$ & 8 & 0,11023 & 50,905 \\
\hline $1: 1: 2: 0,5$ & 14 & 0,18503 & 38,9433 \\
\hline $1: 2: 1: 0,5$ & 34 & 0,18931 & 37,7338 \\
\hline $1: 1: 2: 0,5$ & 28 & 0,19733 & 40,0738 \\
\hline $1: 2: 3 B 0: 0,3: 1 \%$ & 66 & 0,07334 & 58,3933 \\
\hline $1: 1: 2: 0,5$ & 68 & 0,1799 & 42,3813 \\
\hline $1: 2: 3 B 0: 0,5: 0 \%$ & 105 & 0,13492 & 46,78 \\
\hline $1: 3: 4: 0,5$ & 70 & 0,10127 & 55,8154 \\
\hline $1: 2: 3 B L: 0,7$ & 29 & 0,18941 & 35,7813 \\
\hline Obs.: D=Diabásio; B1=Brita 1;BL=Brita 1 "Larga" & \\
\hline
\end{tabular}

Nota-se dos resultados apresentados para pastas, argamassas e concretos que a porosidade está intimamente ligada à capacidade de restrição às deformações solicitantes. Assim, amostras com maior porosidade apresentarão menor capacidade de restrição às deformações impostas. Por outro lado, haverá maior capacidade de restrição a tais deformações considerando casos de amostras com menor porosidade. 
Sabe-se que a porosidade está atrelada à relação água-cimento. Portanto, o gráfico da Figura 23 demonstra a influência de tal parâmetro no módulo de elasticidade dinâmico da pasta. Nesta análise foram utilizadas pastas com relações água-cimento de 0,2 à $0,8 \mathrm{e}$ consideradas, para o traçado das curvas, as idades de 1,7,14,28 e 56 dias, conforme o que é apresentado à seguir:

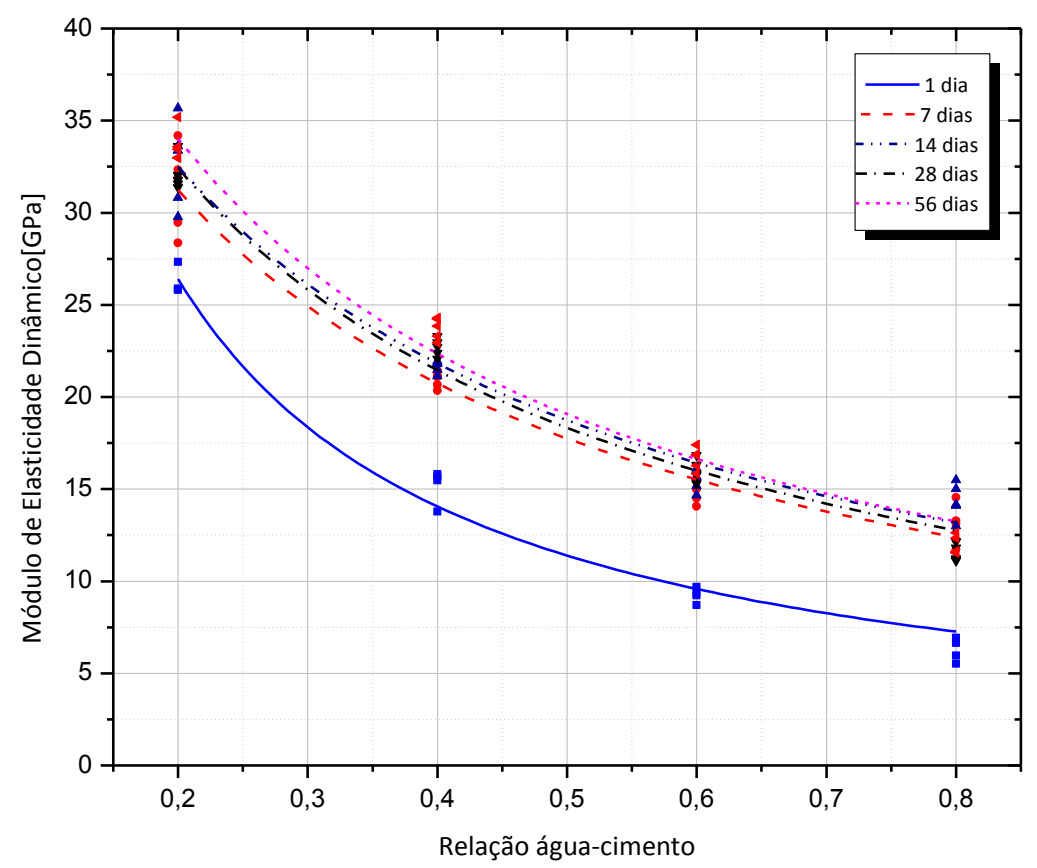

Figura 23 - Influência da relação água-cimento ao Módulo de Elasticidade Dinâmico (Pasta)

Novamente abordando a argamassa como sendo uma mistura composta de areia e pasta, e esta areia sendo inerte em tal mistura, espera-se que exista influência entre a relação águacimento ao módulo dinâmico da argamassa, conforme o gráfico da Figura 24. Na análise, foram utilizadas argamassas com relações água-cimento de 0,3 à 0,7 , traço médio (1:2 cimento:areia, em massa), e consideradas as idades de 1,7,14,28 e 56 dias: 


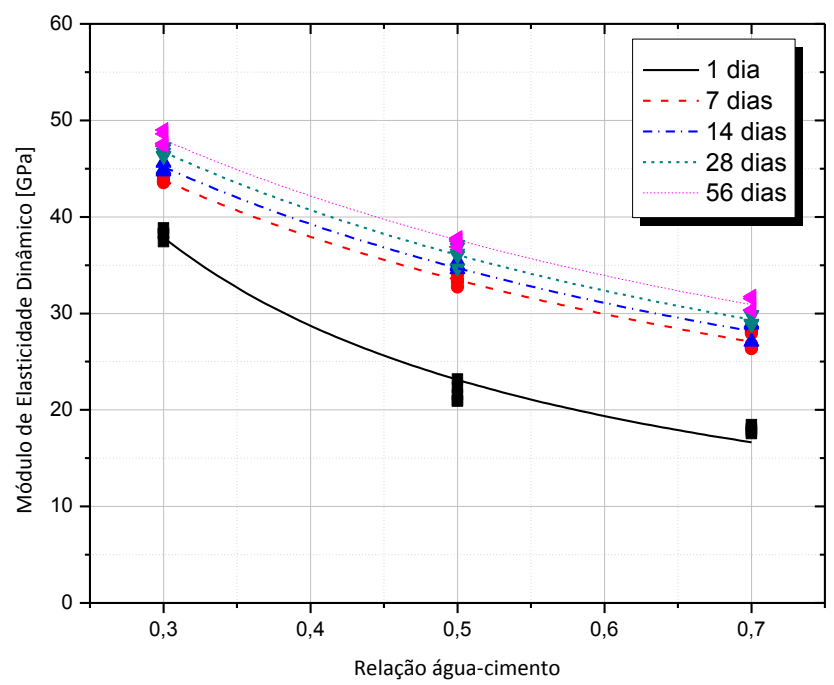

Figura 24 - Influência da relação água-cimento ao Módulo de Elasticidade Dinâmico (Argamassa)

E finalmente considerando o concreto um compósito constituido de argamassa e brita, pode-se avaliar que o fenômeno observado pela variação da relação água-cimento do concreto é semelhante ao caso da argamassa e pasta. Assim, o gráfico da Figura 25 demonstra o efeito de tal parâmetro ao módulo de elasticidade dinâmico do concreto:

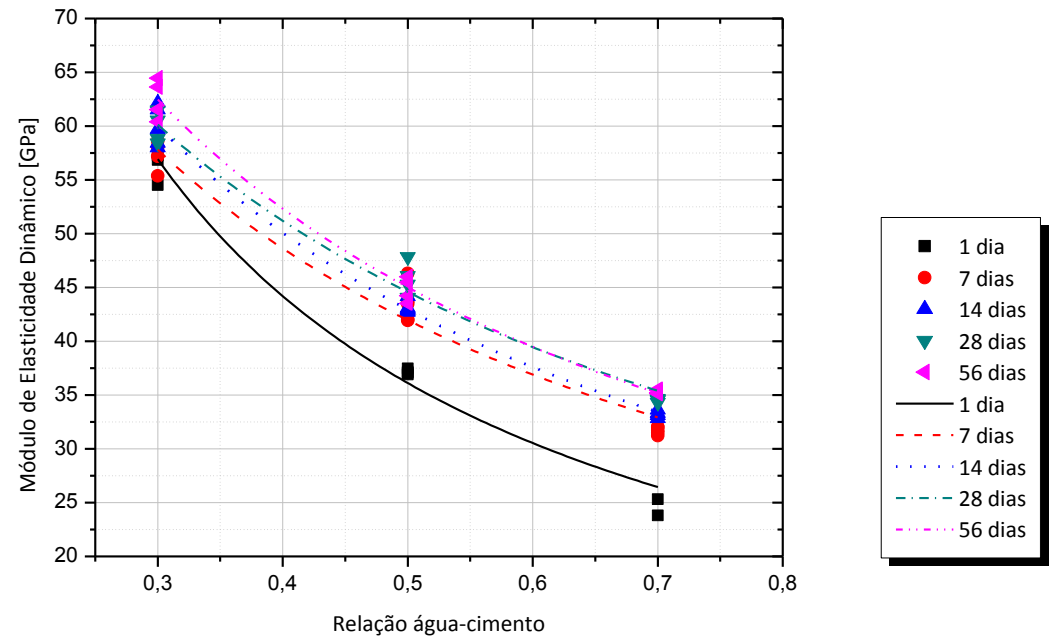

Figura 25 - Influência da relação água-cimento (Concreto)

Aplicando o método dos mínimos quadrados, avaliou-se que a função que melhor se ajustou aos pontos experimentais foi conforme a Equação (29): 


$$
E_{d}=\frac{1}{C_{1}+C_{2} \times(a / c)}
$$

Os parâmetros utilizados para se traçar tais curvas podem ser resumidos conforme a Tabela 21:

Tabela 21 - Parâmetros de curva (influência da relação água-cimento)

\begin{tabular}{|c|c|c|c|c|}
\hline \multicolumn{5}{|c|}{ Pasta } \\
\hline $\begin{array}{c}\text { Idade [Dias] } \\
\text { [dias] }\end{array}$ & $\mathrm{C}_{1}$ & $\mathrm{C}_{2}$ & $\mathbf{R}^{2}$ & $\begin{array}{c}\mathbf{E}_{\mathrm{d}} \\
{[\mathbf{G P a}]}\end{array}$ \\
\hline 1 & 0,0046 & 0,166 & 0,98205 & $E_{d}=1 /[0,00459+0,166 \times(a / c)]$ \\
\hline 7 & 0,0158 & 0,0810 & 0,96697 & $E_{d}=1 /[0,0158+0,0810(a / c)]$ \\
\hline 14 & 0,0150 & 0,0791 & 0,97979 & $E_{d}=1 /[0,0150+0,0791 \times(a / c)]$ \\
\hline 28 & 0,0157 & 0,0753 & 0,96150 & $E_{d}=1 /[0,0157+0,0753 \times(a / c)]$ \\
\hline 56 & 0,0140 & 0,0768 & 0,97955 & $E_{d}=1 /[0,0140+0,0768 \times(a / c)]$ \\
\hline \multicolumn{5}{|c|}{ Argamassa } \\
\hline Idade [Dias] & $\mathrm{C}_{1}$ & $\mathrm{C}_{2}$ & $\mathbf{R}^{2}$ & $\begin{array}{c}\mathbf{E}_{\mathbf{d}} \\
{[\mathrm{GPa}]}\end{array}$ \\
\hline 1 & 0,0012 & 0,0842 & 0,97499 & $E_{d}=1 /[0,0012+0,0842 \times(a / c)]$ \\
\hline 7 & 0,0122 & 0,0353 & 0,99299 & $E_{d}=1 /[0,0122+0,0353(a / c)]$ \\
\hline 14 & 0,0121 & 0,0335 & 0,99199 & $E_{d}=1 /[0,0121+0,0335 \times(a / c)]$ \\
\hline 28 & 0,0119 & 0,0317 & 0,99246 & $E_{d}=1 /[0,0119+0,0317 \times(a / c)]$ \\
\hline 56 & 0,0122 & 0,0288 & 0,99292 & $E_{d}=1 /[0,0122+0,0288 \times(a / c)]$ \\
\hline \multicolumn{5}{|c|}{ Concreto } \\
\hline \multirow{2}{*}{$\begin{array}{l}\text { Idade } \\
\text { [dias] }\end{array}$} & \multirow{2}{*}{$\mathrm{C}_{1}$} & \multirow{2}{*}{$\mathrm{C}_{2}$} & \multirow{2}{*}{$\mathbf{R}^{2}$} & $\mathbf{E}_{\mathrm{d}}$ \\
\hline & & & & [GPa] \\
\hline 1 & 0,0024 & 0,0506 & 0,98546 & $E(a / c)=1 /(0,0024-0,0506 \times(a / c))$ \\
\hline 7 & 0,0075 & 0,0326 & 0,97106 & $E(a / c)=1 /(0,07557-0,0327 \times(a / c))$ \\
\hline 14 & 0,0067 & 0,0331 & 0,98996 & $E(a / c)=1 /(0,00673-0,0331 \times(a / c))$ \\
\hline 28 & 0,0079 & 0,0290 & 0,97999 & $E(a / c)=1 /(0,00792-0,0290 \times(a / c))$ \\
\hline 56 & 0,0067 & 0,0310 & 0,98954 & $E(a / c)=1 /(0,0067-0,0311 \times(a / c))$ \\
\hline
\end{tabular}


Portanto, os resultados anteriores representam a tendência decrescente do módulo de elasticidade dinâmico da pasta, argamasa e concreto em função do progressivo aumento da relação água-cimento. Outro fenômeno observado é que as curvas a partir dos 7 dias são deslocadas verticalmente e ficam contidas em uma determinada região, sendo este deslocamento vertical e convergência de curvas para as idades mais avançadas explicada pelo efeito da evolução do módulo de elasticidade dinâmico em função do tempo.

Assim, esta evolução do módulo de elasticidade dinâmico no tempo para o caso da pasta pode ser contemplada conforme o gráfico da Figura 26. Nesta análise foram utilizadas pastas com relações água-cimento de 0,2 à 0,8 , conforme o que é apresentado pelas curvas à seguir:

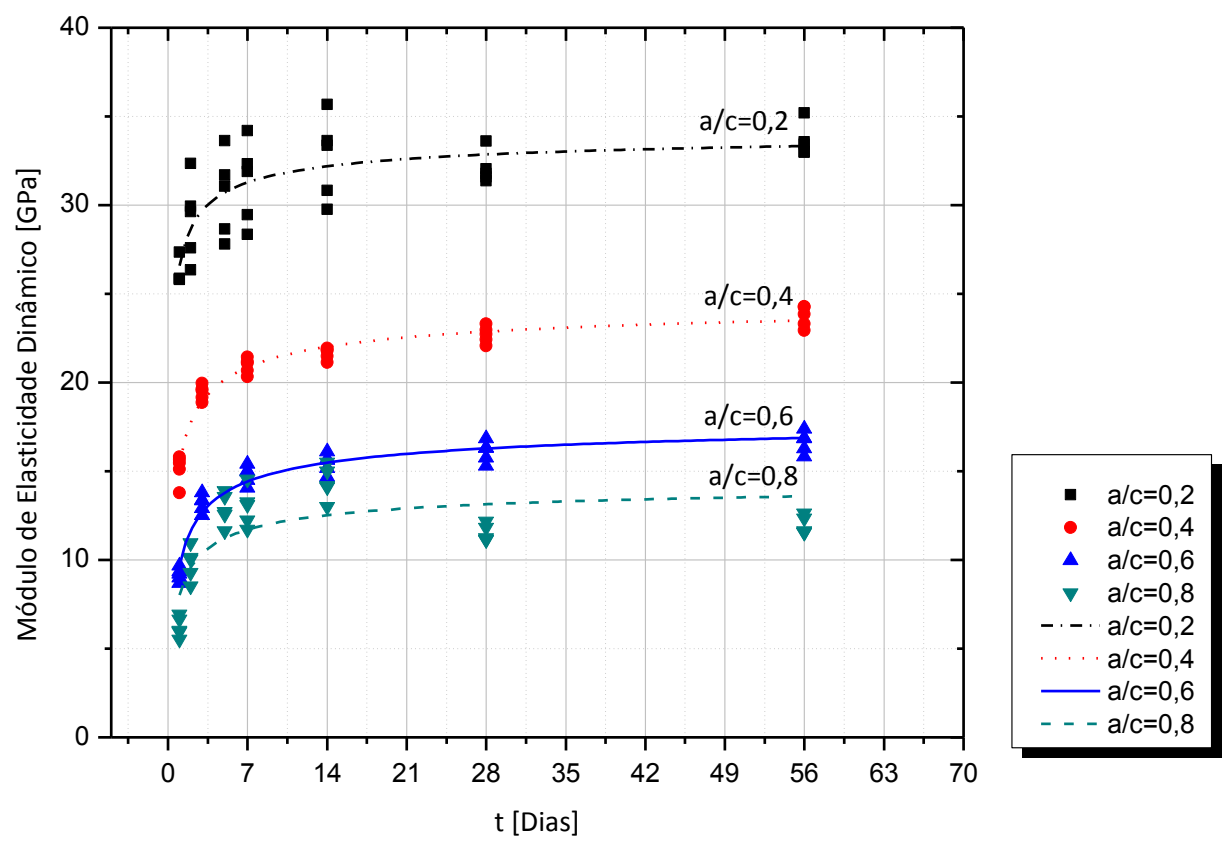

Figura 26 - Influência do tempo ao Módulo de Elasticidade Dinâmico (Pasta).

Considerando novamente que a argamassa é um compósito de pasta e areia, e que areia permanecerá inerte na mistura, pode-se avaliar o impacto da evolução do tempo para argamassas com relações água-cimento de 0,3 à 0,7 e traço médio (1:2 de cimento:areia, em massa), conforme o gráfico da Figura 27: 


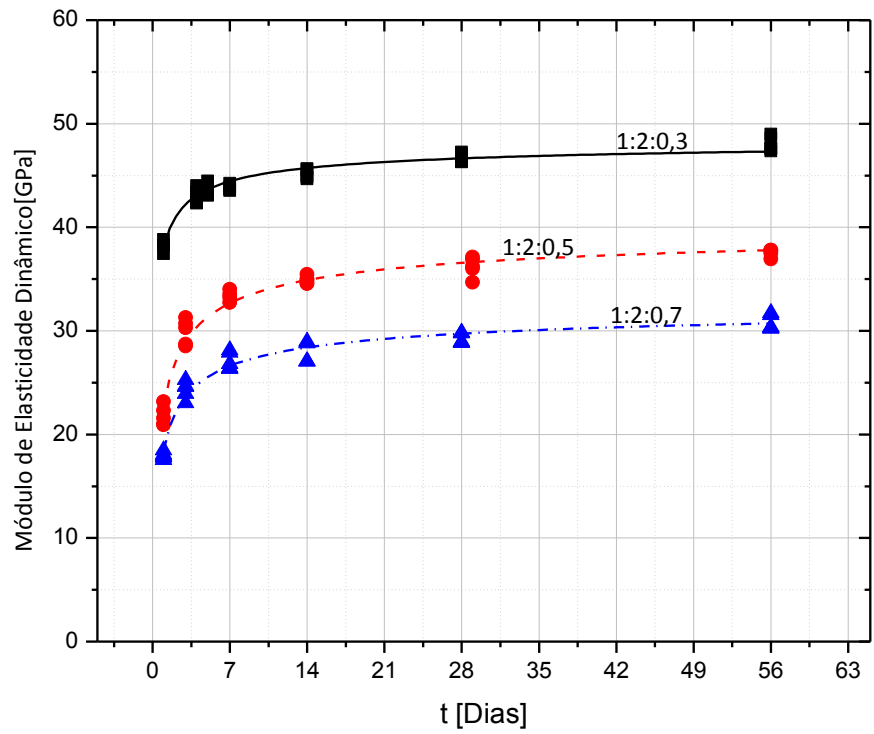

- $1: 2: 0,3$

- $1: 2: 0,5$

- $1: 2: 0,7$

$1: 2: 0,3$

$-\cdots 1: 2: 0,5$

$-\cdot-1: 2: 0,7$

Figura 27 - Influência do tempo ao Módulo de Elasticidade Dinâmico (Argamassa)

Tal fenômeno de evolução do módulo de elasticidade em função do tempo é igualmente observado no caso do concreto. Considerando traços médios com relação água-cimento de 0,3 à 0,7 pode-se avaliar tal contribuição do tempo conforme a Figura 28:

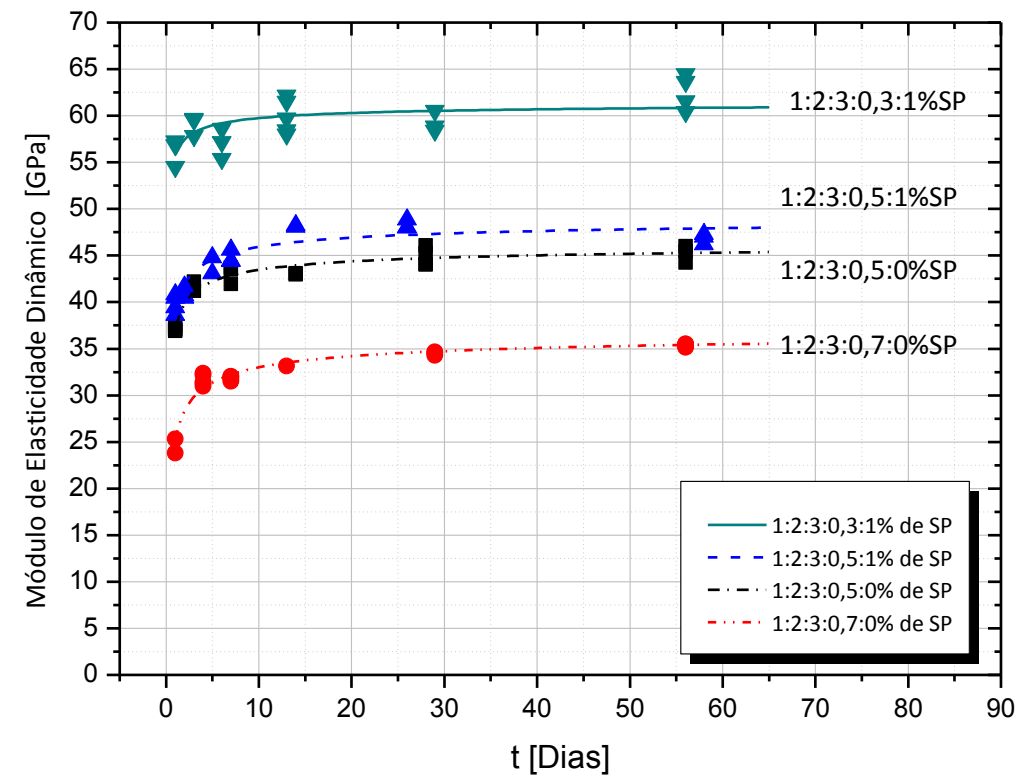

Figura 28 - Evolução do Módulo de Elasticidade Dinâmico em função do tempo (Concreto) 
Para a avaliação do efeito do tempo ao módulo de elasticidade dinâmico da pasta, argamassa e concreto em função do tempo lançou-se mão do método dos mínimos quadrados, juntamente com a equação de evolução contida no CEB-FIP de 2010. Assim, os pontos experimentais foram ajustados conforme a Equação (30):

$$
E(t)=\beta_{E} \times E_{28} \quad \text { Equação (30) }
$$

Em que:

$E(t)$ é a função que representa a evolução do módulo de elásticidade em relação ao tempo; $E_{28}$ é o termo que representa o módulo de elasticidade aos 28 dias;

$\beta_{E}$ é o termo que representa a contribuição do tempo, conforme a Equação (31):

$$
\beta_{E}=\left\{\exp \left\{s\left[1-\left(\frac{28}{t}\right)^{0,5}\right]\right\}\right\}^{0,5}
$$

Alimentando os modelos com valores de tempo por módulo de elasticidade dinâmico, e deixando os valores de $E_{28}$ e $s$ livres, obteve-se os seguintes parâmetros para as curvas: 
Tabela 22 - Parâmetros da curva (maturidade)

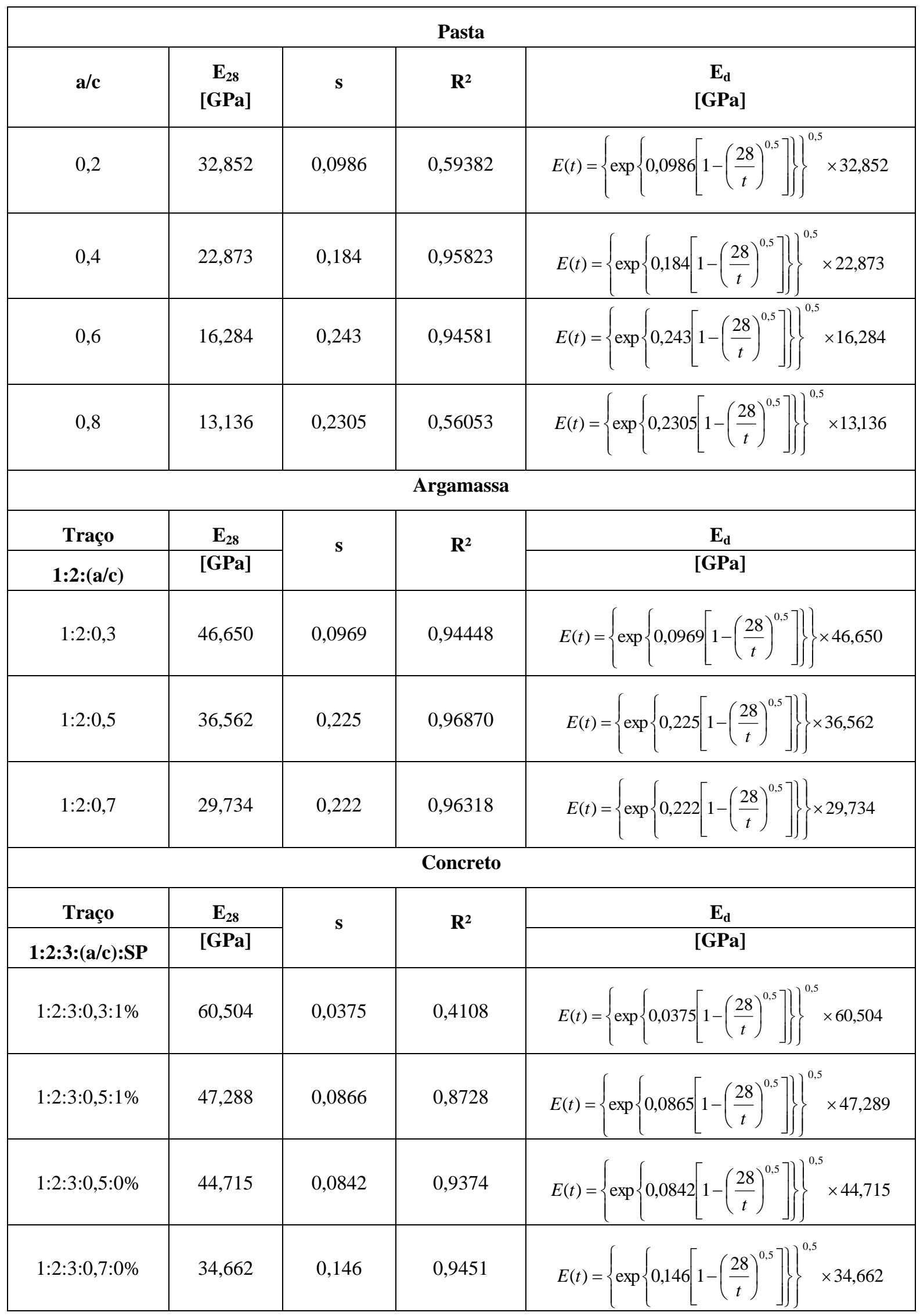


Assim e de acordo com os resultados apresentados anteriormente, pode-se afirmar, que igualmente no caso da pasta, argamassa e concreto o módulo de elasticidade dinâmico do concreto evolui nos primeiros 7 dias, e consequentemente, se estabiliza a partir deste instante. Esta rapidez de cura está intimamente ligada às características do cimento CPV ARI. Uma vez sabendo-se que os grãos de areia e de brita são inertes nas misturas, o mecanismo de formação de produtos de hidratação para o caso do concreto e argamassa passa a ser praticamente igual ao que ocorre na pasta. Portanto, com o decorrer do tempo nota-se o desenvolvimento das reações de hidratação, reações estas benéficas ao ganho de resistência e rigidez do concreto. Também é notório o fenômeno de translação das curvas no sentido vertical, sendo este explicado novamente pela interdependência entre o fator água-cimento e o módulo de elasticidade dinâmico do concreto.

A fração volumétrica dos constituintes impacta fortemente ao módulo de elasticidade da mistura. A Figura 29, por exemplo, demonstra, para argamassas com relação água-cimento fixa em 0,5 , qual o comportamento do módulo de elasticidade dinâmico quando se aumenta progressivamente a proporção, em massa, da razão areiacimento:

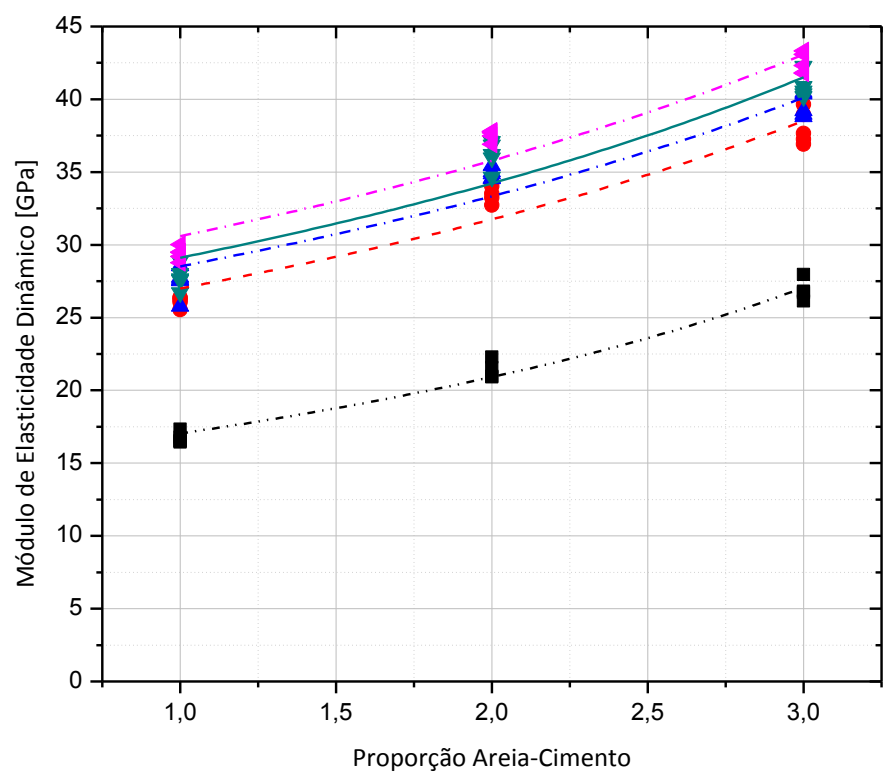

- 1 dia

- 7 dias

- 14 dias

$\nabla 28$ dias

456 dias

-...... 1 dia

- - . 7 dias

-. -. - 14 dias

-28 dias

-. -. - 56 dias

Figura 29 - Influência da proporção de areia na mistura (Argamassa) 
Igualmente ao caso da argamassa, as frações volumétricas dos materiais envolvidos na mistura de concreto também influem ao módulo de elasticidade dinâmico do material. Assim, a Figura 30 demonstra a dependência entre o Módulo de Elasticidade Dinâmico e a proporção de agregado-cimento na mistura para concretos com relação água-cimento fixa em 0,5:

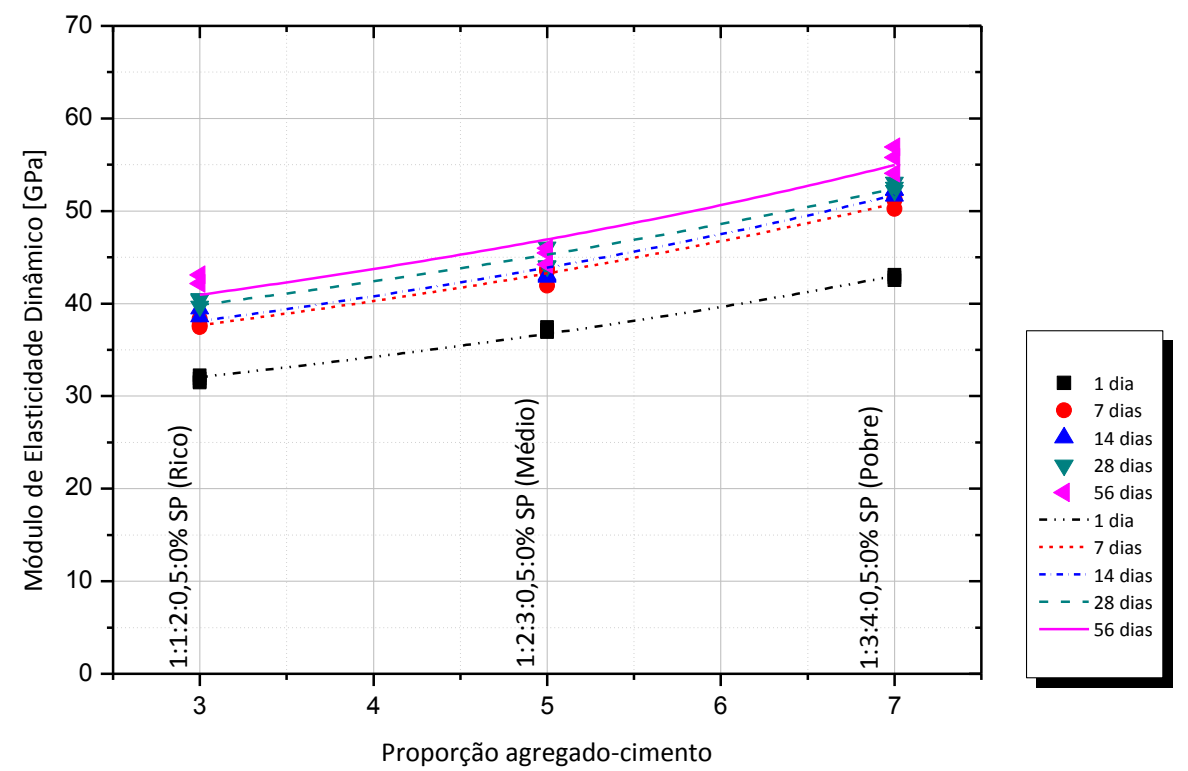

Figura 30: Influência do traço ao Módulo de Elasticidade Dinâmico (Concreto)

Aplicando o método dos mínimos quadrados aos pontos experimentais da Figura 29 e Figura 30, verificou-se, que o melhor ajuste foi conforme a curva da Equação (32):

$$
E_{d}=\frac{1}{C_{3}+C_{4} \times(m)}
$$


Assim, os parâmetros utilizados para se traçar as curvas podem ser resumidos conforme a

Tabela 23: Tabela 23 - Parâmetros das curvas (influência do traço, argamassa e
concreto).

\begin{tabular}{|c|c|c|c|c|}
\hline \multicolumn{5}{|c|}{ Argamassa } \\
\hline $\begin{array}{l}\text { Idade } \\
\text { [Dias] }\end{array}$ & $\mathbf{C}_{3}$ & $\mathrm{C}_{4}$ & $\mathbf{R}^{2}$ & $\begin{array}{c}\mathbf{E}_{\mathbf{d}} \\
{[\mathbf{G P a}]}\end{array}$ \\
\hline 1 & 0,0696 & $-0,0109$ & 0,97553 & $E(m)=\frac{1}{(0,0696-0,0109 \times m)}$ \\
\hline 7 & 0,0426 & $-0,0055$ & 0,93449 & $E(m)=\frac{1}{(0,0426-0,0055 \times m)}$ \\
\hline 14 & 0,0401 & $-0,0050$ & 0,92480 & $E(m)=\frac{1}{(0,0401-0,0050 \times m)}$ \\
\hline 28 & 0,0394 & $-0,0051$ & 0,9065 & $E(m)=\frac{1}{(0,0394-0,0051 \times m)}$ \\
\hline 56 & 0,0374 & $-0,0047$ & 0,93191 & $E(m)=\frac{1}{(0,0374-0,0047 \times m)}$ \\
\hline \multicolumn{5}{|c|}{ Concreto } \\
\hline Idade & \multirow{2}{*}{$\mathbf{C}_{\mathbf{3}}$} & \multirow{2}{*}{$\mathrm{C}_{4}$} & \multirow{2}{*}{$\mathbf{R}^{2}$} & $\mathbf{E}_{\mathbf{d}}$ \\
\hline [dias] & & & & [GPa] \\
\hline 1 & 0,0372 & $-0,0019$ & 0,99072 & $E(m)=\frac{1}{(0,00372-0,0019 \times m)}$ \\
\hline 7 & 0,0317 & $-0,0017$ & 0,98605 & $E(m)=\frac{1}{(0,0317-0,0017 \times m)}$ \\
\hline 14 & 0,0314 & $-0,0017$ & 0,97437 & $E(m)=\frac{1}{(0,0314-0,0017 \times m)}$ \\
\hline 28 & 0,0295 & $-0,0015$ & 0,97613 & $E(m)=\frac{1}{(0,0295-0,0015 \times m)}$ \\
\hline 56 & 0,0291 & $-0,0015$ & 0,90275 & $E(m)=\frac{1}{(0,0291-0,0015 \times m)}$ \\
\hline
\end{tabular}


De acordo com os resultados acima apresentados, pode-se afirmar que o aumento da proporção em massa de areia e brita, e consequentemente, de sua fração volumétrica, gera o aumento ao módulo de elasticidade dinâmico da argamassa e do concreto. Isto pode ser devidamente explicado pela regra da mistura, uma vez que o grão de areia e a brita de diabásio tem módulos de elasticidade dinâmico muito maiores que o módulo de elasticidade dinâmico das pastas estudadas (Tabela 24). Portanto, o progressivo aumento da fração volumétrica de areia e brita tende a gerar o aumento do módulo de elasticidade dinâmico na mistura.

Tabela 24 - Módulos de Elasticidade dinâmico dos componentes do concreto

\begin{tabular}{|c|c|}
\hline Constituinte & Módulo de Elasticidade Dinâmico Médio \\
\hline Pasta $^{*}$ & 4,253 à 37,812 \\
\hline Agregado Graúdo - Diabásio & 70 \\
\hline Grão de Areia (NAFE e DRAKE,1961) & 82,5 \\
\hline *Obtido experimentalmente ${ }^{* *}$ Cálculo no anexo B \\
\hline
\end{tabular}

Voltando um pouco ao caso da argamassa, a Figura 31 demonstra a superposição dos efeitos da variação da proporção de areia-cimento e relação água-cimento aos 28 dias. Através de tais resultados, nota-se que para uma dada proporção areia-cimento fixa $(\mathrm{m}), \mathrm{o}$ aumento da relação água-cimento tende a gerar o progressivo enfraquecimento da argamassa. Por outro lado, também é possível observar que para uma dada relação águacimento fixa $(\mathrm{a} / \mathrm{c})$, o aumento da proporção de areia-cimento $(\mathrm{m})$ gera o salto no módulo de elasticidade dinâmico da argamassa. Assim, observa-se que as curvas são resultantes dos fenômenos de variação da relação água-cimento e proporção areia-cimento. 


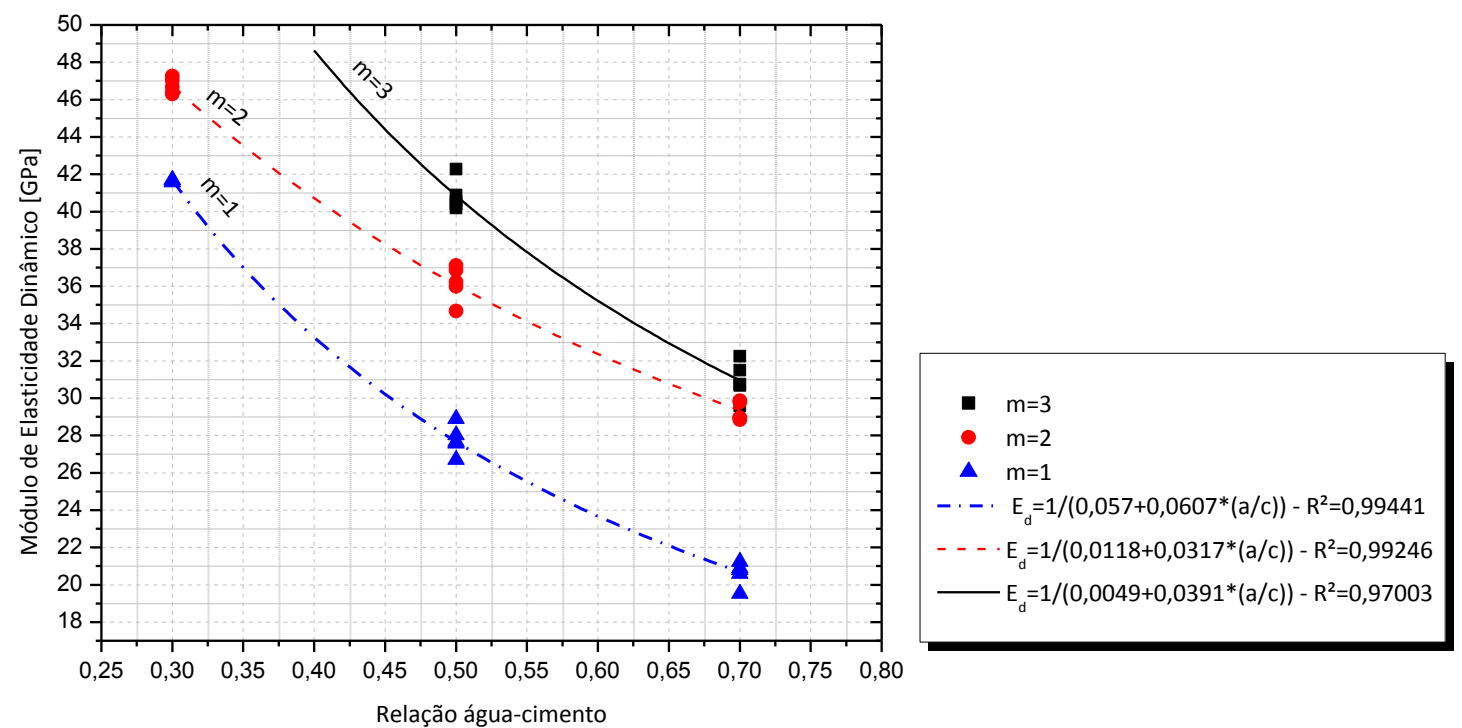

Figura 31 - Variação do Módulo de Elasticidade Dinâmico (Argamassa, 28 dias)

Os parâmetros utilizados para se traçar tais curvas podem ser resumidos conforme a Tabela 25:

Tabela 25 - Parâmetros das curvas (influência do tempo, argamassa)

\begin{tabular}{|c|c|c|c|c|}
\hline $\begin{array}{c}\mathbf{m} \\
{[\mathbf{k g}]}\end{array}$ & $\mathbf{C}_{\mathbf{1}}$ & $\mathbf{C}_{\mathbf{2}}$ & $\mathbf{R}^{\mathbf{2}}$ & $\begin{array}{c}\mathbf{E}_{\mathbf{d}} \\
{[\mathbf{G P a}]}\end{array}$ \\
\hline 3 & 0,0049 & 0,0392 & 0,97003 & $E(a / c)=\frac{1}{(0,0049-0,0392 \times(a / c))}$ \\
\hline 2 & 0,0057 & 0,0608 & 0,99441 & $E(a / c)=\frac{1}{(0,0057-0,00608 \times(a / c))}$ \\
\hline 1 & 0,0119 & 0,0317 & 0,99246 & $E(a / c)=\frac{1}{(0,0119-0,0317 \times(a / c))}$ \\
\hline
\end{tabular}


A avaliação da influência do superplastificante na mistura foi realizada para o caso da pasta, argamassa e concreto. Assim o gráfico da Figura 32 avalia o impacto do aditivo sobre a pasta. Portanto, o mesmo relaciona nos eixos x-y o valor de módulo de elasticidade dinâmico para traços de pastas sem adição (eixo x) e com adições de $1 \%$ e $0,6 \%$ de superplastificante (eixo y).

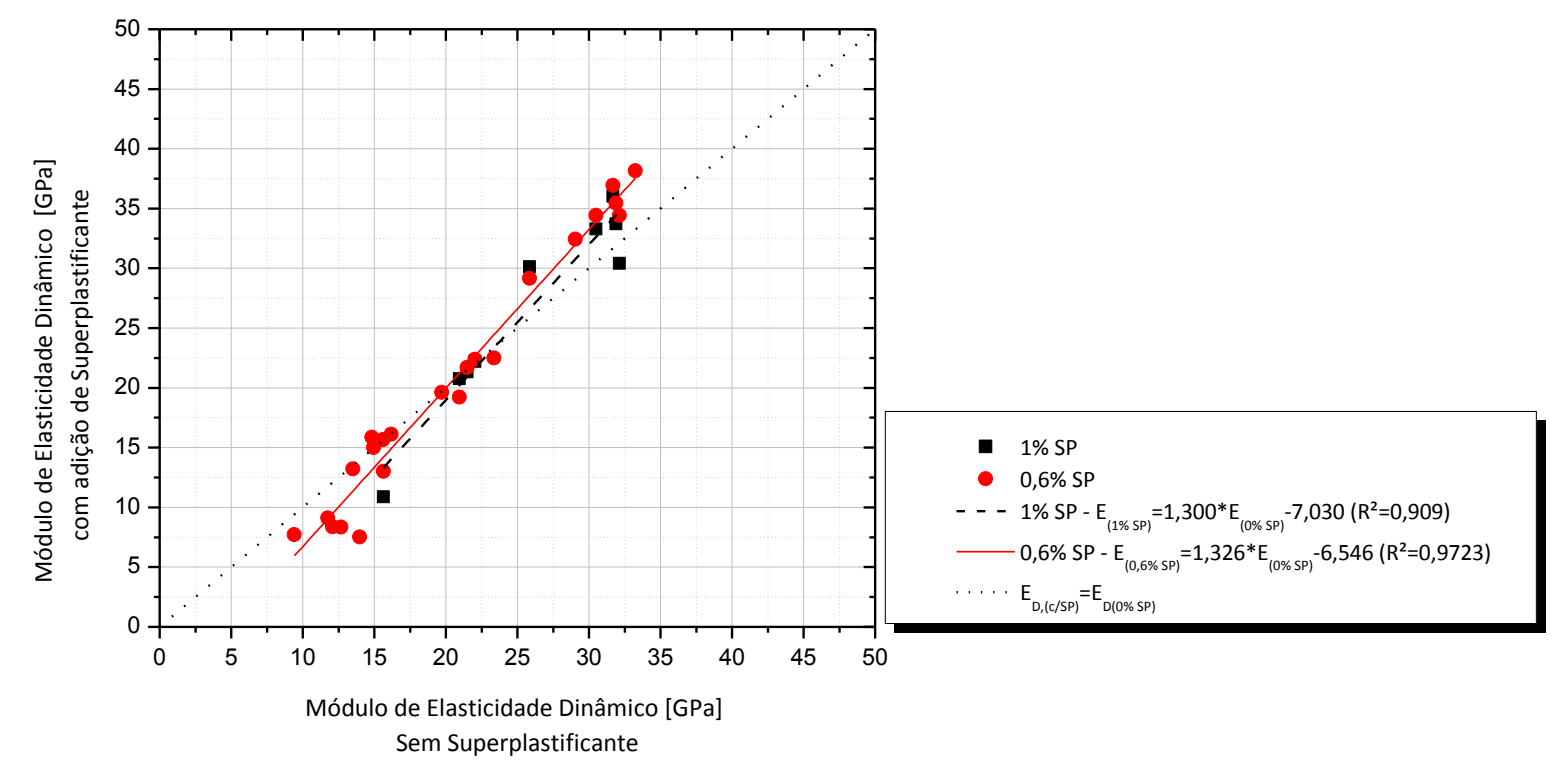

Figura 32 - Influência do uso do Superplastificante (Pasta - Adição de 1\% e 0,6\%)

Igualmente para o caso da argamassa, a influência da adição de $1 \%$ do produto pode ser representada conforme o gráfico da Figura 33:

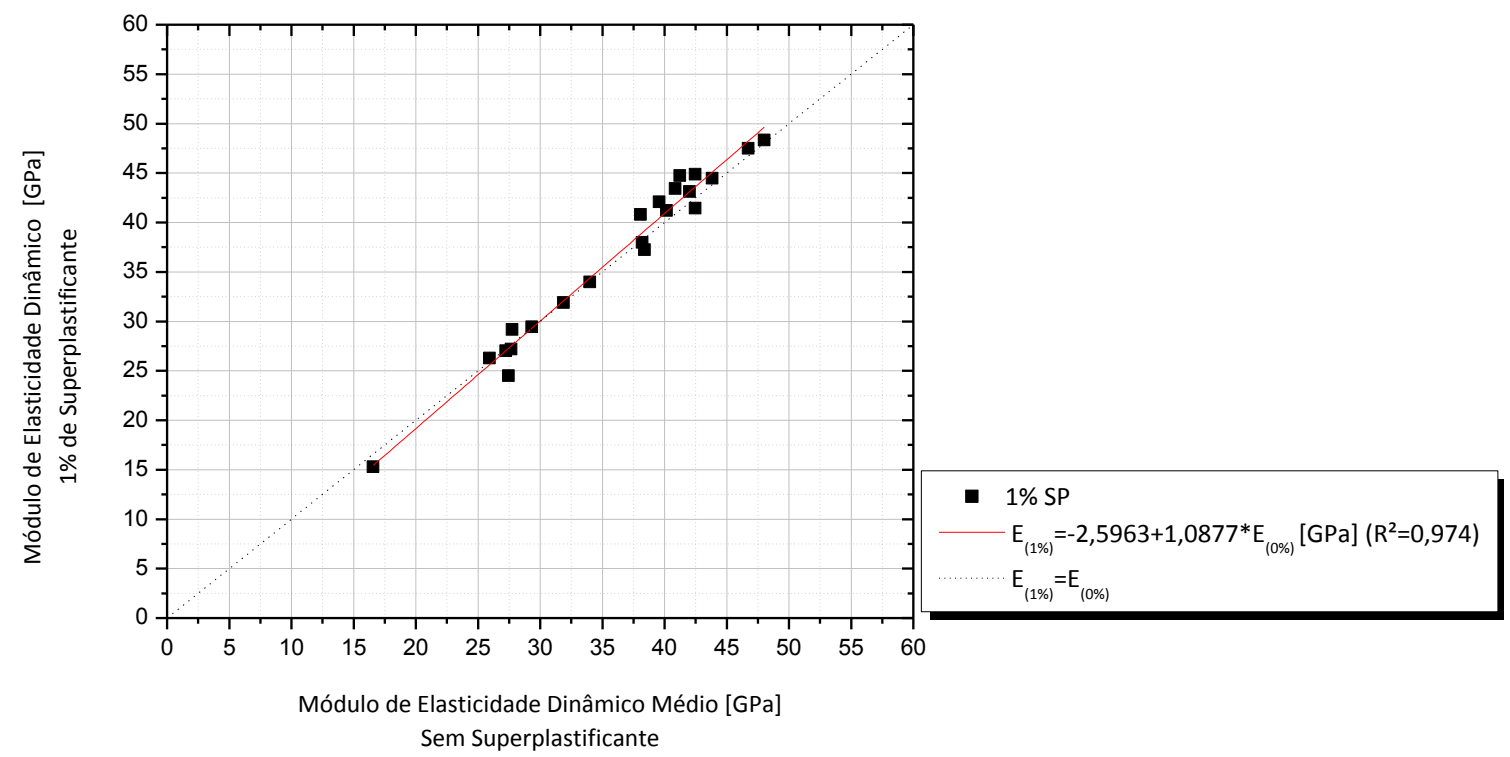

Figura 33 - Influência do uso de Superplastificante (Argamassa - Adição de 1\%) 
E para o caso do concreto, a influência da adição de $1 \%$ do produto pode ser representada conforme o gráfico da Figura 34:

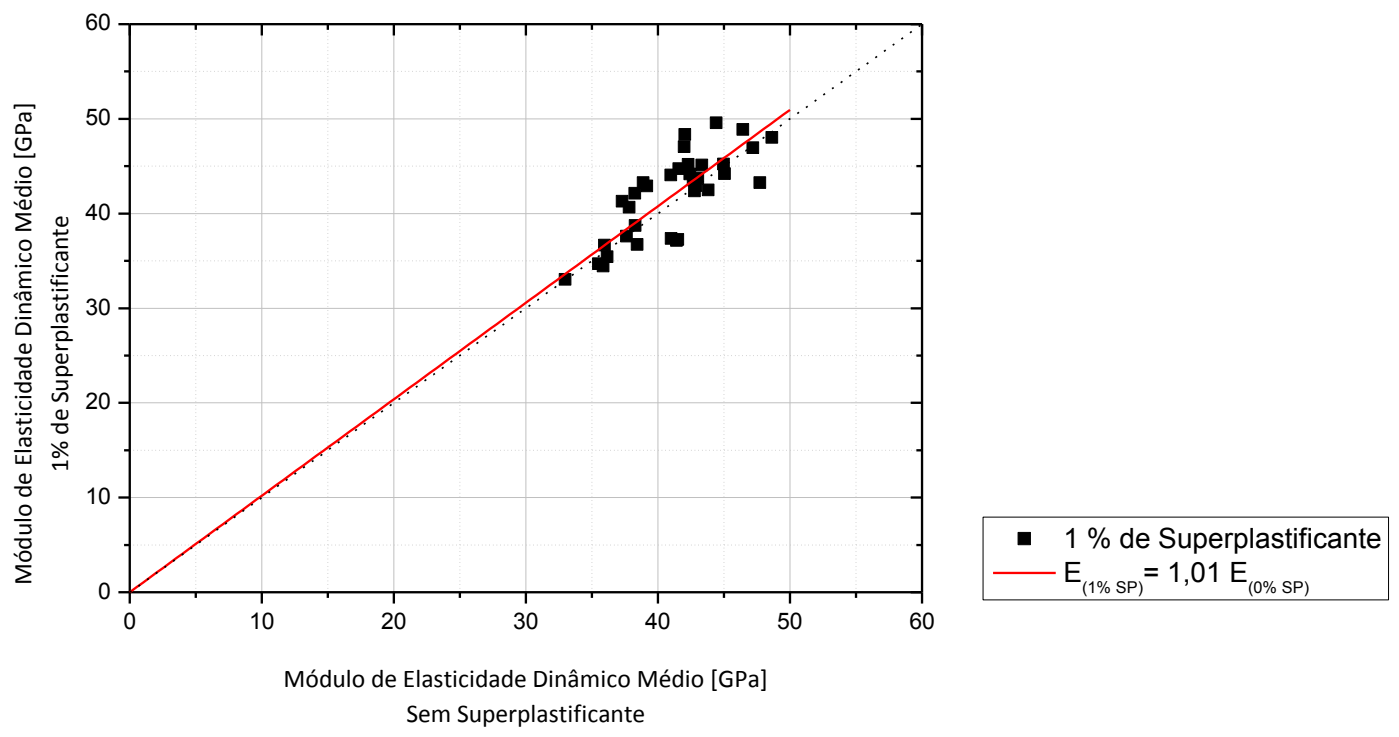

Figura 34 - Influência do uso de Superplastificante (Concreto - Adição de 1\%)

De acordo com a reta de igualdade $\left(\mathrm{E}_{\mathrm{d}, 1 \% \mathrm{SP}}=\mathrm{E}_{\mathrm{d}, 0,6 \% \mathrm{SP}}=\mathrm{E}_{\mathrm{d}, 0 \% \mathrm{SP}}\right)$, pode-se estabelecer que, para o caso da pasta, valores de módulo de elasticidade superiores à $20 \mathrm{GPa}$ apresentam efeito positivo na adição do superplastificante. Entretanto, para pastas com módulo de elasticidade inferiores à $20 \mathrm{GPa}$ a adição do superplastificante passa a ser danosa, já que o Módulo de Elasticidade Dinâmico de pastas sem aditivos tem valores superiores aos resultados de pastas com adição de superplastificante. Já para o caso da argamassa, quando comparada a reta experimental com a de igualdade $\left(\mathrm{E}_{\mathrm{d}, 1 \% \mathrm{SP}}=\mathrm{E}_{\mathrm{d}, 0 \% \mathrm{SP}}\right)$ há efeito positivo da adição do superplastificante para valores de módulo de elasticidade superiores à $30 \mathrm{GPa}$. Entretanto, para valores de módulo de elasticidade inferiores à $30 \mathrm{GPa}$, a adição do superplastificante passa a ser danosa. Todavia, no concreto, a adição de superplastificante parece ser sempre positiva, já que a reta experimental é sempre superior à reta de igualdade $\left(\mathrm{E}_{\mathrm{d}, 1 \% \mathrm{SP}}=\mathrm{E}_{\mathrm{d}, 0 \% \mathrm{SP}}\right)$. Como regra prática para o caso das pastas, pode-se considerar que a utilização do superplastificante deve ser indicada somente para misturas com módulo de elasticidade estimado maior que $20 \mathrm{GPa}$. Para o caso da argamassa esse valor deve ser superior à $30 \mathrm{GPa}$. 
No caso do concreto, ainda a substituição do tipo de agregado graúdo na mistura também pode modificar seu módulo de elaticidade dinâmico. A Figura 35 correlaciona o módulo de elasticidade dinâmico de mesmos traços em massa de concretos contendo agregado graúdo de duas naturezas diferentes: arenito silicificado botucatu (Eixo x) e diabásio (Eixo y).

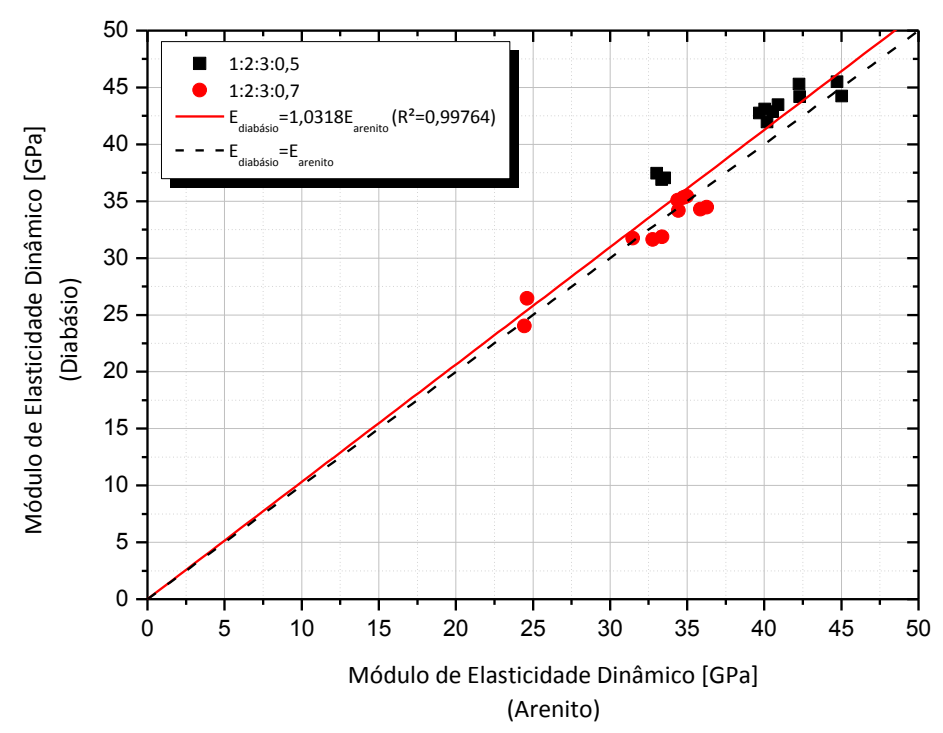

Figura 35 - Concreto: Influência do tipo do agregado graúdo

Espera-se que a comparação feita na Figura 35, para concretos com mesmas idades, traço em massa e distribuição glanulométrica apresente o impacto do módulo de elasticidade dinâmico individual das britas com origens litológicas diferentes: diabásio e arenito. Do gráfico e através da comparação com a reta hipotética $\left(\mathrm{E}_{\mathrm{c}, \text { diabásio }}=\mathrm{E}_{\mathrm{c}, \text { arenito }}\right)$, pode-se concluir que o módulo de elasticidade dinâmico dos concretos fabricados com brita de diabásio são aproximadamente iguais àqueles fabricados com a rocha de origem arenítica. Isto é devidamente explicado pela regra da mistura. Como a densidade do arenito $\left(2,35 \mathrm{~g} / \mathrm{cm}^{3}\right)$ é inferior ao diabásio $\left(2,75 \mathrm{~g} / \mathrm{cm}^{3}\right)$, para se manter a mesma proporção em massa, haverá acréscimo no volume total de agregado graúdo nos concretos fabricados com arenito. Assim sendo, mesmo que o módulo de elasticidade dinâmico do arenito (65 GPa) seja inferior ao diabásio (70GPa), o efeito do aumento da fração volumétrica compensa a diminuição de módulo de elasticidade do agregado, e faz com que o concreto produzido por arenito tenha módulo de elasticidade dinâmico próximo àquele fabricado com 
diabásio. Logo, fica evidente que, para efeito de comparação entre tipos de agregados, seria melhor a dosagem em volume, e não em massa, procedimento do corrente trabalho.

Para o caso do concreto, o diâmetro máximo caracteristico do agregado graúdo exerce influência ao módulo de elasticidade do concreto. Para tal análise foram utilizados concretos de traços médios 1:2:3 (1 de cimento: 2 de areia: 3 de brita, em massa), sendo calculado o valor médio entre o módulo de elasticidade das amostras, aos 28 dias, conforme a figura à seguir:

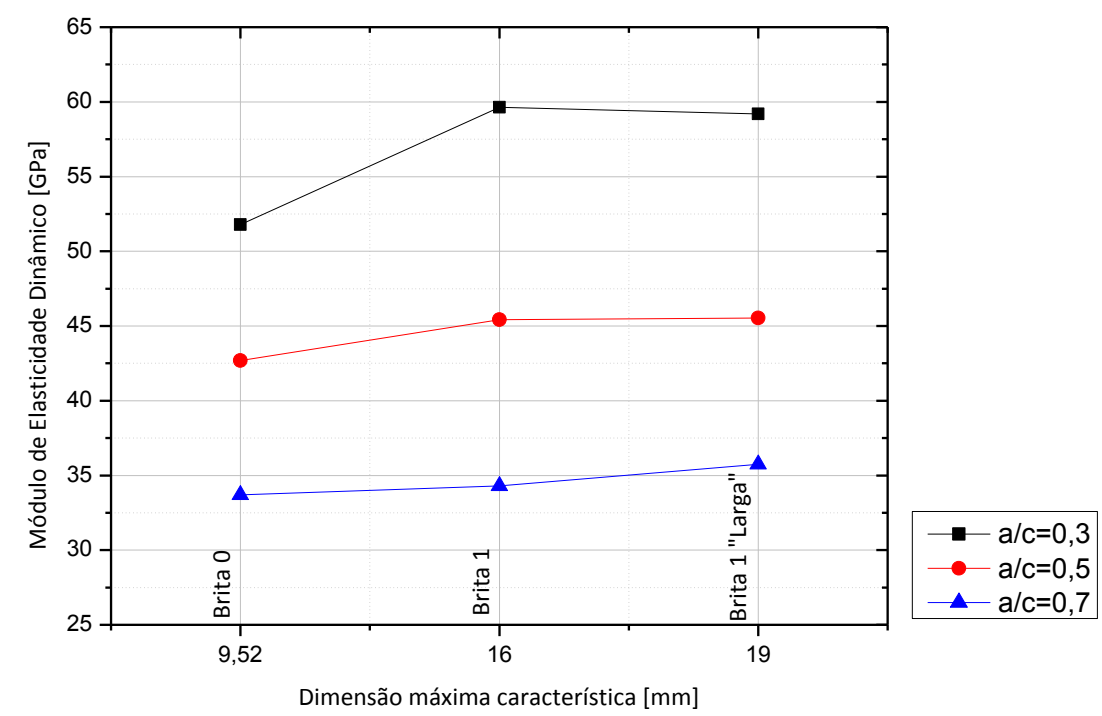

Figura 36 - Influência do tipo do agregado graúdo (Concreto)

Segundo a tendência descrita no gráfico da Figura 36, concretos produzidos com agregados graúdos de menor diâmetro máximo característico tem módulo de elasticidade dinâmico inferior quando comparados àqueles produzidos com agregados graúdos de maior dimensão. Estes resultados estão incompatíveis com as previsões feitas através da literatura, uma vez que concretos com agregados graúdos maiores tendem a formar uma zona de transição mais espessa. Assim, é possível que fatores como a trabalhabilidade e a variabilidade do módulo de elasticidade dinâmico do agregado graúdo tenham mascarado de alguma forma o efeito da zona de transição. 


\subsection{RELAÇÃO ENTRE MÓdULO DE ELASTICIDADE DETERMINADO NA CONFIGURAÇÃO LONGITUDINAL E FLEXIONAL}

Através dos resultados experimentais, pode-se estabelecer a relação entre módulo de elasticidade dinâmico obtido através do modo de vibração longitudinal $\left(\mathrm{E}_{\mathrm{d}, 1}\right)$ e flexional $\left(E_{\mathrm{d}, \mathrm{f}}\right)$. Assim, a Figura 37 demonstra a relação entre o módulo de elasticidade dinâmico obtido através dos dois modos de vibração para o caso da pasta:

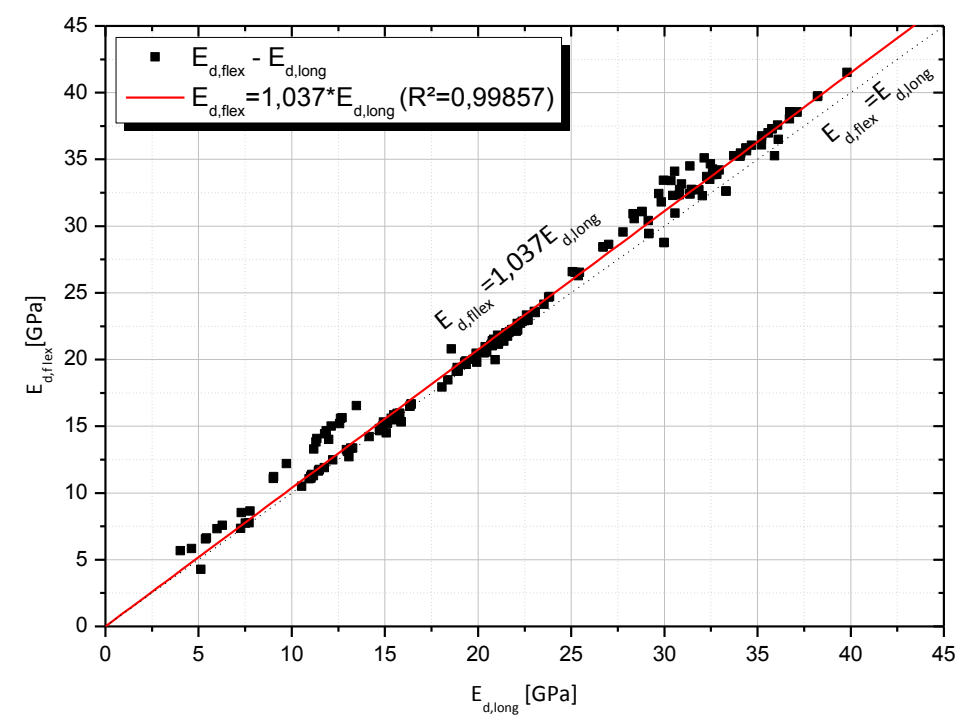

Figura 37 - Relação entre Módulo de Elasticidade dinâmico obtido por modo de vibração longitudinal e flexional (Pasta)

Já para o caso da argamassa, a relação entre $E_{d, f l e x}$ e $E_{d, l o n g}$ pode ser conforme ao gráfico da Figura 38: 


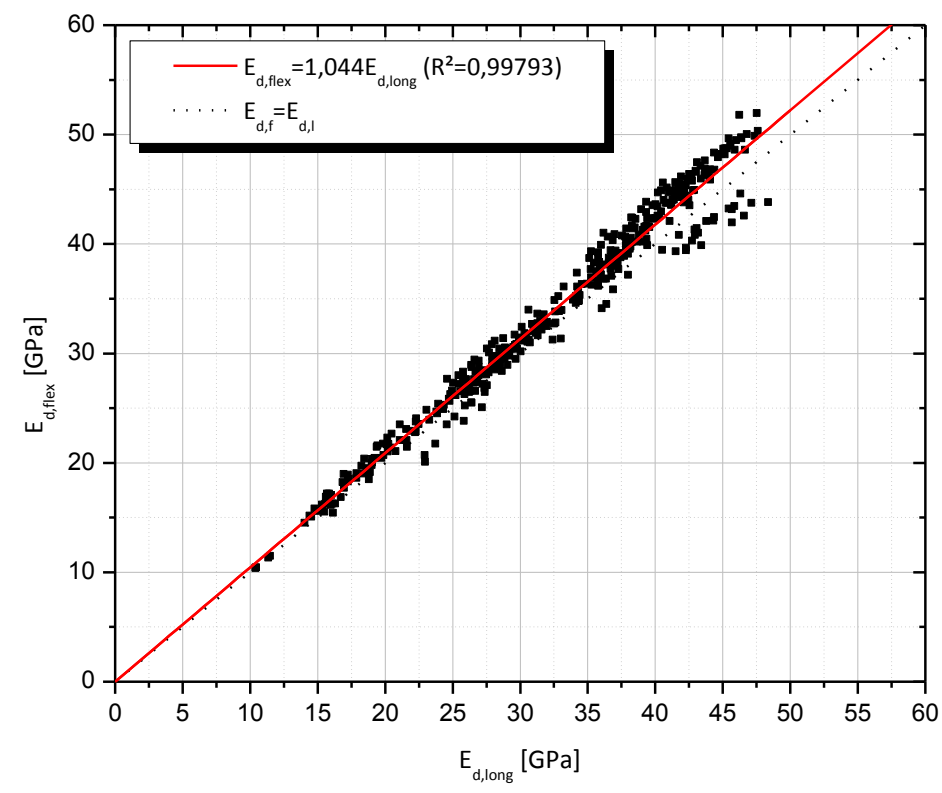

Figura 38 - Relação entre Módulo de Elasticidade dinâmico obtido por modo de vibração longitudinal e flexional (Argamassa)

E finalmente pode-se estabelecer a relação entre módulo de elasticidade dinâmico obtido através do modo de vibração longitudinal e flexional para o caso do concreto, conforme o gráfico a seguir:

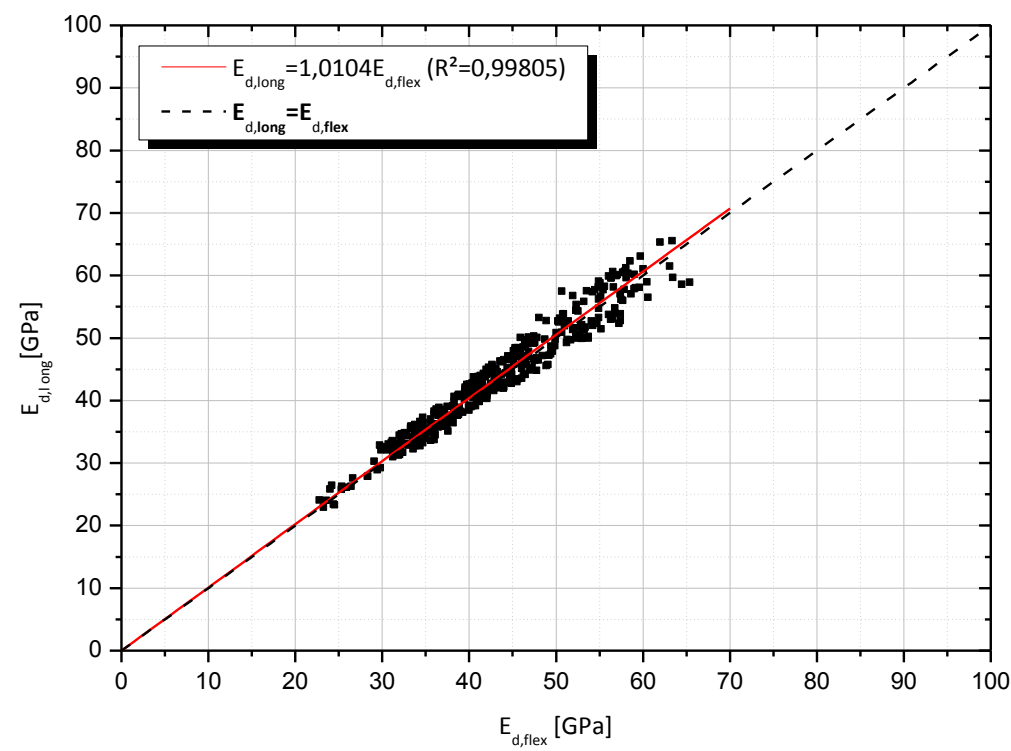

Figura 39 - Relação entre Módulo de Elasticidade dinâmico obtido por modo de vibração longitudinal e flexional (Concreto) 
Portanto e de acordo com os resultados apresentados anteriormente, tanto para o caso do concreto, argamaassa e pasta, o módulo de elasticidade dinâmico obtido pelo modo de vibração longitudinal e flexional são muito próximos, já que, conforme Figura 37, Figura 38 e Figura 39, a reta que define tal relação praticamente coincide com à situação hipotética em que $\mathrm{E}_{\mathrm{d}, \mathrm{flex}}=\mathrm{E}_{\mathrm{d}, \text { long. }}$.

\subsection{MÓDULO DE CISALHAMENTO E COEFICIENTE DE POISSON}

A Figura 40 demonstra que, para o caso da argamassa, o coeficiente de Poisson dinâmico tem pouca correlação com o módulo de elasticidade dinâmico $\left(R^{2}=0,0284\right)$. Neste gráfico, também foram estabelecidos limites superiores e inferiores, com um nível de confiança de $95 \%$. Através de tais limites, pode-se inferir que o coeficiente de Poisson dinâmico está contido em um intervalo entre 0,13 e 0,33.

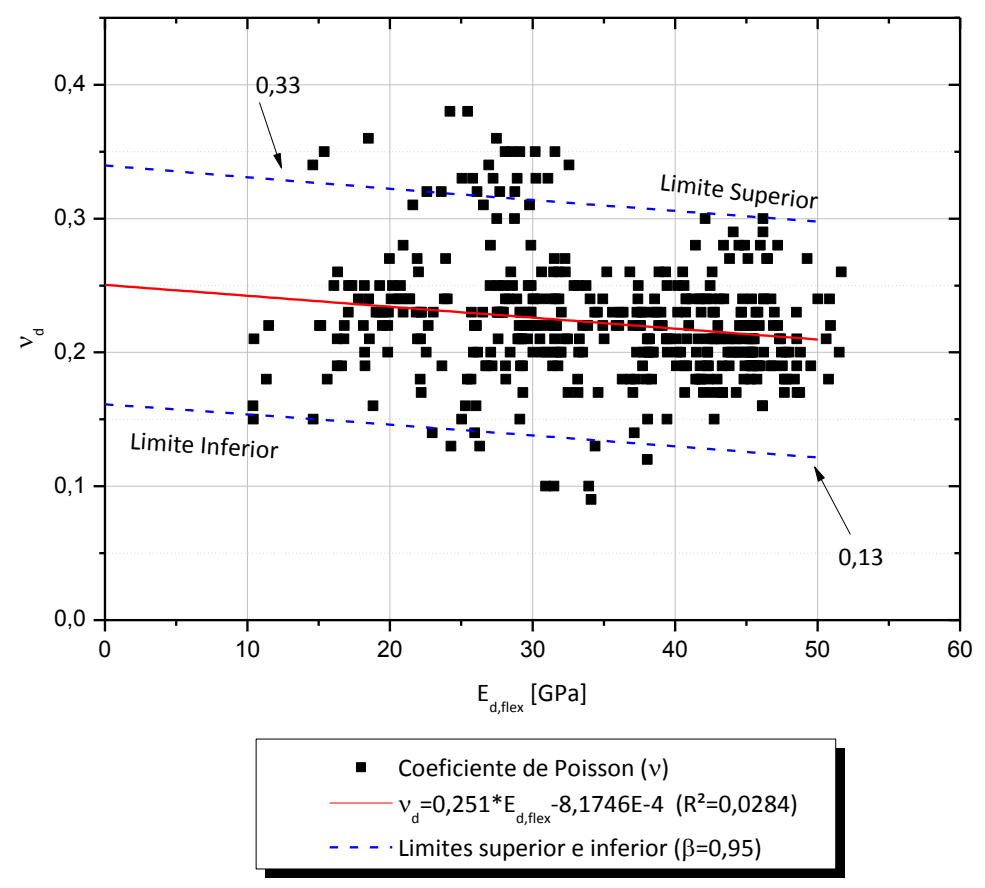
Figura 40 - Relação entre Coeficiente de Poisson e Módulo de Elasticidade
Dinâmico Flexional (Argamassa)

Igualmente ao caso da argamassa, a Figura 41 demonstra que o coeficiente de Poisson dinâmico do concreto tem pouca correlação com seu módulo de elasticidade dinâmico $\left(\mathrm{R}^{2}=0,0014\right)$. Neste gráfico, ainda foram estabelecidos limites superiores e inferiores, com um nível de confiança de 95\%. Através de tais limites, pode-se inferir que o coeficiente de 
Poisson dinâmico está contido em um intervalo entre 0,15 e 0,31. Através do gráfico podese admitir que uma estimativa coerente para o coeficiente de Poisson dinâmico dos concretos produzidos seria na ordem de 0,23 .

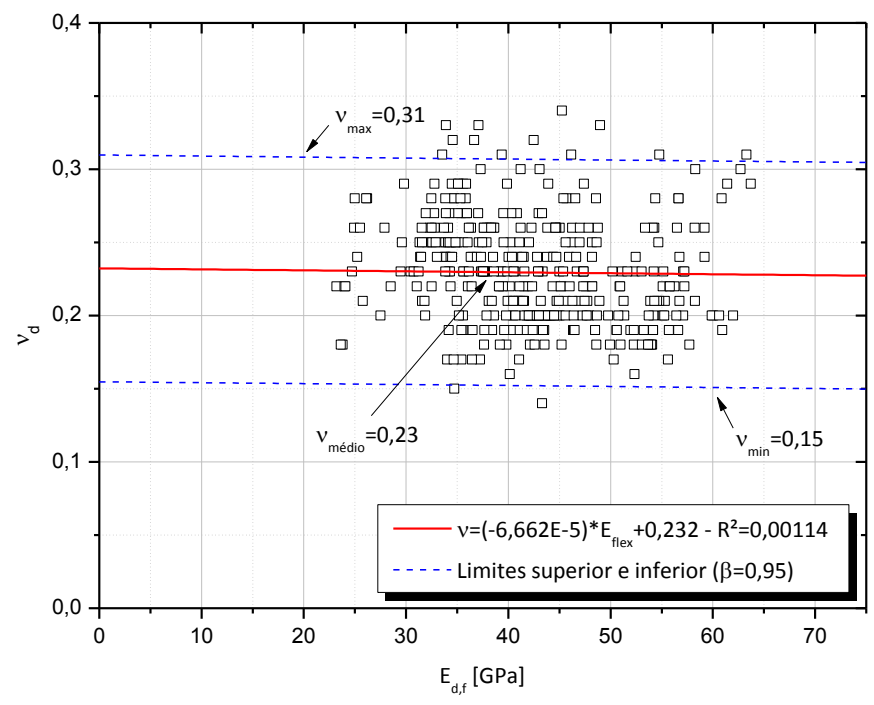

Figura 41 - Relação entre Coeficiente de Poisson e Módulo de Elasticidade dinâmico flexional (Concreto)

É necessário ressaltar que tanto no caso da argamassa quanto do concreto, o procedimento adotado é a comparação do coeficiente de Poisson dinâmico $\left(v_{\mathrm{d}}\right)$ e Módulo de cisalhamento dinâmico $\left(\mathrm{G}_{\mathrm{d}}\right)$ ao módulo de elasticidade dinâmico obtido pelo modo de vibração flexional $\left(\mathrm{E}_{\mathrm{d}, \mathrm{flex}}\right)$. Isto deve ser explicado pelo fato de que as três grandezas são obtidas através do caso em que há superposição dos modos de vibração torcional e flexional.

Adotando a hipótese de que a argamassa seja um material isotrópico, pode-se estabelecer a relação entre o módulo de elasticidade dinâmico obtido pelo modo de vibração flexional $\left(\mathrm{E}_{\mathrm{d}, \mathrm{flex}}\right)$ e módulo de cisalhamento dinâmico $\left(\mathrm{G}_{\mathrm{d}}\right)$. O gráfico da Figura 42 demonstra, então, tal relação para o caso da argamassa: 


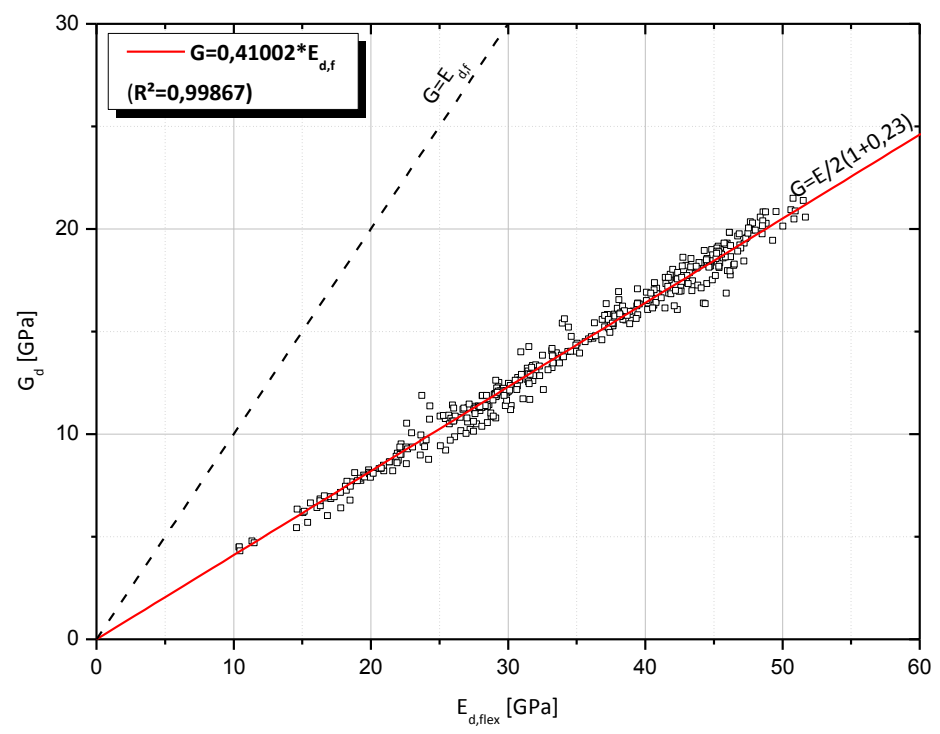

Figura 42 - Relação entre Módulo de Cisalhamento dinâmico e Módulo de Elasticidade flexional (Argamassa)

A mesma hipótese de isotropia é adotada para o caso concreto, em que praticamente a mesma relação linear entre módulo de elasticidade dinâmico e módulo de cisalhamento é obtida conforme a Figura 43:

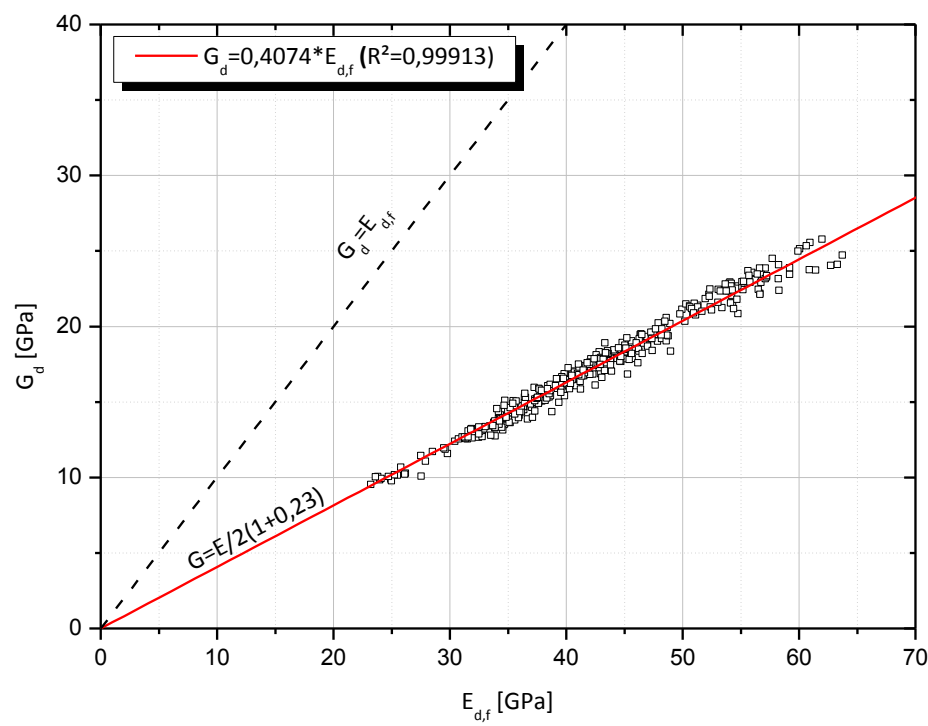

Figura 43 - Relação entre Módulo de Cisalhamento dinâmico e Módulo de Elasticidade flexional (Concreto) 
Ainda é necessário ressaltar que a reta oriunda do ajuste dos pontos experimentais é praticamente a relação de isotropia para coeficiente de Poisson dinâmico de $v_{\mathrm{d}}=0,23$, tanto para o caso do concreto e argamassa.

\subsection{COEFICIENTE DE AMORTECIMENTO}

Conforme o que se demonstra nos gráficos em escala logarítimica das Figura 44 à Figura 49, o coeficiente de amortecimento da pasta, argamassa e concreto apresenta tendência decrescente quando comparado ao módulo de elasticidade dinâmico. Este fenômeno ocorre tanto nos modos de vibração flexional quanto longitudinal, sendo as imperfeições da microestrutura do material, tais como vazios, fendas e zona de transição, os principais responsáveis pelo surgimento do mesmo. Assim, é confirmada a hipótese de que o coeficiente de amortecimento apresenta comportamento experimentalmente inverso ao módulo de elasticidade dinâmico. Isto é devido à dependência que estas duas variáveis tem com a microestrutura do material. Assim, e de acordo com a tendência apresentada nos gráficos subsequentes, quanto mais íntegra a microestrutura da pasta, argamassa ou concreto se apresentar, maior será seu módulo de elasticidade dinâmico, e consequentemente, menor será o coeficiente de amortecimento. Assim, para o caso da pasta, o gráfico que relaciona o coeficiente de amortecimento interno ao módulo de elasticidade dinâmico, respectivamente ao modo de vibração flexional (Figura 44) e longitudinal (Figura 45), é apresentado a seguir:

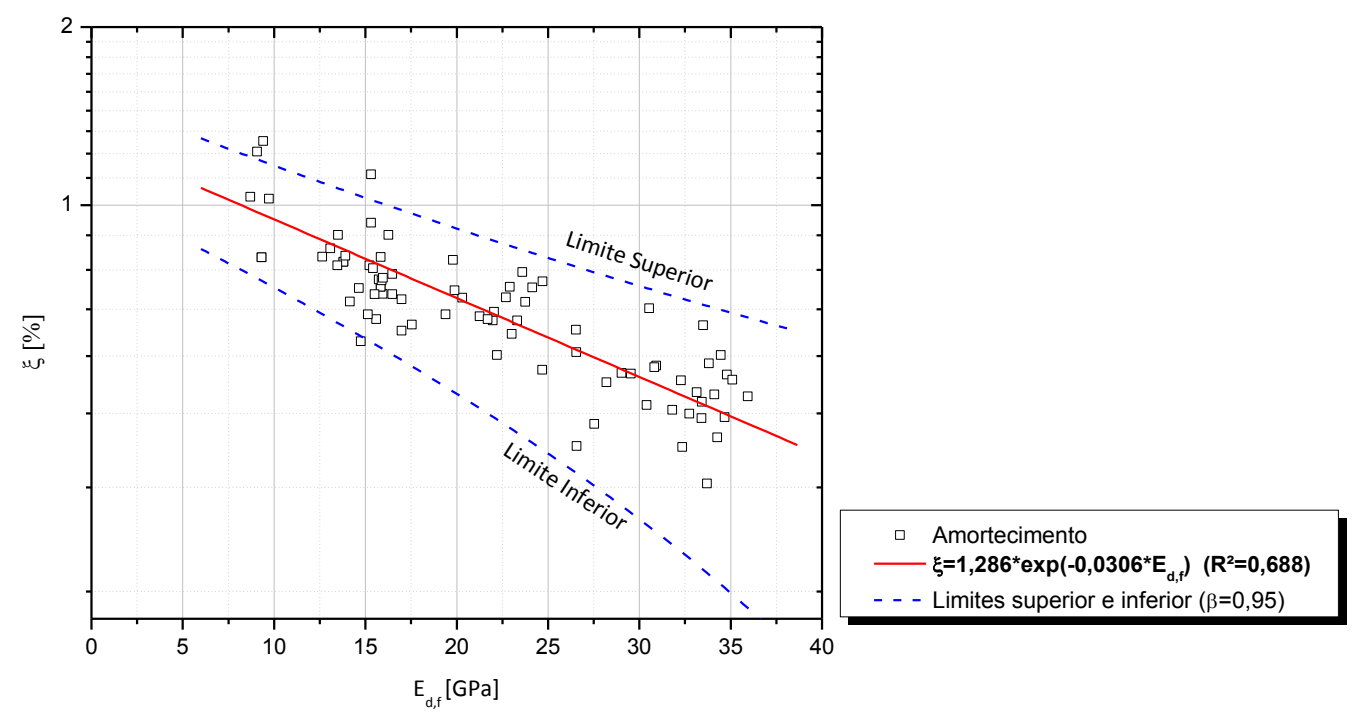




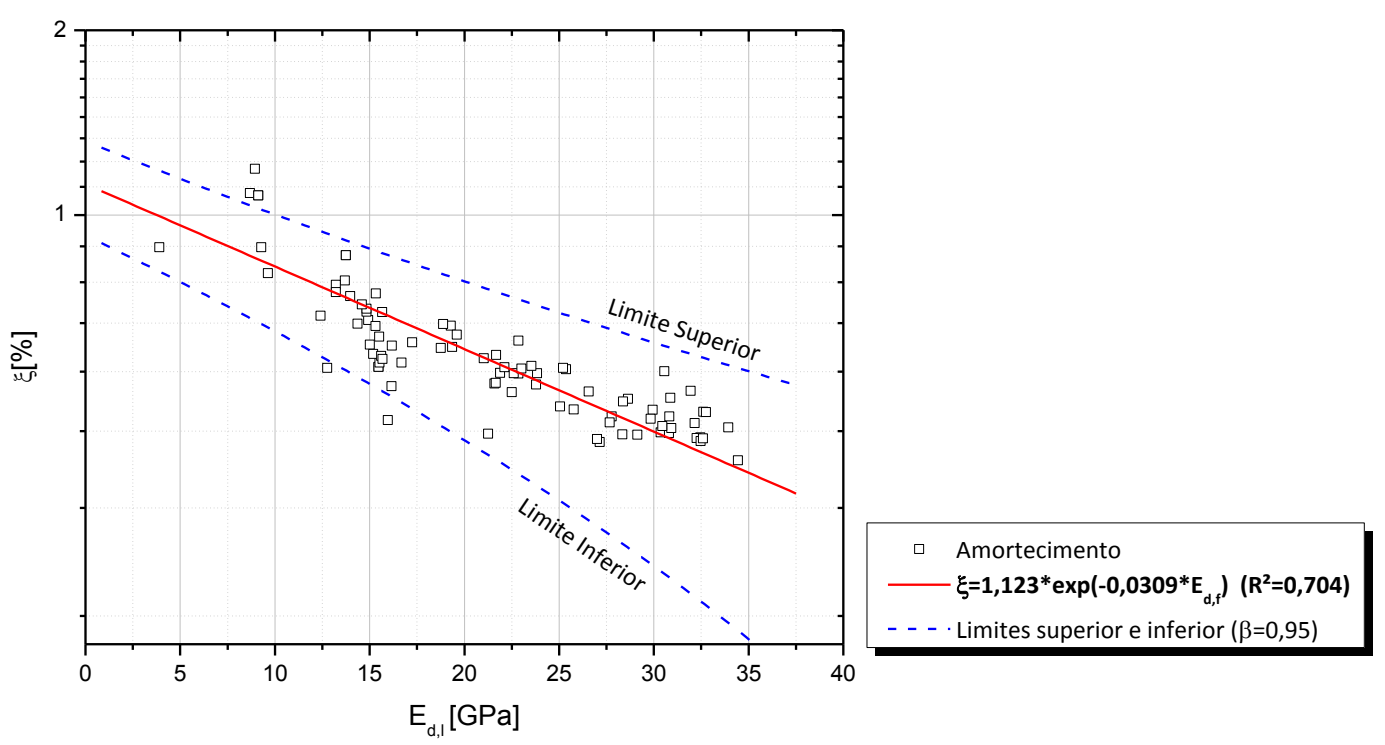

Figura 45 - Relação entre Coeficiente de Amortecimento e Módulo de Elasticidade obtido no modo de vibração longitudinal (Pasta)

Da mesma forma, considerando o caso da argamassa, a relação entre o coeficiente de amortecimento interno e módulo de elasticidade dinâmico, respectivamente ao modo de vibração flexional (Figura 46) e longitudinal (Figura 47), é apresentada a seguir:

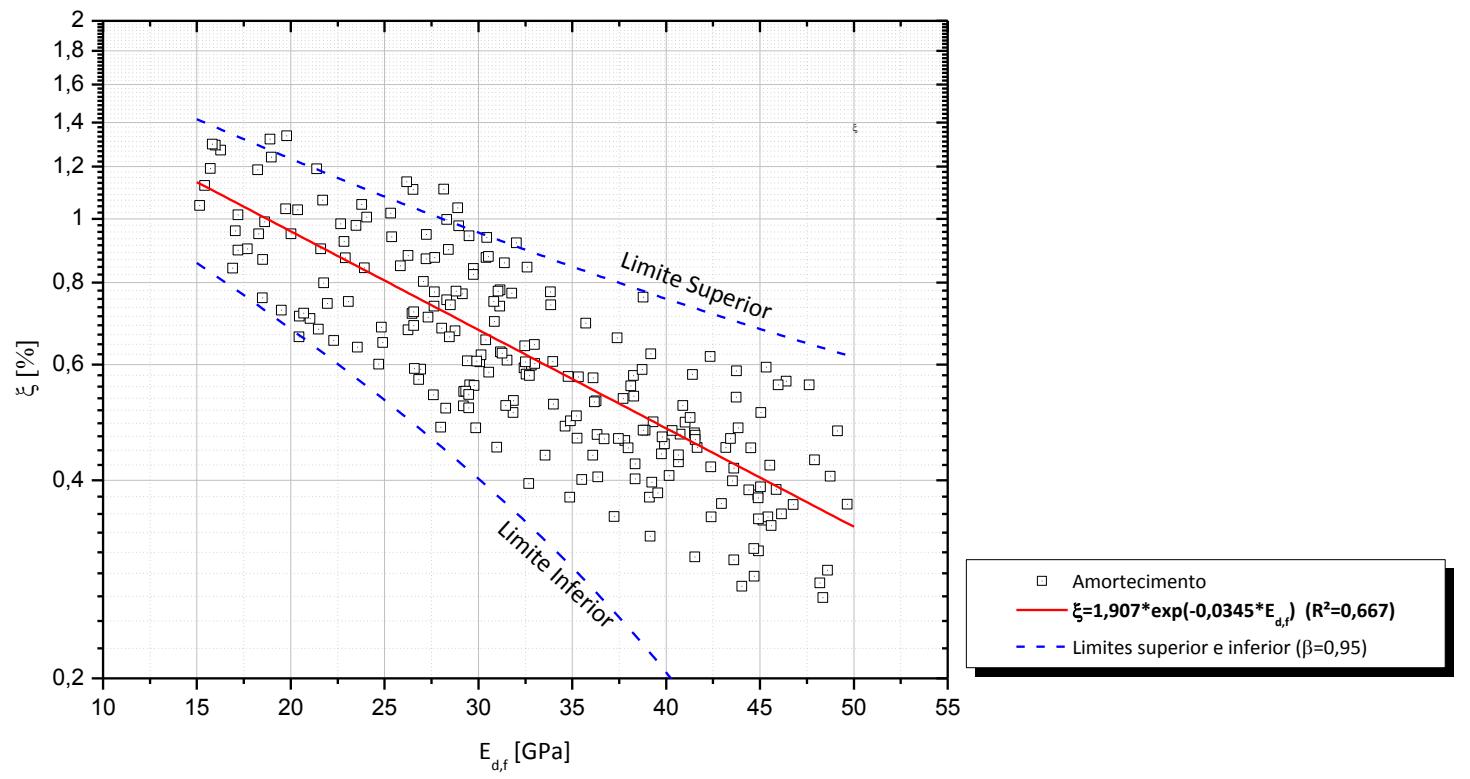

Figura 46 - Relação entre Coeficiente de Amortecimento e Módulo de Elasticidade obtido no modo de vibração flexional (Argamassa) 


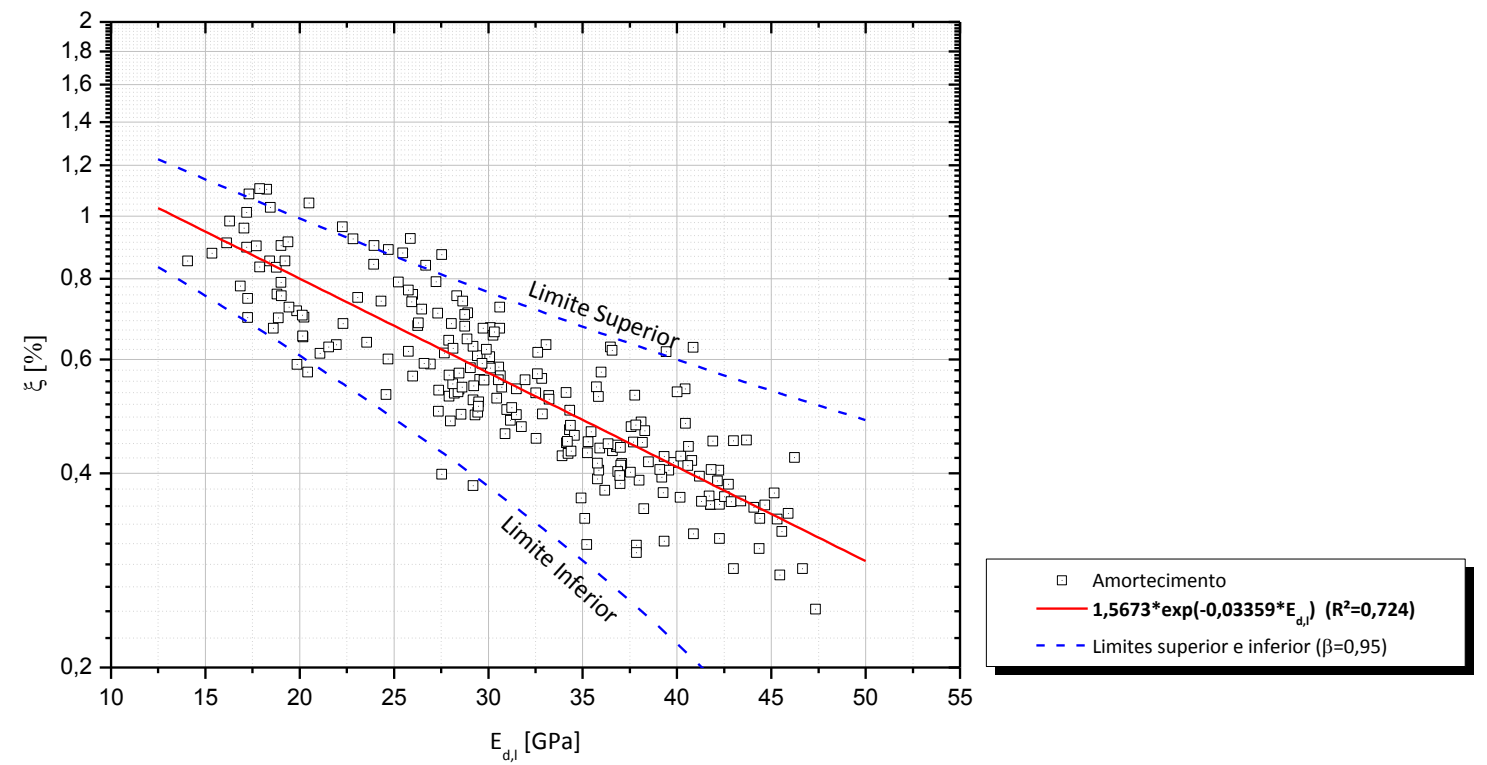

Figura 47 - Relação entre Coeficiente de Amortecimento e Módulo de Elasticidade obtido no modo de vibração longitudinal (Argamassa)

E finalmente para o caso do concreto, o mesmo comportamento do coeficiente de amortecimento interno é observado, ou seja, há tendência decrescente com taxa exponencial do coeficiente de amortecimento interno em função do módulo de elasticidade dinâmico, tanto para o modo de vibração flexional (Figura 48) quanto para o longitudinal (Figura 49): 


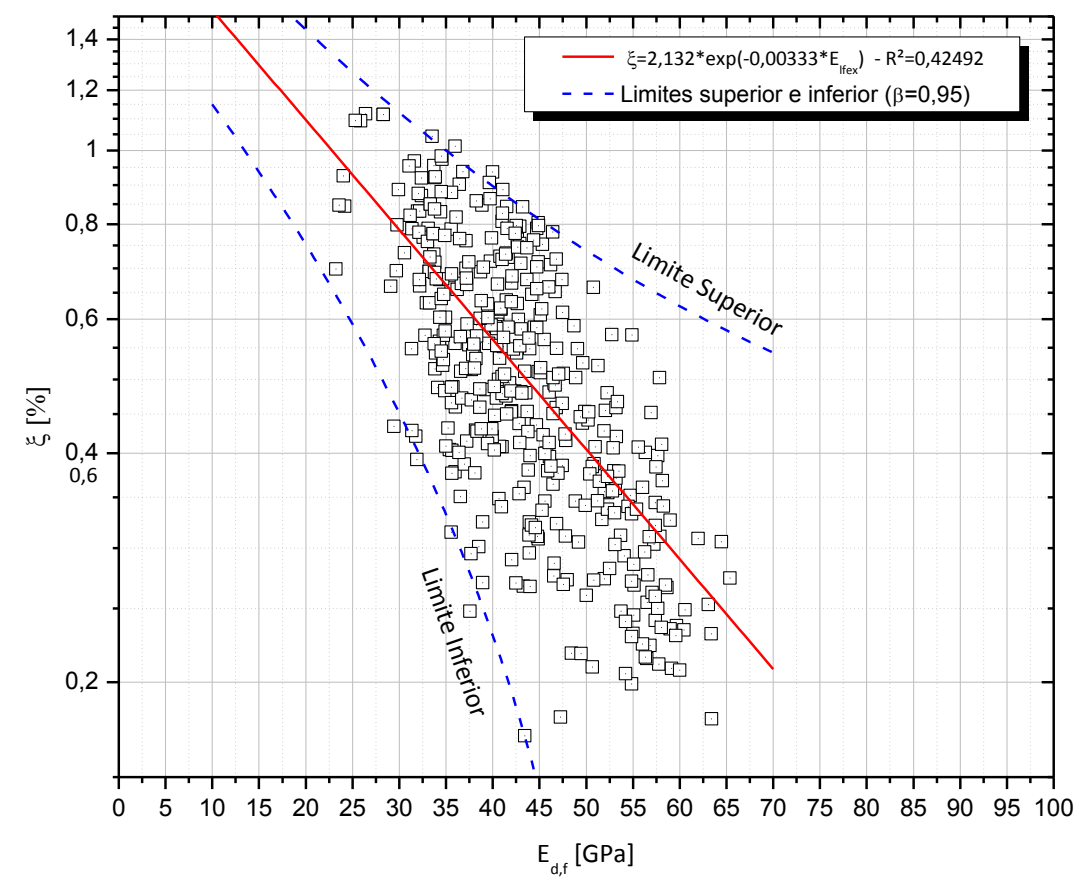

Figura 48 - Relação entre Coeficiente de Amortecimento e Módulo de Elasticidade Flexional (Concreto).

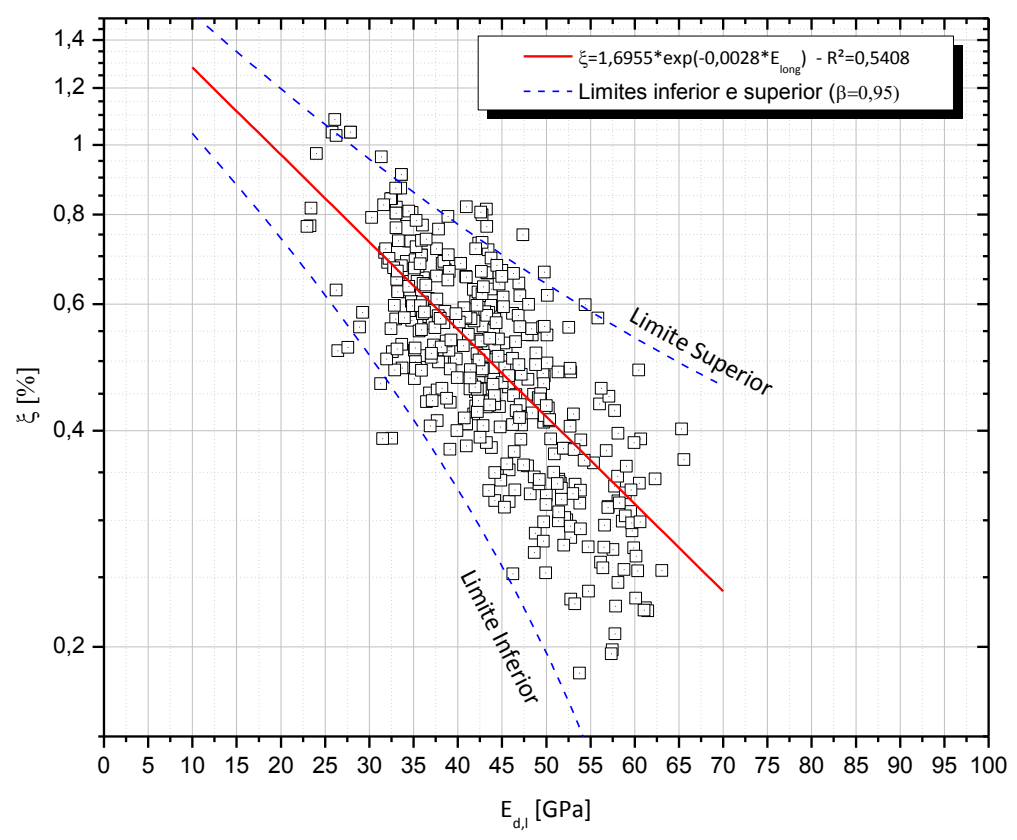

Figura 49 - Relação entre Coeficiente de Amortecimento e Módulo de Elasticidade Longitudinal (Concreto). 
Logo, pode-se afirmar através dos resultados de amortecimento interno anteriormente abordados para pasta, argamassa e concreto, que o parâmetro está contido em um intervalo de aproximadamente $1 \%$ à $0,1 \%$. De fato, BACHMANN et al. (1995) destacam que para os casos de baixo nível de tensão e pouca fissuração, o concreto apresenta valores de amortecimento interno inferiores à $1 \%$, fato este que valida os resultados obtidos no presente trabalho. Todavia, em estruturas de concreto é comum a utilização do valor de $2 \%$ como estimativa do coeficiente de amortecimento. Assim, é importante ressaltar que tal discrepância é fruto da existência de condições de contorno além das condições de integridade do material. A estrutura real, diferentemente das amostras ensaiadas, está sob um determinado nível de tensão, e este gera um certo grau de fissuração na microestrutura do material, fazendo com que aumente o atrito interno do material, e consequentemente, o coeficiente de amortecimento. Paralelamente à isso, há condições de contorno e armaduras, que aumentam ainda mais a dissipação de energia em um regime oscilatório. Portanto, como as amostras estudadas no corrente estão sob vinculação de viga livre-livre e não foram solicitadas, o valor de no máximo $1 \%$ é coerente. 


\subsection{RELAÇÃO ENTRE MÓdULO DE ELASTICIDADE DINÂMICO E ESTÁTICO AOS 28 DIAS}

Através do que é preconizado pela ABNT NBR 8522:2004, foi determinado o módulo de elasticidade estático aos 28 dias, sendo este comparado com o dinâmico. A figura a seguir demonstra a relação obtida entre as duas grandezas:

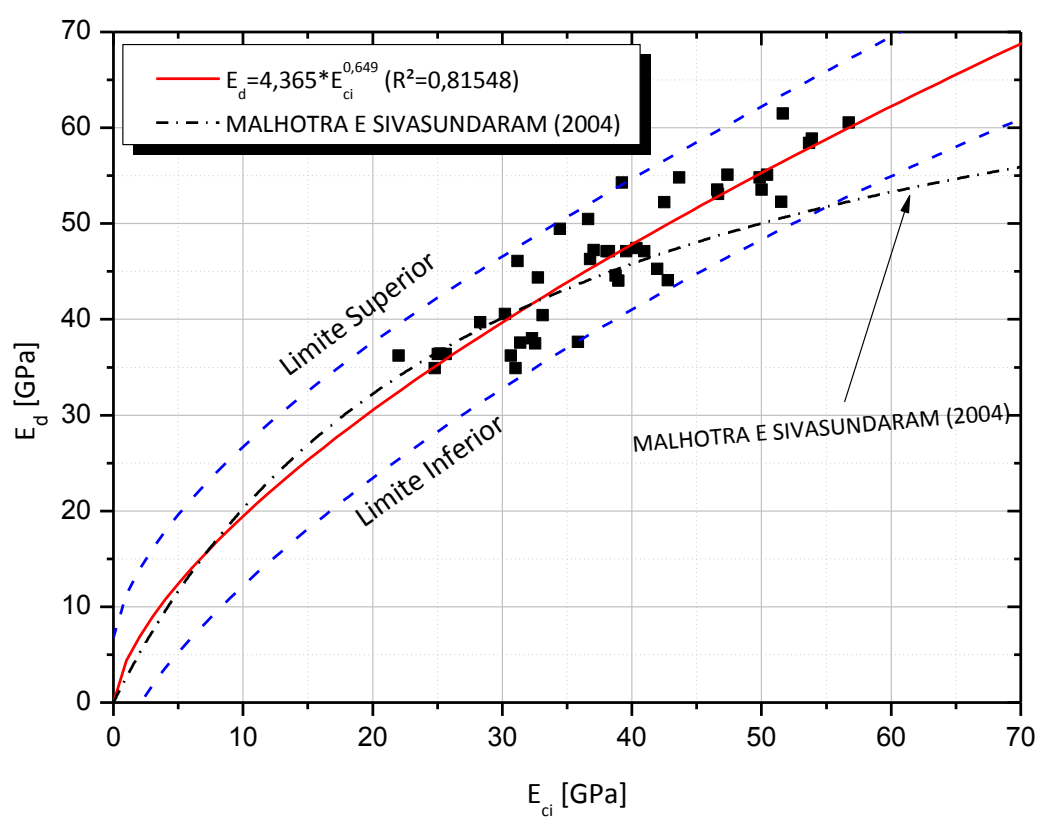

Figura 50 - Relação entre módulo de elasticidade dinâmico e estático, aos 28 dias.

Nota-se, através da figura acima, que há divergência entre a curva da Equação (33), proposta por MALHORTA E SIVASUNDARAM (2004):

$$
\frac{E_{c i}}{E_{d}}=0,368+1,263 \cdot 10^{-5} \cdot E_{c i}, \text { em MPa }
$$

Portanto, não há uma curva universal que relacione o módulo de elasticidade dinâmico ao estático. Assim, esta relação é condicionada à fatores como a maturidade, tipo de agregados empregados na mistura, tipo de cimento, condições de trabalhabilidade e cura dentre outros fatores que impactam de forma diferencial os módulos estático e dinâmico. 


\subsection{RELAÇÃo ENTRE TENSÃo DE RUPtura E Módulo DE ELASTICIDADE DINÂMICO AOS 28 DIAS}

Através dos resultados obtidos através do ensaio estático e acústico pode-se estabelecer para o concreto a relação entre módulo de elasticidade dinâmico e a tensão de ruptura aos 28 dias, conforme o gráfico à seguir:

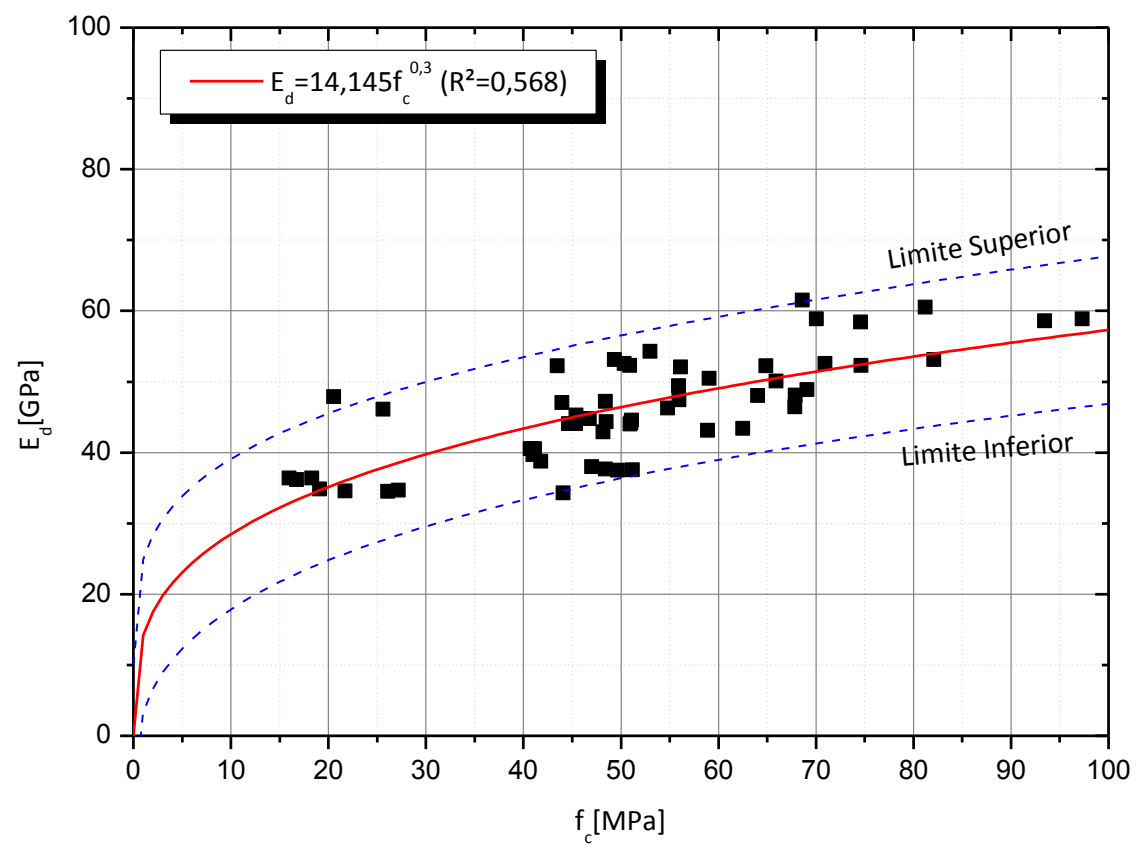

Figura 51 - Relação entre $E_{d}$ e $f_{c m}$ (28 dias)

Assim, estabelecendo limites superiores e inferiores para os valores experimentais, pode-se realizar o ajuste e obter a equação que correlaciona módulo de elasticidade dinâmico e tensão de ruptura aos 28 dias:

$$
E_{d}=14,145 f_{c}^{0,3}
$$

Equação (34)

Em que:

$\mathrm{E}_{\mathrm{d}}$ é o módulo de elasticidade dinâmico do concreto aos 28 dias, em GPa; 
$\mathrm{f}_{\mathrm{c}}$ é a tensão de ruptura do concreto aos 28 dias, em $\mathrm{MPa}$;

\subsection{RELAÇÃo ENTRE TENSÃo DE RUPTURA E MÓdULO DE ELASTICIDADE DINÂMICO AOS 28 DIAS}

Através dos resultados obtidos através do ensaio estático pode-se estabelecer para o concreto a relação entre módulo de elasticidade estático tangente inicial $\left(\mathrm{E}_{\mathrm{ci}}\right)$ e a tensão de ruptura aos 28 dias, conforme o gráfico à seguir:

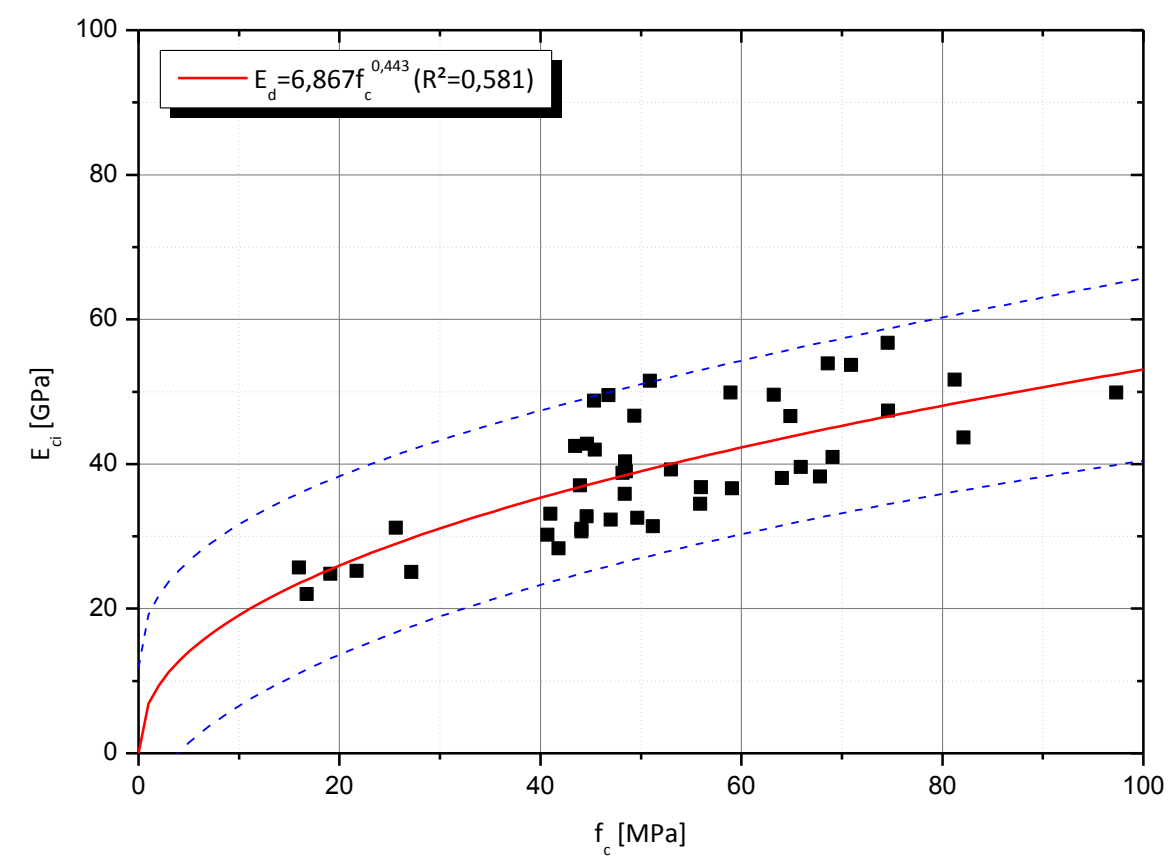

Figura 52 - Relação entre $E_{c i}$ e $f_{c m}$ (28 dias)

Assim, estabelecendo limites superiores e inferiores para os valores experimentais, pode-se realizar o ajuste e obter a equação que correlaciona módulo de elasticidade tangente inicial e tensão de ruptura aos 28 dias:

$$
E_{c i}=6,867 f_{c}^{0,443}
$$

Em que:

$\mathrm{E}_{\mathrm{ci}}$ é o módulo de elasticidade dinâmico do concreto aos 28 dias, em GPa; 
$\mathrm{f}_{\mathrm{c}}$ é a tensão de ruptura do concreto aos 28 dias, em MPa;

\subsection{EQUAÇÕES EMPÍRICAS}

Uma forma de se estimar o módulo de elasticidade dinâmico do concreto é através das equações empíricas. Assim, valendo-se das previsões de $\mathrm{E}_{\mathrm{ci}}$, admite-se a relação entre os módulos de elasticidade estático e dinâmico aos 28 dias, obtida neste trabalho, e contemplada conforme a Equação (36):

$$
E_{d}=4,365 E_{c i}^{0,649} \quad \text { Equação (36) }
$$

As estimativas obtidas para módulo de elasticidade dinâmico, conforme os códigos da ABNT NBR 6118:2014, CEB-FIP de 2010 e ACI 318-11 podem resumidamente apresentados conforme à tabela à seguir:

Tabela 26 - Equações Empíricas

\begin{tabular}{|c|c|c|c|c|c|c|c|}
\hline Traço & $\begin{array}{c}\mathbf{f}_{\mathrm{cm}} \\
{[\mathrm{MPa}]}\end{array}$ & $\begin{array}{c}\mathbf{f}_{\mathbf{c k}} \\
{[\mathrm{MPa}]}\end{array}$ & $\begin{array}{c}\mathbf{f}_{\mathbf{c}}^{\prime} \\
{[\mathrm{MPa}]}\end{array}$ & $\begin{array}{l}\mathbf{E}_{\mathrm{d}, \mathrm{NBR}} \\
{[\mathbf{G P a}]}\end{array}$ & $\begin{array}{l}\mathbf{E}_{\mathrm{d}, \mathrm{CEB}} \\
{[\mathbf{G P a}]}\end{array}$ & $\begin{array}{r}\mathbf{E}_{\mathrm{d}, \mathrm{ACI}} \\
{[\mathrm{GPa}]}\end{array}$ & $\begin{array}{c}\mathbf{E}_{\text {Experimental }} \\
\text { [GPa] }\end{array}$ \\
\hline 1:2:1:0,5 - Traço Rico & 41,360 & 34,760 & 40,471 & 47,537 & 48,923 & 41,520 & 37,670 \\
\hline $1: 2: 3 \mathrm{~B} 0: 0,3: 1 \%$ & 58,570 & 51,970 & 48,923 & 54,164 & 52,747 & 44,156 & 55,390 \\
\hline $\begin{array}{c}\text { 1:3:4:0,5 - Traço } \\
\text { Pobre }\end{array}$ & 38,916 & 32,316 & 34,363 & 46,425 & 48,283 & 39,373 & 52,533 \\
\hline 1:1:2:0,5 - Traço Rico & 33,024 & 26,424 & 35,384 & 43,490 & 46,598 & 39,749 & 39,855 \\
\hline $1: 2: 3: 0,3: 1 \%$ & 60,947 & 54,347 & 54,169 & 54,955 & 53,203 & 45,640 & 59,823 \\
\hline $1: 2: 3: 0,5: 1 \%$ & 55,875 & 49,275 & 54,703 & 53,236 & 52,212 & 45,785 & 47,100 \\
\hline 1:2:3BL:0,5:1\% & 44,922 & 38,322 & 42,614 & 49,065 & 49,805 & 42,221 & 51,561 \\
\hline 1:2:3BL:0,7 & 14,164 & 7,564 & 14,270 & 28,980 & 38,800 & 29,604 & 35,974 \\
\hline 1:2:3BL:0,3:1\% & 79,384 & 72,784 & 72,852 & 60,420 & 56,334 & 50,246 & 58,838 \\
\hline 1:2:3BL:0,5:0\% & 40,724 & 34,124 & 33,168 & 47,253 & 48,759 & 38,924 & 46,991 \\
\hline $1: 2: 3: 0,7-0 \% \mathrm{SP}$ & 27,302 & 20,702 & 13,020 & 40,178 & 44,719 & 28,736 & 34,515 \\
\hline $1: 3: 2: 0,5$ & 40,635 & 34,035 & 37,929 & 47,212 & 48,736 & 40,655 & 43,965 \\
\hline $1: 2: 3: 0,5: 0 \%$ & 30,342 & 23,742 & 13,976 & 42,005 & 45,752 & 29,405 & 45,462 \\
\hline $1: 2: 3 \mathrm{~B} 0: 0,5: 1 \% \mathrm{SP}$ & 47,162 & 40,562 & 37,412 & 49,978 & 50,332 & 40,475 & 43,879 \\
\hline
\end{tabular}


Por conseguinte, a Figura 53 compara em um histograma a relação entre as estimativas empíricas normativas de módulo de elasticidade dinâmico com valores experimentais obtidos através do ensaio acústico, aos 28 dias. Assim, tal gráfico avalia através do ajuste de uma curva normal a relação $\mathrm{E}_{\text {empírica }} / \mathrm{E}_{\text {experimental: }}$ :

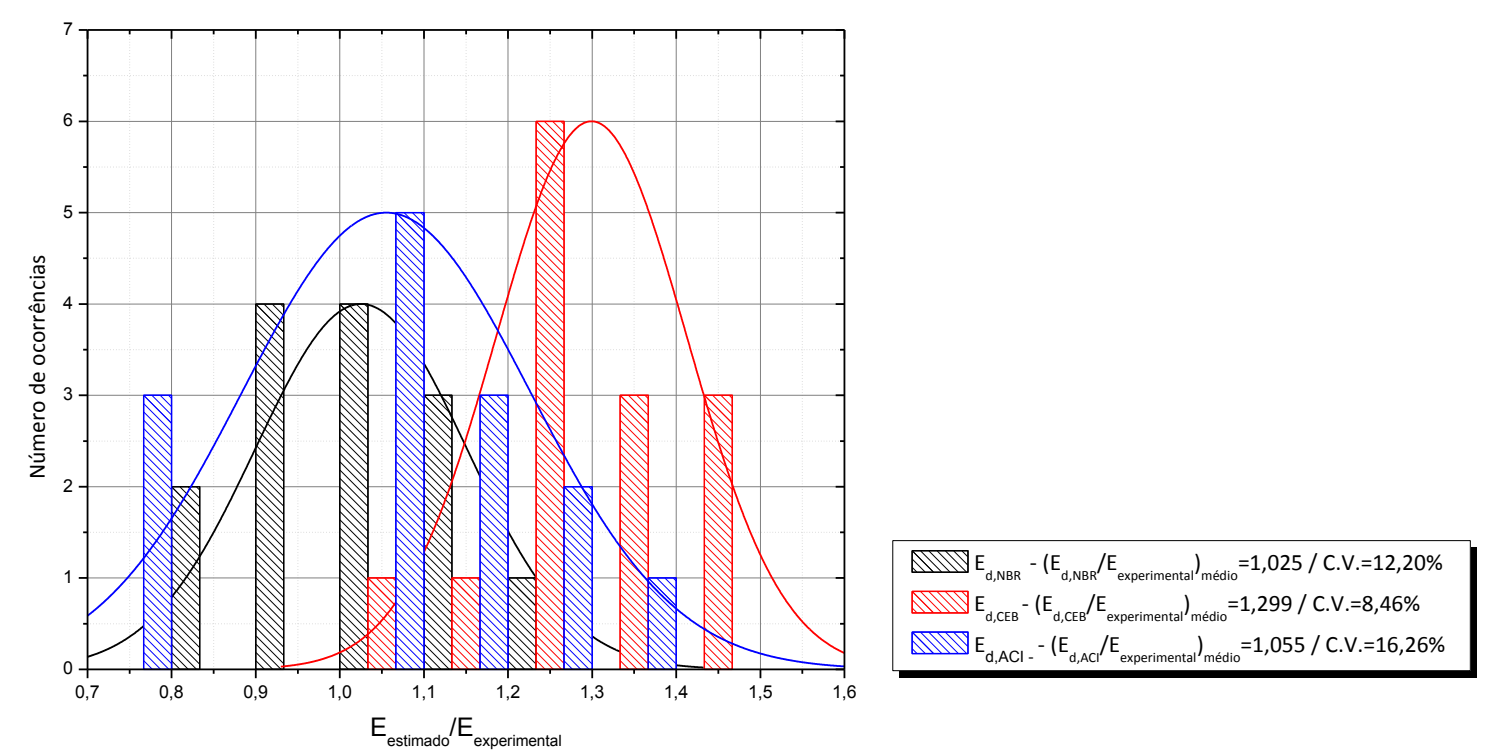

Figura 53 - Comparação entre as Equações Empíricas (Concreto)

Assim e através dos resultados apresentados pelo gráfico da Figura 53, pode-se concluir que, em média, as previsões de módulo de Elasticidade Dinâmico da ABNT NBR 6118:2014 e ACI 318-11 se aproximam dos valores reais $\left(E_{N B R} / E_{\text {experimental }}=1,025\right.$ e $\left.\mathrm{E}_{\mathrm{ACI}} / \mathrm{E}_{\text {experimental }}=1,055\right)$. Todavia, as estimativas da ABNT NBR 6118:2014 apresentam coeficiente de variação inferior àquele verificado no ACI 318-11 (C.V.NBR=12,20\% e C.V.ACI=16,26\%). Assim, estas expressões são válidas para a faixa de concretos estudados na presente pesquisa, sendo a ABNT NBR 6118:2014 a que converge sistematicamente a resultados mais precisos quando comparado ao ACI318-11. Por outro lado, as estimativas feitas pelo CEB-FIP de 2010 divergiram dos valores obtidos experimentalmente, já que em média a relação $\mathrm{E}_{\mathrm{CEB}} / \mathrm{E}_{\text {experimental }}=1,299$. 


\subsection{FORMULAÇÃO PARA MATERIAIS COMPÓSITOS}

A fim de representar o comportamento do concreto, as formulações para materiais compósitos são feitas através da premissa que o concreto é uma mistura composta por argamassa e brita. Esta mesma argamassa, é ainda composta de uma mistura entre pasta e areia. Assim, a Figura 54 representa a ideia a ser adotada nos modelos à seguir:

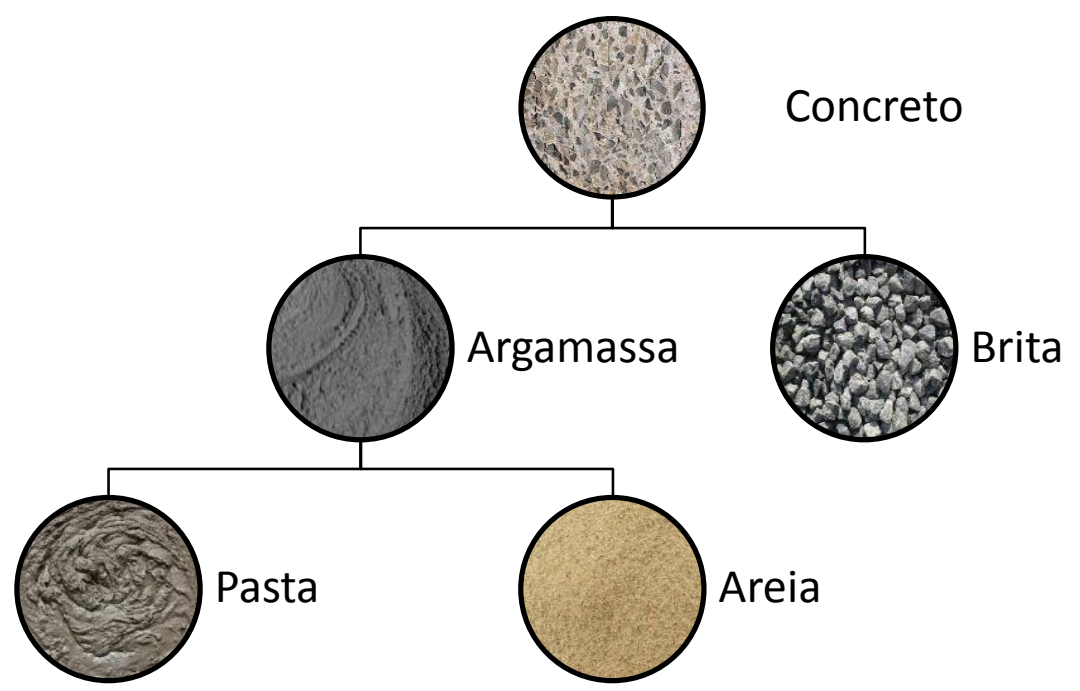

Figura 54 - Formulação de materiais compósitos para o concreto

Como primeiro modelo proposto pode-se admitir, a hipótese de que o concreto seja composto por duas misturas bifásicas. Assim e conforme a idéia ilustrada na Figura 54, pode-se admitir que a argamassa é composta de pasta e areia, e esta mesma argamassa é outrora, componente de um segundo material bifásico juntamente com a brita: o concreto. Por conseguinte, os gráficos abaixo comparam, em um histograma com ajuste para curva

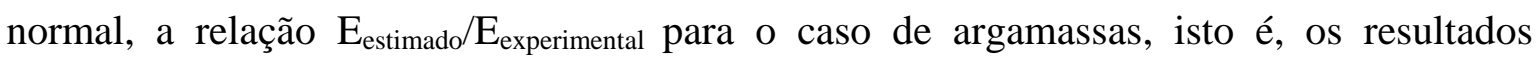
experimentais de módulos de elasticidade dinâmico são comparados com suas as previsões teóricas bifásicas (pasta+areia). É necessário ainda salientar que tal comparação foi realizada para argamassas e pastas de mesma idade e traço. A média entre os modelos em série e paralelo (S-P) e os limites de Hashin-Shtrikman (H-S) foi utilizada como estimativa. Logo, pode-se avaliar a relação $\mathrm{E}_{\text {estimado }} / \mathrm{E}_{\text {experimental, }}$ assim como a medida de coeficiente de variação para os modelos de previsão de comportamento da argamassa. Portanto, a Figura 55 trata do modelo em série e paralelo e a Figura 56 da estimativa através dos limites de Hashin-Shtrikman: 


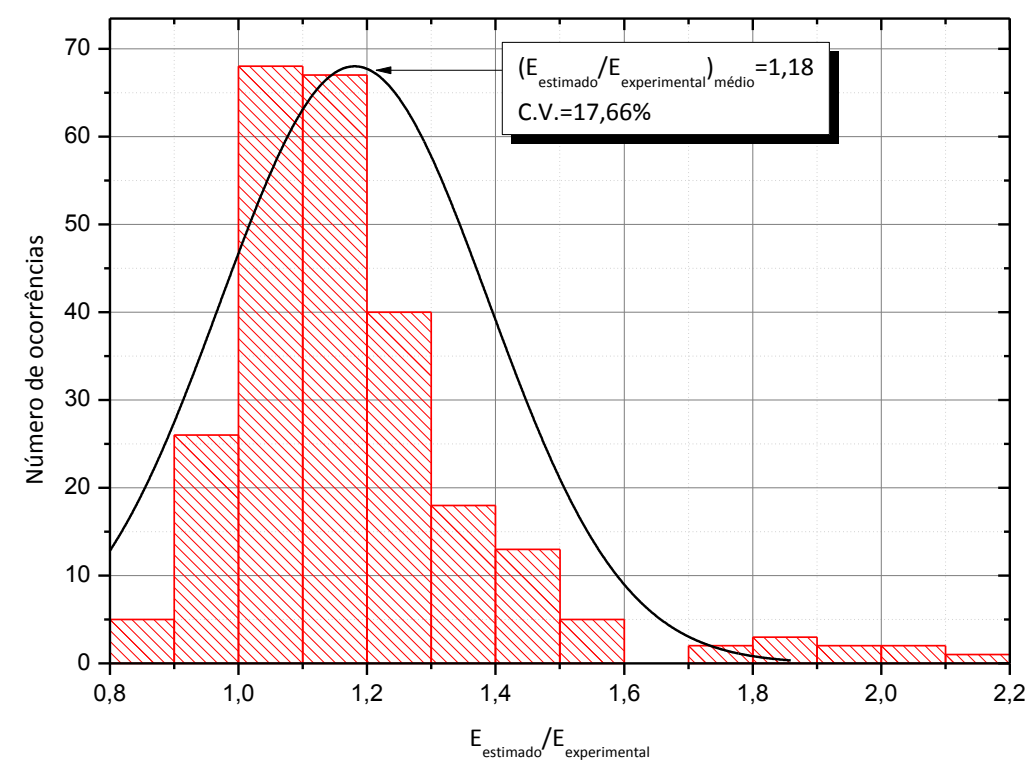

Figura 55 - Histograma e distribuição normal para $E_{\text {estimado }} / E_{\text {experimental }}$ (SérieParalelo, Pasta + Areia $\rightarrow$ Argamassa Teórica)

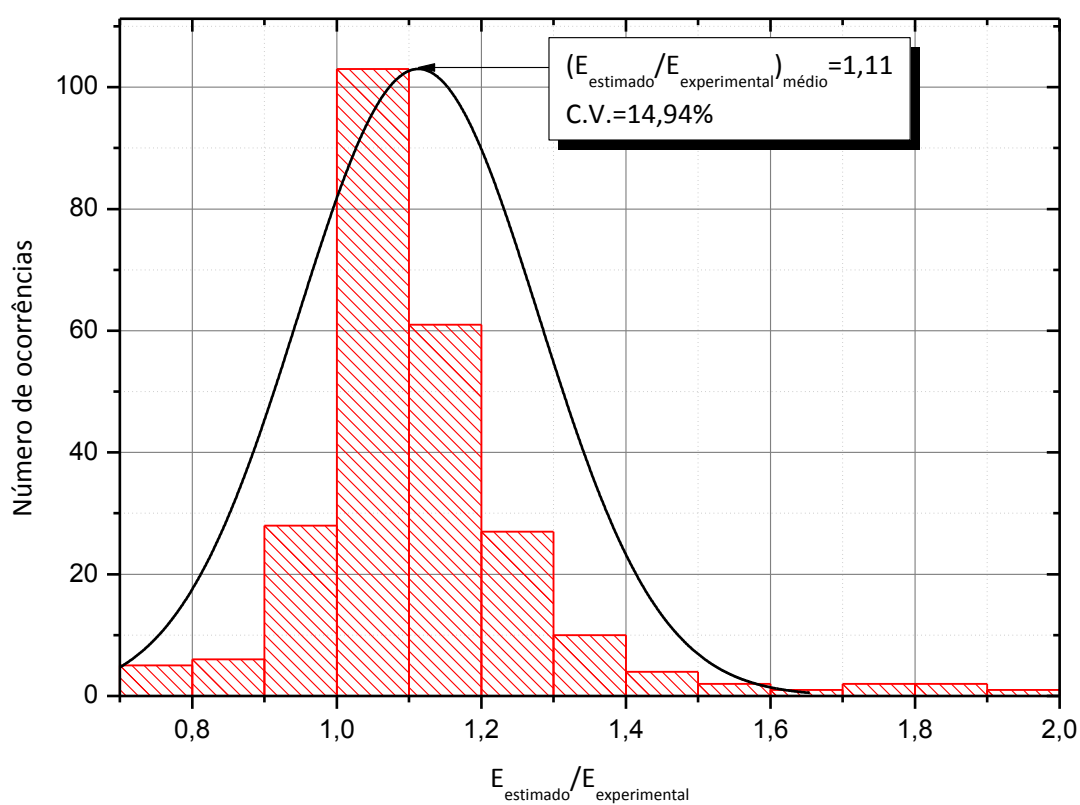

Figura 56 - Histograma e distribuição normal para $E_{\text {estimado }} / E_{\text {experimental }}$ (Hashin-Shtrikman, Pasta + Areia $\rightarrow$ Argamassa Teórica). 
Através dos resultados apresentados, em especial os valores de média e coeficiente de variação, pode-se concluir estatisticamente que a argamassa pode ser estimada como um material bifásico, com relação média entre $\mathrm{E}_{\text {estimado }} / \mathrm{E}_{\text {experimental }}$ igual à 1,18 para o caso do modelo em série e paralelo (S-P) e 1,11 para os limites de Hashin-Shtrikman (H-S). O coeficiente de variação para o modelo em série e paralelo $(17,66 \%)$ foi maior quando comparado à média dos limites de Hashin-Shtrikman (14,94\%). Vale ressaltar que as propriedades elásticas do grão de areia foram adotadas segundo o estudo de NAFE e DRAKE (1961), em que se determinam, através de ondas sísmicas, propriedades físicas de maciços sedimentares marinhos, sendo estes resultados apresentados no Anexo B.

Posteriomente, faz-se necessária a realização da estimativa do módulo de elasticidade dinâmico do concreto. Assim, propõe-se a comparação $\left(\mathrm{E}_{\text {teórico }} / \mathrm{E}_{\text {experimental }}\right)$ entre os resultados experimentais de concreto e o modelo teórico duplamente bifásico, isto é, composto de argamassa teórica (pasta+areia) e brita. Analogamente ao caso anterior das argamassas, adotam-se como estimativas o valor médio entre os modelos de Série e Paralelo (S-P), conforme a Figura 57, e também a média entre os limites de HashinShtrikman (H-S), conforme a Figura 58:

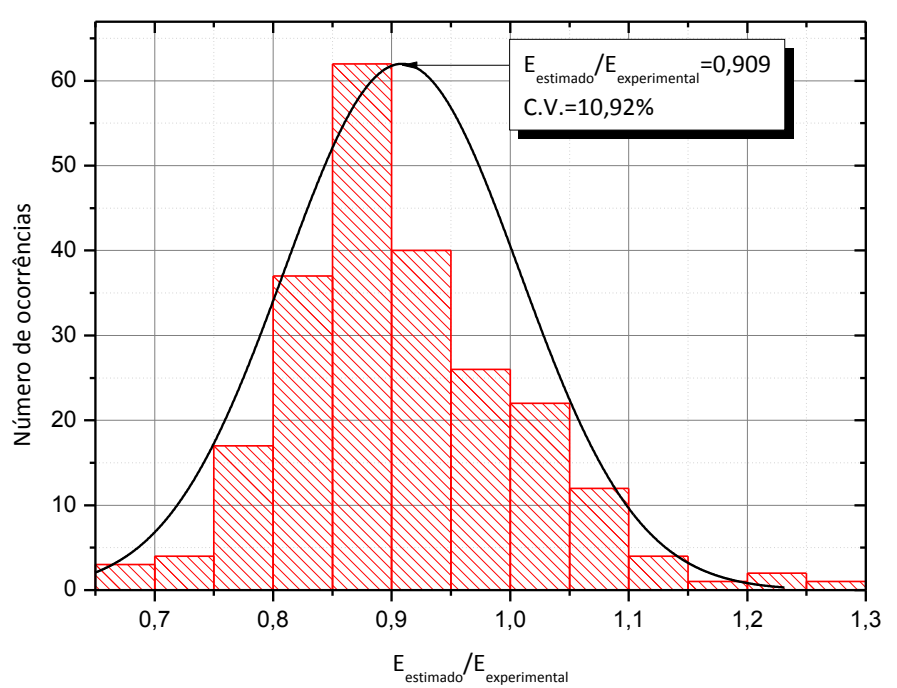

Figura 57 - Histograma e distribuição normal para $E_{\text {estimado }} / E_{\text {experimental }}$ (SérieParalelo, Argamassa teórica + Brita $\rightarrow$ Concreto) . 


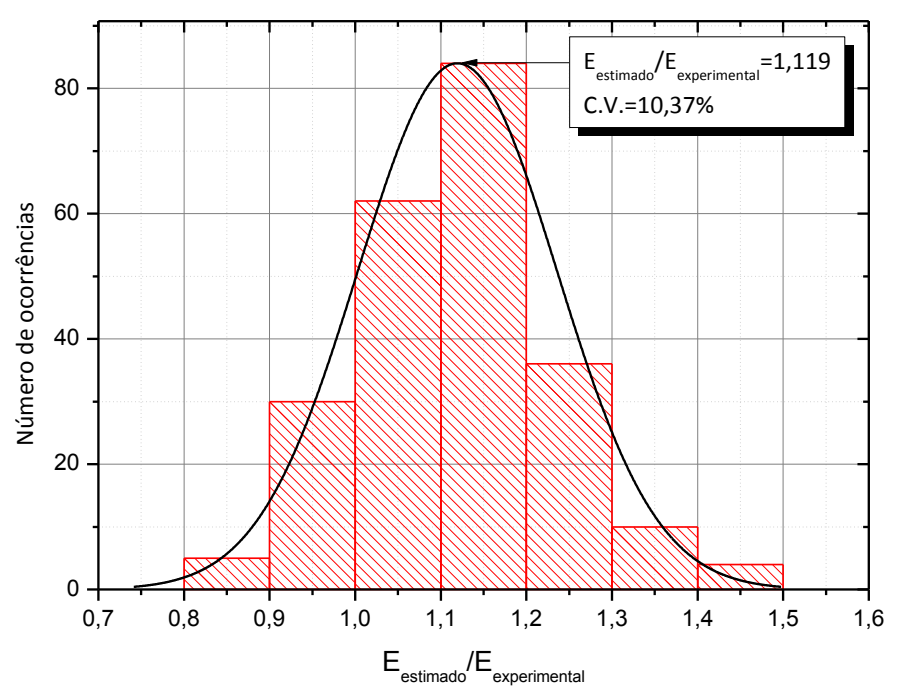

Figura 58 - Histograma e distribuição normal para $E_{\text {estimado }} E_{\text {experimental }}$ (HashinShtrikman, Argamassa teórica + Brita $\rightarrow$ Concreto) .

Os resultados da Figura 57 e Figura 58 demonstram que o módulo de elasticidade dinamico do concreto pode ser estimado através da dupla associação de materiais bifásicos (Argamassa teórica + brita), e tal estimativa apresenta relação média de $\mathrm{E}_{\text {estimado }} / \mathrm{E}_{\text {experimental }}$ igual à 0,909 com coeficiente de variação igual à 10,92\% para o modelo em Série e Paralelo (S-P) e 1,119 com coeficiente de variação igual à 10,37\% para Hashin-Shtrikman. Ainda é necessário ainda evidenciar que os dados utilizados para a realização dos cálculos de tal modelo constam na tabela a seguir:

Tabela 27 - Propriedades Elásticas dos componentes do modelo Pasta + Areia + Agregado Graúdo

\begin{tabular}{|c|c|c|c|}
\hline Componente & $\mathbf{E}_{\mathbf{d}}$ [GPa] & $\boldsymbol{v}_{\mathbf{d}}$ & $\mathbf{G}_{\mathbf{d}}[\mathbf{G P a}]$ \\
\hline Pasta & Variável & $0,23^{*}$ & $G=E / 2(1+v)$ \\
\hline Areia & $82,5^{* *}$ & $0,24^{* *}$ & $G=E / 2(1+v)$ \\
\hline $\begin{array}{c}\text { Agregado Graúdo - } \\
\text { Diabásio }\end{array}$ & $70^{* * *}$ & $0,24^{* * *}$ & $G=E / 2(1+v)$ \\
\hline \multicolumn{2}{|c|}{${ }^{*}$ Estimativa com base nos dados experimentais ${ }^{* *}$ Estimativa com base em NAFE e DRAKE } \\
\multicolumn{2}{|c|}{$(1961)-$ Cálculo no anexo B ${ }^{* * *}$ Valor medido experimentalmente } \\
\hline
\end{tabular}


Uma vez utilizando-se dos resultados experimentais dos módulos elásticos de argamassas, propõe-se a formulação de um único material bifásico para a estimativa do módulo de elasticidade dinâmico do concreto, conforme a figura à seguir:

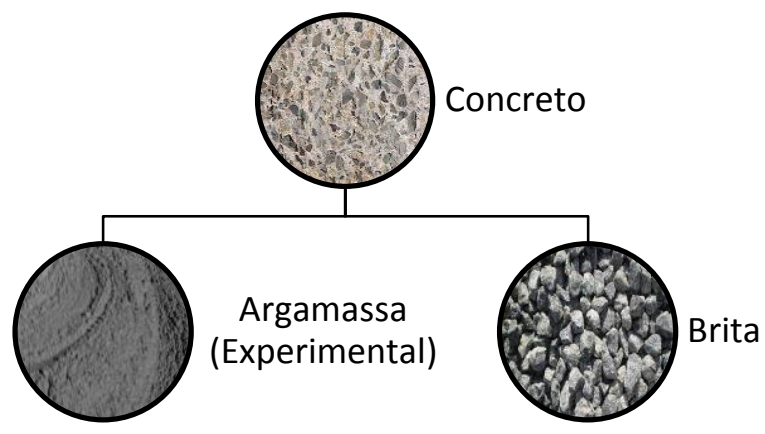

Figura 59 - Modelo Bifásico (Argamassa + Brita)

Assim, considera-se agora o concreto sendo uma única composição bifásica entre argamassa, agora com módulo de elasticidade obtido experimentalmente, e brita. Logo, procura-se comparar a relação entre resultados experimentais e modelos teóricos bifásicos $\left(\mathrm{E}_{\text {estimado }} / \mathrm{E}_{\text {experimental }}\right)$, para concretos de mesma idade e traço. Assim como no caso anteriomente abordado de material duplamente bifásico, adotou-se como estimativa os valores médios entre os modelos em série-paralelo (S-P) e também a média entre os limites de Hashin-Shtrikman (H-S). Portanto os resultados obtidos de $\mathrm{E}_{\text {estimado }} / \mathrm{E}_{\text {experimental }}$ foram organizados nos histogramas da Figura 60 e Figura 61:

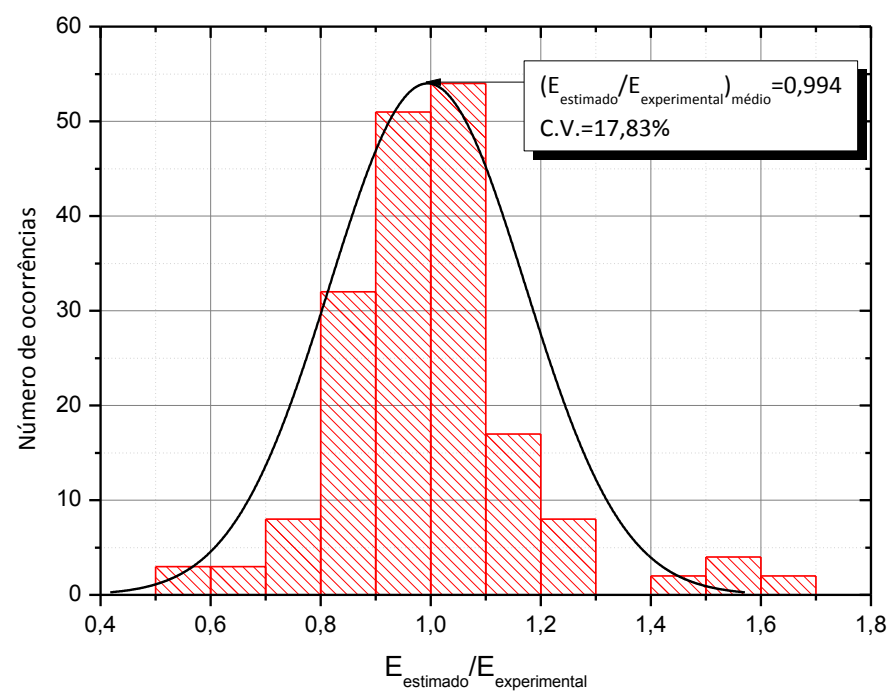

Figura 60 - Histograma e distribuição normal para $E_{\text {estimado }} / E_{\text {experimental }}$ (SérieParalelo, Argamassa Experimental + Brita $\rightarrow$ Concreto) . 


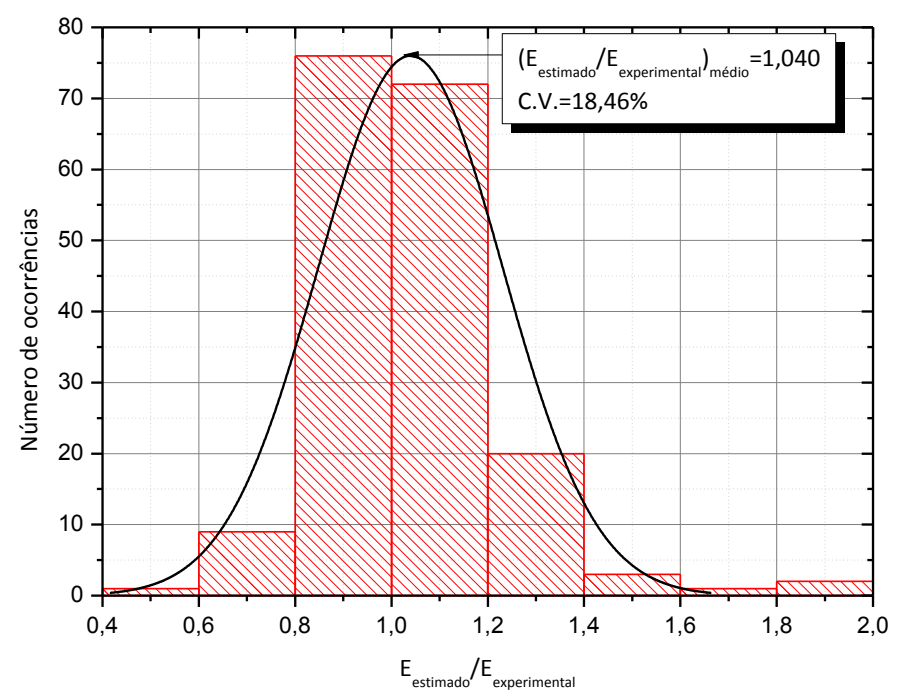

Figura 61 - Histograma e distribuição normal para $E_{\text {estimado }} / E_{\text {experimental }}$ (HashinShtrikman com $v_{\mathrm{d}, \mathrm{est}}=0,23$, Argamassa Experimental + Brita $\rightarrow$ Concreto).

De acordo com os resultados dos histogramas e do ajuste de curvas normais anteriormente apresentados, se estabelece que o modelo em série e paralelo bifásico

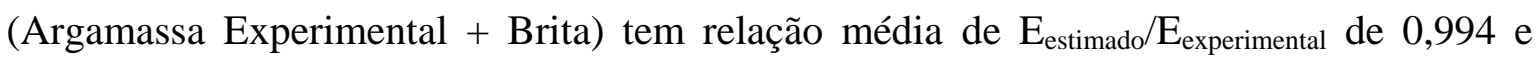
coeficiente de variação de $17,84 \%$. Por outro lado, o modelo que considera a média entre os limites de Hashin-Shtrikman (H-S) apresentam relação média entre $\mathrm{E}_{\text {estimado }} / \mathrm{E}_{\text {experimental }}$ de 1,04 e coeficiente de variação de 18,46\%. Tomando como base os valores médios da

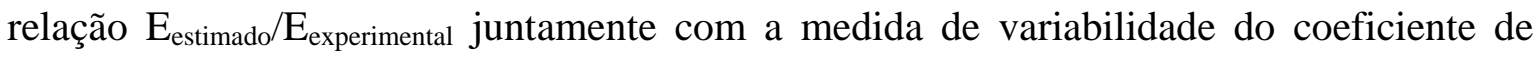
variação, pode-se inferir que o modelo compósito bifásico (Argamassa experimental + Brita) demonstra eficiência na estimativa de módulo de elasticidade dinâmico do concreto. Entretanto como os coeficientes de variação tem grande ordem de grandeza, e assim é necessário que se estabeleça um grande número de amostras para se estimar precisamente o comportamento do concreto. Ainda é necessário evidenciar que os dados utilizados para a realização dos cálculos de tal modelo constam na tabela a seguir: 
Tabela 28 - Propriedades Elásticas dos componentes do modelo (Argamassa Experimental + Agregado Graúdo)

\begin{tabular}{|c|c|c|c|}
\hline Componente & $\mathbf{E}_{\mathbf{d}}[\mathrm{GPa}]$ & $v_{d}$ & $\mathbf{G}_{\mathbf{d}}[\mathbf{G P a}]$ \\
\hline Argamassa & Variável & $0,23^{*}$ & $G=E / 2(1+v)$ \\
\hline $\begin{array}{c}\text { Agregado Graúdo - } \\
\text { Diabásio }\end{array}$ & $70^{* *}$ & $0,24^{* *}$ & $G=E / 2(1+v)$ \\
\hline & va com ba & s exper & \\
\hline
\end{tabular}

Ainda comparando as estimativas teóricas bifásicas com resultados experimentais, propõe-se agora um ajuste ao modelo bifásico proposto anteriormente. Dos resultados anteriores, pode-se inferir que a utilização do coeficiente de Poisson dinâmico estimado em 0,23, e o Módulo de cisalhamento dinâmico obtido através da relação $G_{d}=\frac{E}{2\left(1+v_{d, e s t}\right)}$, converge, em média, a estimativas satisfatórias. Todavia, fora obtido experimentalmente através do Ensaio Acústico, valores experimentais de coeficiente de Poisson e módulo de cisalhamento $\left(v_{\mathrm{d} \text {,exp }} ; \mathrm{G}_{\mathrm{d}, \exp }\right)$, tanto para argamassa quanto para a brita. Assim é possível utilizar tais resultados, para se reconstituir os traços de concreto através dos limites de Hashin-Shtrikman (H-S). Por conseguinte, a Figura 62 compara, em um histograma, os valores experimentais com suas respectivas estimativas teóricas, com $v_{\mathrm{d}, \exp }$ e $\mathrm{G}_{\mathrm{d}, \exp }$ : 


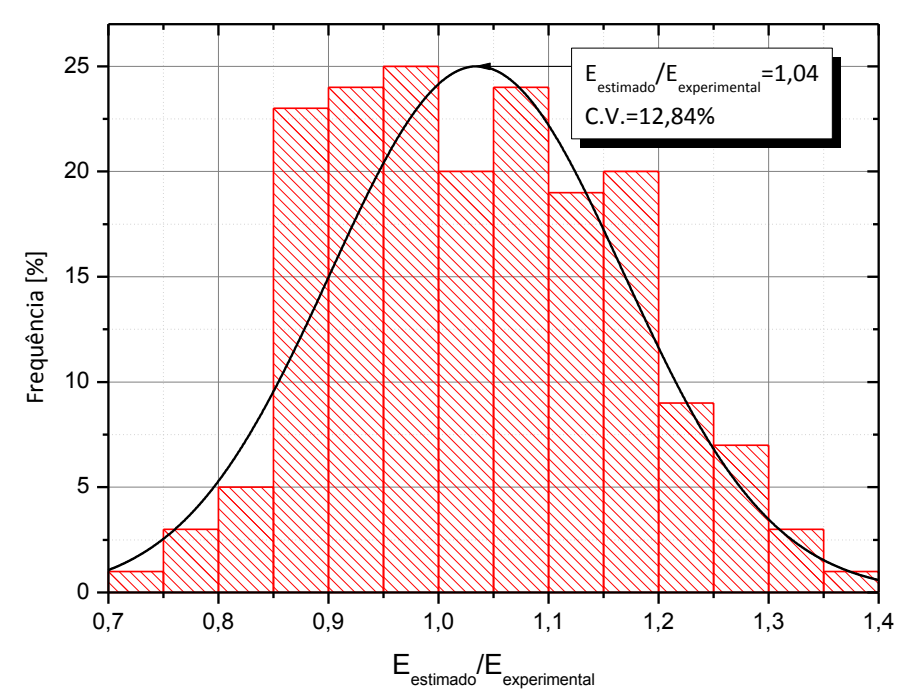

Figura 62 - Histograma e distribuição normal para $E_{\text {estimado }} / E_{\text {experimental }}$ (HashinShtrikman, com $v_{d, \exp }$ e $G_{d, \exp }$, Argamassa Experimental + Brita $\rightarrow$ Concreto).

De acordo com os resultados obtidos pelo gráfico da Figura 62, constata-se que o modelo bifásico (Argamassa Experimental + Brita) com coeficiente de Poisson e Módulo de cisalhamento obtidos experimentalmente $\left(v_{\mathrm{d} \text {,exp }} ; \mathrm{G}_{\mathrm{d}, \exp }\right)$, através da média entre os limites de Hashin-Shtrikman (H-S) converge à valores precisos. O mesmo apresenta relação média entre $\mathrm{E}_{\text {estimado }} / \mathrm{E}_{\text {experimental }}$ de 1,04 e coeficiente de variação de $12,84 \%$.

Realizando ainda uma comparação entre o concreto real e os modelos bifásicos com Poisson estimado $\left(v_{\mathrm{d}, \mathrm{est}}=0,23\right.$ e $\left.G_{d, \text { est }}=E / 2\left(1+v_{d, \text { est }}\right)\right)$ e determinado experimentalmente $\left(v_{d, \exp }\right.$ e $\left.G_{d, \exp }\right)$, obtém-se o histograma da Figura 63: 


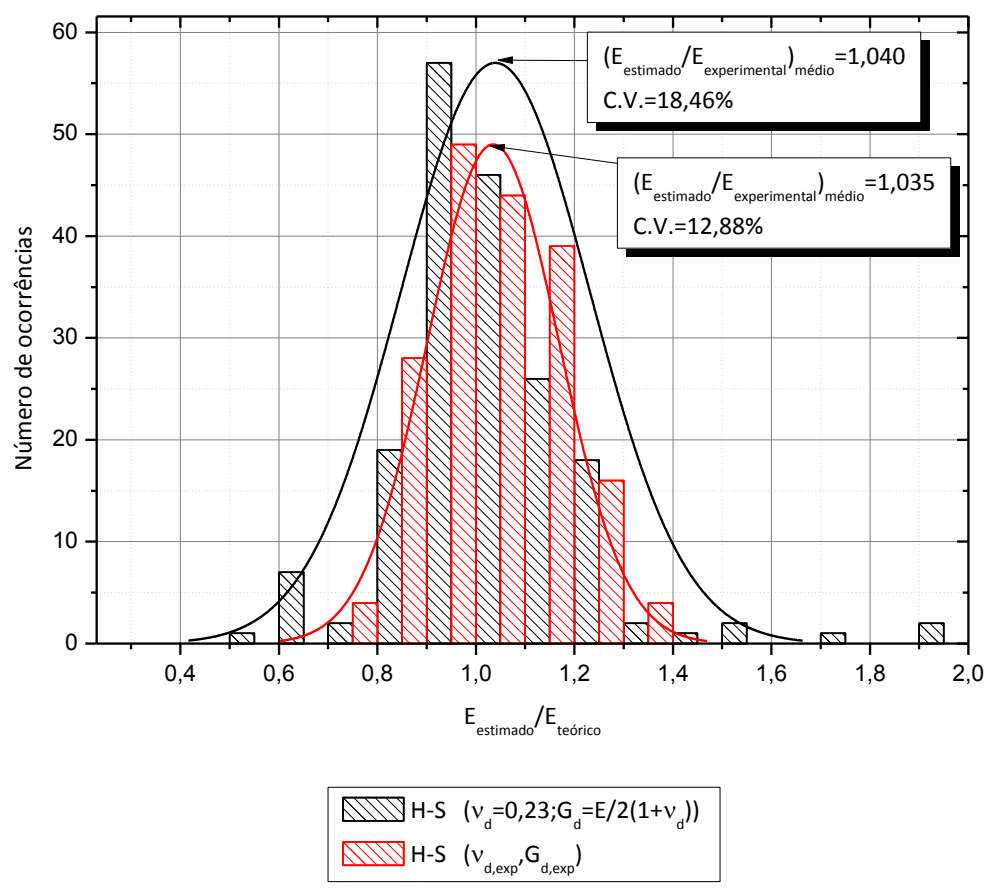

Figura 63 - Histograma e distribuição normal para $E_{\text {estimado }} / E_{\text {experimental }}$ (HashinShtrikman, com $v_{d, \text { est }}=0,23$ e $v_{d, \text { exp }}$, Argamassa Experimental + Brita $\rightarrow$ Concreto).

De acordo com os resultados do gráfico acima, pode-se admitir que para os dois casos, em média, os limites de Hashin-Shtrikman (H-S), são um modelo que se aproxima satisfatóriamente ao módulo de elasticidade dinâmico do concreto, já que $\left(\mathrm{E}_{\text {estimado }} / \mathrm{E}_{\text {experimental }}\right)_{\text {médio }} \cong 1$. Nota-se também que a variabilidade apresentada pelo modelo que leva em conta os valores reais de coeficiente de poisson e módulo de cisalhamento $\left(v_{\mathrm{d}, \exp } ; \mathrm{G}_{\mathrm{d}, \exp }\right)$ é menor que aquele em que se considera o valor de $v_{\mathrm{d} \text {,estimado }}=0,23$. Todavia, mesmo que tal variabilidade seja menor, utilizar o valor de 0,23 como estimativa do coeficiente de Poisson $\left(v_{\mathrm{d}, \text { est }}\right)$ juntamente com a hipótese de isotropia do material, trás resultados estatisticamente satisfatórios. Logo, à medida que se estabelece um número adequado de amostras, o valor estimado pelas formulações teóricas de Hashin-Shtrikman (H-S), seja com um coeficiente de Poisson estimado ou obtido experimentalmente, tende aos valores de módulo de elasticidade dinâmico observados em concretos reais.

Finalmente, pode-se realizar a comparação entre todos os modelos compósitos estabelecidos para a previsão do comportamento do concreto, isto é: 
- Duas misturas bifásicas: constituída de Argamassa Teórica(Pasta+Areia) + Brita;

- Única mistura bifásica: constituída de Argamassa Experimental $\left(v_{\text {d,estimado }}=0,23 ; \mathrm{G}_{\mathrm{d}}=\mathrm{E}_{\mathrm{d}} / 2\left(1+v_{\mathrm{d}, \text { est }}\right)\right)+$ Brita;

- Única mistura bifásica: constituída de Argamassa Experimental ( $v_{\mathrm{d} \text { exp }} \mathrm{e}$ $\left.\mathrm{G}_{\mathrm{d}, \mathrm{exp}}\right)+$ Brita.

Assim, os gráficos subsequentes comparam graficamente tais modelos, em que os valores experimentais do concreto (eixo-x) são comparados aos seus valores estimados pelos modelos teóricos supracitados (eixo-y). Logo, quanto mais próximo $\mathrm{E}_{\text {experimental }}$ estiver de

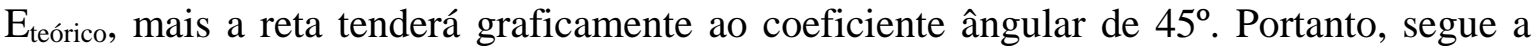
comparação de tais modelos na Figura 64 (Série e Paralelo) e na Figura 65 (HashinShtrikman):

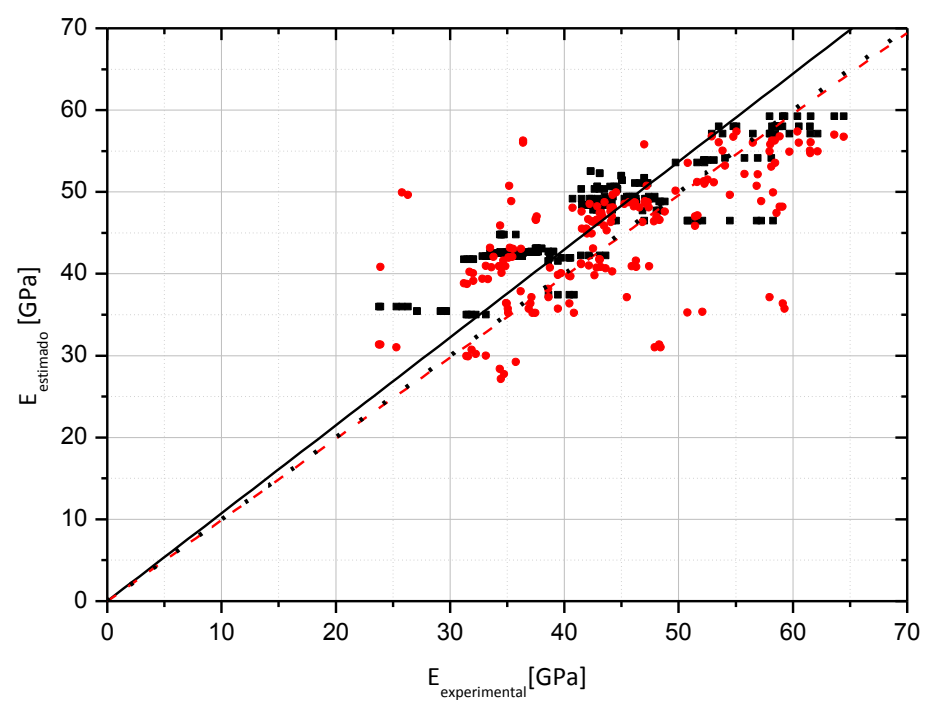

- S-P: Argamassa Teórica (Pasta+Areia) + Brita

- S-P: Argamassa Experimental + Brita

- S-P: Argamassa Teórica (Pasta+Areia) + Brita: $\mathrm{E}_{\text {teo }}=1,074 * \mathrm{E}_{\text {exp }}\left(\mathrm{R}^{2}=0,98914\right)$

- - - S-P: Argamassa Experimental + Brita $E_{\text {estimado }}=0,9922 E_{\text {experimental }}\left(R^{2}=0,97434\right)$

- $\cdot \mathrm{E}_{\text {estimado }}=\mathrm{E}_{\text {experimental }}$

Figura 64 - Comparação entre modelos (S-P) 


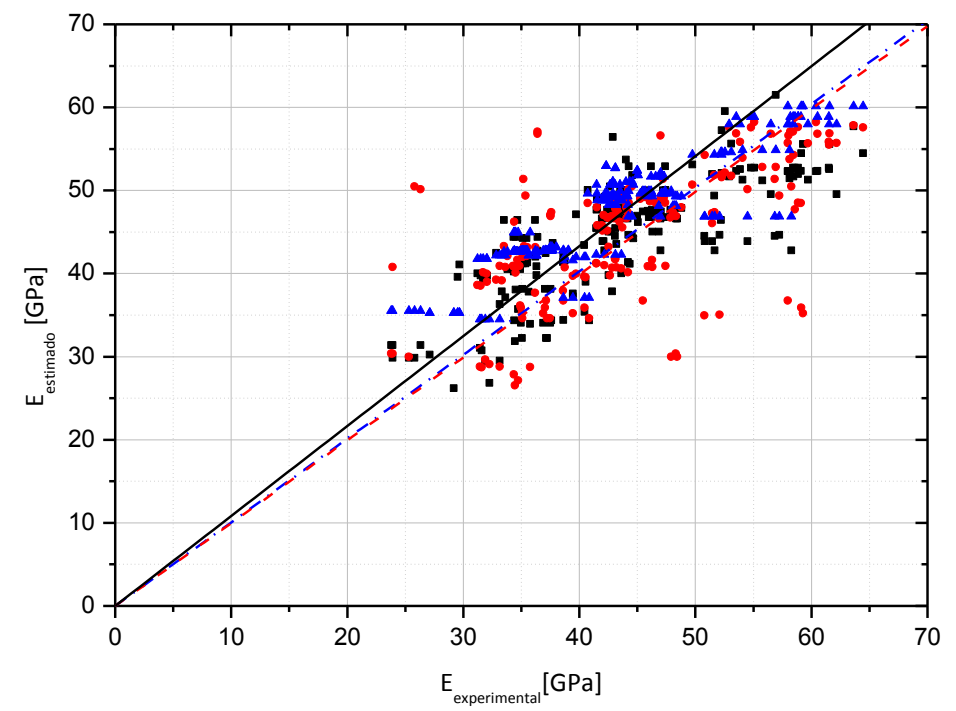

- H-S: Argamassa Teórica (Pasta+Areia) + Brita

- $H-S$ : Argamassa Experimental + Brita $\left(v_{d}=0,23 ; G=E / 2(1+v)\right)$

- H-S: Argamassa Experimental + Brita $\left(v_{\mathrm{d}, \mathrm{exp}} ; \mathrm{G}_{\mathrm{d}, \mathrm{exp}}\right)$

- H-S: Argamassa Teórica (Pasta+Areia) + Brita: $\mathrm{E}_{\text {estimado }}=1,0825 \mathrm{E}_{\text {exp }}\left(R^{2}=0,98409\right)$

- - - H-S: Argamassa Experimental + Brita $\left(v_{d}=0,23 ; G=E / 2(1+v)\right): E_{\text {estimado }}=0,997 E_{\text {exp }}\left(R^{2}=0,97350\right)$

- - - H H S: Argamassa Experimental + Brita $\left(v_{\text {d,exp }} ; G_{\text {d,exp }}\right): E_{\text {teo }}=1,0825 E_{\text {estimado }}\left(R^{2}=0,98978\right)$

Figura 65 - Comparação entre modelos (H-S)

Os parâmetros utilizados para se traçar as retas das Figura 64 e Figura 65 podem ser resumidos conforme a tabela à seguir:

Tabela 29 - Parâmetros de curvas (modelos compósitos)

\begin{tabular}{|c|c|c|c|}
\hline Modelo & Constituintes & $\mathbf{R}^{2}$ & $\begin{array}{c}\mathbf{E}_{\text {estimado }} \\
\text { [GPa] }\end{array}$ \\
\hline Série/Paralelo & Argamassa teórica+Brita & 0,98914 & $E_{\text {estimado }}=1,074 E_{\text {experimental }}$ \\
\hline $\mathrm{H}-\mathrm{S}$ & Argamassa teórica+Brita & 0,98978 & $E_{\text {estimado }}=1,083 E_{\text {experimental }}$ \\
\hline Série/Paralelo & $\begin{array}{c}\text { Argamassa Experimental }+ \\
\text { Brita }\end{array}$ & 0,97434 & $E_{\text {estimado }}=0,993 E_{\text {experimental }}$ \\
\hline $\begin{array}{c}\mathrm{H}-\mathrm{S} \\
\left(v_{\mathrm{d}, \mathrm{est}}=0,23 ; \mathrm{G}_{\mathrm{d}, \mathrm{est}}=\mathrm{E}_{\mathrm{d}} / 2\left(1+v_{\mathrm{d}, \mathrm{est}}\right)\right)\end{array}$ & $\begin{array}{c}\text { Argamassa Experimental }+ \\
\text { Brita }\end{array}$ & 0,9735 & $E_{\text {estimado }}=0,997 E_{\text {experimental }}$ \\
\hline $\begin{array}{c}\mathrm{H}-\mathrm{S} \\
\left(v_{\mathrm{d}, \exp }, \mathrm{G}_{\mathrm{d}, \exp }\right)\end{array}$ & $\begin{array}{c}\text { Argamassa Experimental }+ \\
\text { Brita }\end{array}$ & 0,98255 & $E_{\text {estimado }}=1,003 E_{\text {experimental }}$ \\
\hline
\end{tabular}


De todos os resultados anteriores conclui-se que os modelos bifásicos constituídos de argamassa e brita foram mais precisos do que aqueles compostos por pasta, areia e brita. Isto se deve ao fato de que o módulo de elasticidade dinâmico do grão de areia foi estimado e não determinado. Por outro lado, existem algumas limitações que ainda são notadas nestes modelos.

Da existência de tais limitações, pode-se realizar um estudo sobre o comportamento do erro da estimativa bifásica. Assim, toma-se como referencia o modelo bifásico constituído por argamassa e brita, obtido através da média entre os limites de HashinShtrikman (H-S), calculado pelos valores experimentais de coeficiente de Poisson e módulo de cisalhamento $\left(v_{\mathrm{d}, \exp }, \mathrm{G}_{\mathrm{d}, \exp }\right)$. Logo, a Figura 66 demonstra a evolução de $\mathrm{E}_{\text {experimental }} / \mathrm{E}_{\text {estimado }}$ em função da relação água cimento e diâmetro máximo do agregado graúdo, para o caso de concretos com traços médios (1:2:3 cimento:areia:brita, em massa):

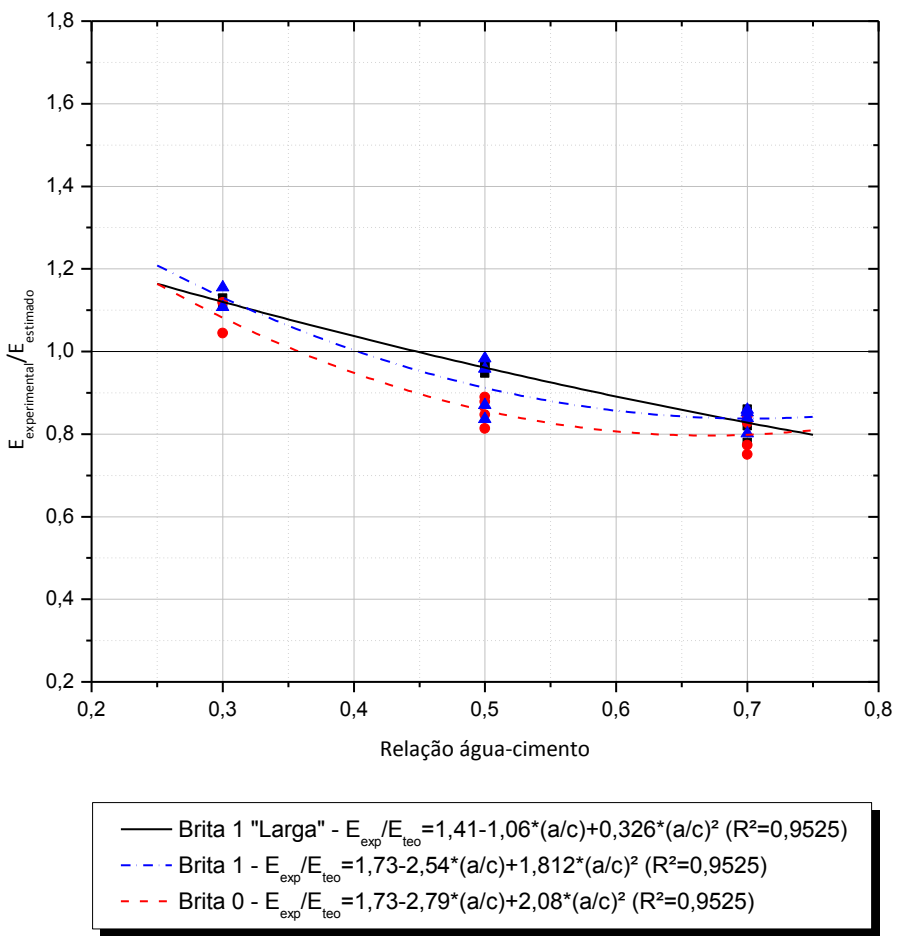

Figura 66 - Erro do modelo teórico em função da relação água-cimento 
Conforme o que ilustra a figura acima, para os três tipos de britas estudados, há divergência $\left(\mathrm{E}_{\mathrm{exp}} / \mathrm{E}_{\text {teoo }} \neq 1\right)$ entre o módulo de elasticidade dinâmico calculado pela previsão bifásica e o valor observado experimentalmente. Tal divergência se deve principalmente ao fato do concreto não ser um material perfeitamente bifásico, já que a não consideração da zona de transição como terceiro componente da mistura tende a gerar um determinado erro. Admitindo-se que nas primeiras idades há fluxo de água da matriz para à periferia do agregado graúdo, e que este fluxo seja o responsável pela formação da zona de transição, é possível afirmar que o observado é semelhante ao relatado por SIMEONOV e AHMAD (1995). Isto é, houve efeito agravante da zona de transição para relações água-cimento superiores à aproximadamente 0,4 , o que fez com que a previsão teórica superestimasse o valor experimental $\left(\mathrm{E}_{\exp } / \mathrm{E}_{\text {teo }}<1\right)$. Por outro lado, para relações água-cimento inferiores à aproximadamente 0,4 houve a atenuação do efeito da zona de transição e possível melhora na rigidez da matriz cimentícia, o que caracterizou o aumento do valor experimental em relação à previsão teórica $\left(\mathrm{E}_{\mathrm{exp}} / \mathrm{E}_{\text {teo }}>1\right)$. Também e ainda conforme o gráfico anterior é necessário salientar que para valores de relação água cimento iguais ou próximos de 0,4 , as previsões teóricas funcionaram bem. Portanto, a diferença entre o modelo compósito e o valor experimental é consequência da zona de transição.

Outro fator que influenciou na divergência entre os valores reais e as estimativas teóricas foi a ação do tempo. Assim, a Figura 67 demonstra, para amostras de 1:2:3:0,5 (cimento:areia: brita: água, em massa), o desenvolvimento da relação $\mathrm{E}_{\text {experimental }} / \mathrm{E}_{\text {estimado }}$ em função da maturidade do concreto: 


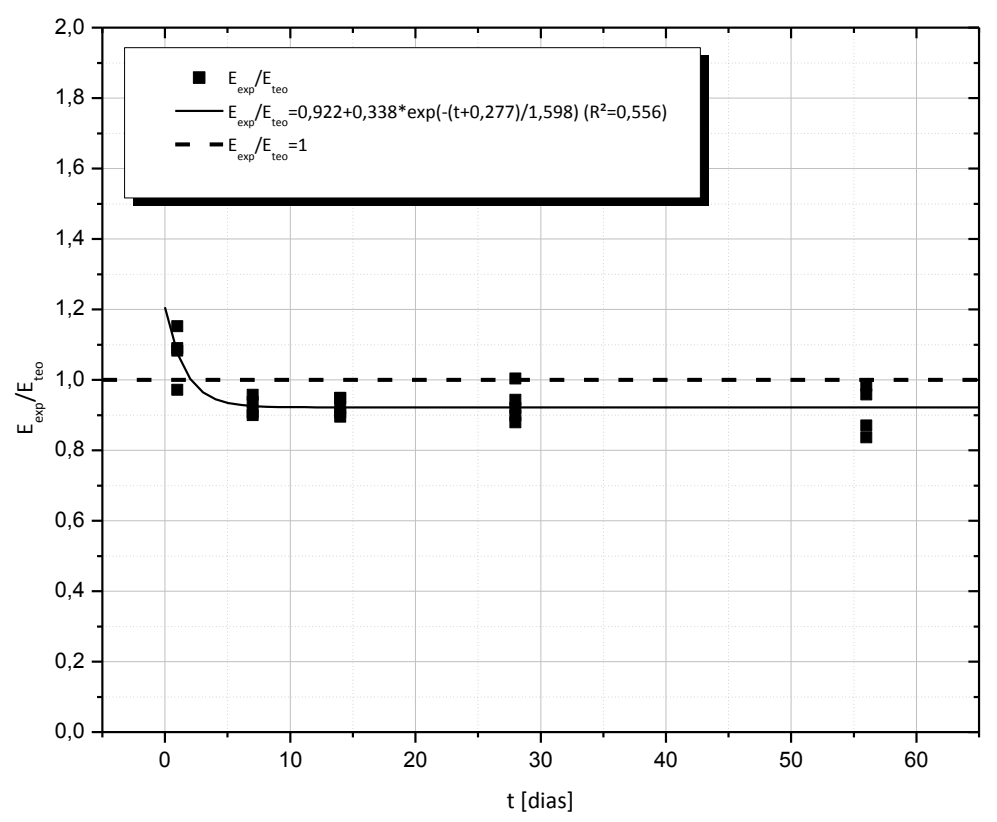

Figura 67 - Erro do modelo teórico em função da maturidade

Nota-se da figura acima que o valor de módulo de elasticidade dinâmico real é maior que a estimativa teórica até o terceiro dia. Após esta idade a estimativa passa a apresentar valor maior que o valor experimental, tendo o valor de erro relativo estabilizado a partir dos 7 dias.

Já a Figura 68 demonstra que o aumento da proporção agregado-cimento, e consequentemente sua fração volumétrica, não gera efeito significativo sobre as previsões de compósitos bifásicos: 


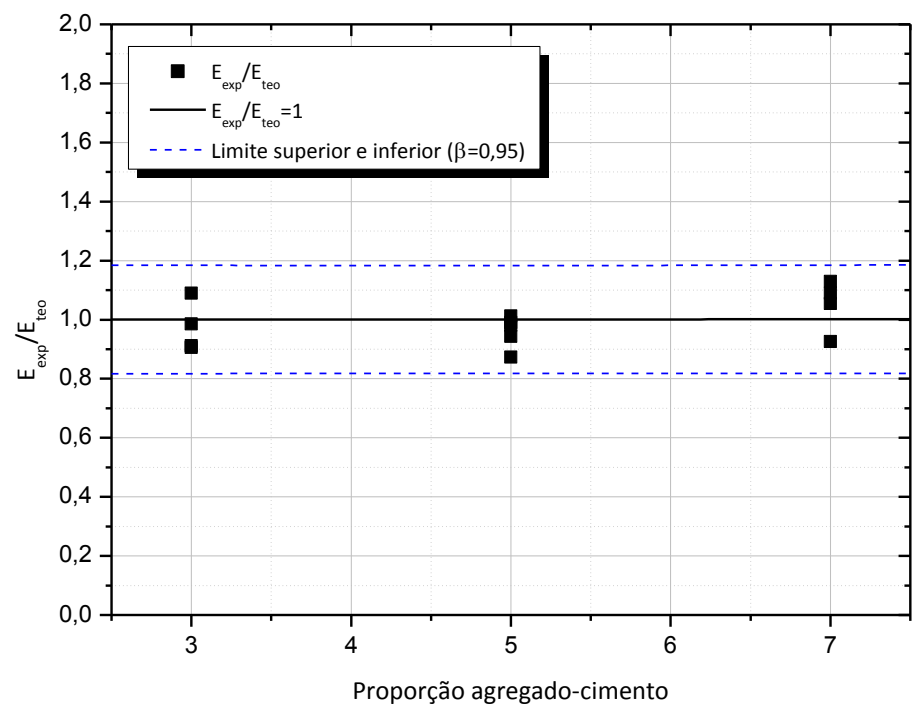

Figura 68 - Erro do modelo teórico bifásico em função da proporção agregadocimento 


\section{CONCLUSÃO}

Através dos resultados do presente trabalho foi possível correlacionar os parâmetros da microestrutura do material concreto com suas propriedades dinâmicas, em especial o módulo de elasticidade dinâmico. A mudança da microestrutura foi induzida basicamente por parâmetros de dosagem e cura, e estas, garantiram inúmeros padrões de microestrutura para se realizar tal estudo.

O entendimento isolado da pasta, areia, argamassa, brita é importante para o conhecimento do compósito concreto. Por exemplo, através dos resultados obtidos constatou-se que a relação água-cimento e a maturidade são fatores que tem forte ligação à pasta. Considerando que os grãos de areia e brita estão inertes na mistura, o mecanismo das reações de hidratação ao longo do tempo, exclusivo da pasta, ocorre de forma análoga nos casos da argamassa e concreto. Por outro lado, o efeito das variações na fração volumétrica e os módulos de elasticidade dinâmicos dos componentes da mistura também se mostraram influentes ao módulo de elasticidade dinâmico do compósito. Uma vez considerada a regra da mistura, pode-se inferir que o módulo de elasticidade do compósito é o módulo de elasticidade da combinação volumétrica dos materiais que estão envolvidos na mistura, isto é, pasta, areia e brita . Já o efeito da presença ou não de superplastificante mostrou-se marginal quando comparado aos outros efeitos análisados. Este efeito foi mais importante no fabrico das amostras do que no resultado final, pois a utilização do superplastificante facilitou as moldagens de traços mais secos. Entretanto, foi demonstrado que seu uso pode ser danoso em alguns casos. Mostrou-se também que o aumento do diâmetro máximo do agregado graúdo não revelou facilmente os efeitos da zona de transição. Isto se deve provavelmente à fatores como a não fixação da trabalhabilidade do concreto e variabilidade das características físicas dos constituintes da mistura. Sugere-se assim, em trabalhos futuros, para concretos de mesma consistência e rígido controle dos materiais envolvidos na mistura, utilizar-se das técnicas de microscopia juntamente com o ensaio acústico para se estudar as características da zona de transição.

Foi possível avaliar o comportamento dinâmico do Módulo de Cisalhamento e coeficiente de Poisson. O módulo de cisalhamento, para o caso argamassa e concreto, demonstrou que varia linearmente de acordo com o módulo de elasticidade dinâmico. Isto se deve à adoção da hipótese de isotropia do material. Por outro lado, o coeficiente de Poisson apresentou pouca variação frente aos padrões de microestrutura. Assim, uma 
estimativa coerente para seu valor dinâmico pode ser estabelecido no valor de 0,23 , tanto para o caso da argamassa quanto para o concreto.

Já os resultados de coeficiente de amortecimento interno apresentaram valores contidos em um intervalo de $0,1 \%$ à $1 \%$, estando dentro dos valores esperados pela literatura. Demonstrou-se, através dos resultados obtidos, que o mesmo tem intima relação com a microestrutura do material, isto é, o mesmo surge através de imperfeições tais como fissuras, poros e zona de transição. Esta é a justificativa pela qual este tem comportamento inverso ao módulo de elasticidade dinâmico. Assim, fica estabelecida a relação entre coeficiente de amortecimento interno, microestrutura e módulo de elasticidade dinâmico.

Também obteve-se a relação entre os módulos de elasticidade dinâmico e estático aos 28 dias, e esta, divergiu da curva proposta pela literatura. Tal curva é singular a variações de dosagens, tipo de agregados, distribuição granulométrica, variações de fração volumétrica, tipos de cimentos e condições de trabalhabilidade e cura, entre outros parâmetros que afetam a microestrutura do material.

As estimativas empíricas, ainda que não considerem fatores como a zona de transição, fração volumétrica e módulo de elasticidade dinâmico individual aos materiais envolvidos na mistura, mostraram-se precisas e satisfatórias, especialmente os casos da ABNT NBR 6118:2014, da qual se obteve relação média entre o valor estimado e o real de $\mathrm{E}_{\mathrm{NBR}} / \mathrm{E}_{\text {experimental }}=1,025$ e o $\mathrm{ACI} 318-11$, em que obteve-se $\mathrm{E}_{\mathrm{ACI}} / \mathrm{E}_{\text {experimental }}=1,055$. Por outro lado, o valor médio da estimativa obtida pelo CEB-FIP de 2010 divergiu muito dos valores de módulo de elasticidade dinâmico real $\left(\mathrm{E}_{\mathrm{ACl}} / \mathrm{E}_{\text {experimental }}=1,299\right)$. Entretanto as estimativas empíricas sempre são dependentes da relação entre $\mathrm{E}_{\mathrm{c} i} / \mathrm{E}_{\mathrm{d}}$, o que as tornam mais incertas quando comparadas as realizadas via formulação para materiais compósitos.

Por outro lado, a aplicabilidade dos modelos teóricos bifásicos foi avaliada para estimativas de módulo de elasticidade dinâmico do concreto. Assim, o primeiro modelo proposto, ou seja, o duplamente bifásico (Argamassa teórica + brita), funcionou de forma satisfatória, ainda que o módulo de elasticidade dinâmico da areia fosse estimado através de resultados de velocidade de ondas $\mathrm{P}$ em maciços marinhos. A relação média entre o valor estimado e o real foi de $\mathrm{E}_{\text {estimado }} / \mathrm{E}_{\text {experimental }}=0,909$ para a média entre série-paralelo $(\mathrm{S}-\mathrm{P})$ e de $\mathrm{E}_{\text {estimado }} / \mathrm{E}_{\text {experimental }}=1,119$ para a média entre os limites de Hashin-Shtrikman (H-S). Por outro lado, o modelo bifásico constituido de argamassa experimental e brita apresentou resultados com maior precisão quando comparado ao duplamente bifásico, pois teve valor de relação média entre o valor estimado e o real $\left(\mathrm{E}_{\text {estimado }} / \mathrm{E}_{\text {experimental }}\right)$ de 
aproximadamente $1\left(\mathrm{E}_{\text {estimado }} / \mathrm{E}_{\text {experimental }}=0,994\right.$ para Série-Paralelo, $E_{\text {estimado }} / \mathrm{E}_{\text {experimental }}=1,04$ para Hashin-Shtrikman com $v_{\mathrm{d} \text {,est }}=0,23$ e $\mathrm{E}_{\text {estimado }} / \mathrm{E}_{\text {experimental }}=1,035$ para Hashin-Shtrikman com $v_{\mathrm{d} \text {,exp }}$ ). O modelo bifásico (Argamassa experimental + Brita) de Hashin-Shtrikman com $v_{\text {d,exp }}$ mostrou-se o mais preciso dentre todas as estimativas. Entretanto os resultados demonstram que a estimativa feita pela média em série-paralelo ( $\mathrm{S}-\mathrm{P})$, ou pela média dos limites de Hashin-Shtrikman (H-S) com valores estimados $\left(v_{\mathrm{d}, \mathrm{est}}=0,23 ; \mathrm{G}_{\mathrm{d}}=\mathrm{E} / 2\left(1+v_{\mathrm{d}, \mathrm{est}}\right)\right)$ convergem à estimativas coerentes. Portanto, à medida que o número de amostras tende a aumentar, o valor da relação média entre o valor estimado e o real ( $\left.\mathrm{E}_{\text {estimado }} / \mathrm{E}_{\text {experimental }}\right)$ tenderá à convergir à 1 , ou seja, na prática, a estimativa teórica tenderá ao valor real. Todavia, os resultados ainda demonstram algumas limitações. Isto se deve ao fato do concreto ser, no mínimo, um material trifásico, composto por argamassa, brita e zona de transição, conforme previsto na literatura básica.

Assim e frente ao fato de que há poucos trabalhos existentes que tratem sobre a microestrutura correlacionada às propriedades dinâmicas do material, pode-se afirmar que o presente estudo contribui para o preenchimento de tal lacuna. Uma vez que o ensaio acústico evidencia não só os módulos elásticos do material, mas também a condição na qual a microestrutura se encontra, pode-se afirmar que a contribuição do estudo avança no sentido de melhorar o entendimento do material em situações dinâmicas, na tentativa, de que o mesmo se comporte de forma satisfatória e segura. 


\section{REFERÊNCIAS BIBLIOGRÁFICAS}

ASSOCIAÇÃO BRASILEIRA DE NORMAS TÉCNICAS - ABNT NBR 6118:2014, A. B. DE N. T. Projeto de estruturas de concreto - Procedimento. , 2007. Rio de Janeiro.

ABNT NBR 8522:2004, A. B. DE N. T. Concreto - Determinação dos módulos estáticos de elasticidade e de deformação e da curva tensão- deformação. Rio de Janeiro, 2003.

ACI318-11, A. C. I. Building Code Requirements for Structural Concrete (ACI 318-11). .

AÏTCIN, P. C.; MEHTA, P. K. Effect of coarse-aggregate characteristics on mechanical. AMERICAN CONCRETE INSTITUTE. Building Code Requirements for Structural Concrete - ACI, p. 318-11, 1990.

ASSOCIAÇÃO BRASILEIRA DE NORMAS TÉCNICAS - ABNT. ABNT NBR 9778:2005 - Argamassa e concreto endurecidos - Determinação da absorção de água, índice de vazios e massa específica. , p. 4, 2005.

ASTM C215-02, A. S. FOR T. M. Standard Test Method for Fundamental Transverse, Longitudinal, and Torsional Resonant Frequencies of Concrete Specimens., 2003.

ASTM E1876-01, A. S. FOR T. M. Standard Test Method for Dynamic Young's Modulus , Shear Modulus , and Poisson 's Ratio by Impulse Excitation of Vibration. , 2001.

BACHMANN, H.; AMMANN, W. J.; EISENMANN, J.; et al. Vibration Problems in Structures - Practical Guidelines. , 1995.

BAWA, N. S.; GRAFT-JOHNSON, J. W. S. Effect of Mix Proportion, Water-Cement Ratio, Age and Curing Conditions on the Dynamic Modulus of Elasticity of Concrete. Build. Sci., v. 3, p. 171-177, 1969.

BENTUR, A. Microstructure interfacial effects and micromechanics of cementitious composites. Adv. Cementitious Mater., Ceram. Trans., v. 16, p. 523-549, 1990.

BESHR, H.; ALMUSALLAM, A.; MASLEHUDDIN, M. Effect of coarse aggregate quality on the mechanical properties of high strength concrete. Construction and Building Materials, v. 17, n. 2, p. 97-103, 2003. Disponível em: <http://linkinghub.elsevier.com/retrieve/pii/S0950061802000971>. .

BOCCACCINI, D. ; BOCCACCINI, A. R. No Title. Journal Nondestructive Evaluation, p. 187-192, 1997.

COMITÉ EURO-INTERNACIONAL DU BÉTON, C.-F. Model Code 2010. , 2010. London.

COSSOLINO, L. C.; PEREIRA, A. H. A. Módulos elásticos : visão geral e métodos de caracterização. , 2010. São Carlos. Disponível em: <www.atcp.com.br>. . 
COUNTO, U. J. No Title. Mag. Concr. Res., v. 16, p. 129-138, 1964.

ELSHARIEF, A.; COHEN, M. D.; OLEK, J. Influence of aggregate size, water cement ratio and age on the microstructure of the interfacial transition zone. Cement and Concrete Research, v. 33, n. 11, p. 1837-1849, 2003. Disponível em:

<http://linkinghub.elsevier.com/retrieve/pii/S0008884603002059>. Acesso em: 22/2/2014.

EWINS, D. J. Modal Testing : Theory and Pratice. New York: Britisg Library, 1994.

GOMES, R. L. Características Tecnológicas e Alterabilidade dos comportimentos entablamento e colunata de derrames basálticos da porção setentrional da Bacia do Paraná, 2001. Escola de Engenharia de São Carlos, Universidade de São Paulo.

HAACH, V. G.; CARRAZEDO, R.; OLIVEIRA, L. M. F.; CORRÊA, M. R. S.

Application of acoustic tests to mechanical characterization of masonry mortars. NDT \& $\mathbf{E}$ International, v. 59, p. 18-24, 2013. Elsevier. Disponível em:

<http://linkinghub.elsevier.com/retrieve/pii/S0963869513000777>. Acesso em: 7/3/2014.

HANSEN, T. C. No Title. ACI Materials Journal, v. 62, p. 193-216, 1965.

HASHIN, Z.; SHTRIKMAN, S. A VARIATIONAL APPROACH TO THE THEORY OF THE ELASTIC BEHAVIOUR OF MULTIPHASE MATERIALS. Journal Mech. Phys. Solids, v. 11, n. 42, p. 127-140, 1963.

HILL, R. The Elastic Behaviour of a Crystalline Aggregate. Proc. Phys. Soc., v. 65, p. 349-354, 1952.

HIRSCH, T. J. No Title. ACI Materials Journal, v. 59, p. 427, 1962.

KLISZCZEWICZ, A.; AJDUKIEWICZ, A. Differences in instantaneous deformability of HS/HPC according to the kind of coarse aggregate. Cement and Concrete Composites, v. 24, n. 2, p. 263-267, 2002. Disponível em:

<http://linkinghub.elsevier.com/retrieve/pii/S0958946501000130>. .

LYDON, F. D.; IACOVOU, M. SOME FACTORS AFFECTING THE DYNAMIC MODULUS OF ELASTICITY OF HIGH STRENGTH CONCRETE. Cement and Concrete Research, v. 25, n. 6, p. 1246-1256, 1995.

MACKENZIE, J. K. No Title. Proc. Phys. Soc., v. 63B, p. 2-11, 1950.

MALHOTRA, V. M.; SIVASUNDARAM, V. Resonant Frequency Methods.

Nondestructive testing of concrete. 1st ed., 2004. New York: CRC PRESS.

MASO, J. C. Proceedings of the Seventh International Congress on the Chemistry of Cements,. , 1980. Paris: Editions Septima.

MASO, J. C.; OLLIVIER, J. P.; BOURDETTE, B. Interfacial Transition Zone in Concrete. Advn. Cem. Bas. Mat., v. 7355, n. 94, 1995. 
MCCONNELL, K. G.; VAROTO, P. S. Vibration Testing: Theory and Practice. John Wiley ed.2008.

MEHTA, P.K.; MONTEIRO, P. J. M. Concreto: Estrutura, Propriedades e Materiais. $3^{\mathrm{a}}$ ed. New York: McGraw-Hil, 2008.

MELO NETO, A. A.; HELENE, R. P. Módulo de Elasticidade : Dosagem e Avaliação de Modelos de Previsão do Módulo de Elasticidade de Concretos. , 2002. Belo Horizonte: IBRACON.

MONTEIRO, P. J. M. MICROSTRUCTURE OF CONCRETE AND ITS INFLUENCE ON THE MECHANICAL PROPERTIES, 1985. Berkeley: UNIVERSITY OF CALIFORNIA.

MONTEIRO, P. J. M.; CHANG, C. T. The elastic moduli of calcium hydroxide. Cement and Concrete Research, v. 25, n. 8, p. 1605-1609, 1995. Disponível em:

<http://linkinghub.elsevier.com/retrieve/pii/0008884695001549>. .

MONTEIRO, P. J. M.; MASO, J. C.; OLLIVIER, J. P. Particle Size Analysis of the Sand. Cement and Concrete Research, v. 15, p. 953-958, 1985.

MONTIJA, F. C. ASPECTOS DA VARIABILIDADE EXPERIMENTAL DO ENSAIO DE MÓDULO DE DEFORMAÇÃO DO CONCRETO, 2007. Escola Politécnica da Universidade de São Paulo.

NEVILLE, A. M. Propriedades Do Concreto. 2ª ed. São Paulo: PINI, 1997.

NILSEN, U.; MONTEIRO, P. J. M. CONCRETE: A THREE PHASE MATERIAL. Cement and Concrete Research, v. 23, p. 147-151, 1993.

PACELLI DE ANDRADE, W. . Concretos: Massa, Estrutural, Projetado e compactado com rolo (Ensaios e Propriedades). PINI, 1997.

PARAGUASSU, A. .; RODRIGUES, J. E.; GANDOLFI, N.; ZUQUETTE, L. V. PORTILLO, E. Z. F. Arenito Botucatu Silicificado: caracterização, explotação e usos. , 1993. São Paulo: Congresso Italo-brasileiro de Engenharia de Minas.

PICKETT, G. Equations for Computing Elastic Constants from Flexural and Torsional Resonant Frequencies of Vibration of Prisms and Cylinders. Proceedings of the American Society for Testing Materials, v. 45, p. 846-866, 1945.

REUSS, A. Berchung der Fiessgrenze von Mischkristallen auf Grund der Plastizi ä tsbedingung für Einkristalle. Zeitschrift für Angewandte Mathematik und Mechanik, v. 9, n. 1, p. 49-58, 1929.

SHAH, S. P.; AHMAD, S. H. High Performance Concretes and Applications. London: Arnold, Edward, 1994.

SHEHATA. Deformações Instantâneas do Concreto. In: G. C. Isaia (Ed.); Concreto, Ensino, Pesquisa e Realizações. Ibracon ed., p.631-685, 2005. São Paulo. 
SILVA, C. W. DE; SILVA, D.; CLARENCE, W.; SILVA, C. W. DE. Vibration: Fundamentals and pratice. CRC Press ed.New York, 2000.

SIMEONOV, P.; AHMAD, S. Effect of transition zone on the elastic behavior of cementbased composites. Cement and Concrete Research, v. 25, n. 1, p. 165-176, 1995. Disponível em: <http://linkinghub.elsevier.com/retrieve/pii/000888469400124H>. .

TOPÇU, İ. B. Alternative estimation of the modulus of elasticity for dam concrete. Cement and Concrete Research, v. 35, n. 11, p. 2199-2202, 2005. Disponível em: <http://linkinghub.elsevier.com/retrieve/pii/S0008884604003837>. Acesso em: 16/2/2014.

TOPÇU, İ. B.; BILIR, T.; BOĞA, A. R. Estimation of the modulus of elasticity of slag concrete by using composite material models. Construction and Building Materials, $v$. 24, n. 5, p. 741-748, 2010. Disponível em:

<http://linkinghub.elsevier.com/retrieve/pii/S0950061809003717>. Acesso em: 13/2/2014.

VOIGT, W. Über die Beziehung zwischen den beiden Elastizi ä tskonstanten isotroper Körper. wied. ann. journal, v. 38, p. 573-587, 1889. 


\section{APÊNDICE A - CONTROLE DE MATERIAIS}

Neste anexo serão apresentados os dados referentes ao controle de materiais utilizados na pesquisa.

O cimento utilizado foi CPV-ARI, do fabricante Holcim ${ }^{\circledR}$, cujos principais parâmetros constam no relatório de qualidade fornecido pelo fabricante conforme a tabela a seguir:

Tabela 30 - Dados da qualidade do cimento utilizado (Fonte: Holcim ${ }^{\circledR}$ )

\begin{tabular}{|c|c|c|c|c|c|}
\hline ENSAIOS & PERÍODO & $\begin{array}{r}15.07 .2014- \\
31.07 .2014\end{array}$ & $\begin{array}{c}02.08 .2014 \text { - } \\
19.08 .2014\end{array}$ & 21.08.2014 & $\begin{array}{c}\text { LIMITES } \\
\text { ANBT: NBR5733 }\end{array}$ \\
\hline Blaine $\left(\mathrm{cm}^{2} / \mathrm{g}\right)$ & $\begin{array}{c}\text { Média } \\
\text { Desv. Pad. }\end{array}$ & $\begin{array}{c}4759 \\
52\end{array}$ & $\begin{array}{c}4741 \\
87\end{array}$ & $\begin{array}{c}\mathbf{4 8 1 8} \\
49\end{array}$ & $\geq \mathbf{3 0 0 0}$ \\
\hline $\begin{array}{l}\text { Início Pega } \\
\quad(\min )\end{array}$ & $\begin{array}{l}\text { Média } \\
\text { Desv. Pad. }\end{array}$ & $\begin{array}{c}130 \\
10\end{array}$ & $\begin{array}{c}128 \\
8\end{array}$ & $\begin{array}{c}121 \\
8\end{array}$ & $\geq 60$ \\
\hline $\begin{array}{c}\text { Fim Pega } \\
(\text { min) }\end{array}$ & $\begin{array}{c}\text { Média } \\
\text { Desv. Pad. }\end{array}$ & $\begin{array}{c}\mathbf{1 8 8} \\
11\end{array}$ & $\begin{array}{c}182 \\
8\end{array}$ & $\begin{array}{c}178 \\
7\end{array}$ & $\leq 600$ \\
\hline $\begin{array}{c}\text { R } 1 \text { dia (MPa) } \\
\quad \text { NBR } 7215\end{array}$ & $\begin{array}{c}\text { Média } \\
\text { Desv. Pad. }\end{array}$ & $\begin{array}{l}\mathbf{2 8 , 3} \\
0,71\end{array}$ & $\begin{array}{l}\mathbf{2 8 , 7} \\
0,48\end{array}$ & $\begin{array}{l}\mathbf{2 8 , 9} \\
0,74\end{array}$ & $\geq 14,0$ \\
\hline $\begin{array}{c}\text { R } 3 \text { dias } \\
\text { (MPa) }\end{array}$ & $\begin{array}{l}\text { Média } \\
\text { Desv. Pad. }\end{array}$ & $\begin{array}{l}\mathbf{4 0 , 5} \\
0,35\end{array}$ & $\begin{array}{l}\mathbf{4 0 , 5} \\
0,97\end{array}$ & $\begin{array}{l}\mathbf{4 1 , 0} \\
0,82\end{array}$ & $\geq 24,0$ \\
\hline $\begin{array}{c}\text { R } 7 \text { dias } \\
(\mathrm{MPa})\end{array}$ & $\begin{array}{c}\text { Média } \\
\text { Desv. Pad. }\end{array}$ & $\begin{array}{l}\mathbf{4 4 , 8} \\
0,49\end{array}$ & $\begin{array}{l}\mathbf{4 5 , 1} \\
0,74\end{array}$ & & $\geq 34,0$ \\
\hline $\begin{array}{c}\text { R } 28 \text { dias } \\
\text { (MPa) }\end{array}$ & $\begin{array}{l}\text { Média } \\
\text { Desv. Pad. }\end{array}$ & $\begin{array}{l}\mathbf{5 3 , 8} \\
0,65\end{array}$ & & & \\
\hline
\end{tabular}


Tabela 31 - Análise química do cimento utilizado (Fonte: Holcim ${ }^{\circledR}$ )

\begin{tabular}{|c|c|c|c|c|c|}
\hline \multicolumn{7}{|c|}{ ANÁLISE QUÍMICA [\%] } \\
\hline $\mathrm{SiO}_{2}$ & NBR 14656 & $\mathbf{1 9 , 0 4}$ & $\mathbf{1 9 , 1 5}$ & $\mathbf{3 , 2 0}$ & \\
\hline $\mathrm{Al}_{2} \mathbf{O}_{3}$ & NBR 14656 & $\mathbf{4 , 7 5}$ & $\mathbf{4 , 8 8}$ & & \\
\hline $\mathbf{F e}_{2} \mathbf{O}_{3}$ & NBR 14656 & $\mathbf{2 , 9 9}$ & $\mathbf{3 , 0 2}$ & $\mathbf{0 , 7 0}$ & \\
\hline $\mathbf{C a O}$ & NBR 14656 & $\mathbf{6 3 , 3 1}$ & $\mathbf{6 3 , 2 6}$ & & \\
\hline $\mathbf{M g O}$ & NBR 14656 & $\mathbf{0 , 7 0}$ & $\mathbf{0 , 7 3}$ & $\mathbf{0 , 7 0}$ & \\
\hline $\mathbf{S O}_{3}$ & NBR 14656 & $\mathbf{2 , 9 3}$ & $\mathbf{2 , 9 8}$ & $\mathbf{2 , 8 3}$ & $\leq \mathbf{4 , 5}$ \\
\hline $\mathbf{C O}_{2}$ & NBR NM 20 & $\mathbf{2 , 7 1}$ & $\mathbf{2 , 7 4}$ & $\mathbf{2 , 6 0}$ & $\leq \mathbf{3 , 0}$ \\
\hline $\mathrm{K}_{2} \mathbf{O}$ & NBR NM 20 & $\mathbf{0 , 8 1}$ & $\mathbf{0 , 7 8}$ & & \\
\hline $\mathbf{C}_{\mathbf{3}} \mathbf{A}$ (Teórico) & Equação Bogue & $\mathbf{7 , 7 2}$ & $\mathbf{7 , 7 5}$ & $\mathbf{7 , 8 0}$ & \\
\hline
\end{tabular}

Assim, o cimento foi estocado em lugar seco e coberto, e sua utilização foi de no máximo 30 dias após a compra.

Já areia utilizada nas argamassas e concretos foi seca ao sol e peneirada. Esta apresenta densidade de $2,65 \mathrm{~g} / \mathrm{cm}^{3}$ e tem a a curva granulométrica conforme a figura a seguir:

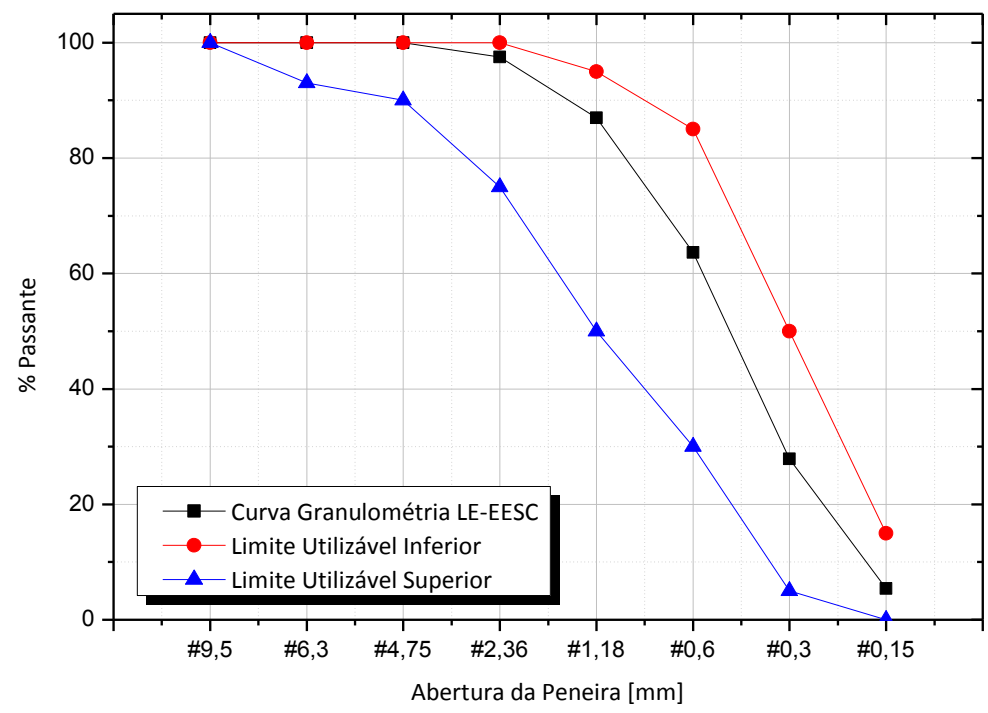

Figura 69 - Curva Granulométrica da Areia utilizada 
Nas dosagens de concreto foim utilizadas as seguintes graduações de brita: Brita 0 $\left(D_{\text {máx }}=9,52 \mathrm{~mm}\right)$, Brita $1\left(D_{\text {máx }}=16 \mathrm{~mm}\right)$ e Brita 1 "Larga" $\left(D_{\text {máx }}=19 \mathrm{~mm}\right)$. Assim, as curvas granulométricas podem ser apresentadas conforme a figura à seguir:

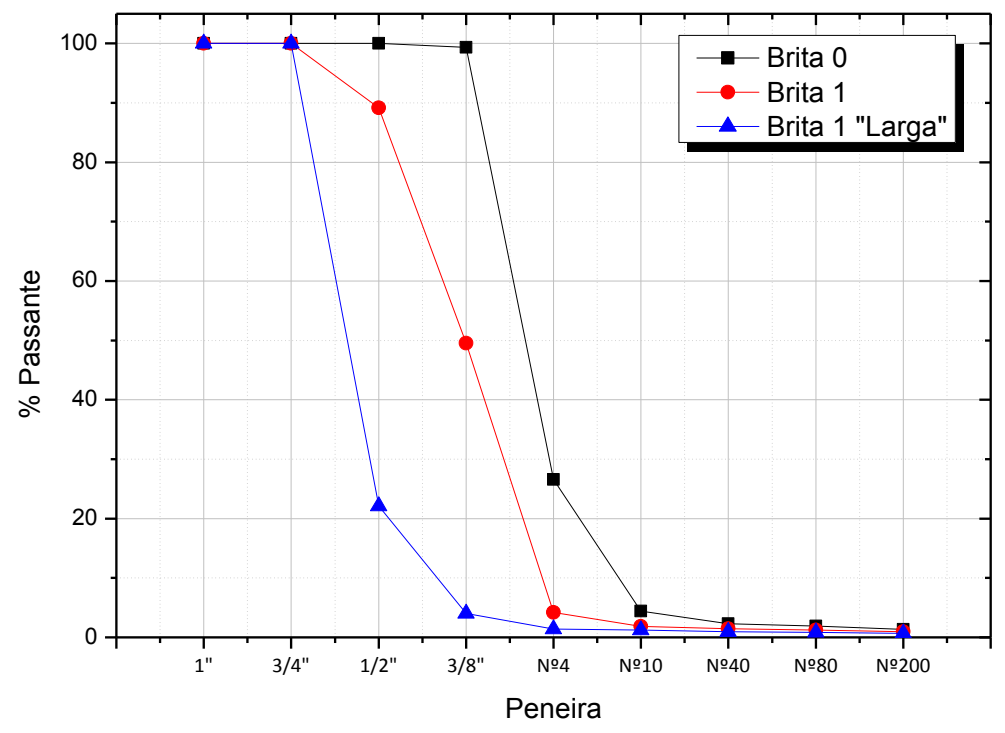

Figura 70 - Curva Granulométrica do agregado graúdo (Diabásio).

Tal brita tem como rocha de origem o diabásio, que apresenta densidade de $2,75 \mathrm{~g} / \mathrm{cm}^{3}$. explorado na pedreira do "vinte nove", do grupo Bandeirantes, na cidade de São Carlos-SP

- Figura 71. Sistematicamente, após o recebimento do fornecedor, realizou-se a secagem do material ao sol.

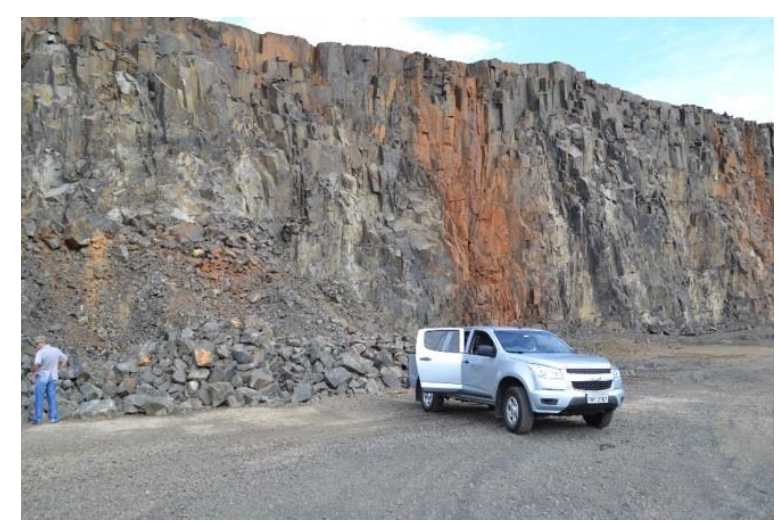

Figura 71 - Pedreira do "Vinte e Nove" - Grupo Bandeirantes 
É necessário ainda salientar que tanto a classificação litológica quanto detalhes sobre a rocha podem ser apresentados na tabela à seguir, segundo GOMES (2001):

Tabela 32 - Características do diabásio utilizado no estudo (Fonte: GOMES (2001))

\begin{tabular}{|c|c|}
\hline Rocha & Diabásio \\
\hline Formação & Serra Geral \\
\hline Grupo & São Bento \\
\hline Localização da Pedreira & 207.374 E/ 7.575.310 S / Z. 23K \\
\hline Tipo de rocha & Ígnea intrusiva básica \\
\hline Coloração & Cinza \\
\hline Granulação & Fina-média \\
\hline Minerais & Plagioclásio, piroxênio e o anfibólio \\
\hline
\end{tabular}

Também foram fabricados concretos utilizando a brita 1 de arenito silicificado botucatu (Pedreira do Araújo - São Carlos, SP), cuja curva granulométrica pode ser contemplada e também comparada ao agregado graúdo fabricado de diabásio, conforme a figura à seguir:

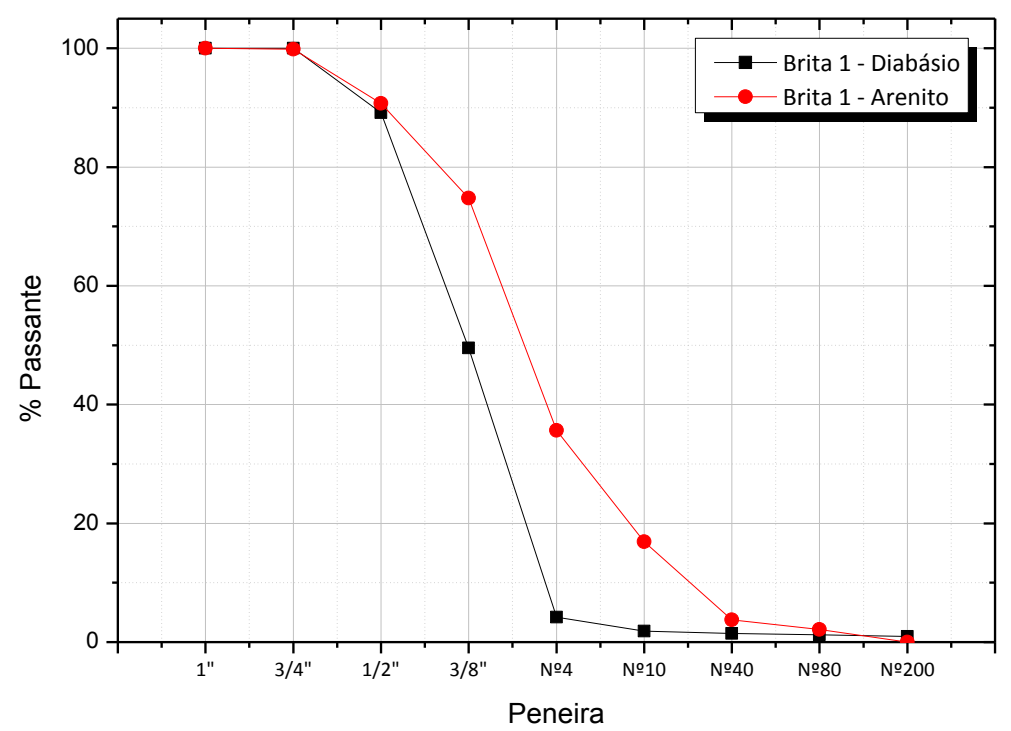

Figura 72 - Curva Granulométrica da Brita 1 (Arenito comparado ao Diabásio). 
Segundo PARAGUASSU et al. (1993), pode-se apresentar a classificação litológica e detalhes sobre o arenito silicificado botucatu, conforme a tabela à seguir:

Tabela 33 - Características do diabásio utilizado no estudo (Fonte: (PARAGUASSU et al., 1993))

\begin{tabular}{|c|c|}
\hline Rocha & Arenito Silicificado Botucatu \\
\hline Formação & Formação Botucatu \\
\hline Grupo & São Bento \\
\hline Localização da Pedreira & $\begin{array}{c}207.748 \text { E/7.557.920 S / Z. 23K - próxima a } \\
\text { rodovia Washington Luís, sentido São } \\
\text { Carlos - Rio Claro }\end{array}$ \\
\hline Tipo de rocha & Sedimentar \\
\hline Coloração & Variando do amarelo ao vermelho \\
\hline Granulação & Fina-média \\
\hline Minerais & Grãos de quartzo cimentados por sílica \\
\hline
\end{tabular}




\section{APÊNDICE B - CÁLCULO DO MÓDULO DE ELASTICIDADE DINÂMICO DA AREIA}

As propriedades elásticas do grão de areia foram adotadas segundo o estudo de NAFE e DRAKE (1961), em que se determinam, através de ondas sísmicas, propriedades físicas de maciços sedimentares marinhos, sendo estes resultados obtidos conforme a Equação (37) e apresentados na Tabela 34:

Tabela 34 - Propriedades Elásticas estimadas do grão de areia (NAFE e DRAKE, 1961).

\begin{tabular}{|c|c|}
\hline Grandeza Física & Valor \\
\hline Velocidade da onda de compressão $[\mathrm{m} / \mathrm{s}]^{*}$ & 6000 \\
\hline Densidade $\left[\mathrm{g} / \mathrm{cm}^{3}\right]^{* *}$ & 2,65 \\
\hline Coeficiente de Poisson & 0,25 \\
\hline Módulo de Elasticidade Dinâmico & 82,5 \\
\hline *Obtido Experimentalmente por NAFE E DRAKE (1965) \\
*** Densidade da Areia do Laboratório de Estruturas - LE EESC USP
\end{tabular}

$$
V_{p}=\sqrt{\frac{E(1-v)}{\rho(1-2 v)(1+v)}}
$$


